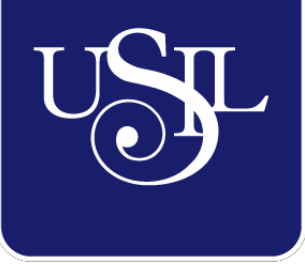

UNIVERSIDAD

SAN IGNACIO

DE LOYOLA

ESCUELA DE POSTGRADO

\title{
PLAN DE NEGOCIO PARA LA IMPLEMENTACIÓN DE UN RESTAURANTE EN VILLA EL SALVADOR, LIMA 2018
}

Trabajo de Investigación para optar el grado de:

\section{VALERIA MERCEDES CABALLERO PIGNATARO}

Maestro en Ciencias Empresariales con Mención en Gestión Financiera

$$
\text { VÍCTOR ENRIQUE JARA CHÁVEZ }
$$

Maestro en Ciencias Empresariales con Mención en Gestión de Proyectos

\section{Asesora:}

Dra. Nidia Ruth Vilchez Yucra

Lima - Perú

2020 


\section{Dedicatoria}

A todos los que nos ayudaron a culminar esta nueva aventura profesional: Profesores, familiares, amigos y compañeros. 


\section{Tabla de Contenidos}

Tabla de Contenidos 3

Introducción $\quad 13$

Resumen Ejecutivo 14

Capítulo I. Generalidades 16

1.1 Antecedentes 16

$\begin{array}{lll}1.2 & \text { Determinación del Problema } & 18\end{array}$

$\begin{array}{lll}1.3 & \text { Justificación del Proyecto } & 18\end{array}$

1.4 Objetivos Generales y Específicos 19

1.5 Alcances y Limitaciones 19

Capítulo II. Estructura Económica del Sector 21

2.1. Descripción del Estado Actual de la Industria 21

2.1.1. Segmentación de la industria 21

2.1.2. Empresas que la conforman (ubicación, volumen de ventas, empleados, etc.) 22

2.2. Tendencias de la Industria 23

2.3. Análisis Estructural del Sector Industrial 23

2.4. Análisis de la Competencia 29

2.4.1. Empresas que ofrecen el mismo producto o servicio, indicando las semejanzas y diferencias que tienen con el proyecto de empresa. $\quad 29$

2.4.2. Participación de mercado de cada uno de ellos. 29

2.4.3. Matriz de perfil competitivo. 31

2.5. Análisis del Contexto Actual y Esperado 34

2.5.1. Análisis político-gubernamental. 34

2.5.2. Análisis económico. 36

2.5.3. Análisis legal. 36

2.5.4. Análisis cultural.

2.5.5. Análisis tecnológico. 38

2.5.6. Análisis ecológico. 38

2.6. Oportunidades y Amenazas 39

Capítulo III. Estudio de Mercado 43

3.1. Descripción del Servicio o Producto 43

3.2. Selección del Segmento de Mercado 43

3.3. Investigación Cualitativa 47

3.3.1. Proceso de muestreo. 48

3.3.2. Diseño de instrumento. 50

3.3.3. Análisis y procesamiento de datos. 51 
3.4. Investigación Cuantitativa 64

3.4.1. Proceso de muestreo 65

3.4.2. Diseño de Instrumento 67

3.4.3. Análisis y procesamiento de datos 68

3.5. Conclusiones Y Recomendaciones Del Estudio Cualitativo Y Cuantitativo $\quad 91$

3.6. Perfil Del Consumidor Tipo Y Sus Variantes 93

Capítulo IV. Proyección Del Mercado Objetivo 94

4.1. El Ámbito de la Proyección 94

4.2. Selección del Método de Proyección 95

4.2.1. Mercado Potencial 96

4.2.2. Mercado Disponible 98

4.2.3. Mercado Efectivo 98

4.2.4. Mercado Objetivo 99

$\begin{array}{ll}\text { Capítulo V. Plan de Marketing } & 100\end{array}$

5.1. Estrategias de Marketing 100

$\begin{array}{ll}\text { 5.1.1. Estrategia de producto } & 100\end{array}$

5.1.2. Estrategia de precio 106

5.1.3. Estrategia de distribución y plaza 107

5.1.4. Estrategia de promoción y publicidad 108

$\begin{array}{lll}5.1 .4 & \text { Estrategia de personas } & 111\end{array}$

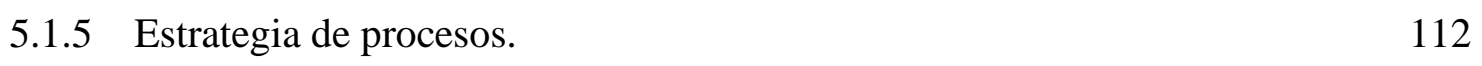

$\begin{array}{lll}\text { 5.1.6 Estrategia de presencia física } & 117\end{array}$

$\begin{array}{lll}5.2 & \text { Estrategia de Ventas } & 118\end{array}$

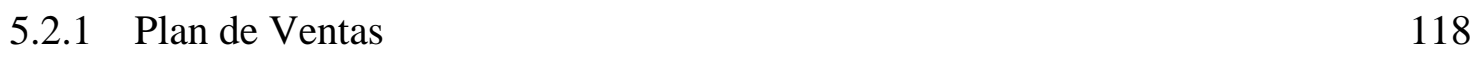

5.2.2 Política de servicios y garantías $\quad 119$

$\begin{array}{ll}\text { Capítulo VI. Pronóstico de Ventas } & 120\end{array}$

6.1. Fundamentos y Supuestos 120

6.2. Justificación 129

6.3 Análisis De Los Riesgos Y Aspectos Críticos Que Impactan En El Pronóstico 129

Capítulo VII. Ingeniería del Proyecto 131

7.1. Estudio de ingeniería 131

7.1.1 Modelamiento y selección de procesos productivos 131

7.1.2 Selección del equipamiento 133

7.1.3 Layout 135

$\begin{array}{ll}\text { 7.1.4 Distribución de equipos y maquinarias } & 137\end{array}$

7.2 Determinación del tamaño 139 
7.2.2. Recursos

7.2.3. Tecnología

7.2.4. Flexibilidad

7.2.5. Selección del tamaño ideal

7.3. Estudio de localización

7.3.1. Definición de factores locacionales

7.3.2. Consideraciones legales

7.3.2.1. Identificación del marco legal

7.3.2.2. Ordenamiento jurídico de la empresa

7.4 Determinación de la localización óptima

8.1. Caracterización de la cultura organizacional deseada 148

8.1.1. Visión

8.1.2. Misión

8.1.3. Principios

8.2. Formulación de Estrategias del Negocio

8.3. Determinación de las ventajas competitivas críticas

8.4. Diseño de la estructura organizacional deseada

8.5. Diseño de los perfiles de puesto clave

8.6. Remuneraciones, compensaciones e incentivos

8.7. Política de recursos humanos

9.1.2. La Inversión en capital de trabajo

9.1.3. Costo del proyecto

9.1.4. Inversiones futuras.

9.2. Financiamiento.

9.2.1. Endeudamiento y condiciones.

9.2.2. Capital y costo de oportunidad

9.2.3. Costo de capital promedio ponderado 
9.3.5. Presupuesto de marketing y ventas

$\begin{array}{ll}\text { 9.3.6. Presupuesto de gastos financieros } & 178\end{array}$

$\begin{array}{ll}\text { 9.4. Presupuestos de Resultados } & 179\end{array}$

9.4.1 Estado de Ganancias y Pérdidas $\quad 179$

9.4.2. Estado de Situación Financiera proyectado 179

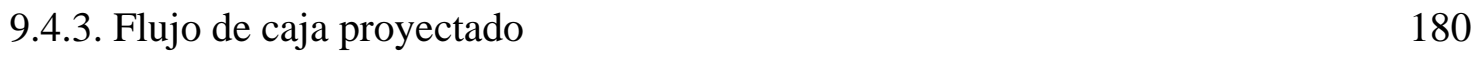

Capítulo X. Evaluación Económica Financiera 183

10.1. Evaluación Financiera 183

$\begin{array}{ll}\text { 10.1.1. TIR } & 183\end{array}$

10.1.2. VAN 183

10.1.3. Periodo de Recuperación de la Inversión Descontado 184

$\begin{array}{ll}\text { 10.1.4. ROE } & 184\end{array}$

$\begin{array}{ll}\text { 10.1.5. Ratios } & 184\end{array}$

10.2. Análisis de Riesgo 185

10.2.1. Análisis de punto de equilibrio $\quad 185$

10.2.2. Análisis de sensibilidad 186

10.2.4. Identificación de riesgos del proyecto 186

Conclusiones y Recomendaciones 191

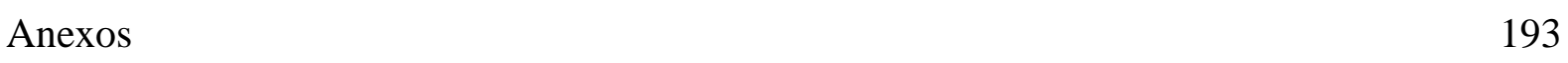

Anexo 1: Fichas Técnicas de Focus Group 193

Anexo 2: Guía de pautas de Focus Group 197

Anexo 3: Ficha técnica de entrevista a profundidad - Docente de carrera de

Administración de Hoteles y Restaurantes en ISIL. 202

Anexo 4: Guía de entrevista a profundidad - Coordinador y Docente de la carrera de

Administración de Hoteles y Restaurantes en ISIL. 203

Anexo 5: Ficha técnica de entrevista a profundidad - Dueño de restaurante 208

Anexo 6: Guía de entrevista a profundidad - Dueño de restaurante 209

Anexo 7: Ficha técnica de entrevista a profundidad - Chef 215

Anexo 8: Guía de entrevista a profundidad - Chef 216

Anexo 9: Detalle de inversiones en activo fijos 223

Anexo 10: Detalle de costeo por tipo de plato 227

Anexo 11: Detalle de plan de marketing anual, año 1

Encuesta 236

$\begin{array}{ll}\text { Referencias } & 248\end{array}$ 


\section{Índice de Tablas}

Tabla 1 Distribución de Restaurantes Categorizados y No Categorizados..............................22

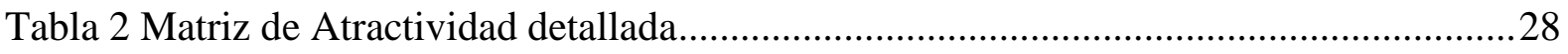

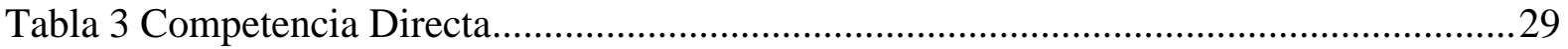

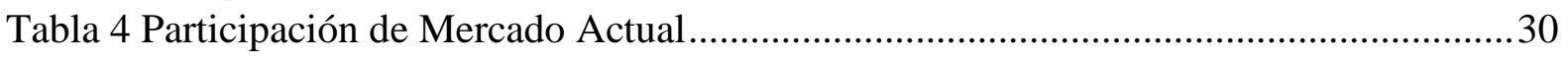

Tabla 5 Participación de Mercado incluyendo el proyecto.................................................... 31

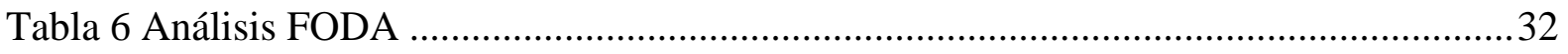

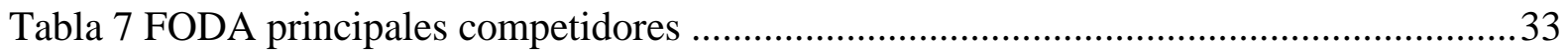

Tabla 8 Matriz del perfil competitivo de la Competencia Directa......................................... 34

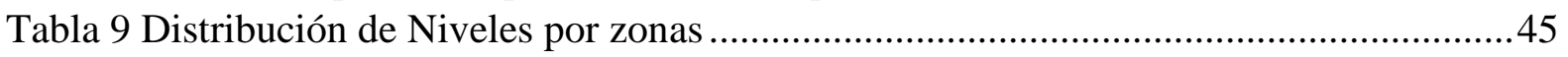

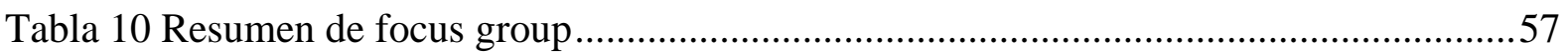

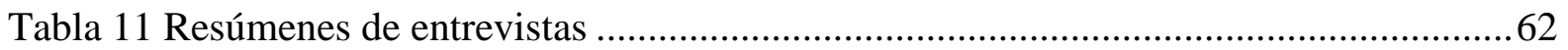

Tabla 12 Perfil del Consumidor Tipo y sus Variantes ........................................................... 93

Tabla 13 Población histórica de Villa el Salvador ................................................................. 95

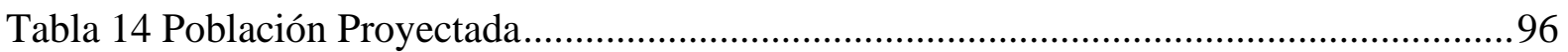

Tabla 15 Distribución de la población por Territorios (En porcentaje) ..................................97

Tabla 16 Población quinquenal en Villa El Salvador (en número de personas) ......................97

Tabla 17 Distribución de la población por Estrato Socioeconómico (En porcentaje) .............97

Tabla 18 Mercado Potencial (en número de personas) ..........................................................98

Tabla 19 Mercado Disponible (en número de personas) .................................................... 98

Tabla 20 Mercado Efectivo (en número de personas) ...........................................................98

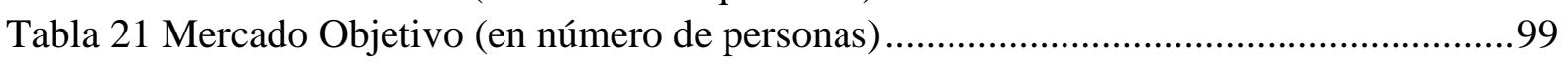

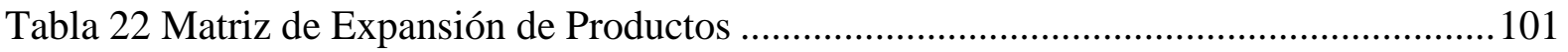

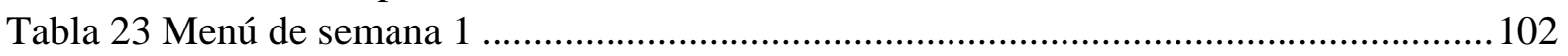

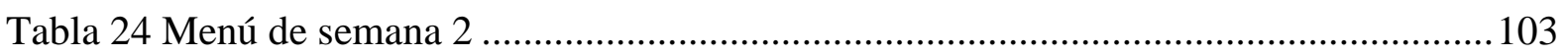

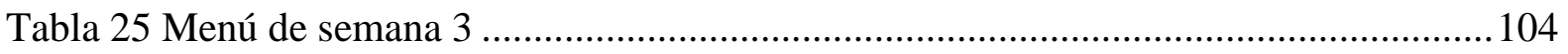

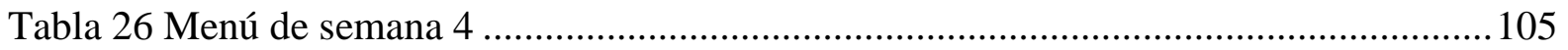

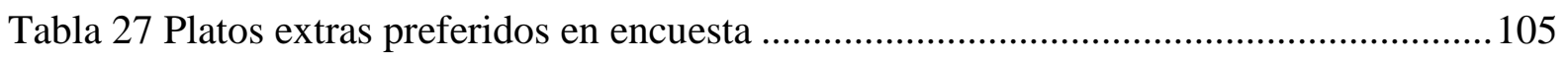

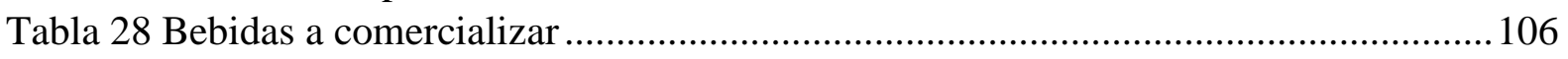

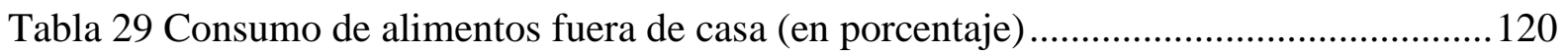

Tabla 30 Mercado Objetivo de almuerzos (en número de personas)....................................120

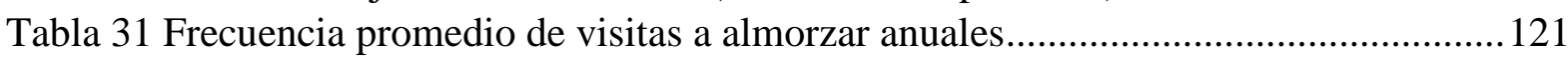

Tabla 32 Ventas promedio por visita en almuerzos (en número) .......................................121

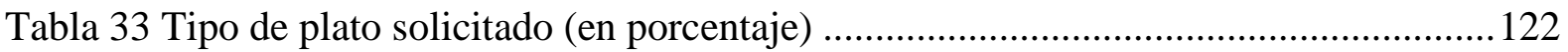

Tabla 34 Modalidad de entrega (en porcentaje) ................................................................ 122

Tabla 35 Número de almuerzos a comercializar anuales (en unidades y por tipo) ................ 122

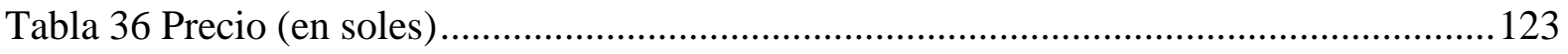

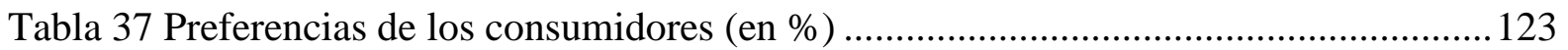

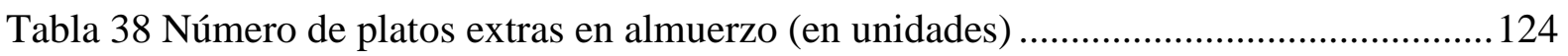

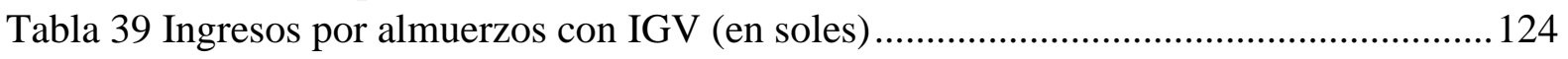

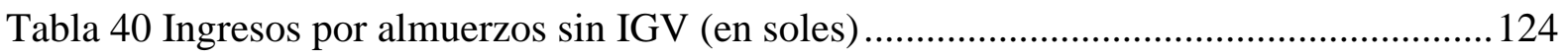

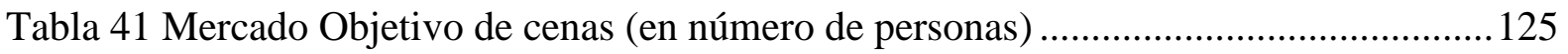

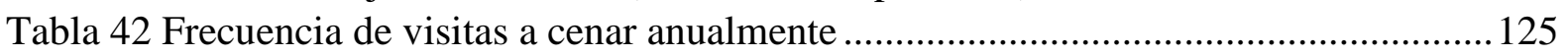

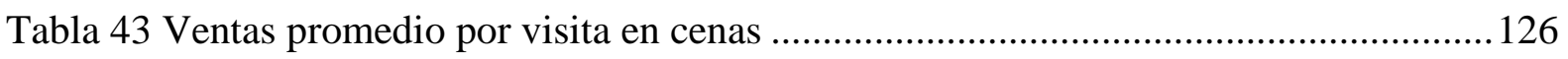

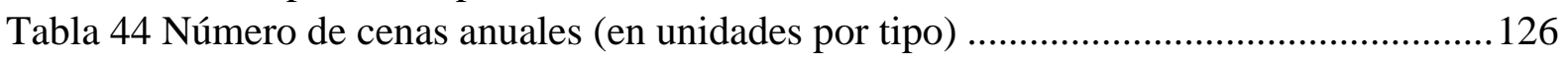

Tabla 45 Ingresos por cenas y por tipo de cena con IGV (en soles) ...................................127

Tabla 46 Ingresos por cenas y por tipo de cena sin IGV (en soles) ..................................... 127 


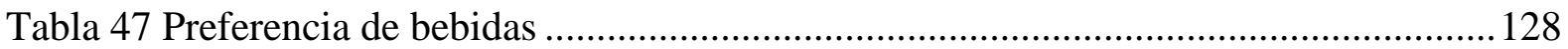

Tabla 48 Ingresos consolidados de bebidas con IGV (en soles)......................................... 128

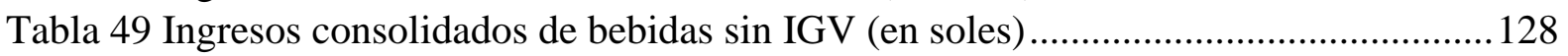

Tabla 50 Ingresos consolidados por tipo con IGV (en soles) ............................................. 129

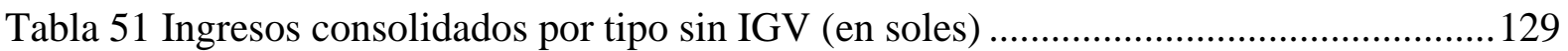

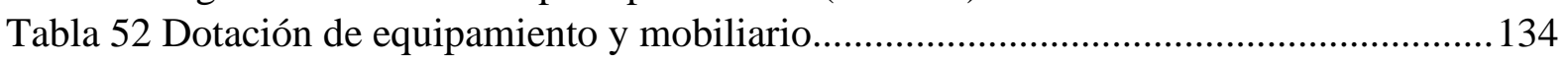

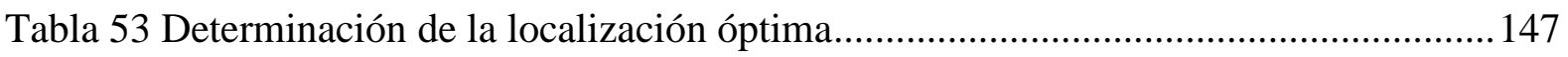

Tabla 54 Cálculo de número de Mozos, turno Almuerzo .................................................... 152

Tabla 55 Cálculo de número de Mozos, turno Cena.............................................................. 152

Tabla 56 Cálculo de número de Personal de Cocina, turno Almuerzo ..................................... 153

Tabla 57 Cálculo de número de Personal de Cocina, turno Cena........................................... 153

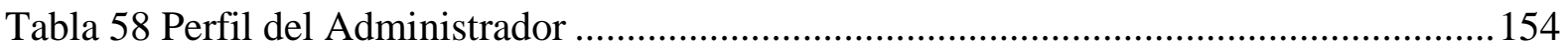

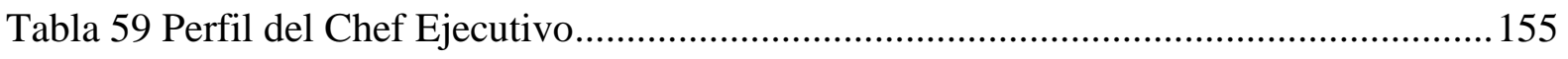

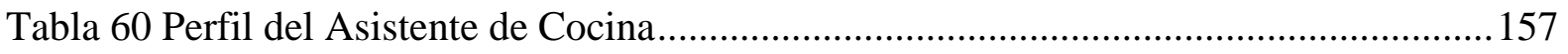

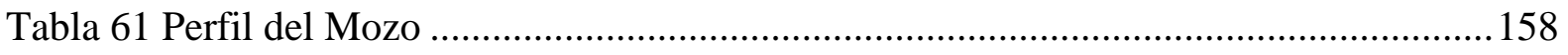

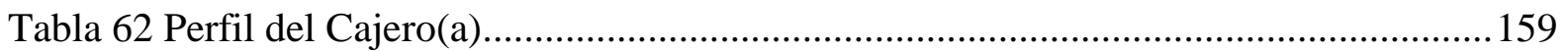

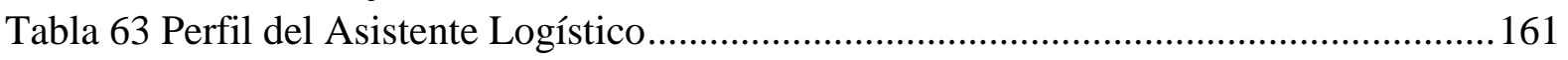

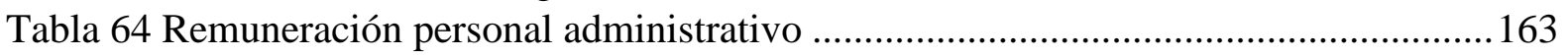

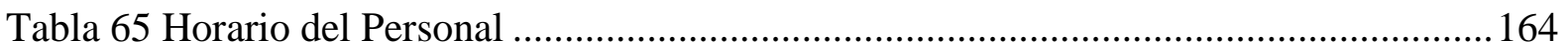

Tabla 66 Inversión en Activos Fijos de Producción (en soles).............................................. 168

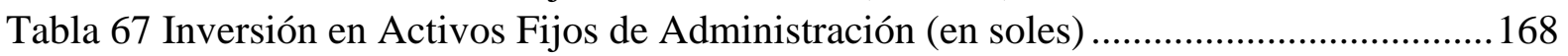

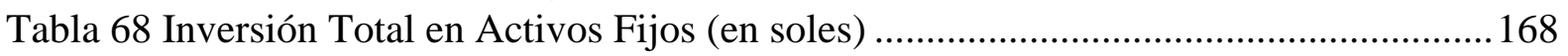

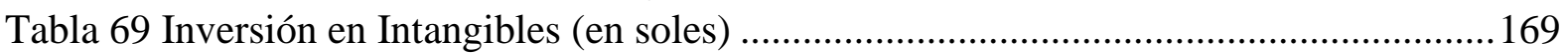

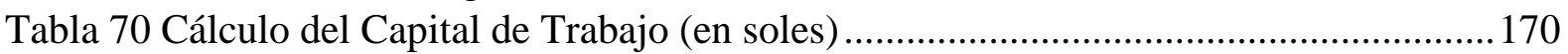

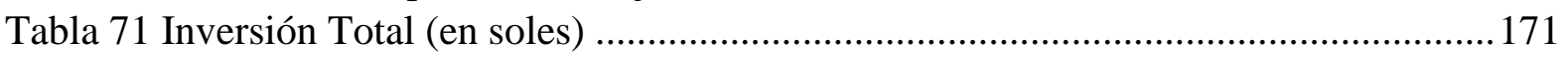

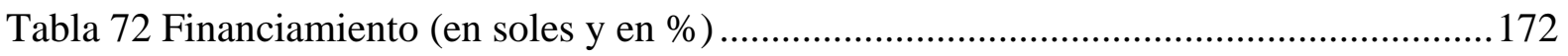

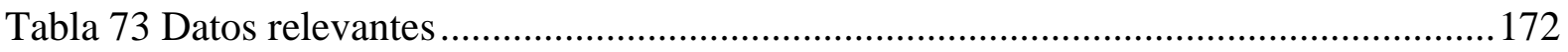

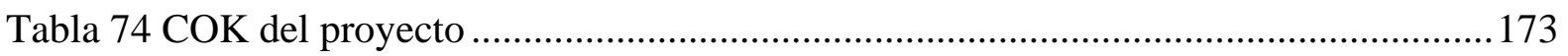

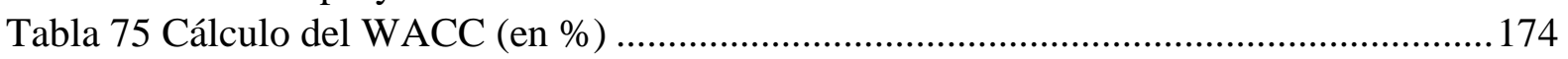

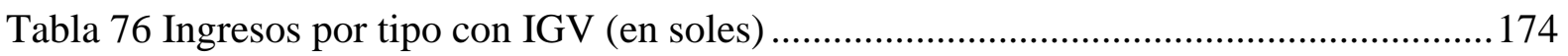

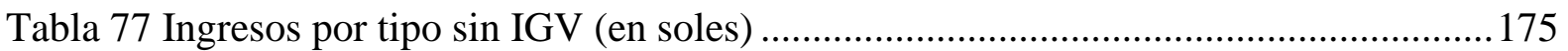

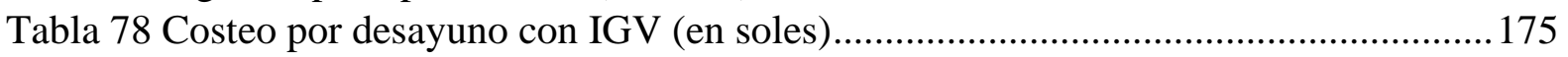

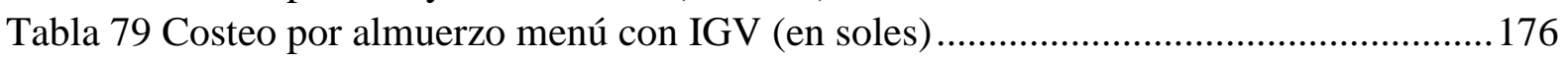

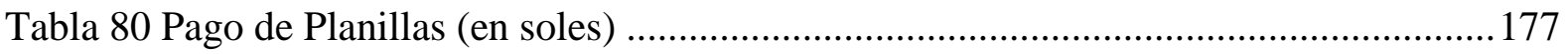

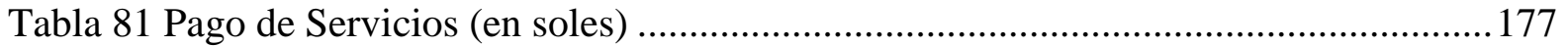

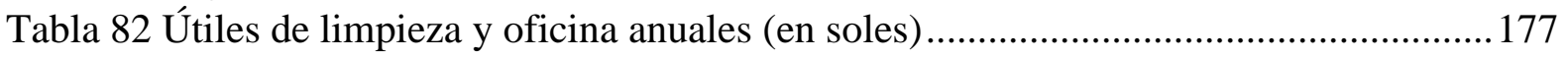

Tabla 83 Presupuesto proyectado de gastos de ventas (en soles) ......................................... 178

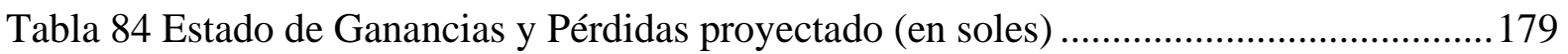

Tabla 85 Estado de Situación Financiera proyectada (en soles) ...........................................180

Tabla 86 Flujo de Caja Libre para el Accionista (en soles) ................................................. 181

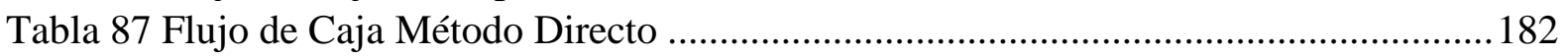

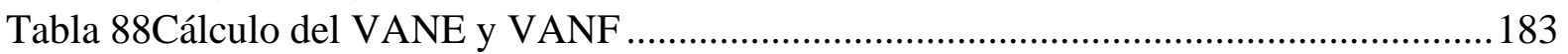

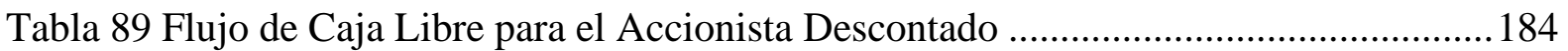

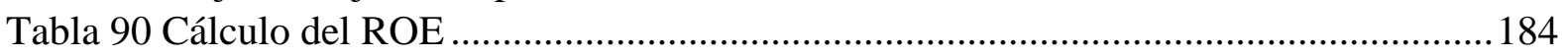

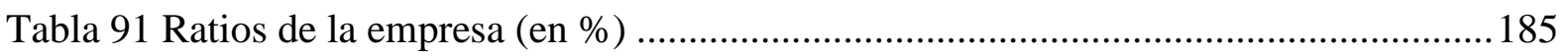

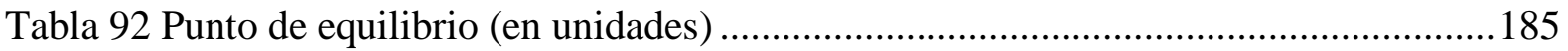

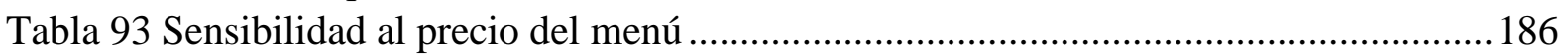

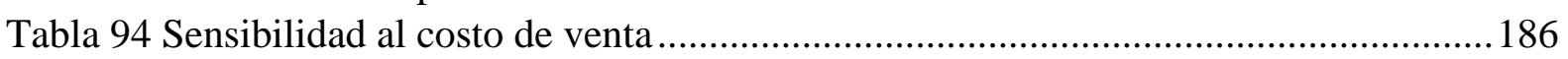




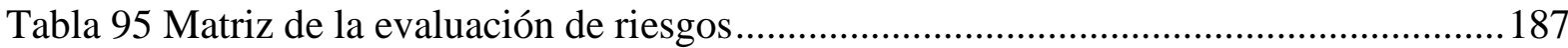

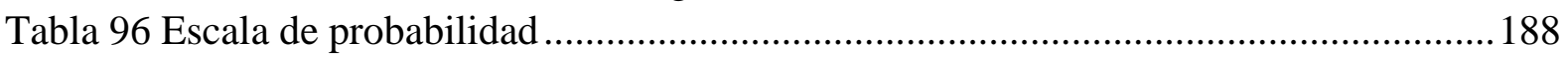

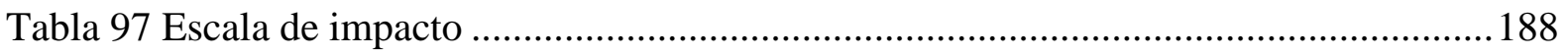

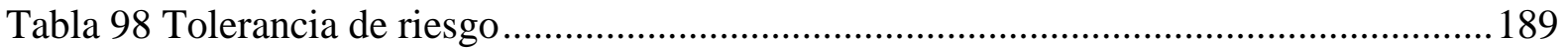

Tabla 99 Evaluación, Análisis y Estrategia de respuesta.....................................................190 


\section{Índice de Ilustraciones}

Ilustración 1. Evolución porcentual del PBI a través de los años, adaptado de "Estadísticas,

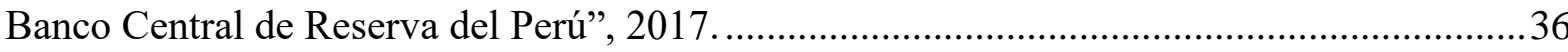
Ilustración 2. Pregunta filtro 1: ¿Podría decir qué edad tiene? Adaptado de encuesta aplicada.

Ilustración 3. Pregunta filtro 2: ¿Vive, labora o estudia cerca al lugar donde actualmente nos encontramos (Territorio III)? Adaptado de encuesta aplicada.

Ilustración 4. Pregunta filtro 3: En el último mes, ¿ha salido a comer fuera de casa? Adaptado de encuesta aplicada.

Ilustración 5. Pregunta general 1: ¿Qué tipo de comida prefiere entre días de semana?

Adaptado de encuesta aplicada.

Ilustración 6. Pregunta general 2: ¿Qué comidas consume fuera de casa? Adaptado de encuesta aplicada.

Ilustración 7. Pregunta general 3: Por lo general, ¿qué días suele ir a comer fuera de casa?

Adaptado de encuesta aplicada.

Ilustración 8. Pregunta general 4: ¿Suele desayunar fuera de casa? Adaptado de encuesta

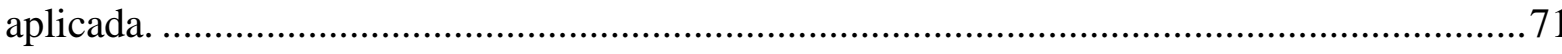

Ilustración 9. Pregunta general 5: ¿Cuántas veces por semana suele desayunar fuera de casa?

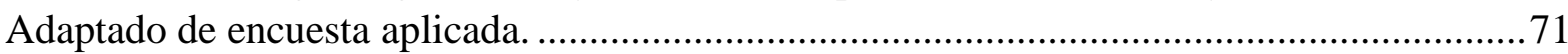

Ilustración 10. Pregunta general 6: ¿Con cuántas personas suele desayunar fuera de casa?...72

Ilustración 11. Pregunta general 7: ¿Cuántas veces por semana suele almorzar fuera de casa?

Ilustración 12. Pregunta general 8: ¿Con cuántas personas suele almorzar fuera de casa?

Adaptado de encuesta aplicada.

Ilustración 13. Pregunta general 9: ¿Cuántas veces por semana suele cenar fuera de casa?

Adaptado de encuesta aplicada.

Ilustración 14. Pregunta general 10: ¿Con cuántas personas suele cenar fuera de casa?

Adaptado de encuesta aplicada.

Ilustración 15. Pregunta general 11: ¿Con qué sueles acompañar su almuerzo o cena?

Adaptado de encuesta aplicada.

Ilustración 16. Pregunta 12. ¿Por qué motivo suele ir a comer fuera de casa? Adaptado de encuesta aplicada.

Ilustración 17. Pregunta general 13: Clasifique los distintos atributos de restaurantes por orden de importancia. 1 es muy importante y 8 es menos importante. Adaptado de encuesta aplicada.

Ilustración 18. Pregunta general 14: Cuando sale a comer fuera de casa ¿Ud. prefiere pedir menú o plato a la carta? Adaptado de encuesta aplicada.

Ilustración 19. Pregunta general 15: ¿Cuánto está dispuesto a pagar por un menú? Adaptado

de encuesta aplicada..

Ilustración 20. Pregunta general 16: ¿Cuánto está dispuesto a pagar por un plato a la carta?

Adaptado de encuesta aplicada.

Ilustración 21. Pregunta general 17: ¿Cuánto tiempo está dispuesto a esperar por un menú?

Adaptado de encuesta aplicada.

Ilustración 22. Pregunta general 18: ¿Cuánto tiempo está dispuesto a esperar por un plato a la

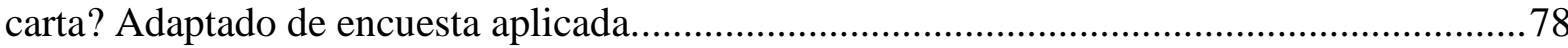

Ilustración 23. Pregunta general 18.1: ¿Cuál es su horario habitual de almuerzo? Adaptado de encuesta aplicada. 
Ilustración 24. Pregunta general 18.2: ¿Cuál es el tiempo que demora en almorzar? Adaptado de encuesta aplicada...

Ilustración 25. Pregunta general 18.3: ¿Cuál es su horario habitual de cena? Adaptado de encuesta aplicada.

Ilustración 26. Pregunta general 18.4: ¿Cuál es el tiempo que demora en cenar? Adaptado de encuesta aplicada.

Ilustración 27. Pregunta general 19: ¿Suele pedir delivery? De ser negativa la respuesta, indique el motivo. Adaptado de encuesta aplicada.

Ilustración 28. Pregunta general 20: Cuando pide un servicio delivery ¿para cuántas personas lo solicita? Adaptado de encuesta aplicada.

Ilustración 29. Pregunta general 21: Le cobran algún recargo adicional por el servicio de delivery? Adaptado de encuesta aplicada.

Ilustración 30. Pregunta general 22: ¿Qué ambiente prefiere para almorzar? Adaptado de encuesta aplicada.

Ilustración 31. Pregunta general 23: ¿Ud. tiene algún restaurante preferido en esta zona?

(Territorio III de Villa El Salvador). Adaptado de encuesta aplicada. ..................................82 Ilustración 32. Pregunta general 24: Si en la pregunta anterior su respuesta ha sido positiva, ¿cuál es? Adaptado de encuesta aplicada.

Ilustración 33. Pregunta general 25: ¿Cómo suele enterarse sobre nuevos restaurantes?

Adaptado de encuesta aplicada.

Ilustración 34. Pregunta general 26: ¿Cómo suele enterarse del menú o carta del día de un restaurante? Adaptado de encuesta aplicada.

Ilustración 35. Pregunta sobre propuesta de valor 1: ¿Ud. Iría a este restaurante? Adaptado de encuesta aplicada.

Ilustración 36. Pregunta sobre propuesta de valor 2. ¿Ud. pediría delivery de este restaurante?

Adaptado de encuesta aplicada.

Ilustración 37. Pregunta sobre propuesta de valor 3: ¿Qué desayunos le gustaría encontrar?

Adaptado de encuesta aplicada.

Ilustración 38. Pregunta sobre propuesta de valor 4: ¿Cuánto estaría dispuesto a pagar por un

desayuno en este restaurante? Adaptado de encuesta aplicada.

Ilustración 39. Pregunta sobre propuesta de valor 5: ¿Cuál de estas entradas le gustaría encontrar en el restaurante? Adaptado de encuesta aplicada.

Ilustración 40. Pregunta sobre propuesta de valor 6: ¿Qué tipo de plato de fondo desearía encontrar? Adaptado de encuesta aplicada.

Ilustración 41. Pregunta sobre propuesta de valor 7: ¿Qué tipo de refresco le gustaría encontrar? Adaptado de encuesta aplicada.

Ilustración 42. Pregunta sobre propuesta de valor 8: ¿Cuánto estaría dispuesto a pagar por menú de este restaurante? Adaptado de encuesta aplicada.

Ilustración 43. Pregunta sobre propuesta de valor 9: ¿Qué platos a la carta le gustaría encontrar? Adaptado de encuesta aplicada.

Ilustración 44. Pregunta sobre propuesta de valor 10: ¿Cuánto estaría dispuesto a pagar por un plato a la carta de este restaurante? Adaptado de encuesta aplicada.

Ilustración 45. Pregunta sobre propuesta de valor 11: ¿Le gustaría encontrar bebidas alcohólicas los fines de semana? Adaptado de encuesta aplicada.

Ilustración 46. Pregunta sobre propuesta de valor 12: ¿Qué bebidas alcohólicas le gustaría encontrar? Adaptado de encuesta aplicada.

Ilustración 47. Pregunta sobre propuesta de valor 13: ¿Qué nombre le gustaría que tenga este restaurante? Adaptado de encuesta aplicada. 
Ilustración 48. Pregunta sobre propuesta de valor 14: ¿Qué metodo de pago prefiere utilizar? Adaptado de encuesta aplicada. 91

Ilustración 49. Volante con el plano de ubicación del local ................................................... 107

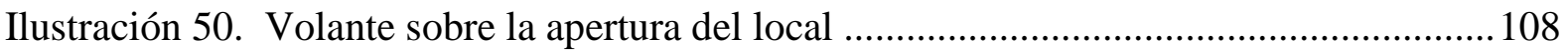

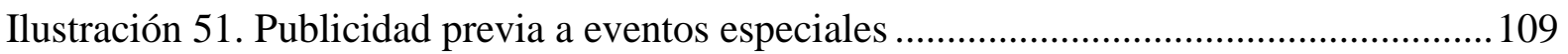

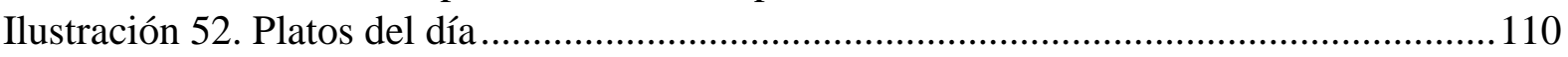

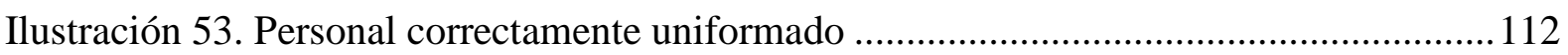

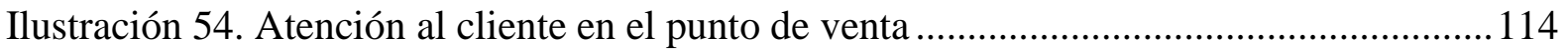

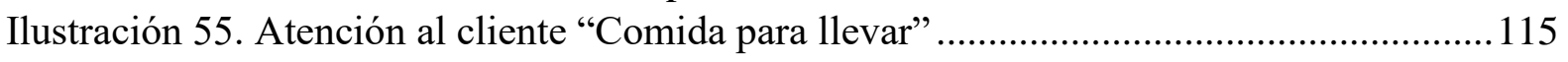

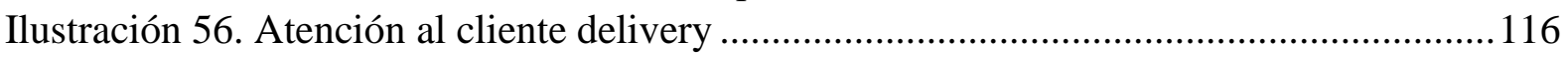

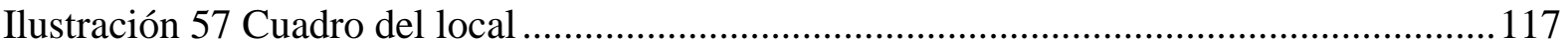

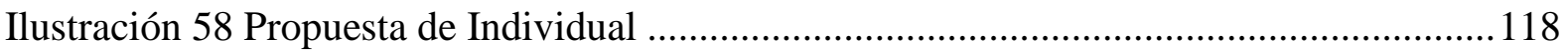

Ilustración 59. Flujo de la preparación del Menú y/o Platos a la Carta ................................. 132

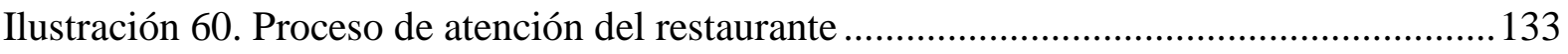

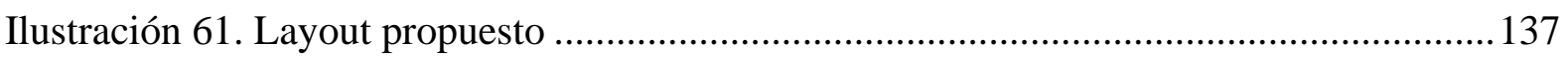

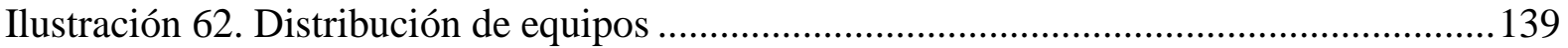

Ilustración 63. Mapa de Distribución Territorial de Villa El Salvador................................... 143

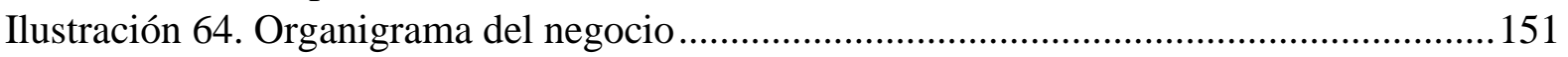




\section{Introducción}

La gastronomía peruana desde hace muchos años es un fuerte motor para el desarrollo económico y turístico del Perú. Es la cocina peruana el tipo de comida preferido por todos los sectores y estratos sociales de la población local y extranjera, razón por la cual es reconocida mundialmente como una de las mejores.

El presente proyecto tiene como meta evaluar la viabilidad de la implementación de un restaurante de comida peruana en el distrito de Villa El Salvador, teniendo el municipio amplias oportunidades de desarrollo; debido a las fuertes inversiones que se tienen en cartera y a la perseverancia de su población.

Para tal propósito, se llevó a cabo un plan de trabajo, el cual incluyó la búsqueda previa de información relevante al tema elegido, para lo que se ha consultado diferentes fuentes bibliográficas, tanto escritas como electrónicas. Seguidamente, se procedió al manejo de datos estadísticos de la Municipalidad de Villa El Salvador, los cuales fueron recaudados para la utilización de los métodos de proyección de mercado objetivo, utilizando el método de proyección cuantitativo causal de regresión.

En base a los resultados obtenidos con los instrumentos aplicados para la recolección de datos, se procedió a elaborar las estrategias de marketing, estrategias de precios, de promoción y publicidad. De igual manera, se planificaron las estrategias de personas y de procesos para lograr el desempeño adecuado y alcanzar todos los objetivos de la empresa.

De acuerdo con las inferencias elaboradas con la información que resultó en el procesamiento de los datos recabados, entre otras conclusiones, se determina que, según el análisis financiero, el presente proyecto es económicamente viable. Además, el proyecto es muy sensible al precio de los servicios ofertados. 


\section{Resumen Ejecutivo}

A continuación, se presenta el resumen de los capítulos contenidos en el plan de negocios:

- Capítulo 1: Generalidades. En este capítulo se presenta los objetivos, alcances y

limitaciones que tiene el proyecto de hacer un restaurante en el distrito de Villa El Salvador.

- Capítulo 2: Estructura Económica del sector. Se detalla la información del sector gastronómico en el distrito de Villa El Salvador, así como también la situación actual de la gastronomía peruana.

- Capítulo 3: Estudio de Mercado. Abarca el estudio a nivel cualitativo (focus group y entrevistas en profundidad); y cuantitativo (encuestas) a nivel Villa El Salvador el cual demuestra la importancia de la estadística para el cálculo del mercado objetivo.

- Capítulo 4: Proyección del mercado objetivo. Determina el tamaño del mercado potencial, disponible, efectivo y objetivo.

- Capítulo 5: Plan de Marketing. Define las estrategias de desarrollo de producto y de distribución del restaurante, con ayuda del análisis del marketing mix, esto con el fin de promocionar y dar a conocer la idea de negocio.

- Capítulo 6: Pronóstico de Ventas. Se define la demanda proyectada para los próximos cinco años de vida útil que tendrá el presente proyecto.

- Capítulo 7: Ingeniería del Proyecto. Se define todos los aspectos técnicos como el layout, tecnología a utilizar, recursos, etc.

- Capítulo 8: Aspectos Organizacionales. Se define la parte estrategia de la organización, así como sus valores y principios.

- Capítulo 9 y 10: Planificación Financiera y Evaluación Económica y financiera. Se presentan los estados financieros proyectados principales y la evaluación de la rentabilidad del Plan de Negocios, a través de la determinación de los indicadores de viabilidad económica como son el VAN y TIR. 
- Finalmente, se establecen las conclusiones y recomendaciones planteadas para poder hacer de este proyecto un negocio rentable, salvaguardando la higiene en toda la cadena de valor y asegurando la calidad de los platos preparados cumpliendo con las exigencias de los clientes. 


\section{Capítulo I. Generalidades}

\subsection{Antecedentes}

La propuesta de los restaurantes nace en el siglo XVII en Francia cuando Boulanger, un emprendedor local, abre un pequeño comedor dentro de un establecimiento donde vendía sopas y caldos. Este lugar fue llamado restaurant que en francés significa restaurador; ya que llenaba de energía a sus comensales. En el restaurante de Boulanger, Champú d'Oiseau, se cobraba precios suficientemente altos que marcaban distinción entre las personas que lo visitaban. De esta manera, los restaurantes se hicieron más populares y rentables, y los cocineros que trabajaban de forma privada para familias de altos ingresos empezaron a abrir sus negocios o fueron contratados por un grupo de emprendedores: los restauradores.

Los inmigrantes de Europa recrearon en América los establecimientos de comida y bebidas en el siglo XVIII, los mismos que tuvieron un alto nivel de popularidad. Desde entonces, se crearon las tabernas que vendían comida y distintos licores como cerveza, vino y ron, convirtiéndose en importantes centros de reunión dentro de sus comunidades. En el siglo XIX, creció el número y la variedad de comida ofrecida en establecimientos de manera sorprendente, por lo que se industrializó y la provisión de este servicio se volvió menos costosa; de esta manera las personas que no tenían facilidad para cocinar en sus hogares adquirían comida a un precio bajo. Al mismo tiempo, se especializó este servicio en hoteles y restaurantes, los mismos que ofrecían comida y licores exclusivos para el creciente número de personas adineradas de América. Desde entonces, comer fuera de casa se convirtió en un importante concepto dentro de la vida de los americanos. (Dittmer, 2002).

Con la llegada de los españoles y posteriores inmigraciones hacia el Perú, se generó un intercambio cultural y culinario. En primera instancia, la gastronomía peruana se convirtió en una combinación entre la cocina amerindia y europea, teniendo como base el maíz, papas y frijoles, complementados por el arroz, trigo y carne que trajeron los españoles. A medida que los inmigrantes llegaron con los años provenientes de África, China y Japón, los 
elementos de las tradicionales gastronomías extranjeras fueron incorporados a la mezcla amerindia-española; en consecuencia, se creó una gastronomía peruana variada con la influencia de distintas etnias y beneficiada por una amplísima diversidad climática y una despensa biológica envidiable. (Influencias históricas de la gastronomía peruana, gediscovery.edu.pe, 2016).

Con la pacificación nacional y el crecimiento económico experimentado en la década de 2000, distintos personajes incursionaron en el sector, tales como: Rosita Yimura, Bernardo Roca Rey, Mariano Valderrama y Tony Custer. Hubo un cambio conceptual de la cocina, es así como Pedro Miguel Sciaffino preparaba comida peruana moderna en la Huaka Pucllana y Gastón Acurio igualaba el valor de los huariques con el de los establecimientos más lujosos a través de su programa televisivo Aventura Culinaria, emitido en señal abierta.

En el 2004, Rafael Piqueras, peruano de nacimiento, fue el primer cocinero sudamericano en presentarse en Madrid Fusión, el congreso de gastronomía más importante del mundo. Con esto, se consolidó el prestigio de la cocina peruana en Europa. En el 2007, con Gastón Acurio en la presidencia, se fundó Apega y en el 2008, se desarrolló la primera edición de Mistura, la feria gastronómica con mayor concurrencia a nivel nacional donde acuden celebridades de la cocina tales como Ferran Adrià y René Redzepi. (semanaeconomica.com, 2015).

Desde entonces, todos los años en el mes de septiembre se realiza Mistura, incluso para la edición de 2017, ya cuentan con un local propio. Adicionalmente, se organiza la feria Expo alimentaria, la más grande la región que constituye el punto de encuentro internacional de empresas exportadoras y compradores provenientes de todo el mundo. También, se realiza Gastromaq, feria internacional que reúne información y contactos de proveedores para la industria gastronómica. (Guías de Negocios e Inversión en el Perú, EY, 2016).

Durante los últimos años, Perú ha venido recibiendo distintos reconocimientos como el mejor destino culinario a nivel mundial, entre ellos el ofrecido por el World Travel 
Awards, importante premiación internacional que galardonan la excelencia en todos los sectores relacionados a la industria del turismo.

\subsection{Determinación del Problema}

Según los resultados en los últimos censos, Lima Metropolitana concentra el 32,3\% de la población peruana con 9485400 de habitantes, existiendo en promedio 272.3 habitantes por kilómetro cuadrado. Además, se identifica una tasa de Crecimiento Promedio anual a nivel departamental de los Censos 2007 y 2017 de 1.2\% (INEI, 2018).

De acuerdo a los datos brindados por la municipalidad e Villa El Salvador, a mayo del 2019, existían 586 restaurantes en actividad. De esta manera, el servicio de alojamiento y comida constituían el 21.09\% de la actividad económica del distrito. (Perú: Estructura Empresarial, INEI, 2014).

Mediante la observación directa del distrito se ha detectado que Villa El Salvador, el cual viene creciendo económicamente de manera sostenida con la construcción de zonas industriales y comerciales alrededor, cuenta con pocos restaurantes que ofrezcan comida de calidad junto a un servicio diferenciado. Esto ocasiona una demanda insatisfecha en medio de un escenario donde se puede desarrollar un negocio dado el volumen poblacional y comercial (INEI, 2018c).

En conclusión, el presente proyecto de investigación desarrolla una oferta gastronómica de calidad y a precios módicos en el distrito de Villa el Salvador, donde se ofrecerá una carta de comida variada y contará con una infraestructura adecuada destinada a los vecinos de la zona, trabajadores y estudiantes que realicen sus labores en áreas aledañas al restaurante en mención.

\subsection{Justificación del Proyecto}

Se identificó que, en Lima Metropolitana, dado el contexto social que se experimenta, las personas que trabajan poseen poco tiempo disponible para preparar sus alimentos, lo que les obliga a consumirlos fuera de casa. Según un estudio Arellano Marketing, publicado en el 
2017, el $80 \%$ de personas come fuera del hogar, pagando en promedio S/ 9.12 diarios. (RPP Noticias, 2017).

Además, según la Encuesta Mensual de Comercio, Restaurants y Servicios 2018, el grupo de restaurantes en el mes de julio creció en $2.20 \%$, siguiendo la tendencia positiva de los últimos 16 meses. Lo que permite reconocer que el ingreso al sector es favorable. (INEI, 2018d)

El presente plan de negocio busca ofrecer una alternativa diferenciada para la demanda insatisfecha descrita en el apartado anterior. Asimismo, se busca difundir de manera positiva la gastronomía peruana en el distrito de Villa el Salvador y la zona sur de Lima, que concentra casi el 6\% de la población de Lima Metropolitana.

\subsection{Objetivos Generales y Específicos}

El proyecto tiene como objetivo general la elaboración de un plan de negocio para la implementación de un restaurante de comida criolla, marina y bebidas en el distrito de Villa el Salvador, Lima, Perú 2018.

Los objetivos específicos son:

a) Conocer la estructura del sector gastronómico del distrito de Villa el Salvador.

b) Realizar un estudio de mercado del proyecto.

c) Realizar ingeniería del proyecto y determinar la estructura organizacional para la empresa.

d) Elaborar el plan de marketing.

e) Elaborar la planificación financiera.

f) Evaluar la viabilidad económico-financiera del proyecto.

\subsection{Alcances y Limitaciones}

La investigación abarca únicamente al sector gastronómico en el Territorio III del distrito de Villa el Salvador. 
El presente proyecto tendrá las siguientes limitaciones:

a) Acceso a la información de la competencia.

b) Acceso limitado a la información de la Municipalidad de Villa el Salvador.

c) Antigüedad de la información del sector. 


\section{Capítulo II. Estructura Económica del Sector}

\subsection{Descripción del Estado Actual de la Industria}

La industria de la comida, y en general la cultura gastronómica en nuestro país, da cuenta de un vertiginoso y continuo desarrollo. En los últimos quince años, se ha producido un espectacular boom gastronómico en el Perú, ha habido un claro repunte que la convierte en una fuerza dinamizadora de la economía nacional.

En Lima Metropolitana y la Provincia Constitucional del Callao, existen 47

mil restaurantes: en Lima Centro, se ubican 14 mil 635 restaurantes (31.1\%); en Lima Norte, 11 mil 19 restaurantes (23.4\%); en Lima Este, 10 mil 251 restaurantes (21.8\%); en Lima Sur, 7 mil 159 restaurantes (15.2\%); y en el Callao, 3 mil 944 restaurantes (8.4\%). De acuerdo con la sociedad Peruana de Gastronomía (Apega), el gasto en alimentación en el 2011 fue de 45,000 millones de soles aproximadamente, lo que representa el 9.5\% del PBI (Producto Bruto Interno). (INEI: Lima tiene 9 millones 752 mil habitantes al cumplir 480 años de fundación, andina.com.pe, 2015).

Actualmente, se considera a los restaurantes peruanos como los mejores de América Latina y líderes en el mundo. Perú ha sido, incluso, considerado en los World Travel Awards, por cinco años consecutivos, como el mejor destino gastronómico mundial y va camino a convertirse en un fuerte dinamizador de la economía. (Perú fue elegido por quinto año consecutivo como el Mejor Destino Culinario del Mundo, peru21.pe, 2016).

\subsubsection{Segmentación de la industria}

El MINCETUR (Ministerio de Comercio Exterior y Turismo) es el órgano encargado para la categorización y calificación de los restaurantes de acuerdo con las características que posee en función a infraestructura, servicios, competencias del personal y buenas prácticas de higiene.

De acuerdo con el Reglamento de Restaurantes Decreto Supremo No 025-2004 de MINCETUR, los restaurantes se segmentan en dos categorías: Categorizados (1 a 5 
tenedores) y No Categorizados. Solo el $1.5 \%$ del total de restaurantes en Perú está Categorizado.

Tabla 1

Distribución de Restaurantes Categorizados y No Categorizados

\begin{tabular}{cccc}
\hline Categoría En Número De & Cantidad De & Números De & Número De \\
Tenedores & Establecimientos & Mesas & Sillas \\
\hline Un Tenedor & 524 & 6,408 & 23,250 \\
Dos Tenedores & 301 & 6,756 & 24,536 \\
Tres Tenedores & 139 & 3,125 & 12,171 \\
Cuatro Tenedores & 6 & 340 & 1,270 \\
Cinco Tenedores & 15 & 439 & 1,848 \\
Sin Clasificación & 64,906 & 369,522 & $1,320,992$ \\
\hline Total & 65,891 & 386,590 & $1,384,067$ \\
\hline
\end{tabular}

Nota: Adaptado de "MINCETUR", por el Observatorio Turístico del País, 2014.

Por otro lado, los restaurantes pueden clasificarse en: cocina tradicional, cocina extranjera, fusión, comida rápida, temáticos, hoteleros, cafeterías, comedores, en los transportes, áreas de descanso, centros comerciales, a domicilio y take-away. (Gallego, J. 2001).

El presente proyecto cumple con los requisitos mínimos de restaurantes de un tenedor publicados por Decreto Supremo No 025-2004 de MINCETUR. Además, este restaurante ofrece comida tradicional, criolla y marina.

\subsubsection{Empresas que la conforman (ubicación, volumen de ventas, empleados,} etc.)

Según la relación de licencias vigentes entregada por la Municipalidad de Villa El Salvador en mayo 2019, existen 586 restaurantes en el distrito, los cuales se dividen en: bares (11\%), campestres $(6 \%)$, cevicherías $(14 \%)$, chifas $(13 \%)$, criollos $(21 \%)$, juguerías $(10 \%)$, 
pizzerías $(8 \%)$, y pollerías y brasas (17\%). Estos establecimientos se ubican alrededor de los nueve territorios zonificados.

\subsection{Tendencias de la Industria}

Según el Instituto Nacional de Estadística e Informática (INEI), en julio de 2018 el sector de restaurantes creció en $2.56 \%$, registrando 16 meses de crecimiento positivo. En el 2015, la frecuencia promedio que una persona comía en restaurantes era de 2.24, valor que aumentó en el 2017, en un 24\%; ya que la frecuencia promedio por persona era 2.77. (INEI, 2018d).

Según la Agencia Andina, publicado en el diario de Gestión, "Salir a comer es una de las principales actividades que los peruanos realizan en su tiempo libre", hay un reconocimiento de la población y de los turistas por la calidad de la comida peruana. (Gestión, 2017).

Además de esto, el distrito de Villa El Salvador será sede de los Juegos Panamericanos en el 2019, razón por la cual se está construyendo una villa deportiva, la cual tendrá un área de 450,000 metros cuadrados y representa una inversión de USD 300 millones. Esta construcción consiste en 2,200 departamentos, zonas médicas, gimnasios, parques y un coliseo. Esta inversión en infraestructura conlleva una buena oportunidad de desarrollo para el distrito en todos los sectores. (Sede de los Panamericanos se construirá en Villa El Salvador, gestión.pe, 2016).

\subsection{Análisis Estructural del Sector Industrial}

El sector industrial se rige de acuerdo con la combinación de cinco fuerzas competitivas basadas en la propuesta de Michael E. Porter, profesor de la Harvard y referente en temas sobre administración estratégica. (Griffin, 2011). Estas fuerzas son:

a) Rivalidad entre competidores existentes. Thompson \& Strickland (2004) sostienen que "es la más poderosa de las cinco fuerzas competitivas que consiste en lograr una posición y la preferencia del comprador por el producto o servicio de uno en vez del de los vendedores 
rivales" (p.83). En el rubro del presente proyecto, la atractividad con respecto a la rivalidad entre competidores es baja debido a la gran cantidad de restaurante que existen en la ciudad de Lima, en el año 2012 era cerca de 39 mil 895 restaurantes y específicamente en la zona sur de la ciudad 7 mil 129 restaurantes (INEI). Para este análisis se considera lo siguiente:

- Número de competidores: Existe una fuerte competencia en el distrito debido a la gran cantidad de restaurantes que hay, esto de acuerdo a la relación de licencias vigentes entregada por la Municipalidad de Villa El Salvador a mayo 2019, existían 586 restaurantes en el distrito.

- Costos fijos: Se tiene en cuenta los pagos de servicios, sueldos y costos de alquiler, los cuales ya están plenamente establecidos.

- Crecimiento de la demanda: Es la demanda y atracción existente hacia los restaurantes de comida criolla, la cual está en crecimiento.

b) La amenaza de nuevos entrantes al mercado. Griffin (2011) sostiene que "es el grado al que los nuevos competidores pueden entrar con facilidad a un mercado o a un segmento de mercado" (p.83). La atractividad con respecto a la amenaza de ingreso de nuevos entrantes es baja debido a que incursionar en el rubro gastronómico es bastante asequible para cualquier emprendedor, sin embargo, se necesita un capital adecuado para hacer este negocio rentable y atractivo, prueba de esto es que en el año 2013 se preveía un crecimiento anual de $15 \%$ en la formación de nuevos restaurantes según Bernardo Roca Rey, presidente de la Sociedad Peruana de Gastronomía (Apega). (Existen 100 mil restaurantes en Perú, peru21.pe, 2013). Para este análisis se considera lo siguiente:

- Economías de escala: Las cadenas de restaurantes como Norkys o Rokys tienen una mayor ventaja debido a su manejo organizacional y rentabilidad gracias a la cantidad de locales que posee, es por esto que se necesita una buena inversión para poder lograr esto. 
- Diferenciación del producto: Existen en la zona diversos restaurantes, sin embargo, estos ofrecen platos de una forma muy convencional, el presente proyecto brinda un diferenciador que es la ambientación y la presentación de los platos.

- Costos por el cambio: Obtener la fidelidad del cliente requiere acciones y estrategias, esto se plantea a hacer en el presente proyecto, sin embargo, al consumidor le es fácil cambiar de restaurante si es que no encuentra un buen diferenciador.

- Requisitos de capital: Este sector tiene una necesidad de inversión alta si es que se quiere implementar un restaurante formal y adecuado, sin embargo, la informalidad permite que se improvise otro tipo de establecimientos del rubro.

- Acceso a canales de distribución: Este sector posee un canal de distribución simple, la cual se da en el local de comida, es por esto que el desafío es encontrar un local en una ubicación estratégica.

c) La amenaza de productos sustitutos. Griffin (2011) sostiene que "es el grado al que los productos o servicios alternos pueden suplantar o disminuir la necesidad de productos o servicios existentes" (p.83). Se considera que la atractividad con respecto a este factor es alta, debido a que, dentro del distrito de Villa el Salvador, no existen propuestas semejantes a las ofrecidas por este proyecto debido al incremento de venta de comida al paso de manera informal. Para este análisis se considera lo siguiente:

- Disponibilidad de sustitutos: Actualmente no se encuentran muchos restaurantes con características similares al de este proyecto, sin embargo, la cantidad de locales que ofrecen platos de comida similar es alta.

- Precio relativo entre el producto ofrecido y el sustituto: Hay una gran cantidad de restaurantes que diversos tipos de comida a diferentes precios.

d) El poder de negociación de los compradores. Griffin (2011) sostiene que "es el grado al que los compradores de bienes o servicios en una industria tienen la capacidad de 
influir en los proveedores" (p.83). La atractividad de este factor es regular, debido a la gran cantidad de restaurantes que existen hoy en Lima, 39 mil 895 restaurantes según INEI (2012). Son los clientes los que pueden exigir una mayor calidad en los productos ofrecidos o demandar un precio menor y son los restaurantes lo que deben adecuarse a las exigencias de los compradores debido a que estos pueden migrar a otro restaurante fácilmente. Para este análisis se considera lo siguiente:

- Concentración de clientes: Existe una gran cantidad de clientes que tienen preferencia por los platos de comida criollos, por lo tanto, el nivel de concentración de clientes es alto.

- Diferenciación: Los clientes escogen el restaurante según la variedad de los platos y los precios, este proyecto se diferencia por ofrecer una experiencia diferente a los restaurantes tradicionales, con productos de calidad, atención al cliente adecuada e infraestructura pintoresca.

- Costo de cambio para el consumidor: En el restaurante propuesto no se cobra costo de ingreso, es por esto que al consumidor no le genera ningún costo cambiar de opción.

e) El poder de negociación los proveedores, Griffin (2011) sostiene que "es el grado al que los proveedores tienen la capacidad de influir en los probables compradores”. La atractividad de este factor es alta debido a que dentro del sector gastronómico existe una gran cantidad de proveedores de diversos insumos y equipos para el sector gastronómico. En el 2016, se dio la tercera edición de la Feria Internacional de proveedores para la gastronomía y el sector hotelero, el cual convocó cerca de 150 expositores entre nacionales y extranjeros los cuales mostraron sus diversos productos entre maquinarias y equipamiento para restaurantes, suministros, alimentos, bebidas, insumos, etc. (150 expositores nacionales y extranjeros participarán en Gastromaq Perú 2016, larepublica.pe, 2016). 
Para este análisis se considera lo siguiente:

- Concentración de proveedores: La concentración de proveedores es variada debido a que se puede acceder a una gran cantidad de insumos de manera rápida y a diferentes precios.

- Costo por cambio de proveedor: Los restaurantes no asumen algún costo por cambiar de proveedor ya que esta variable es amplia y no asegura un vínculo definitivo.

- Disponibilidad de insumos sustitutos: Son pocos los insumos que puedan sustituir a los ingredientes empleados para la preparación de los platos ya que la mayoría de estos están disponibles todo el año.

A continuación, se detalla la matriz empleada para poder determinar el nivel de atractividad de la industria, se utilizaron ponderaciones y pesos determinados de acuerdo a la información brindada por las entrevistas realizadas a expertos (profesor de la carrera de gastronomía, chef y dueño de restaurante) y según el estudio del sector gastronómico realizado. 
Tabla 2

Matriz de Atractividad detallada

\begin{tabular}{|c|c|c|c|c|c|c|c|c|}
\hline Elemento de análisis & $\begin{array}{c}\text { Peso } \\
\text { del }\end{array}$ & Ponderación & & $\begin{array}{l}\text { Nive } \\
\text { tracti }\end{array}$ & $\begin{array}{l}\text { I de } \\
\text { vidac }\end{array}$ & & Resultado & Total \\
\hline & factor & & 1 & 23 & 4 & 5 & & \\
\hline \multicolumn{9}{|l|}{ 1.Amenaza de nuevos entrantes } \\
\hline Economías de escala & \multirow{6}{*}{0.15} & 0.20 & & $\mathrm{x}$ & & & & \\
\hline Costos por el cambio & & 0.15 & & $x$ & x & & & \\
\hline Requisitos de capital. & & 0.30 & $\mathrm{x}$ & & & & 2.8 & 0.30 \\
\hline Acceso a canales de distribución. & & 0.10 & & & $\mathrm{x}$ & & & \\
\hline Diferenciación del producto. & & 0.25 & & & & $\mathrm{x}$ & & \\
\hline Resultado ponderado & & 1.00 & & & & & Baja & \\
\hline \multicolumn{9}{|l|}{$\begin{array}{l}\text { 2. Poder de negociación de los } \\
\text { proveedores }\end{array}$} \\
\hline Concentración de proveedores & \multirow{4}{*}{0.25} & 0.35 & & & & $\mathrm{x}$ & & \\
\hline Costos por cambio de proveedor & & 0.40 & & & $\mathrm{x}$ & & 4.6 & 1.00 \\
\hline Disponibilidad de insumos sustitutos. & & 0.25 & & & & $\mathrm{x}$ & & \\
\hline Resultado ponderado & & 1.00 & & & & & Alta & \\
\hline \multicolumn{9}{|l|}{$\begin{array}{l}\text { 3. Poder de negociación de los } \\
\text { compradores }\end{array}$} \\
\hline Concentración de clientes & \multirow{4}{*}{0.20} & 0.45 & & & $\mathrm{x}$ & & & \\
\hline Diferenciación & & 0.30 & & & & $\mathrm{x}$ & 3.8 & 0.60 \\
\hline Costos de cambio para el consumidor & & 0.25 & & $\mathrm{x}$ & & & & \\
\hline Resultado ponderado & & 1.00 & & & & & Regular & \\
\hline \multicolumn{9}{|l|}{ 4. Amenaza de productos sustitutos } \\
\hline Disponibilidad de sustitutos & \multirow{3}{*}{0.15} & 0.70 & & & & $\mathrm{x}$ & & \\
\hline $\begin{array}{l}\text { Precio relativo entre el producto ofrecido } \\
\text { y el sustituto }\end{array}$ & & 0.30 & & $\mathrm{x}$ & & & 4.1 & 0.60 \\
\hline Resultado ponderado & & 1.00 & & & & & Alta & \\
\hline \multicolumn{9}{|l|}{$\begin{array}{l}\text { 5. Rivalidad entre competidores } \\
\text { existentes }\end{array}$} \\
\hline Número de competidores & \multirow{3}{*}{0.25} & 0.40 & $\mathrm{x}$ & & & & & \\
\hline Costos fijos & & 0.15 & & $\mathrm{x}$ & & & 2.95 & 0.50 \\
\hline Crecimiento de la demanda & & 0.45 & & & & $\mathrm{x}$ & & \\
\hline Resultado ponderado & & 1.00 & & & & & Baja & \\
\hline Evaluación General & 1.00 & 1. Muy & & ajo $3 . r$ & Regular & 4. Alt & 5. Muy Alto & 3.00 \\
\hline
\end{tabular}
Nota Fuente. Elaboración propia

En conclusión, se trata de una industria con regular atractividad, en la cual la propuesta ofrecida puede generar una gran aceptación por parte del público en un mercado amplio y altamente competitivo en la cual la diferenciación es clave para obtener los mayores beneficios. 


\subsection{Análisis de la Competencia}

\subsubsection{Empresas que ofrecen el mismo producto o servicio, indicando las} semejanzas y diferencias que tienen con el proyecto de empresa.

Debido a que en el presente proyecto se ofrecen platos criollos, marinos y bebidas, se considera como competencia directa a aquellos establecimientos que ofrecen productos similares para satisfacer la misma necesidad de alimentación y se ubican dentro del Territorio III, el cual comprende los grupos [7 - 25] del Sector 3, y cuyos límites son: Av. Bolívar al norte, Av. 200 millas al sur, Av. Revolución al este y Av. Mariano Pastor Sevilla al oeste. (Plan Operativo Institucional con Enfoque de Resultados y Perspectiva de Programación Multianual, Municipalidad de Villa El Salvador, 2016)

\section{Tabla 3}

Competencia Directa

\begin{tabular}{cccc}
\hline Restaurante & Referencia & Tipo de Comida & Aforo \\
\hline Puerto Palmeras & Av. César Vallejo & Criolla y Marina & 60 \\
El Encanto Marino & Av. César Vallejo & Marina & 64 \\
Chifa When Wha & Av. César Vallejo & Chifa & 205 \\
Sabor Perú & Av. Juan Velasco Alvarado & Criolla y Marina & 84 \\
Marino Blue & Av. Revolución & Criolla y Marina & 67 \\
El Paraíso del Paladar & Av. César Vallejo & Criolla & 56 \\
Roky's & Av. Juan Velasco Alvarado & Pollos y Brasas & 120 \\
Norky's & Av. Revolución & Pollos y Brasas & 126 \\
\hline
\end{tabular}

Nota Fuente primaria, encuesta aplicada.

\subsubsection{Participación de mercado de cada uno de ellos.}

Se realizó un estudio de campo para poder determinar cuál es el número de visitas por año de los restaurantes que conforman la competencia directa del proyecto, los cuales se ubican detro del territorio III de Villa El Salvador, el valor a utilizar para determinar la participación de mercado fueron las ventas de cada restaurante y este dato fue calculado en base al aforo del local, los días de atención y el porcentaje de ocupación utilizando además de esto un valor de ticket promedio determinado por visita de campo. El detalle se muestra en la siguiente tabla: 


\section{Tabla 4}

Participación de Mercado Actual

\begin{tabular}{|c|c|c|c|c|c|c|c|c|c|c|}
\hline $\begin{array}{c}\text { Restaura } \\
\text { nte }\end{array}$ & $\begin{array}{c}\text { Referen } \\
\text { cia }\end{array}$ & $\begin{array}{c}\text { Tipo } \\
\text { de } \\
\text { Comid } \\
\text { a }\end{array}$ & $\begin{array}{c}\text { Afo } \\
\text { ro }\end{array}$ & $\begin{array}{c}\text { Días de } \\
\text { Atenció } \\
\text { n en } \\
\text { promed } \\
\text { io } \\
\end{array}$ & $\begin{array}{c}\text { Total } \\
\text { año }\end{array}$ & $\begin{array}{c}\% \\
\text { Ocupa } \\
\text { ción }\end{array}$ & $\begin{array}{c}\text { Total } \\
\text { visitas } \\
\text { por año }\end{array}$ & $\begin{array}{c}\text { Ticket } \\
\text { promed } \\
\text { io }\end{array}$ & $\begin{array}{l}\text { Total por } \\
\text { año }\end{array}$ & $\begin{array}{c}\text { Participaci } \\
\text { ón de } \\
\text { Mercado }\end{array}$ \\
\hline $\begin{array}{c}\text { Puerto } \\
\text { Palmeras }\end{array}$ & $\begin{array}{c}\text { Av. } \\
\text { César } \\
\text { Vallejo }\end{array}$ & $\begin{array}{c}\text { Criolla } \\
\mathrm{y} \\
\text { Marina }\end{array}$ & 60 & 301 & 18060 & $70 \%$ & 12,642 & 45 & $\begin{array}{c}\mathrm{S} / .568,89 \\
0\end{array}$ & $7.79 \%$ \\
\hline $\begin{array}{c}\text { El } \\
\text { Encanto } \\
\text { Marino }\end{array}$ & $\begin{array}{c}\text { Av. } \\
\text { César } \\
\text { Vallejo }\end{array}$ & Marina & 64 & 301 & 19264 & $60 \%$ & 11,558 & 45 & $\begin{array}{c}\mathrm{S} / .520,12 \\
8\end{array}$ & $7.12 \%$ \\
\hline $\begin{array}{l}\text { Chifa } \\
\text { When } \\
\text { Wha }\end{array}$ & $\begin{array}{c}\text { Av. } \\
\text { César } \\
\text { Vallejo }\end{array}$ & Chifa & 205 & 301 & 61705 & $60 \%$ & 37,023 & 45 & $\begin{array}{c}\text { S/.1,666,0 } \\
35\end{array}$ & $22.81 \%$ \\
\hline $\begin{array}{l}\text { Sabor } \\
\text { Perú }\end{array}$ & $\begin{array}{l}\text { Av. Juan } \\
\text { Velasco } \\
\text { Alvarado }\end{array}$ & $\begin{array}{c}\text { Criolla } \\
\text { y } \\
\text { Marina }\end{array}$ & 84 & 301 & 25284 & $70 \%$ & 17,699 & 45 & $\begin{array}{c}\mathrm{S} / .796,44 \\
6\end{array}$ & $10.91 \%$ \\
\hline $\begin{array}{l}\text { Marino } \\
\text { Blue }\end{array}$ & $\begin{array}{c}\text { Av. } \\
\text { Revoluci } \\
\text { ón }\end{array}$ & $\begin{array}{c}\text { Criolla } \\
\mathrm{y} \\
\text { Marina }\end{array}$ & 67 & 301 & 20167 & $80 \%$ & 16,134 & 45 & $\begin{array}{c}\mathrm{S} / .726,01 \\
2\end{array}$ & $9.94 \%$ \\
\hline $\begin{array}{c}\text { El Paraíso } \\
\text { del } \\
\text { Paladar }\end{array}$ & $\begin{array}{c}\text { Av. } \\
\text { César } \\
\text { Vallejo }\end{array}$ & Criolla & 56 & 301 & 16856 & $70 \%$ & 11,799 & 45 & $\begin{array}{c}\mathrm{S} / .530,96 \\
4\end{array}$ & $7.27 \%$ \\
\hline Roky’s & $\begin{array}{l}\text { Av. Juan } \\
\text { Velasco } \\
\text { Alvarado }\end{array}$ & $\begin{array}{c}\text { Pollos } \\
\text { y } \\
\text { Brasas }\end{array}$ & 120 & 301 & 36120 & $80 \%$ & 28,896 & 45 & $\begin{array}{c}\text { S/.1,300,3 } \\
20\end{array}$ & $17.80 \%$ \\
\hline Norky's & $\begin{array}{l}\text { Av. } \\
\text { Revoluci } \\
\text { ón }\end{array}$ & $\begin{array}{c}\text { Pollos } \\
\text { y } \\
\text { Brasas }\end{array}$ & 126 & 301 & 37926 & $70 \%$ & 26,548 & 45 & $\begin{array}{c}\text { S/.1,194,6 } \\
69\end{array}$ & $16.36 \%$ \\
\hline Total & & & & & & & & & $7,303,464$ & $100.00 \%$ \\
\hline
\end{tabular}

Nota Fuente primaria, Observación directa.

De acuerdo a la tabla mostrada anteriormente y según las ventas proyectadas en el primer año detalladas en la tabla 84; la cual es de S/. 634,627, se pronostica una participación de mercado de $7.99 \%$ en el primer año, esto se muestra a continuación: 


\section{Tabla 5}

Participación de Mercado incluyendo el proyecto

\begin{tabular}{|c|c|c|}
\hline Restaurante & $\begin{array}{l}\text { Total por } \\
\text { año }\end{array}$ & $\begin{array}{c}\text { Participación } \\
\text { de Mercado }\end{array}$ \\
\hline $\begin{array}{l}\text { Puerto } \\
\text { Palmeras }\end{array}$ & S/.568,890 & $7.17 \%$ \\
\hline $\begin{array}{l}\text { El Encanto } \\
\text { Marino }\end{array}$ & S/.520,128 & $6.55 \%$ \\
\hline $\begin{array}{l}\text { Chifa When } \\
\text { Wha }\end{array}$ & S/.1,666,035 & $20.99 \%$ \\
\hline Sabor Perú & S/.796,446 & $10.03 \%$ \\
\hline Marino Blue & S/.726,012 & $9.15 \%$ \\
\hline $\begin{array}{l}\text { El Paraíso } \\
\text { del Paladar }\end{array}$ & S/.530,964 & $6.69 \%$ \\
\hline Roky’s & S/.1,300,320 & $16.38 \%$ \\
\hline Norky’s & S/.1,194,669 & $15.05 \%$ \\
\hline $\begin{array}{c}\text { Entre } \\
\text { Copas y } \\
\text { Tenedores }\end{array}$ & S/.634,627 & $7.99 \%$ \\
\hline Total & $7,938,091$ & $100.00 \%$ \\
\hline
\end{tabular}

\subsubsection{Matriz de perfil competitivo.}

La Matriz de Perfil Competitivo (MPC) identifica a los principales competidores, así como sus fortalezas y debilidades. Para la elaboración de la matriz MPC, se realizó un análisis FODA (Fortalezas, Oportunidades, Debilidades y Amenazas). 
Tabla 6

Análisis FODA

\begin{tabular}{|c|c|c|}
\hline FODA & FORTALEZAS & DEBILIDADES \\
\hline & $\begin{array}{l}\text { F1. Idea de negocio con una } \\
\text { ambientación temática novedosa. }\end{array}$ & $\begin{array}{l}\text { D1. Rápida perecibilidad de los } \\
\text { insumos. }\end{array}$ \\
\hline & F2. Variedad de platos. & $\begin{array}{l}\text { D2. Poca experiencia en el sector } \\
\text { gastronómico. }\end{array}$ \\
\hline & $\begin{array}{l}\text { F3. Disponibilidad de un local } \\
\text { ubicado en un lugar estratégico. } \\
\text { F4. Personal con experiencia en } \\
\text { elaboración de platos criollos y marino }\end{array}$ & $\begin{array}{l}\text { D3. Estacionamiento limitado. } \\
\text { S. }\end{array}$ \\
\hline & F5. Fácil acceso al financiamiento. & \\
\hline & F6. Contar con servicio delivery. & \\
\hline OPORTUNIDADES & OFENSIVA & REORIENTACIÓN \\
\hline O1. Boom Gastronómico. & $\begin{array}{l}\text { Diversificar platos de otras regiones. } \\
(\mathrm{F} 2, \mathrm{~F} 4, \mathrm{O} 1, \mathrm{O} 3)\end{array}$ & $\begin{array}{l}\text { Buscar información para } \\
\text { retroalimentación de distintas fuentes. } \\
(\mathrm{O} 1, \mathrm{D} 2)\end{array}$ \\
\hline $\begin{array}{l}\text { O2. Aumento sostenido del gasto } \\
\text { destinado al consumo de comida } \\
\text { fuera de casa. }\end{array}$ & $\begin{array}{l}\text { Acceder a mejores condiciones } \\
\text { financieras. (F5, O4) }\end{array}$ & $\begin{array}{l}\text { Recibir orientación por parte del } \\
\text { Estado para la implementación } \\
\text { adecuada del restaurante. (D2, O4) }\end{array}$ \\
\hline $\begin{array}{l}\text { O3. Orgullo nacional por la } \\
\text { gastronomía. }\end{array}$ & $\begin{array}{l}\text { Publicitar sin incurrir en mayores } \\
\text { gastos. (F1, F3, O6) }\end{array}$ & $\begin{array}{l}\text { Recibir constante feedback por parte } \\
\text { de los clientes. (D2, O6) }\end{array}$ \\
\hline $\begin{array}{l}\text { O4. Promoción por parte del } \\
\text { Estado de la pequeña empresa. }\end{array}$ & $\begin{array}{l}\text { Flexibilizar lugar de entrega y pago a } \\
\text { través de YaPe y transferencias } \\
\text { bancarias. (F6, O5, O6) }\end{array}$ & $\begin{array}{l}\text { Informar a los clientes de } \\
\text { estacionamientos aledaños. (O6, D3) }\end{array}$ \\
\hline O5. Nuevas modalidades de pago. & $\begin{array}{l}\text { Recolectar opiniones de clientes } \\
\text { sobre platos ofrecidos. (F2, F4, O6) }\end{array}$ & \\
\hline \multicolumn{3}{|l|}{$\begin{array}{l}\text { O6. Nuevas modalidades de } \\
\text { comunicación. }\end{array}$} \\
\hline AMENAZAS & DEFENSIVA & SUPERVIVENCIA \\
\hline $\begin{array}{l}\text { A1. Variación del precio de } \\
\text { insumos. }\end{array}$ & $\begin{array}{l}\text { Controlar adecuadamente los } \\
\text { insumos. (F2, F4, A1) }\end{array}$ & $\begin{array}{l}\text { Analizar el traspaso o liquidación del } \\
\text { negocio luego de recuperar inversión. } \\
\text { (D2, A3) }\end{array}$ \\
\hline $\begin{array}{l}\text { A2. Variación del precio del } \\
\text { alquiler. }\end{array}$ & $\begin{array}{l}\text { Contar con respaldo financiero frente } \\
\text { a proveedores (letras de pago, } \\
\text { garantías). (F5, A1) }\end{array}$ & $\begin{array}{l}\text { Promociones de platos o extras con } \\
\text { insumos próximos a vencer. (D1, A4) }\end{array}$ \\
\hline $\begin{array}{l}\text { A3. Bajas barreras de entrada a } \\
\text { nuevos competidores. }\end{array}$ & Evaluar la compra del local. (F5, A2) & \\
\hline $\begin{array}{l}\text { A4. Expansión de tiendas de } \\
\text { conveniencia. }\end{array}$ & $\begin{array}{l}\text { Solicitar mayor seguridad en la } \\
\text { Comisaría de VES aledaña. (F3, A5) }\end{array}$ & \\
\hline \multicolumn{3}{|l|}{$\begin{array}{l}\text { A5. Poca seguridad alrededor de la } \\
\text { zona. }\end{array}$} \\
\hline $\begin{array}{l}\text { A6. Propagación de virus e } \\
\text { infecciones que pueda afectar la } \\
\text { salud de los comensales y } \\
\text { colaboradores. }\end{array}$ & & \\
\hline
\end{tabular}

Nota Fuente. Elaboración propia 
A continuación, se presenta el FODA de los principales competidores cercanos al local:

\section{Tabla 7}

FODA principales competidores

\begin{tabular}{|c|c|c|c|c|}
\hline Restaurantes & Fortalezas & Oportunidades & Debilidades & Amenazas \\
\hline El encanto Marino & - Shows en vivo & $\begin{array}{l}\text { - Carta constantemente } \\
\text { renovada }\end{array}$ & $\begin{array}{l}\text { - No cuenta con } \\
\text { estacionamiento. }\end{array}$ & $\begin{array}{l}\text { - Productos altamente } \\
\text { perecibles. } \\
\text { - Vedas por parte del } \\
\text { gobierno }\end{array}$ \\
\hline $\begin{array}{c}\text { El Paraíso del } \\
\text { Paladar }\end{array}$ & $\begin{array}{l}\text { - Especialista en comida } \\
\text { criolla } \\
\text { - Cuenta con whatsap de } \\
\text { menús }\end{array}$ & $\begin{array}{l}\text { - Ampliación del local } \\
\text { al segundo piso }\end{array}$ & $\begin{array}{l}\text { - Poco tiempo en el } \\
\text { mercado }\end{array}$ & $\begin{array}{l}\text { - Rodeado de } \\
\text { ambulantes que } \\
\text { ofrecen comida al paso }\end{array}$ \\
\hline Puerto Palmeras & $\begin{array}{l}\text { - Especialidad en platos } \\
\text { criollos y marinos } \\
\text {-Años que lleva en el } \\
\text { mercado }\end{array}$ & $\begin{array}{l}\text { - Combinaciones } \\
\text { marinas y criollas }\end{array}$ & - Carta no renovada & $\begin{array}{l}\text { - Poca seguridad en la } \\
\text { zona. }\end{array}$ \\
\hline Marino Blue & $\begin{array}{l}\text { - Atención personalizada } \\
\text { - Pedidos por delivery altos }\end{array}$ & $\begin{array}{l}\text { - Cercanía a avenida } \\
\text { comercial para llegar a } \\
\text { más clientes. }\end{array}$ & $\begin{array}{l}\text { - Poco recordado por el } \\
\text { público }\end{array}$ & $\begin{array}{l}\text { - Locales más grandes } \\
\text { pueden opacar el } \\
\text { negocio. }\end{array}$ \\
\hline When Wha & $\begin{array}{l}\text { - Local amplio y moderno } \\
\text { - Chifa ampliamente } \\
\text { conocido en el distito de } \\
\text { VES } \\
\text { - Se puede realizar eventos }\end{array}$ & $\begin{array}{l}\text { - Realización de } \\
\text { eventos y reuniones de } \\
\text { empresas del distrito. }\end{array}$ & $\begin{array}{l}\text { - Alejado de la zona } \\
\text { comercial del distrito }\end{array}$ & $\begin{array}{l}\text { - Promociones en la } \\
\text { carta de chifas de la } \\
\text { zona. }\end{array}$ \\
\hline Sabor Perú & $\begin{array}{l}\text { - Musica criolla los fines de } \\
\text { semana } \\
\text { - Buffet Criollo }\end{array}$ & $\begin{array}{l}\text { - Construcción de } \\
\text { nuevo local }\end{array}$ & $\begin{array}{l}\text { - Poca cantidad de } \\
\text { meseros }\end{array}$ & $\begin{array}{l}\text { - Pistas en mal estado } \\
\text { que dificultan el } \\
\text { acceso. }\end{array}$ \\
\hline Roky's & $\begin{array}{l}\text { - Posee gran cantidad de } \\
\text { restaurantes } \\
\text { - Buenas promociones en la } \\
\text { carta } \\
\text { - Buenas atención }\end{array}$ & $\begin{array}{l}\text { - Facilidad para } \\
\text { aperturar nuevos } \\
\text { locales en otros } \\
\text { distritos }\end{array}$ & $\begin{array}{l}\text { - Está asociado más al } \\
\text { consumo de pollo a la } \\
\text { brasa por parte de la } \\
\text { población }\end{array}$ & $\begin{array}{l}\text { - Apertura de nuevas } \\
\text { pollerías generando } \\
\text { una fuerte rivalidad }\end{array}$ \\
\hline Norky's & $\begin{array}{l}\text { - Posee gran cantidad de } \\
\text { restaurantes } \\
\text { - Buenas promociones en la } \\
\text { carta } \\
\text { - Buena atención }\end{array}$ & $\begin{array}{l}\text { - Facilidad para } \\
\text { aperturar nuevos } \\
\text { locales en otros } \\
\text { distritos }\end{array}$ & $\begin{array}{l}\text { - Está asociado más al } \\
\text { consumo de pollo a la } \\
\text { brasa por parte de la } \\
\text { población }\end{array}$ & $\begin{array}{l}\text { - Apertura de nuevas } \\
\text { pollerías generando } \\
\text { una fuerte rivalidad }\end{array}$ \\
\hline
\end{tabular}

Nota Fuente primaria. Observación directa.

A continuación, se presenta la matriz del perfil competitivo. Los factores críticos y ponderaciones se obtuvieron de la entrevista a profundidad con el señor Jorge Cerna, Docente y Coordinador de la carrera de Administración de Hoteles y Restaurantes en ISIL (ver anexo

$3)$. 
Tabla 8

Matriz del perfil competitivo de la Competencia Directa

\begin{tabular}{|c|c|c|c|c|c|c|c|c|c|c|c|c|c|c|c|c|c|}
\hline \multirow[b]{3}{*}{ Factor Crítico } & \multirow{3}{*}{ Pond } & \multicolumn{2}{|c|}{$\begin{array}{c}\text { El } \\
\text { encanto } \\
\text { Marino }\end{array}$} & \multicolumn{2}{|c|}{$\begin{array}{l}\text { Puerto } \\
\text { Palmeras }\end{array}$} & \multicolumn{2}{|c|}{$\begin{array}{c}\text { El Paraíso } \\
\text { del } \\
\text { Paladar }\end{array}$} & \multicolumn{2}{|c|}{$\begin{array}{l}\text { Marino } \\
\text { Blue }\end{array}$} & \multicolumn{2}{|c|}{$\begin{array}{l}\text { When } \\
\text { Wha }\end{array}$} & \multicolumn{2}{|c|}{$\begin{array}{l}\text { Sabor } \\
\text { Perú }\end{array}$} & \multicolumn{2}{|c|}{ Roky's } & \multicolumn{2}{|c|}{ Norky's } \\
\hline & & Pto & & & & Pto & & Pto & & & & Pto & & Pto & & Pto & \\
\hline & & $\mathbf{s}$ & Nota & Ptos & Nota & $\mathbf{s}$ & Nota & $\mathbf{s}$ & Nota & Ptos & Nota & $\mathbf{s}$ & Nota & $\mathbf{s}$ & Nota & $\mathbf{s}$ & Nota \\
\hline $\begin{array}{l}\text { Tecnología } \\
\text { utilizada en los } \\
\text { procesos }\end{array}$ & $15 \%$ & 3 & $\begin{array}{c}0.4 \\
5\end{array}$ & 4 & 0.6 & 2 & 0.3 & 2 & 0.3 & 2 & 0.3 & 1 & 0.15 & 3 & 0.45 & 3 & 0.45 \\
\hline $\begin{array}{c}\text { Personal } \\
\text { Capacitado }\end{array}$ & $20 \%$ & 4 & 0.8 & 4 & 0.8 & 2 & 0.4 & 2 & 0.4 & 2 & 0.4 & 2 & 0.4 & 4 & 0.8 & 4 & 0.8 \\
\hline $\begin{array}{l}\text { Capacidad y } \\
\text { Nivel de } \\
\text { Comunicación }\end{array}$ & $10 \%$ & 3 & 0.3 & 4 & 0.4 & 1 & 0.1 & 1 & 0.1 & 2 & 0.2 & 1 & 0.1 & 4 & 0.4 & 4 & 0.4 \\
\hline $\begin{array}{l}\text { Calidad de } \\
\text { Productos y } \\
\text { Servicio }\end{array}$ & $20 \%$ & 4 & 0.8 & 4 & 0.8 & 2 & 0.4 & 3 & 0.6 & 4 & 0.8 & 3 & 0.6 & 4 & 0.8 & 4 & 0.8 \\
\hline $\begin{array}{c}\text { Precios } \\
\text { competitivos }\end{array}$ & $20 \%$ & 3 & 0.6 & 3 & 0.6 & 4 & 0.8 & 4 & 0.8 & 3 & 0.6 & 3 & 0.6 & 1 & 0.2 & 2 & 0.4 \\
\hline $\begin{array}{l}\text { Posicionamient } \\
\text { o en el mercado }\end{array}$ & $15 \%$ & 3 & $\begin{array}{c}0.4 \\
5\end{array}$ & 4 & 0.6 & 2 & 0.3 & 1 & 0.15 & 1 & 0.15 & 2 & 0.3 & 3 & 0.45 & 4 & 0.6 \\
\hline Total & $\begin{array}{c}100 \\
\%\end{array}$ & & 3.40 & & 3.80 & & 2.30 & & 2.35 & & 2.45 & & 2.15 & & 3.10 & & 3.45 \\
\hline
\end{tabular}

Calificación:

$\begin{array}{llll}\text { 1= Debilidad } & \begin{array}{l}2=\text { Debilidad } \\ \text { Mayor }\end{array} & \begin{array}{l}3=\text { Fortaleza } \\ \text { menor }\end{array} & \begin{array}{l}4=\text { Fortaleza } \\ \text { mayor }\end{array}\end{array}$

Nota Fuente primaria. observación directa.

\subsection{Análisis del Contexto Actual y Esperado}

El contexto actual y esperado para el sector la componen las variables del macro entorno que son: Político-Gubernamental, Económico, Legal, Cultural, Tecnológico y Ecológico.

\subsubsection{Análisis político-gubernamental.}

Actualmente, el gobierno peruano impulsa programas de fomento para la creación de empresas, prueba de esto es la aprobación del Decreto Legislativo 1332 que permite crear empresas en 24 horas, con esta medida una persona puede formar su empresa en menor tiempo y a un menor costo, apoyados en los Centros de Desarrollo Empresarial (CDE) ubicados a nivel nacional. (Produce: Constitución de empresas en 24 horas se hará realidad en dos semanas, gestion.pe, 2017).

La Superintendencia Nacional de los Registro Públicos (SUNARP) facilitará también la constitución de empresas a "costo cero"; de esta manera, las personas que decidan iniciar un negocio podrán realizarlo a través de los $\mathrm{CDE}$ en los cuales estarán exonerados del pago 
del pago de tasas registrales, siempre que el capital social de la empresa no supere la Unidad Impositiva Tributaria (S/ 4,200). Esta exoneración del pago implica que la persona que desea abrir una nueva empresa dejará de pagar S/.20.00 por el trámite de reserva de nombre, S/ 44.00 por derecho de calificación, así como el derecho de inscripción. (Sunarp facilitará constitución de empresas a "costo cero", elcomercio.pe, 2017).

Otra forma de apoyo por parte del gobierno es el impulso de la gastronomía mediante la Comisión de Promoción del Perú para la Exportación y el Turismo (PROMPERÚ) organismo adscrito al Ministerio de Comercio Exterior y Turismo (MINCETUR) la cual organiza ferias gastronómicas a nivel nacional como "Perú, Mucho Gusto" con el objetivo de promover los principales destinos nacionales a través de la gastronomía de las diferentes regiones. (Libro 'Perú, Mucho Gusto’ gana premio internacional en España, gestión.pe, 2017).

En cuanto a la seguridad ciudadana, en el 2003, el Gobierno Central ha promulgado la Ley N ${ }^{\circ}$ 27933, Ley del Sistema Nacional de Seguridad Ciudadana (SINASEC), que tiene por objetivo articular esfuerzos entre el Estado y la sociedad civil organizada, a través de asociaciones de vecinos con el objetivo de prevenir acciones de violencia, asaltos, etc., que constituya una amenaza a la integridad física de los vecinos y de los transeúntes en general.

Finalmente, el distrito de Villa el Salvador, por su parte, ha creado el Comité Distrital de Seguridad Ciudadana del distrito de Villa el Salvador que tiene como principal objetivo otorgar de un instrumento sistemático para el correcto diagnóstico, planificación a corto, mediano y largo plazo, así como la ejecución coherente de políticas de Seguridad Ciudadana, para de Distrito de Villa El salvador. Esto en base al Art. 197º de la Constitución Política del Perú: “las municipalidades promueven, apoyan y reglamentan la participación vecinal en el desarrollo local, asimismo, brindan servicios de seguridad ciudadana, con la cooperación de la Policía Nacional del Perú, conforme a Ley”. 


\subsubsection{Análisis económico.}

De acuerdo con el Fondo Monetario Internacional (2018), a lo largo de los últimos diez años, el crecimiento económico del Perú ha sido uno de los más altos de la región, teniendo una tasa de crecimiento promedio de 5.9 en por ciento en los últimos 10 años y en un escenario de baja inflación (promediando $2.9 \%$ ). Según esta misma fuente se espera que el PBI para el 2019 sea de $4.1 \%$, un poco mayor al crecimiento promedio esperado de la región. Así mismo, el BCRP proyecta el crecimiento esperado del PBI para el 2019 en 4.2\% según se observa en su Reporte de Inflación 2018 y 2019 realizado en junio del presente año.

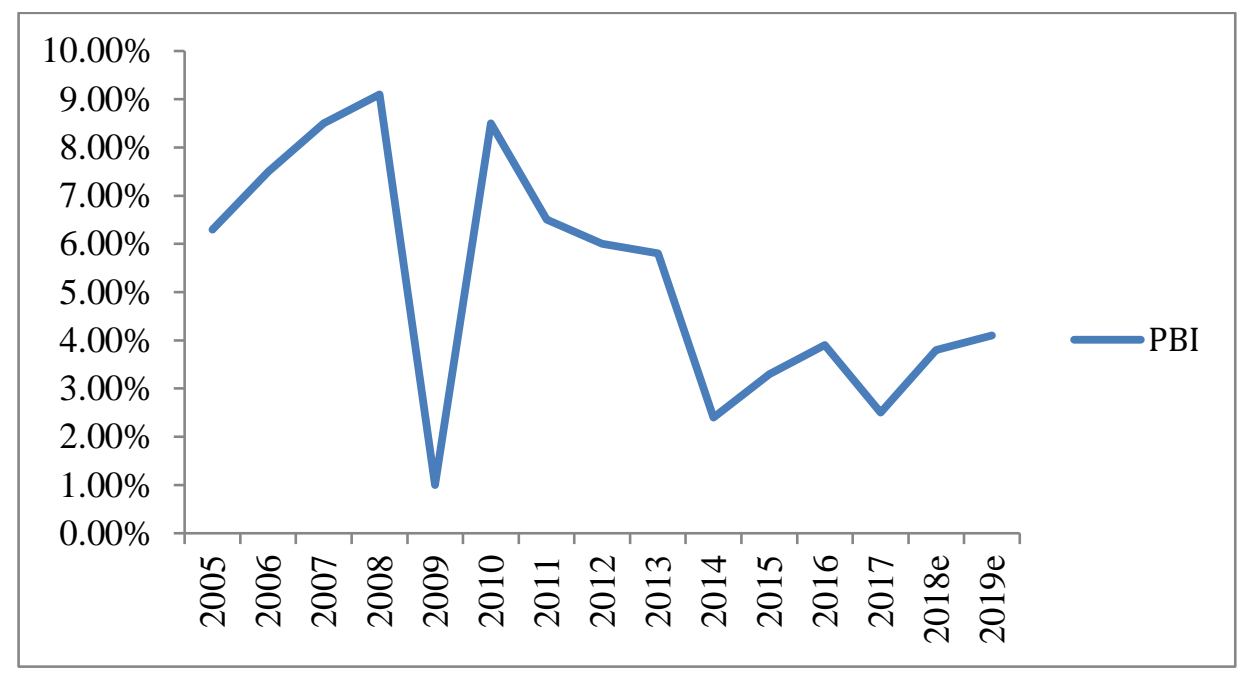

Ilustración 1. Evolución porcentual del PBI a través de los años, adaptado de "Estadísticas, Banco Central de Reserva del Perú", 2017.

Según Carla Morelli, gerente comercial de Gastromaq, feria de proveedores para el sector gastronómico y hotelero, comenta que: "La gastronomía representa el 6\% del PBI anual y es un sector importante para el crecimiento de nuestro país, más aún cuando tenemos al sector minero de baja". (Sector gastronómico genera 60 mil puestos laborales y tiene crecimiento sostenible, larepublica.pe, 2018).

\subsubsection{Análisis legal.}

Actualmente, para poder abrir un restaurante en Lima Metropolitana se debe contar con una licencia de funcionamiento las cuales son otorgadas por las municipalidades distritales y provinciales, en el caso del presente proyecto la municipalidad de Villa El Salvador solicita completar un formulario de solicitud - declaración jurada para la apertura 
de un local comercial que está clasificado como grupo 2 que son locales que deben cumplir ciertos requisitos para la instalación de un restaurante o local comercial donde se sirvan alimentos; además las inspecciones técnicas de seguridad son realizadas también por la municipalidad de Villa El Salvador para posteriormente entregar la licencia de funcionamiento correspondiente. (Como abrir un restaurante paso a paso, pymex.pe, 2013).

Todos los restaurantes deben cumplir con las normas sanitarias dictadas por el Ministerio de Salud (MINSA) mediante la resolución ministerial № 363-2005/MINSA "Norma Sanitaria Para El Funcionamiento De Restaurantes y Servicios Afines" con el objetivo de asegurar la calidad y limpieza de todos los alimentos y bebidas en las diferentes etapas de la cadena alimentaria que van desde la compra de los insumos necesarios para la preparación de los platos y bebidas hasta la comercialización del producto terminado.

El MINCETUR ha formulado un reglamento de restaurantes mediante decreto supremo $N^{\circ} 25$ - 2004- MINCETUR para la categorización, calificación y supervisión del funcionamiento de los restaurantes clasificándolos en cinco, cuatro, tres, dos o un tenedor según la calidad de los platos y del servicio prestado. Este reglamento se aplica a todos los establecimientos que prestan el servicio de restaurante en el país y es deber de estos establecimientos adaptarse a dichas normas.

\subsubsection{Análisis cultural.}

Según el INEI, el consumo promedio de alimentos fuera del hogar por parte de los limeños ha venido incrementándose de forma sostenida y en el año 2012 el gasto per cápita ascendió a $34.7 \%$ es decir, S/35.00 de cada S/100.00 gastan los limeños en alimentos consumidos fuera del hogar. (INEI: limeños destinan 35\% de su gasto en alimentos a comer fuera del hogar, gestión.pe, 2013). Esto muestra que, para los limeños comer fuera del hogar se ha convertido en el algo cotidiano y frecuente debido a la gran cantidad de restaurantes que tiene la ciudad de Lima. 
Otro aspecto importante para los peruanos es el orgullo que sienten por su comida, que según la encuesta realizada por la empresa GFK en el año 2012, el $90 \%$ de peruanos respondió que se siente orgulloso de su comida, esto debido a la gran variedad culinaria que posee la gastronomía peruana la cual está hecha para todos los gustos. (El 90\% de peruanos siente orgullo por su comida, y el ceviche es el plato, larepublica.pe, 2012).

\subsubsection{Análisis tecnológico.}

Actualmente el sector gastronómico busca innovar los procedimientos y procesos para la preparación de los platos con el objetivo de disminuir tiempos y asegurar la calidad del producto final en beneficio del cliente. Además de esto, la creación de nuevos platos es importante ya que se le ofrece al consumidor algo único y diferenciado y lo que este busca son productos naturales, sin aditivos ni colorantes. (Las tendencias de la gastronomía peruana en el 2016, semanaeconomica.com, 2016).

Un punto importante también son las aplicaciones para celulares o las páginas web de los restaurantes que buscan facilitar al consumidor la elección de su plato de forma más rápida y personalizada cuando el cliente solicita un servicio delivery. Existen también softwares para restaurantes que permiten minimizar los tiempos al momento de tomar la orden del cliente y de agilizar y unir todas las áreas del restaurante.

\subsubsection{Análisis ecológico.}

Los restaurantes pueden disminuir el número de desechos de varias maneras como por ejemplo evitando el uso de platos y vasos descartables para servir la comida y las bebidas cambiándolos por material de vidrio y porcelana. La utilización de desechos orgánicos también es una alternativa utilizada por varios restaurantes para generar abono orgánico y así evitar el desperdicio de esta clase de desechos.

El consumo de alimentos orgánicos también es favorable para el medio ambiente ya que se evita la utilización de insumos químicos como plaguicidas o fertilizantes químicos que puedan afectar el suelo, el agua o hasta incluso la salud de las personas. En la última década 
el interés por los productos orgánicos se ha ido incrementando en $70 \%$ y esta tendencia apunta a que siga creciendo, según el grupo de productores Ecológica Perú. (El consumo de productos orgánicos crece entre los peruanos, actualidadambiental.pe, 2015).

Finalmente es importante mencionar desde este aspecto, la Ley 30884 publicada el 19 de diciembre de 2018: "Ley que regula el plástico de un solo uso y los recipientes o envases descartables”. Esta ley es importante pues como se verá más adelante el 38\% de los encuestados solicita su almuerzo a través del servicio de delivery. Por lo tanto, el proyecto deberá de estar adecuado a la normativa vigente. La adecuación integral de la presente Ley tendrá un plazo de tres años a partir de su fecha de publicación.

\subsection{Oportunidades y Amenazas}

\section{a) Oportunidades.}

- Boom Gastronómico: La gastronomía peruana viene ganando mayor presencia a nivel mundial con los distintos reconocimientos que ha recibido, tal como el World Travel Awards. Además, distinguidos cocineros concursan en importantes competencias gastronómicas y distintos restaurantes peruano - fusión han sido inaugurados alrededor del mundo en países lejanos como Vietnam y Rusia. (Cocina Peruana llega a la lejana Moscú. Peru.com, 2016).

- Aumento sostenido del gasto destinado al consumo de comida fuera del hogar: Según el INEI, el consumo promedio de alimentos fuera del hogar por parte de los limeños ha venido incrementándose de forma sostenida. En el año 2012, el gasto per cápita ascendió a 34.7 \%; es decir, los limeños gastan S/35.00 de cada S/100.00 en alimentos consumidos fuera del hogar. (INEI: Limeños destinan 35\% de su gasto en alimentos a comer fuera del hogar, gestión.pe, 2013).

- Orgullo nacional por la gastronomía: Según una encuesta nacional urbana elaborada por la empresa GFK a 1,450 peruanos, el 90\% de ellos respondió que se sentía orgulloso de la gastronomía peruana, siendo los platos favoritos: ceviche, 
pachamanca, cuy chactado y arroz con pollo. (El 90\% de los peruanos siente orgullo por su comida, y el ceviche es el plato bandera, La República, 2012). Esto indica que los restaurantes que ofrecen platos criollos o nacionales tienen un lugar importante dentro de las preferencias de los consumidores peruanos.

- Promoción de la competitividad, formalización y desarrollo de la micro y pequeña empresa: Según Ley N 30056, las empresas constituidas bajo el régimen de MYPEs tienen los siguientes beneficios:

○ Tributarios: Si la empresa no supera las 300 UIT de ingresos netos anuales, se cancela el $1 \%$ de los ingresos netos obtenidos en el mes. Si en cualquier mes los ingresos netos superan las 300 UIT, se paga el $1.5 \%$.

o Constitucionales: El trámite de constitución y formalización se concluye en 72 horas. Las empresas constituidas como personas jurídicas realizan el trámite con Escritura Pública, sin necesidad de presentar la Minuta de Constitución.

o Laborables: El empleador no está obligado al pago de CTS, utilidades ni asignación familiar. Solo debe pagar un sueldo de gratificación y quince días de vacaciones al año.

o Contables: La Contabilidad se lleva a través de Registro de Ventas, Registro de Compras y Libro Diario Simplificado.

o Financieros: Se creó el Fondo de Garantía Empresarial (FOGEM) y el Programa Especial de Apoyo Financiero para MYPE (PROPYME) para facilitar la entrega de créditos directos a través de entidades financieras.

- Nuevas modalidades de pago: Cada vez, resulta ser más fácil mover el dinero de manera electrónica, ya sea por transferencia bancaria o aplicativos como Yape del Banco de Crédito del Perú (BCP) o Lukita del BBVA Continental. Además, en el 2018, se lanzó al mercado, el Point Of Sale (POS) lowcost de Izipay, el cual acepta todas las tarjetas y brinda servicios electrónicos a comisiones reducidas. 
- Nuevas modalidades de comunicación: Las empresas utilizan distintas redes sociales para estar en contacto con sus clientes, y ofrecer productos y servicios de manera virtual, estas pueden ser WhatsApp, Facebook Messenger, Instagram, Twitter o Skype.

\section{b) Amenazas.}

- Variación del precio de insumos: Estos cambios suelen estar relacionados a problemas climatológicos o huelgas de transportistas y agricultores que exigen condiciones más favorables para ellos.

- Variación del precio del alquiler: Cuando el local donde se opera no es propio, se está expuesto al riesgo de que el arrendador decida arbitrariamente incrementar su precio. Este riesgo se mitiga con la firma de un contrato por uno o dos años y se penaliza la precancelación del mismo.

- Bajas barreras de entrada a nuevos competidores: La inversión que se requiere para inaugurar un negocio de restauración no es alta.

- Expansión de tiendas de conveniencia: Según Rolando Arellano, desde el 2018, en Lima, se ha experimentado una masificación de este tipo de establecimientos, los cuales cuentan con autorización municipal para atender más de 18 horas al día y tienen una amplia gama de productos, bebidas y productos de bazar. Estas tiendan desplazan a los supermercados, bodegas y restaurantes. (¿Cómo se explica el boom de las tiendas de conveniencia en el Perú?, andina.pe, 2018).

- Poca seguridad alrededor de la zona: Según el Sistema Integrado de Estadísticas de la Criminalidad y Seguridad Ciudadana presentado por el INEI, San Juan de Miraflores es el distrito con mayor índice de victimización con 40\%, seguido de Puente Piedra (35.5\%), San Juan de Lurigancho (33.2\%),Carabayllo (32.9\%) y Villa El Salvador (32.5\%). (Conoce los distritos de Lima con mayores hechos delictivos, andina.pe, 
- Propagación de virus e infecciones que pueda afectar la salud de los comensales y colaboradores. 


\section{Capítulo III. Estudio de Mercado}

\subsection{Descripción del Servicio o Producto}

El producto es cualquier bien tangible que se ofrezca a un mercado para su atención, uso o consumo y que podría satisfacer las necesidades de los consumidores. El servicio es un conjunto de actividades intangibles que se ofrece por una venta y no tiene como resultado la posesión de algo. (Kotler \& Armstrong, 2012)

El producto es un conjunto de elementos físicos y químicos engranados de tal manera que le ofrece al usuario posibilidades de utilización. La primera dimensión de un producto es la que se refiere a sus características organolépticas, que se determinan en el proceso productivo, a través de controles científicos estandarizados, el productor del bien puede valorar esas características fisicoquímicas. La segunda dimensión se basa en criterios subjetivos, tales como imágenes, ideas, hábitos y juicios de valor que el consumidor emite sobre los productos. El consumidor identifica los productos por su marca. En este proceso de diferenciación, el consumidor reconoce las marcas, a las que le asigna una imagen determinada. (Bonta \& Farber, 2005).

El presente proyecto ofrece productos tangibles como son: a) platos criollos como lomo saltado, frejoles con seco, ají de gallina, entre otros; b) platos marinos como ceviches, caldos de pescado; c) bebidas con y sin alcohol. Estos productos serán ofrecidos en un ambiente colorido y pintoresco, con cuadros llenos de frases de tipografía artística relacionadas a lo criollo y buena sazón de la comida peruana, complementada con música y videos para el entretenimiento del cliente y que este pueda pasar un momento agradable. El menú costará, S/ 11; los platos a la carta, S/ 18; y las bebidas, entre S/ 3 - S/ 5.

\subsection{Selección del Segmento de Mercado}

La segmentación de mercados es el proceso de dividir mercados grandes y heterogéneos en grupos más pequeños para llegar a ellos de manera más eficiente y efectiva, ofreciéndoles bienes y servicios que se ajusten a sus necesidades. La segmentación se puede 
aplicar a los mercados de consumidores, de negocios e internacionales. (Kotler \& Armstrong, 2012). En el presente proyecto se desarrolló la segmentación de consumidores a través de las siguientes variables:

\section{a) Segmentación geográfica.}

Se divide el mercado en distintas unidades geográficas como países, regiones, estados, municipios, ciudades o zonas. Una empresa puede operar en una o más zonas geográficas, tomando en consideración la diferencia de necesidades y deseos entre zonas.

Este proyecto se segmentó de forma geográfica abarcando solamente el Territorio III del distrito de Villa El Salvador, que es en donde se establecerá el negocio.

\section{b) Segmentación demográfica.}

El mercado se divide en grupos según variables como edad, género, tamaño de familia, ciclo de vida familiar, ingreso, ocupación, escolaridad, religión, raza, generación y nacionalidad (Kotler \& Armstrong, 2012).

A continuación, el detalle de la segmentación demográfica para el presente proyecto:

- Edad: De 18 a 65 años.

- Género: Hombres y mujeres.

- Ciclo de vida familiar: Joven soltero; casado, sin hijos; casado, con hijos; padres solteros; parejas no casadas; maduro, casado, sin hijos menores de 18 años; maduro, soltero; otros.

\section{c) Segmentación Psicográfica.}

Se divide a los mercados en diferentes grupos según el nivel socioeconómico, estilos de vida o características de personalidad. A continuación, el detalle de la segmentación Psicográfica para el presente proyecto:

- Estrato socioeconómico: Los estratos socioeconómicos son cinco: Alto, Medio Alto, Medio, Medio Bajo y Bajo. Para el presente proyecto sólo se considerarán a aquellos cuyo NSE son A, B y C debido a que estos tienen ingresos más altos y por lo tanto 
estarían en condiciones de adquirir este servicio. Según la Asociación Peruana de Investigación de Mercado (APEIM 2017), la población de Villa El Salvador que pertenecía a estos niveles socioeconómicos era de $56.20 \%$ de la población total, según se indica en la Tabla 5.

\section{Tabla 9}

Distribución de Niveles por zonas APEIM

\begin{tabular}{cccccc}
\hline & NSE A & NSE B & NSE C & NSE D & NSE E \\
\hline Zona 1 & 0.00 & 13.90 & 44.10 & 31.10 & 11.00 \\
Zona 2 & 2.60 & 26.40 & 51.90 & 18.50 & 0.60 \\
Zona 3 & 1.1 & 14.9 & 42.9 & 31.6 & 9.5 \\
Zona 4 & 2.9 & 29.6 & 41.7 & 23.3 & 2.5 \\
Zona 6 & 1.4 & 14.8 & 46.6 & 29 & 8.2 \\
Zona 7 & 13.5 & 59.7 & 20.3 & 6.2 & 0.3 \\
Zona 8 & 34 & 44.9 & 13.1 & 6.6 & 1.4 \\
\hline Zona 9 & 3 & 31.5 & 40.6 & 20.3 & 4.6 \\
\hline Zona 10 & 1.5 & 21 & 44.8 & 22.9 & 9.8 \\
\hline Otros & 0 & 12.8 & 31.9 & 34 & 21.3 \\
\hline Nota Adaptado de “Niveles Socioeconómicos 2017” de APEIM, 2017, p. 10.
\end{tabular}

- Estilos de vida: Según la consultora Arellano Marketing (2016), existen seis estilos de vida:

o Sofisticados: Hombres y mujeres, de ingresos más altos y menos edad que el promedio. Son modernos, instruidos, cosmopolitas y valoran mucho la imagen personal. Son marcadores de tendencias, siguen la moda y son consumidores de productos saludables. 
o Progresistas: Hombres que buscan siempre progresar a nivel personal y familiar, pertenecen a todos los NSE. Por lo general, son obreros y empresarios emprendedores formales e informales, movidos por el deseo de superarse; por esta razón siempre están en búsqueda de nuevas oportunidades. Son prácticos y modernos.

o Modernas: Mujeres que trabajan, estudian y buscan su realización personal y familiar. Pertenecen a todos los NSE. Les importa su imagen personal y buscan el reconocimiento social. Son modernas, rechazan el machismo y les encanta salir de compras, prefiriendo los productos de marca y todos aquellos que les faciliten las tareas domésticas.

- Adaptados: Hombres trabajadores, tradicionales y orientados a la familia que valoran mucho su estatus social. No son marcadores de tendencias ni gustan de la moda. Por lo general, trabajan como oficinistas, empleados de nivel medio, profesores, obreros o en actividades independientes de mediano nivel.

o Conservadoras: Mujeres de tendencia bastante religiosa y tradicional, buscan el bienestar de toda la familia y pertenecen a todos los NSE. Utilizan ropa conservadora y solo utilizan maquillaje de forma ocasional. Su pasatiempo favorito es ver telenovelas y jugar los hijos.

○ Austeros: Hombres y mujeres de escasos recursos económicos, que viven resignados a su suerte. Son reacios a los cambios y adversos a los riesgos. Muchos son inmigrantes y tienen el porcentaje más alto de personas de origen indígena. (Estilos de Vida. Arellano marketing.com, 2016).

El proyecto está abocado a personas cuyos estilos de vida sean progresistas, modernos, adaptados, conservadores y que vivan en el distrito de Villa El Salvador. 


\section{d) Segmentación Conductual.}

Se divide al mercado según conocimientos, actitudes, usos o respuestas frente al consumo de un producto. Dentro de las principales variables se encuentra: ocasiones, beneficios buscados, estatus del usuario, frecuencia de uso y situación de lealtad (Kotler \& Armstrong, 2012). En este proyecto se segmentó por:

- Ocasiones: Personas que buscan tomar alimentos de manera diaria fuera de casa por motivos laborales o busquen celebrar alguna ocasión especial.

- Beneficios buscados: Consumidores que busquen comida de calidad, buen sabor y un servicio de atención diferenciado.

- Frecuencia de uso: Consumidores que consuman alimentos fuera de casa por lo menos una vez al mes o de manera diaria debido a que viven, laboran o estudian cerca del área de influencia para el presente proyecto.

\subsection{Investigación Cualitativa}

El objetivo de la investigación cualitativa es comprender distintos fenómenos, explorándolos de manera más profunda desde la perspectiva de los participantes en un ambiente natural y acorde al contexto de la investigación que se realiza. Según Marshall y Preissle (como se cita en Hernández, Fernández \& Baptista, 2014), se debe utilizar cuando el fenómeno que se analiza ha sido poco explorado o no existe ninguna investigación previa.

Por otro lado, la recolección de datos ocurre en el ambiente natural de las unidades muéstrales y es llevada a cabo por el mismo investigador utilizando distintas técnicas:

- Observación: Se realiza una observación investigativa, la cual no se limita al sentido de la vista, sino a todos los sentidos para explorar, describir, comprender, identificar y generar hipótesis sobre determinada problemática.

- Entrevistas: Según Janesick (como se cita en Hernández, Fernández \& Baptista, 2014), las entrevistas son reuniones íntimas para intercambiar información entre un entrevistador y entrevistado, a través de preguntas y respuestas se logra concretar 
conceptos respecto a un tema. Las entrevistas pueden ser estructuradas, semiestructuradas y abierta, la diferencia radica en la guía de preguntas utilizada.

- Sesiones en profundidad o grupos de enfoque: Son entrevistas grupales de tres a diez personas, en las que los participantes conversan profundamente sobre un tema en un ambiente informal bajo la conducción de un moderador. El objetivo de estas sesiones es que los participantes generen conceptos colectivamente, analizando experiencias, emociones, creencias o sucesos.

- Documentos, registros, materiales y artefactos: Estos instrumentos sirven para conocer los antecedentes de un ambiente, vivencias o situaciones que se producen en él y su funcionamiento diario. Algunos ejemplos de estos objetos son: cartas, diarios personales, fotografías, grabaciones de audio y video, etcétera.

- Biografías e historias de vida: Se estudia la vida de una o un grupo de personas que experimentaron el objeto de estudio de la investigación. Para realizarla se utiliza entrevistas a profundidad y revisión de objetos personales e históricos. (Hernández, Fernández \& Baptista, 2014).

En la investigación cualitativa del proyecto, se utilizaron las técnicas de grupos de enfoque y entrevistas (Ver anexos 1, 3, 5 y 7) empleando como instrumentos guía de pautas (Ver anexo 2) y guías de entrevistas. (Ver anexos 4, 6 y 8). En el proyecto, se realizaron cuatro grupos de enfoque y tres entrevistas a profundidad.

\subsubsection{Proceso de muestreo.}

La muestra es el conjunto de personas, eventos o sucesos, sobre el que se debe recolectar datos sin necesidad de ser estadísticamente representativos del universo que se estudia; ya que el objetivo de este tipo de investigación es la profundidad para entender un fenómeno de estudio y responder a las preguntas de investigación, sin extrapolar los resultados. 
Los tipos de muestra que suelen utilizarse son no probabilísticos o dirigidos: Participantes voluntarios, muestra de expertos, casos tipo, muestra por cuotas y muestras orientadas a la investigación cualitativa. (Hernández, Fernández \& Baptista, 2014).

Para elaborar los focus group, se utilizó un proceso de muestreo no probabilístico de tipo participantes voluntarios, se les hizo una invitación a las personas que cumplían con los criterios de segmentación previamente establecidos.

Para elaborar las entrevistas a profundidad, se utilizó un proceso de muestreo no probabilístico de tipo muestra de expertos. Se buscó entrevistar a personas con experiencia en la implementación y gestión de restaurantes, las cuales fueron un chef, un dueño de restaurantes y un profesor de la carrera de Administración de Hoteles y Restaurantes del Instituto San Ignacio de Loyola (ISIL).

Como conclusiones, en el caso de los focus group, las personas que fueron convocadas debían ser mayores de 18 años, que trabajen, estudien o vivan cerca de la zona donde se establece el restaurante; es decir, estas personas tienen un cierto conocimiento de los locales de comida que hay dentro del territorio III, que es la zona en donde se encuentra ubicado el proyecto, esta información ayuda a poder determinar cuáles son los gustos y preferencias de las personas que circulan o conviven en esta zona.

Las personas convocadas a los focus group al ser progresistas buscan la mejora económica que los beneficie a ellos y a sus familias; ya que son personas trabajadoras y cuentan con un poder adquisitivo suficiente para poder consumir alimentos fuera de sus casas de forma frecuente; al ser modernas están en busca de nuevas alternativas que ofrece el mercado, en este caso son las nuevas alternativas gastronómicas; sin embargo, son adaptados ya que la comida criolla, al ser la más tradicional, es de amplia preferencia en estos grupos de personas convocadas a los focus group.

En cuanto a los niveles socioeconómicos establecidos para los focus group, se tuvo en cuenta los precios de los menús que ofrece el nuevo restaurante. 


\subsubsection{Diseño de instrumento.}

Según Hernández, Fernández y Baptista (2014) un instrumento dentro de la investigación cualitativa es "el acopio de datos en los ambientes naturales y cotidianos de los participantes o unidades de análisis" (p.397) esto con el objetivo de servir de medio para que el investigador pueda apuntar los testimonios o datos sobre las variables que tiene en consideración (Hernández, Fernández \& Baptista, 2014).

Para la siguiente investigación, dentro de la técnica de grupo de enfoque se utilizó la guía de pautas que consta de las siguientes partes:

- Introducción, en la cual se realizará una presentación del coordinador y se explicarán los objetivos de la convocatoria.

- Presentación y explicación de la dinámica.

- Rompimiento de hielo para poder eliminar la tensión.

- 2 preguntas para asociar palabras.

- 16 preguntas generales sobre el tema de investigación para conocer gustos y preferencias gastronómicas.

- 15 preguntas específicas sobre el tema de investigación para entrar en mayor detalle.

- 9 preguntas sobre la preferencia y opiniones de otros restaurantes.

- Cierre del Focus Group.

Para la técnica de entrevista a profundidad, se realizaron entrevistas semiestructuradas, pues se formularon preguntas ya establecidas y se añadieron preguntas adicionales para obtener más información de algunos conceptos (Hernández, Fernández \& Baptista, 2014). Estas entrevistas se realizaron a través de una guía de preguntas a tres expertos del sector gastronómico:

a) Docente de la carrera de Administración de Hoteles y Restaurantes en un instituto, respondió 15 preguntas (Ver Anexo 4).

b) Inversionista y gestor de un restaurante del rubro, respondió 21 (Ver Anexo 6). 
c) Chef de un restaurante criollo, respondió 19 preguntas (Ver Anexo 8).

\subsubsection{Análisis y procesamiento de datos.}

En la investigación cualitativa el análisis de los datos se basa en información no estructurada en la cual los investigadores se encargan de darle una configuración con el propósito de estudiarlos de forma clara, comprender e interpretar la información obtenida y generar hipótesis y teorías basadas en los datos obtenidos. (Hernández, Fernández \& Baptista, 2014).

\section{- Análisis Del Focus Group N¹}

Este focus group fue realizado el día 2 de agosto de 2017 en Villa El Salvador, teniendo como participantes a seis trabajadores de distintas empresas de la zona: Augusto Quines, Jimmy Paredes, Cesar Aldana, Roberto Vera, Ricardo Saldarriaga y Paul Rojas. Los resultados:

Todos los entrevistados respondieron que el buen servicio y la buena atención son aspectos fundamentales cuando acuden a un restaurante. En cuanto a gustos, la mayoría se inclina por la comida criolla y la comida marina. También indicaron que durante días laborales la mayoría sale de su centro de trabajo a buscar algún restaurante y fines de semana o feriado también salen a comer fuera de casa.

La mayoría de entrevistados comentaron que prefieren pagar en efectivo y muy rara vez usan alguna tarjeta de crédito o débito. Otro punto importante es que los entrevistados indicaron que son ellos quienes toman la decisión al momento de elegir el restaurante; sin embargo, escuchan las opiniones de familiares como esposas o hijos. La mayoría considera a Gastón Acurio como un referente de la comida peruana, y tienen en cuenta el sabor y la calidad de la comida al momento de pedir un menú o plato a la carta. La mayoría de los entrevistados comentan que de lunes a viernes consumen menú y fines de semana platos a la carta y están dispuestos a pagar entre 10 a 12 soles como máximo en un menú y de 15 a 20 soles por un plato a la carta. 
La mayoría de entrevistados valora más la limpieza de un restaurante y la atención del personal. También, tienen en consideración que el restaurante tenga delivery; sin embargo, no es indispensable para ellos. Todos los entrevistados usan Facebook, pero nunca han pedido delivery mediante este tipo de redes sociales.

En cuanto a la propuesta de valor del restaurante, todos los entrevistados se interesaron en la idea que se les planteó. Dentro del menú de platos criollos, esperan encontrar estofado de pollo, arroz con pollo, lomo saltado y ají de gallina. En cuanto a comida marina, la mayoría de entrevistados espera encontrar ceviches y platos a base de mariscos.

Por otro lado, la mitad de los entrevistados están dispuestos a probar las alternativas de comida fusión y la otra mitad no está interesada. En cuanto a bebidas, la limonada y la chicha morada son las favoritas de los entrevistados y también les interesa bebidas con alcohol como la cerveza.

Otro aspecto importante de los entrevistados es que les es indiferente si el restaurante cuenta con música o no; sin embargo, si en caso hubiese música les gustaría que tuviese volumen bajo para poder conversar tranquilamente. El nombre tentativo del restaurante, Entre Copas y Tenedores, para la mayoría de entrevistados está relacionado con el concepto de restobar; ya que lo relacionan con buena comida y con bebidas alcohólicas. Para la mayoría de entrevistados, si el restaurante resulta de su agrado, lo recomiendan con familiares o amigos.

Finalmente, la mayoría de entrevistados no tiene un restaurante referente dentro del distrito y lo que esperan de un restaurante ideal es que la comida tenga un buen sabor y la atención sea óptima y cubra sus expectativas. 


\section{- Análisis Del Focus Group N²}

Este focus group fue realizado el día 3 de agosto de 2017 en Villa El Salvador, teniendo como participantes a cinco trabajadores de distintas empresas de la zona: Leiter Flores, José Córdova, Enrique Coba, Alejandro Morales y Jimmy Paredes.

Los resultados fueron:

Todos los entrevistados comentaron que lo que buscan en un restaurante es comida tradicional del Perú que tenga un buen sabor. Algunos mencionaron que buscan tranquilidad, limpieza y rapidez.

Cuando le preguntaron a los entrevistados sobre el plato de comida que les viene a la mente, mencionaron solo platos criollos, tales como: lomo saltado, ají de gallina y arroz con pollo.

Con respecto a donde suelen ir a almorzar, la mayoría de entrevistados almuerza en el comedor interno de la empresa, el cual tiene concesionario. Durante los días libres, ellos no piden delivery, prefieren ir a comer a un restaurante y pedir algo que no coman regularmente como pollo a la brasa o costillas. Además, lo que más les gusta es la comida marina y de la sierra. Además, manifestaron que desayunan de 7 a 10 am; almuerzan de 12 a 3 pm y cenan de 6 a $8: 30 \mathrm{pm}$.

Por otro lado, solo van a comer afuera durante los fines de semana, pueden ir solos o acompañados de su familia, pero dado que son jefes de hogar, ellos son los que usualmente eligen los platos que van a servirse. Al elegir entre un menú o un plato a la carta los días de semana, la mayoría prefiere comprar menú, cuyo precio oscila entre S/. 8 y S/. 12. De comprar un plato a la carta, pagarían en promedio S/ 25.

Al preguntarles por lo que más valoran en la comida, todos coinciden que les importa más la sazón del plato de fondo, no les gusta que les sirvan el plato muy lleno porque se pueden ensuciar. Con respecto a lo que más valoran en un restaurante, todos coinciden en que demandan un ambiente limpio, tranquilo y con un servicio rápido. 
Con respecto al tiempo de espera, si se tratase de un menú donde la comida ya está preparada, están dispuestos a esperar en promedio 10 minutos; pero si se trata de un plato a la carta, como máximo 20 minutos.

Los entrevistados manifiestan que nunca piden servicio delivery; ya que por la zona en la que trabajan, no hay empresas que provean de estos servicios. Si piden delivery, es de comida rápida, pero no de comida tradicional porque no encuentran el servicio cerca de ellos. Cuando les preguntaron si utilizaban las redes sociales para seguir a nuevos restaurantes, los entrevistaron comentaron que solo seguían a cadenas de restaurantes de comida rápida y solo a los restaurantes que son de sus amigos para apoyarlos con publicidad.

Los platos que prefieren los entrevistados en un restaurante son de comida criolla y marina. Con respecto a las bebidas no alcohólicas, les gustaría chicha morada, limonada y jugo de frutas variadas; respecto a bebidas alcohólicas, les gustaría encontrar cerveza.

Si se trata de una ocasión especial, les gusta ir a restaurantes campestres o costumbristas. Si se trata de un día cualquiera, no tienen un restaurante preferido, depende su ubicación, solo van a donde han tenido una buena experiencia. Lo que más valoran de estos restaurantes es la disponibilidad de platos, limpieza del local y personal, y la rapidez en la atención. Los entrevistados también manifestaron que ninguno de sus restaurantes preferidos se encuentra en Villa El Salvador y tampoco encuentran un restaurante que cumpla con sus expectativas dentro o cerca a Villa El Salvador.

$\mathrm{Su}$ restaurante ideal sería aquel que se encuentre cerca de su centro de labores, que cuente con el servicio de delivery, que tenga una amplia disponibilidad de platos, buena sazón y limpieza. 


\section{- Análisis del Focus Group N³}

Este focus group fue realizado el día 7 de agosto de 2017 en Villa El Salvador, teniendo como participantes a cinco trabajadores de distintas empresas de la zona: Miguel Ángel Naupoma, Michael Lazo, Raúl Sánchez, Hugo Huapaya, Wilber Ramos,

La mayoría de entrevistados tienen preferencia por la comida criolla y algunos por la comida marina, esto aplica para platos a la carta y menús; la mayoría de entrevistados come en su centro de trabajo, sin embargo, almuerzan en un restaurante al menos un día a la semana, pero días no laborables todos los entrevistados salen a comer a un restaurante. Los entrevistados ponen énfasis en la variedad de los platos a la carta y menús a encontrar, es decir prefieren la variedad de platos dentro de su preferencia en la comida criolla. La mayoría de entrevistados tienen como referente gastronómico al chef Gastón Acurio. La gran parte de entrevistados prefieren menú de lunes a viernes y fines de semana se inclinan por platos a la carta, sin embargo, existen algunas excepciones si es que tienen algún antojo. El rango de precios para comprar un menú oscila de 7 a 10 soles y en platos a la carta pagarían entre 25 hasta 35 soles.

Lo que más valoran la mayoría de entrevistados en un restaurante es el sabor de la comida, además de esto tienen en consideración la limpieza y el orden del restaurante. La atención del restaurante también es importante para los entrevistados, sin embargo, el sabor de la comida es más importante.

La mayoría de entrevistados esperaría como máximo 5 minutos por un menú y 15 minutos por un plato a la carta. Los entrevistados acudirían a un restaurante por recomendación de un conocido, los entrevistados manifestaron que les gustaría tener un acompañamiento musical relajado como la música criolla y que si utilizarían el sistema delivery. 


\section{- Análisis Del Focus Group N4}

Este focus group fue realizado el día 8 de agosto de 2017 en Villa El Salvador, teniendo como participantes a cinco trabajadores de distintas empresas de la zona: Nelson Chambi, Federico Cueva, Oreol Fabián, Víctor Cepeda, Luciano Quispe y José Palomino. Los resultados fueron:

La mayoría de los entrevistados comentaron que les gustaría encontrar comida criolla y marina. Con respecto a donde suelen ir a almorzar durante los días laborables, la mayoría de entrevistados comentaron que almuerzan dentro de sus empresas, platos como: menestras, mariscos y platos de la sierra como pachamanca. Durante los fines de semana, prefieren salir de casa y consumir algo que no coman regularmente.

Por otro lado, la frecuencia de veces que piden en la semana laborable platos a la carta fluctúa entre una y dos veces. Al elegir entre un menú o un plato a la carta, la mayoría prefiere comprar menú, cuyo precio fluctúe entre S/ 8 y S/ 15. De pedir un plato a la carta, pagarían en promedio S/ 25.

Al preguntarles por lo que más valoran en la comida, todos coinciden que les importa la sazón, la calidad y la higiene. Con respecto a lo que más valoran en un restaurante, todos coinciden en que deben de tener una excelente atención.

Con respecto al tiempo de espera, si se tratase de un menú donde la comida ya está preparada, están dispuestos a esperar en promedio cinco minutos para el plato de entrada y que inmediatamente llegue el plato de fondo; sin embargo, de tratarse de un plato a la carta, estarían dispuestos a pagar como máximo 20 minutos. Además, la mayoría mencionó que prefieren como bebida de acompañamiento la chicha o limonada.

Además, los entrevistados manifestaron que les gustaría tener un acompañamiento musical criollo y que sí están dispuesto a pedir el servicio de delivery. 
Tabla 10

Resumen de focus group

\begin{tabular}{|c|c|c|c|c|}
\hline PREGUNTA & FOCUS 1 & FOCUS 2 & FOCUS 3 & CONCLUSIÓN \\
\hline $\begin{array}{l}\text { ¿Dónde suele comer, } \\
\text { fuera o dentro de su } \\
\text { trabajo? }\end{array}$ & $\begin{array}{l}\text { De los seis } \\
\text { entrevistados, cinco } \\
\text { indicaron almorzar } \\
\text { fuera del trabajo. }\end{array}$ & $\begin{array}{l}\text { Fue compartido en el } \\
\text { trabajo y restaurante }\end{array}$ & $\begin{array}{l}\text { De los seis } \\
\text { entrevistados, cuatro } \\
\text { indicaron almorzar } \\
\text { dentro del trabajo. }\end{array}$ & $\begin{array}{l}\text { La preferencia por } \\
\text { comer dentro de su } \\
\text { centro de trabajo o en } \\
\text { un restaurante, es } \\
\text { compartida. }\end{array}$ \\
\hline $\begin{array}{l}\text { ¿Dónde suele comer en } \\
\text { domingos y feriados? }\end{array}$ & $\begin{array}{l}\text { Los seis entrevistados } \\
\text { indicaron que comen } \\
\text { en un restaurante. }\end{array}$ & $\begin{array}{l}\text { Cinco entrevistados } \\
\text { indicaron comer en un } \\
\text { restaurante. }\end{array}$ & $\begin{array}{l}\text { De los seis } \\
\text { entrevistados, solo la } \\
\text { mitad indicó comer en } \\
\text { un restaurante. }\end{array}$ & $\begin{array}{l}\text { Se puede indicar que } \\
\text { prefieren comer en un } \\
\text { restaurante. }\end{array}$ \\
\hline $\begin{array}{c}\text { ¿Cuántas veces suelen } \\
\text { comer fuera de casa en } \\
\text { la semana? }\end{array}$ & $\begin{array}{l}\text { Todos indicaron que } \\
\text { comen en un } \\
\text { restaurante los fines de } \\
\text { semana. }\end{array}$ & $\begin{array}{l}\text { Todos indicaron que } \\
\text { comen en un } \\
\text { restaurante los fines de } \\
\text { semana. }\end{array}$ & $\begin{array}{l}\text { Todos indicaron que } \\
\text { comen en un } \\
\text { restaurante los fines de } \\
\text { semana. }\end{array}$ & $\begin{array}{l}\text { Todos indicaron que } \\
\text { comen en un } \\
\text { restaurante los fines de } \\
\text { semana. }\end{array}$ \\
\hline $\begin{array}{l}\text { ¿Cuál es la } \\
\text { característica que más } \\
\text { valoran en un } \\
\text { restaurante? }\end{array}$ & $\begin{array}{c}\text { Los seis entrevistados } \\
\text { indicaron limpieza y } \\
\text { atención. }\end{array}$ & $\begin{array}{c}\text { Los seis entrevistados } \\
\text { indicaron limpieza y } \\
\text { atención. }\end{array}$ & $\begin{array}{c}\text { Los seis entrevistados } \\
\text { indicaron limpieza y } \\
\text { atención. }\end{array}$ & $\begin{array}{c}\text { Los seis entrevistados } \\
\text { indicaron limpieza y } \\
\text { orden. }\end{array}$ \\
\hline $\begin{array}{l}\text { ¿En la semana que } \\
\text { prefieren pedir, menú o } \\
\text { a la carta? }\end{array}$ & $\begin{array}{c}\text { Días de semana } \\
\text { prefieren menú; y fines } \\
\text { de semana, platos a la } \\
\text { carta. }\end{array}$ & $\begin{array}{l}\text { Días de semana } \\
\text { prefieren comer el } \\
\text { menú y fines de } \\
\text { semana los platos a la } \\
\text { carta. }\end{array}$ & $\begin{array}{l}\text { Días de semana } \\
\text { prefieren comer el } \\
\text { menú y fines de } \\
\text { semana los platos a la } \\
\text { carta. }\end{array}$ & $\begin{array}{l}\text { Días de semana } \\
\text { prefieren comer el } \\
\text { menú y fines de } \\
\text { semana los platos a la } \\
\text { carta. }\end{array}$ \\
\hline $\begin{array}{l}\text { ¿Usan frecuentemente } \\
\text { el servicio de delivery? }\end{array}$ & $\begin{array}{l}\text { Todos indicaron el uso } \\
\text { recurrente del delivery. }\end{array}$ & $\begin{array}{l}\text { Poco usual pedir } \\
\text { delivery. }\end{array}$ & $\begin{array}{l}\text { Poco usual pedir } \\
\text { delivery. }\end{array}$ & $\begin{array}{l}\text { El uso de delivery de } \\
\text { menú es más solicitado } \\
\text { en días de semana, los } \\
\text { fines de semana } \\
\text { prefieren visitar el } \\
\text { restaurante. }\end{array}$ \\
\hline $\begin{array}{l}\text { ¿Por qué medio de } \\
\text { publicidad conocen } \\
\text { nuevos restaurantes? }\end{array}$ & $\begin{array}{l}\text { Todos indicaron el uso } \\
\text { recurrente de } \\
\text { Facebook. }\end{array}$ & Por conocidos. & Por conocidos & $\begin{array}{l}\text { Por recomendación de } \\
\text { un amigo o familiar. }\end{array}$ \\
\hline $\begin{array}{c}\text { ¿Están dispuesto a } \\
\text { pagar por un menú } 8 \text { a } \\
10 \text { soles? }\end{array}$ & $\begin{array}{l}\text { Sí, están dispuestos a } \\
\text { pagar por un menú de } \\
8 \text { a } 10 \text { soles como } \\
\text { máximo. }\end{array}$ & $\begin{array}{l}\text { Sí, están dispuestos a } \\
\text { pagar por un menú de } \\
8 \text { a } 10 \text { soles como } \\
\text { máximo. }\end{array}$ & $\begin{array}{l}\text { Sí, están dispuestos a } \\
\text { pagar por un menú de } \\
8 \text { a } 10 \text { soles como } \\
\text { máximo. }\end{array}$ & $\begin{array}{l}\text { Sí, están dispuestos a } \\
\text { pagar por un menú de } \\
8 \text { a } 10 \text { soles como } \\
\text { máximo. }\end{array}$ \\
\hline $\begin{array}{l}\text { ¿Están dispuesto a } \\
\text { pagar por un plato a la } \\
\text { carta } 18 \text { a } 20 \text { soles? }\end{array}$ & $\begin{array}{l}\text { Sí, podrían pagar ese } \\
\text { precio. }\end{array}$ & $\begin{array}{l}\text { Sí, podrían pagar ese } \\
\text { precio. }\end{array}$ & $\begin{array}{l}\text { Sí, podrían pagar ese } \\
\text { precio. }\end{array}$ & $\begin{array}{l}\text { Sí, están dispuestos a } \\
\text { pagar por un menú de } \\
18 \text { a } 25 \text { soles como } \\
\text { máximo. }\end{array}$ \\
\hline $\begin{array}{l}\text { ¿Qué tipo de comida } \\
\text { les gustaría que ofrezca } \\
\text { un restaurante? }\end{array}$ & $\begin{array}{l}\text { Les gustaría marino } \\
\text { criollo y criollo fusión. }\end{array}$ & $\begin{array}{c}\text { Les gustaría marino y } \\
\text { criollo. }\end{array}$ & $\begin{array}{c}\text { Les gustaría marino y } \\
\text { criollo. }\end{array}$ & $\begin{array}{l}\text { La preferencia por el } \\
\text { tipo de menú es el } \\
\text { criollo los días de } \\
\text { semana y el marino los } \\
\text { fines de semana. }\end{array}$ \\
\hline $\begin{array}{l}\text { ¿Qué bebidas les } \\
\text { gustaría que le } \\
\text { ofrezcan en un } \\
\text { restaurante? }\end{array}$ & $\begin{array}{l}\text { La preferencia por las } \\
\text { bebidas son la chicha y } \\
\text { la limonada. }\end{array}$ & $\begin{array}{l}\text { La preferencia por las } \\
\text { bebidas son la chicha y } \\
\text { la limonada. }\end{array}$ & $\begin{array}{l}\text { La preferencia por las } \\
\text { bebidas son la chicha y } \\
\text { la limonada. }\end{array}$ & $\begin{array}{l}\text { La preferencia por las } \\
\text { bebidas son la chicha y } \\
\text { la limonada. }\end{array}$ \\
\hline $\begin{array}{c}\text { ¿Qué les gusta más de } \\
\text { un restaurante? }\end{array}$ & $\begin{array}{l}\text { Les agrada más la } \\
\text { atención y la buena } \\
\text { sazón de la comida. }\end{array}$ & $\begin{array}{l}\text { Les agrada más la } \\
\text { buena sazón de la } \\
\text { comida. }\end{array}$ & $\begin{array}{l}\text { Les agrada más la } \\
\text { atención y la buena } \\
\text { sazón de la comida. }\end{array}$ & $\begin{array}{l}\text { Les agrada más la } \\
\text { atención y la buena } \\
\text { sazón de la comida. }\end{array}$ \\
\hline $\begin{array}{l}\text { ¿En VES que } \\
\text { restaurante } \\
\text { recomendarían? }\end{array}$ & $\begin{array}{l}\text { No tienen un } \\
\text { restaurante preferido y } \\
\text { no recuerdan el } \\
\text { nombre de los } \\
\text { restaurantes que } \\
\text { visitan. }\end{array}$ & $\begin{array}{l}\text { No tienen un } \\
\text { restaurante preferido y } \\
\text { no recuerdan el } \\
\text { nombre de los } \\
\text { restaurantes que } \\
\text { visitan. }\end{array}$ & $\begin{array}{l}\text { No tienen un } \\
\text { restaurante preferido y } \\
\text { no recuerdan el } \\
\text { nombre de los } \\
\text { restaurantes que } \\
\text { visitan. }\end{array}$ & $\begin{array}{l}\text { No tienen un } \\
\text { restaurante preferido y } \\
\text { no recuerdan el } \\
\text { nombre de los } \\
\text { restaurantes que } \\
\text { visitan. }\end{array}$ \\
\hline
\end{tabular}


- Análisis de la Entrevista No 1: Coordinador y Docente de la Carrera de Administración de Hoteles y Restaurantes de ISIL

El objetivo es conocer, con principios básicos, que es lo que debe saber un emprendedor que está pensando en incursionar en el mundo de la gastronomía y a lo que se enfrenta en el mercado peruano.

El entrevistado, coordinador de la carrera de administración de hoteles y restaurantes de ISIL, empezó su carrera profesional trabajando en un hotel, el Cesar Hotel de Miraflores específicamente, despertando su pasión por la cocina y todo lo que implica estar dentro de este mundo. A partir de esto decidió capacitarse, formando parte de Le Cordon Bleu, incrementando sus expectativas de ingresar en el mercado gastronómico peruano.

El mercado gastronómico implica mucho sacrificio, las dificultades son innumerables pero los retos son los que impulsan a superar todas estas vallas. Uno de los retos más importantes fue llevar la gastronomía peruana a otros continentes, como Europa, ha sido una de sus mayores satisfacciones.

La virtud de una persona que se dedica a este negocio es tener una buena predisposición por atender las necesidades del cliente y estar atento a sus preferencias, es muy importante que en la cocina se cuente con una variedad de suministros que permiten una atención rápida, de calidad y segura, que satisfagan al tipo de cliente que se atiende en un sector del mercado.

La rentabilidad de este negocio está asegurada, el crecimiento del consumo de comida peruana en nuestro país y el extranjero, el crecimiento del emprendedor que se dedica a este negocio es muy rápido, siendo por seguro que es un mercado que seguirá creciendo ya que la demanda del consumidor es una necesidad básica del ser humano.

Con respecto a los ratios de rentabilidad, se puede tener un parámetro de estimación por plato, el cual es sugerido por el señor con un valor de $25 \%$ como mínimo, con relación al precio de venta. Se puede clasificar como platos a la carta y platos de venta masiva, que, 
según el tiempo de preparación y la complejidad de la preparación, esta puede variar. Para el costeo, se utilizan cuatro factores principales, como el costo de los insumos, la mano de obra, los gastos de servicios y el margen de utilidad que creas conveniente, según el mercado objetivo.

El tiempo promedio de preparación de un plato no debe exceder los 15 minutos, hablando de platos a la carta, pero los platos considerados de venta masiva deben tener un tiempo mucho menor a este, debido que el objetivo de estos platos es satisfacer las necesidades del cliente que tiene los tiempos cortos para comer. Hay algunas técnicas para disminuir el tiempo de cocción de los alimentos, como el blanqueado o pre cocción, que ayudan a disminuir la elaboración de los platos solicitados. Existen platos de alta y baja dificultad de preparación sobre todo los que requieren de salsa base de fondo, estos se deben hacer con anticipación para tenerlo listo para el satisfacer el servicio ofertado; también no debemos olvidar tener insumos básicos en la cocina como sal, pimienta, aceite, papa, arroz, hierbas aromáticas y luego depende de la carta; se debe tener en cuenta la clase de insumos y materia prima que se debe tener en stock, debido a que son elementos perecibles y tienen un alto riesgo de que en poco tiempo ya no brinden las condiciones mínimas de salubridad para el consumo humano y menos para brindar un servicio de calidad a los comensales.

Los platos de mayor demanda en el mercado dependen mucho de sector; por ejemplo, en Lima la comida criolla definitivamente es la de mayor demanda, en el norte son los pescados y mariscos, en la sierra central los platos típicos de la región. En Lima, hablando específicamente, hay mucha preferencia por el chifa, platos con influencia italiana, etc; que es lo mejor que se maneja en el país.

Los nuevos profesionales de la gastronomía en el Perú están orientados a la comida peruana, también interés por la comida italiana y francesa, la comida oriental que son comunes en nuestro medio. 
Finalmente, se puede recomendar que la dedicación y el sacrificio vienen de la mano con el progreso en el mercado de la gastronomía, se debe manejar muy bien la gestión del suministro de insumos, conocer el mercado de consumidores, tener todos los recursos necesarios para realizar un producto de calidad, hablando de materia prima, insumos, mano de obra, equipos, inmueble, higiene, etc. Estos factores son importantes para el nivel de ventas y la rentabilidad.

- Análisis de la entrevista Nº 2: Dueño del Restaurante "El Punto del Sabor"

De acuerdo con la información obtenida se puede analizar que el negocio de restaurantes, como cualquier otro negocio, tiene sus ventajas y desventajas. Esta entrevista tiene como finalidad poder rescatar la experiencia necesaria para poder crear un negocio exitoso. A partir de ello se concluyó que la gestión de los permisos de la municipalidad y de defensa civil es importante para el inicio del proyecto. El éxito del restaurante dependerá, con respecto a la competencia, la innovación de los productos, así mismo, la importancia de la calidad del servicio y de los productos será un factor relevante para la aceptación del cliente.

El almacenamiento del producto deberá ser debidamente controlado para un adecuado aprovechamiento de los mismos. El liderazgo en la cocina y con los mozos deberá ser debidamente definido para un adecuado desempeño. El reclutamiento del personal deberá ser enfocado a la proactividad y confiabilidad de los mismos. Tener un adecuado procedimiento del control de ventas, será el pilar para una excelente gestión del crecimiento de la empresa.

Se debe de manejar una lista de proveedores para poder cotizar los productos y poder valorizar la rentabilidad del plato que se desee vender. Finalmente, una correcta administración de la publicidad en las redes sociales será, en esta época, fundamental para el éxito de la empresa. 
- Análisis de la entrevista № 3: Chef de restaurante "Manos Morenas"

El objetivo es conocer de forma puntual como puede gestionarse adecuadamente la cocina en un restaurante. El entrevistado es cocinero desde el 2001 y su especialidad es la comida criolla.

El entrevistado indica que actualmente la tendencia es hacer comida fusión, es decir se busca la innovación al momento de preparar los platos, sin embargo, es la comida criolla la que tiene mayor preferencia por parte de los clientes manteniendo su nivel de ventas durante todo el año, a diferencia de la comida marina o el pollo a la brasa que presenta altas y bajas según la estación del año, esto nos muestra que la comida criolla está de alguna forma arraigada en los gustos del cliente.

De acuerdo con el entrevistado la creatividad de un chef sale a la luz cuando esté dispone de insumos limitados, sin embargo, al existir en el Perú una gran variedad de ingredientes la cantidad de combinaciones es muy amplia, pese a esto hay insumos indispensables dentro de toda cocina peruana como es el arroz, la papa o los ajíes, esto debido a la preferencia que existe por la comida criolla que en su mayoría de veces va acompañada por una porción de arroz o papa.

Otro punto importante dentro de una cocina es la rotación de los insumos utilizando métodos PEPS (primeras entradas y primeras salidas), esto para asegurar que no perezcan los productos almacenados. Es necesario también acortar los tiempos de preparación de los platos mediante técnicas de pre cocinado, esto con el fin de dar un servicio rápido y eficiente al cliente.

Dentro de toda cocina, es el chef quien determinar el rol o papel de cada ayudante, esto en relación con las habilidades que posean los colaboradores, también va a depender mucho la cantidad de ayudantes de cocina con la capacidad de atención del restaurante. El entrevistado también nos indica que los avances tecnológicos dentro del mundo de la 
gastronomía son importantes debido a que permiten acortar tiempos de preparación de los alimentos, esto es fundamental dentro de una adecuada gestión de un restaurante.

Se indica también que se trata de sacar el máximo provecho a los insumos empleados en la cocina, esto con la finalidad de abaratar costos y reducir las mermas, además de esto depende del tipo de almacenamiento la duración de los alimentos, es el chef o jefe de cocina quien determina cuánto tiempo va a durar determinados productos.

El entrevistado también señala que no hay una fecha establecida de cambio de utensilios de cocina, esto depende mucho del uso adecuado que se haga de cada utensilio, también existen Buenas Prácticas de Manufactura que se deben cumplir para la correcta manipulación de los alimentos y para asegurar la higiene dentro de una cocina, evitando la contaminación de los productos.

Finalmente, es necesario tener muy seguro a cuántas personas se piensa atender teniendo en cuenta el tamaño del salón que debe ser proporcional a la cocina. Luego hay que tener en cuenta la ubicación de restaurante (alrededores) y aplicar un buen servicio ya que este aspecto es fundamental y muy importante para que el cliente regrese al local.

\section{Tabla 11}

Resúmenes de entrevistas

\begin{tabular}{|c|c|c|}
\hline PREGUNTAS & $\begin{array}{l}\text { ENTREVISTA 1: DOCENTE } \\
\text { ISIL }\end{array}$ & CONCLUSIÓN \\
\hline $\begin{array}{l}\text { ¿Qué retos y dificultades tuvo en } \\
\text { su profesión? }\end{array}$ & Adaptación de Horarios. & \multirow{7}{*}{$\begin{array}{l}\text { Se debe manejar bien la gestión de } \\
\text { lo insumos y estar al tanto de las } \\
\text { preferencias y necesidades del } \\
\text { cliente. También, indicó que, en } \\
\text { promedio, estos negocios tienen } \\
\text { una rentabilidad de } 25 \% \text {. }\end{array}$} \\
\hline $\begin{array}{l}\text { ¿Cuán rentable es para usted la } \\
\text { gastronomía en el Perú? }\end{array}$ & En crecimiento. & \\
\hline $\begin{array}{l}\text { ¿Cuáles considera usted que son } \\
\text { los platos de mayor demanda? }\end{array}$ & Criollo y Chifa. & \\
\hline $\begin{array}{l}\text { ¿Cuál es el porcentaje mínimo de } \\
\text { ganancia por plato? }\end{array}$ & $\begin{array}{c}\text { No menor al } 25 \% \text { con relación al } \\
\text { precio de venta. }\end{array}$ & \\
\hline $\begin{array}{l}\text { ¿Cómo y qué métodos se utilizan } \\
\text { para costear un plato de comida? }\end{array}$ & $\begin{array}{c}\text { Costo de insumos, mano de obra, } \\
\text { gastos generales (servicios) y la } \\
\text { rentabilidad. }\end{array}$ & \\
\hline $\begin{array}{l}\text { ¿Cuál es el tiempo promedio de } \\
\text { preparación de un plato a la } \\
\text { carta? }\end{array}$ & No debe exceder los 15 minutos. & \\
\hline $\begin{array}{l}\text { ¿En qué tipo de comida se } \\
\text { especializan más sus alumnos? }\end{array}$ & Criolla y comida oriental. & \\
\hline
\end{tabular}




\section{PREGUNTAS}

\section{ENTREVISTA 2: DUEÑO} RESTAURANTE

\section{CONCLUSIÓN}

\begin{abstract}
¿Qué tipo de comida ofrece?
¿Qué restricciones, dificultades o riesgos tuvo antes de abrir su restaurante?
\end{abstract}

¿Cuáles considera que son los factores de éxito en un negocio de este tipo?

¿Cuál es el perfil del cliente que comúnmente visita su restaurante?

¿Cuál ha sido la clave para atraer nuevos clientes?

¿Qué técnicas usa para fidelizar y retener a sus clientes?

¿En qué se diferencia de su competencia directa?

¿Qué factores cree usted que tienen en consideración las personas para escoger determinado restaurante? ¿Cuál es el precio promedio que cobra para cada tipo de plato? Por ejemplo: Platos marinos, platos criollos y menú. ¿Cuál cree que son los principales errores que cometen los pequeños negocios que empiezan a emprender en la gastronomía?

¿Cuáles son las herramientas de publicidad que usa para con su restaurante?

\author{
Criollo y marino. \\ Desabastecimiento de insumos, \\ precios elevados debido a desastres \\ naturales, licencia de \\ funcionamiento.
}

Innovación, platos fusión.

Trabajadores, familias, clase media.

Innovación en el servicio.

Buen sabor y servicio.

Sazón, ambiente y atención.

Estacionamiento, atención y un agradable ambiente.

Un menú esta entre 9 y 15 soles, mientras que los platos a la carta están entre 18 y 25 soles.

No saben manejar sus costos al margen.

Al principio volantes luego promocionarse por las redes.
Para un dueño de restaurante, la comida más demandada es la criolla y marina. Para tener éxito, recomienda la innovación en platos fusión, el servicio, tener una buena sazón y un ambiente y atención de calidad. Además, considera importante contar con una zona de parqueo; ya que la mayoría de personas tienen movilidad propia. Además, indicó que los precios de menús fluctúan entre 9 y 15 soles en zonas residenciales y entre 8 y 10 soles en zonas rurales. La manera más efectiva para darse a conocer son las redes sociales. 


\begin{tabular}{|c|c|c|}
\hline PREGUNTAS & $\begin{array}{l}\text { ENTREVISTA 3: CHEF } \\
\text { RESTAURANTE }\end{array}$ & CONCLUSIÓN \\
\hline $\begin{array}{l}\text { ¿Cuál considera usted que es } \\
\text { la tendencia en el rubro } \\
\text { gastronómico peruano? }\end{array}$ & La comida fusión. & \\
\hline $\begin{array}{l}\text { ¿Cuáles son los platos que } \\
\text { más le piden? }\end{array}$ & Lomo saltado y ceviche. & \\
\hline $\begin{array}{l}\text { ¿Las preferencias de los } \\
\text { comensales suelen cambiar de } \\
\text { forma periódica? }\end{array}$ & $\begin{array}{l}\text { En verano se consume bastante } \\
\text { ceviche y en invierno el pollo a la } \\
\text { brasa. La comida criolla si } \\
\text { mantiene su nivel de venta todo el } \\
\text { año. }\end{array}$ & $\begin{array}{l}\text { Para un Chef de restaurante, } \\
\text { está marcado el tipo de comida } \\
\text { que los comensales peruanos } \\
\text { consumen, estas son las }\end{array}$ \\
\hline $\begin{array}{l}\text { ¿Cuál considera usted que es } \\
\text { el plato más representativo de } \\
\text { la comida peruana y por qué? }\end{array}$ & $\begin{array}{l}\text { El ceviche debido a que muchos } \\
\text { restaurantes de comida criolla. }\end{array}$ & $\begin{array}{l}\text { comidas marinas y criollas } \\
\text { (resaltando al lomo saltado y } \\
\text { ceviche como sus preferidas). }\end{array}$ \\
\hline $\begin{array}{l}\text { ¿Cuál considera que es el } \\
\text { tiempo promedio para poder } \\
\text { atender un plato a la carta y } \\
\text { un menú? }\end{array}$ & $\begin{array}{l}15 \text { minutos para platos a la carta } \\
\text { como máximo, el menú debería } \\
\text { salir en } 5 \text { minutos debido a que ya } \\
\text { se tiene hecho el plato. }\end{array}$ & $\begin{array}{l}\text { Además, se tiene en } \\
\text { consideración que cocinar un } \\
\text { plato a la carta no debe de durar } \\
\text { más de } 15 \text { minutos y un menú }\end{array}$ \\
\hline $\begin{array}{l}\text { ¿Cuántos ayudantes de cocina } \\
\text { necesita un día de semana, y } \\
\text { cuántos los fines de semana? }\end{array}$ & $\begin{array}{l}\text { Si se va a tener } 100 \text { personas en el } \\
\text { restaurante, se necesitan } 6 \text { en } \\
\text { cocina en diversas áreas (fríos, } \\
\text { calientes y frituras). }\end{array}$ & $\begin{array}{l}\text { no más de } 5 \text { minutos. } \\
\text { Recomienda que, si se planea } \\
\text { vender más menús, no es } \\
\text { necesario tener una cocina muy }\end{array}$ \\
\hline $\begin{array}{l}\text { Para un emprendedor, } \\
\text { ¿Alguna apreciación o } \\
\text { consejo con respecto a una } \\
\text { adecuada gestión de la cocina } \\
\text { en un restaurante? }\end{array}$ & $\begin{array}{l}\text { Si se va a dar menú no es una } \\
\text { cocina muy grande, si hay platos a } \\
\text { la carta si se necesita una cocina } \\
\text { amplia. si el cliente ve que existe } \\
\text { un servicio muy bueno a pesar de } \\
\text { que la comida no es tan buena, el } \\
\text { cliente va a volver a tu restaurante. }\end{array}$ & amplia. \\
\hline
\end{tabular}

Nota Fuente. Elaboración propia

\subsection{Investigación Cuantitativa}

Según Hernández, Fernández y Baptista (2014), en la investigación cuantitativa “se

utiliza la recolección de datos para probar hipótesis con base en la medición numérica y el análisis estadístico, con el fin de establecer pautas de comportamiento y probar teorías" (p.04).

Para la recolección de datos cuantitativos, se utilizan los cuestionarios que emplean un grupo de preguntas para evaluar una o más variables. Estas preguntas se clasifican en dos tipos:

- Preguntas Cerradas: Contienen alternativas de respuesta ya establecidas y definidas, resultando más fáciles de estudiar y examinar. 
- Preguntas Abiertas: No existen alternativas de respuesta y son apropiadas cuando no hay información disponible sobre las probables respuestas de los individuos de estudio.

Para el presente proyecto el objetivo de la investigación cuantitativa es determinar y cuantificar la demanda que tendrá el restaurante en el distrito de Villa el Salvador.

\subsubsection{Proceso de muestreo}

De acuerdo con Hernández, Fernández y Baptista (2014), la muestra dentro del proceso cuantitativo es "un subgrupo de la población de interés sobre el cual se recolectarán datos, y que tiene que definirse y delimitarse de antemano con precisión, además de que debe ser representativo de la población" (p.173).

Los tipos de muestra que suelen utilizarse para la investigación cuantitativa son las muestras probabilísticas, donde el total de elementos de la población poseen igual probabilidad de ser elegidos para la muestra al ser determinado las particularidades y características de la población y el tamaño de la muestra mediante una elección aleatoria o deliberada de la unidad de muestreo o análisis. Los tipos de muestras probabilísticas son: Muestra aleatoria simple, muestra estratificada y muestra por racimos. (Hernández, Fernández \& Baptista, 2014).

Para este proyecto, se utilizó un proceso de muestra aleatoria simple. Las cuatro personas encargadas de encuestar fueron instruidas de posicionarse en el Territorio III de manera equidistante en forma de un cuadrado, limitándose a la Av. Bolívar por el norte, Av. 200 millas por el sur, Av. Revolución por el este y Av. Mariano Pastor Sevilla por el oeste. A los encuestados, se les aplicaron tres preguntas filtro (1. Edad, 2. Residente o visitante y 3. Comer fuera de casa en el último mes). 
A continuación, se obtiene el cálculo del tamaño de muestra, considerando los siguientes aspectos:

- Total de población que vive en el Territorio III de Villa El Salvador en el 2018 (N), igual al 7.93\% de 493,072; es decir 39,100 personas.

- Nivel de confianza: Es el porcentaje de intervalos que incluye el parámetro de la población. Se considera un nivel de confianza de 95\%; por lo tanto, se tiene una probabilidad de éxito (p) de $95 \%$ y una probabilidad de fracaso (q) de $5 \%$.

- Error estadístico (e): Es la diferencia entre el valor del parámetro de la población y el valor del estimador de la muestra, por lo tanto, se considera un error muy bajo de + / 0.05 .

- Considerando una distribución normal estándar en los datos con dos colas, se obtiene un valor $Z=Z(1-\alpha / 2)=Z(1-0.05 / 2)=Z(0.975)=1.96$.

A continuación, el cálculo para determinar el tamaño de muestra óptimo en una población finita:

Tamaño de la muestra (finita): $n=\frac{N * Z^{2} * p *(q)}{e^{2} *(N-1)+Z^{2} * p *(q)}=\frac{39,100 * 1.96^{2} * 0.95 * 0.05}{0.05^{2} *(39,099)+1.96^{2} * 0.95 * 0.05}=72.6$

De esta manera, se puede afirmar que con un nivel de confianza del 95\%, a partir de 73 encuestas, se puede inferir los gustos y preferencias del total de la población del Territorio III de Villa El Salvador.

Debido a que el tamaño de la muestra previamente calculado resulta muy pequeño, se considera el modelo de estimación más pesimista (McDaniel y Roger Gates), en el que la población es infinita y el valor de P es 0.50 .

Tamaño de la muestra (infinita): $n=\frac{Z^{2} * p *(1-p)}{e^{2}}=\frac{1.96^{2} * 0.5 *(1-0.5)}{0.05^{2}}=384.03$

De esta manera, se puede afirmar que con un nivel de confianza del 95\%, a partir de 384 encuestas, se puede inferir los gustos y preferencias del total de la población de Villa El Salvador, considerando un margen de error de $+/-5 \%$. 


\subsubsection{Diseño de Instrumento}

Según Hernández, Fernández y Baptista (2014), un instrumento dentro de la investigación cuantitativa es un "recurso que utiliza el investigador para registrar información o datos sobre las variables que tiene en mente" (p.199) esto con el propósito de plasmar y medir la opinión del entrevistado.

En la investigación cuantitativa, se aplica el cuestionario para evaluar las variables de interés para el investigador, estas variables figuran en el cuestionario a realizar y deben describir de forma más aproximada lo que el investigador desea analizar para su interés.

La aplicación del cuestionario permitió recabar información por medio de preguntas confiables organizadas en un cuestionario impreso, el encuestado lee y lo responde por escrito, esta técnica de encuesta cuenta con una estructura lógica que permitió obtener suposiciones o ideas que ayudó a estudiar a los comensales sobre sus gustos y deseos de cómo ser atendido. En el cuestionario elaborado, se consideraron preguntas relacionadas a: i) Preferencia del tipo de comida, ii) Preferencia del tipo de servicio, iii) Aceptación de la propuesta de valor, iv) Competencia y v) Precio. Se elaboró un cuestionario de cuarenta y cinco preguntas, de las cuales tres son de filtro, cuarenta preguntas generales y dos de control. Del total de preguntas, ocho son dicotómicas; veinticinco son multivariables y una de escala de Likert. 


\subsubsection{Análisis y procesamiento de datos}

\section{a) Preguntas filtro}

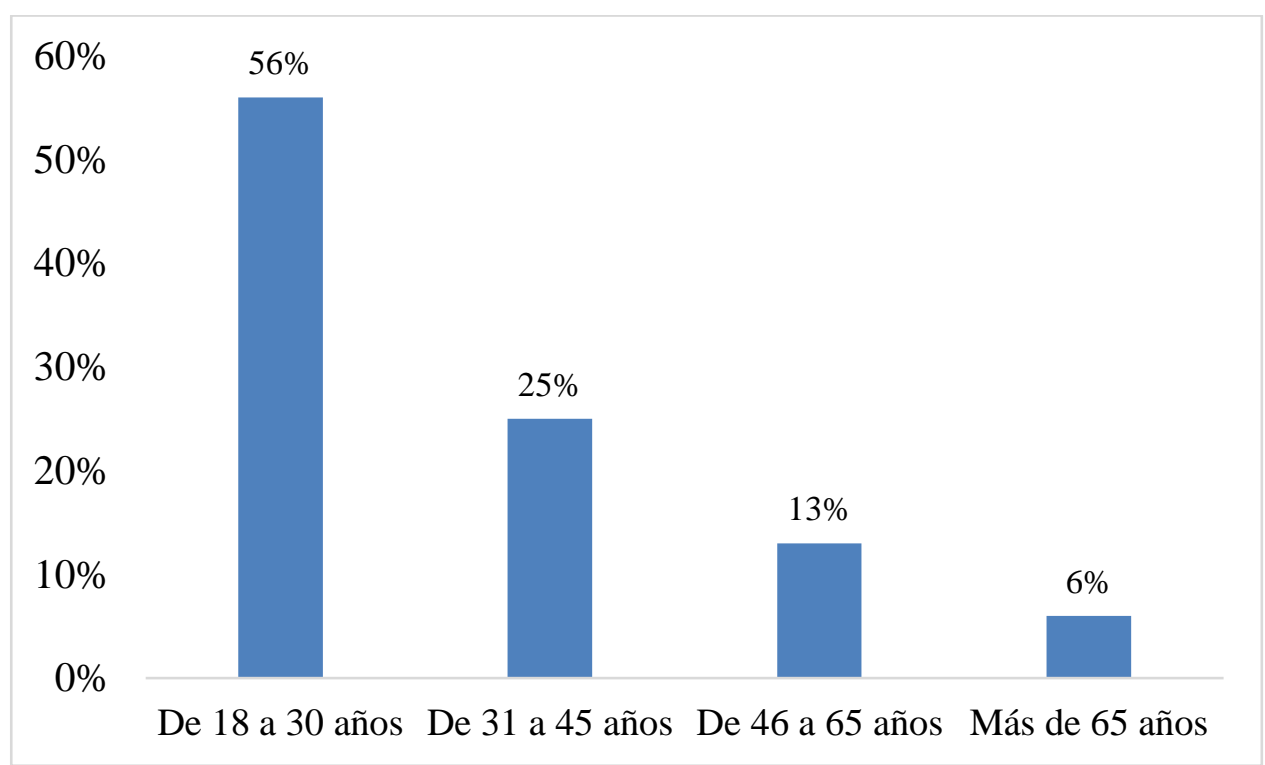

Ilustración 2. Pregunta filtro 1: ¿Podría decir qué edad tiene? Adaptado de encuesta aplicada.

Se puede concluir que el $56 \%$ de las personas encuestadas se encuentra entre los $18 \mathrm{y}$ 30 años, el $25 \%$ entre los 31 y 45 años, el 13\% entre los 46 y 65 años y el $6 \%$ son mayores de 65 años.

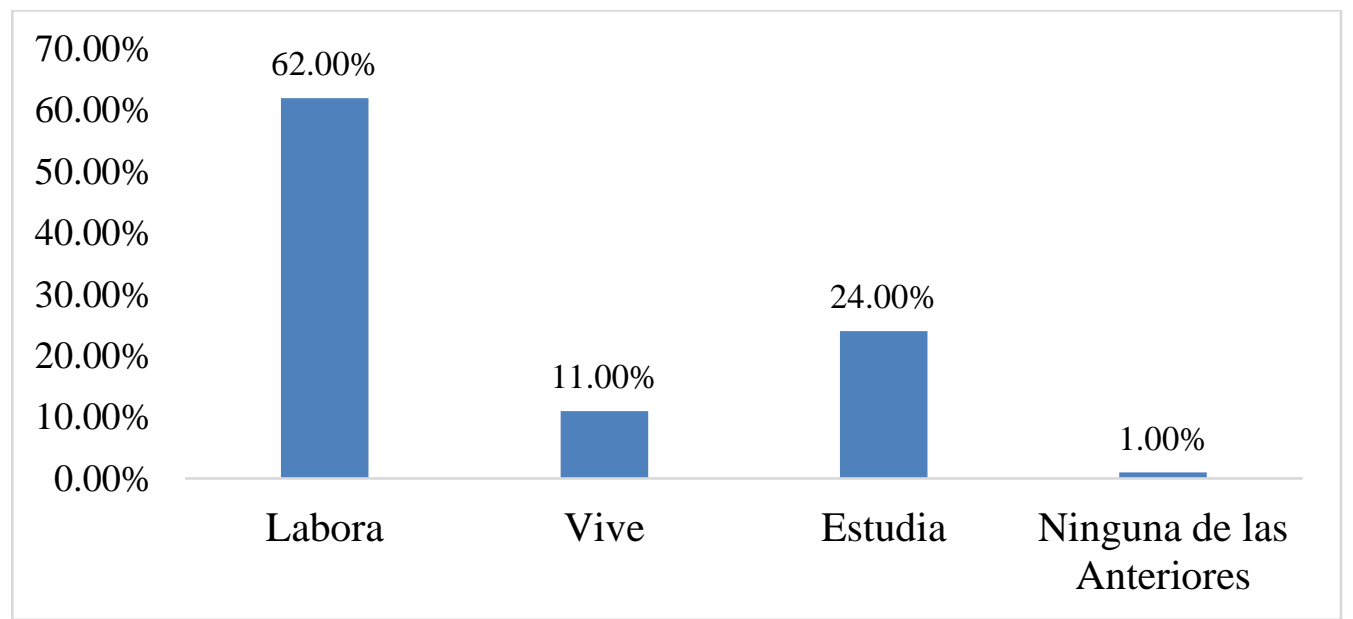

Ilustración 3. Pregunta filtro 2: ¿Vive, labora o estudia cerca al lugar donde actualmente nos encontramos (Territorio III)? Adaptado de encuesta aplicada.

El 62\% de los encuestados indicaron que laboran en el distrito de Villa el Salvador, el $24 \%$ estudia y el $11 \%$ vive cerca al lugar de la encuesta. 


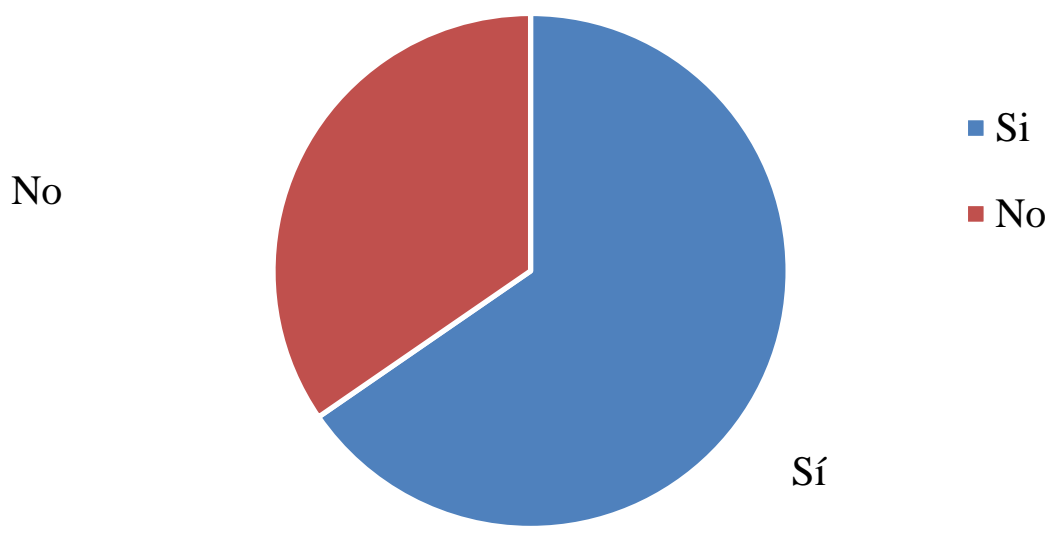

Ilustración 4. Pregunta filtro 3: En el último mes, ¿ha salido a comer fuera de casa? Adaptado de encuesta aplicada.

El $65.40 \%$ de los encuestados ha salido a comer fuera de casa en el último mes.

\section{b) Preguntas Generales}

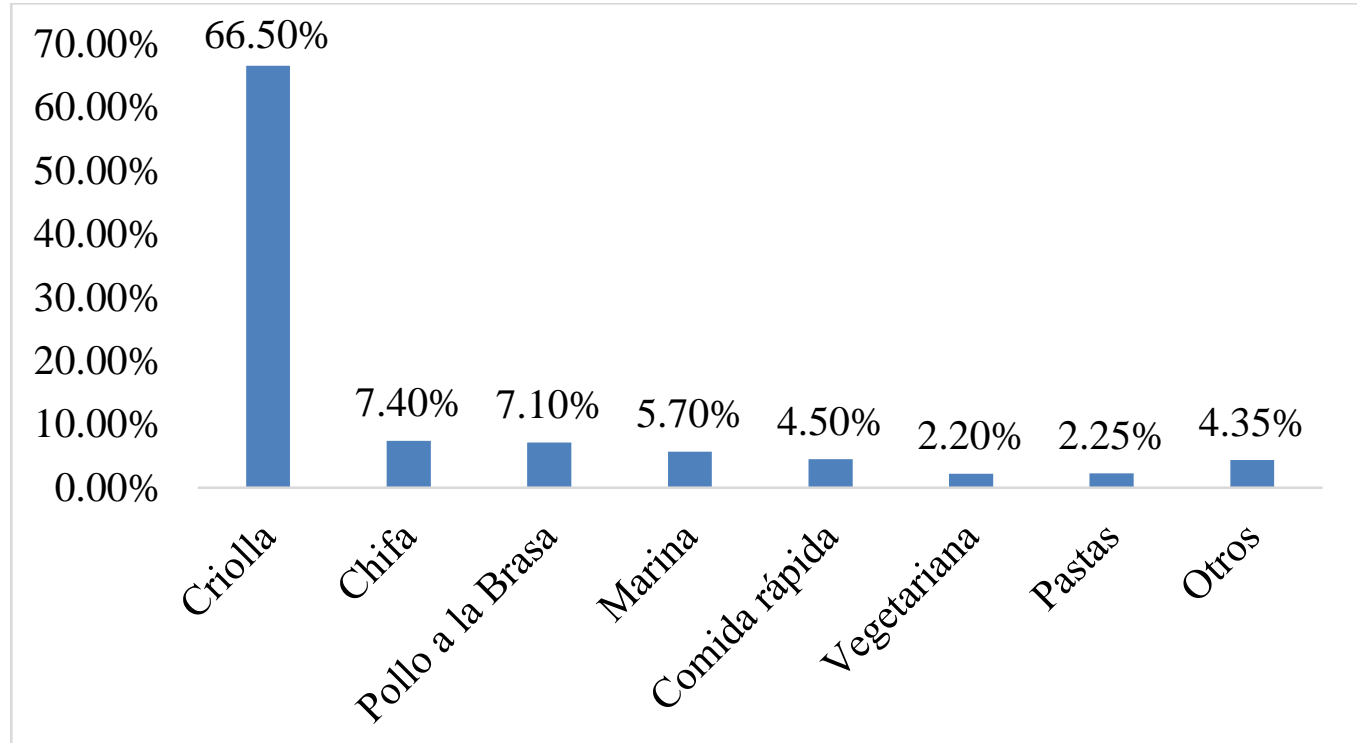

Ilustración 5. Pregunta general 1: ¿Qué tipo de comida prefiere entre días de semana? Adaptado de encuesta aplicada.

Se observa que la mayoría de los encuestados prefiere la comida criolla (66.5\%), seguida por el chifa y pollo a la brasa. 


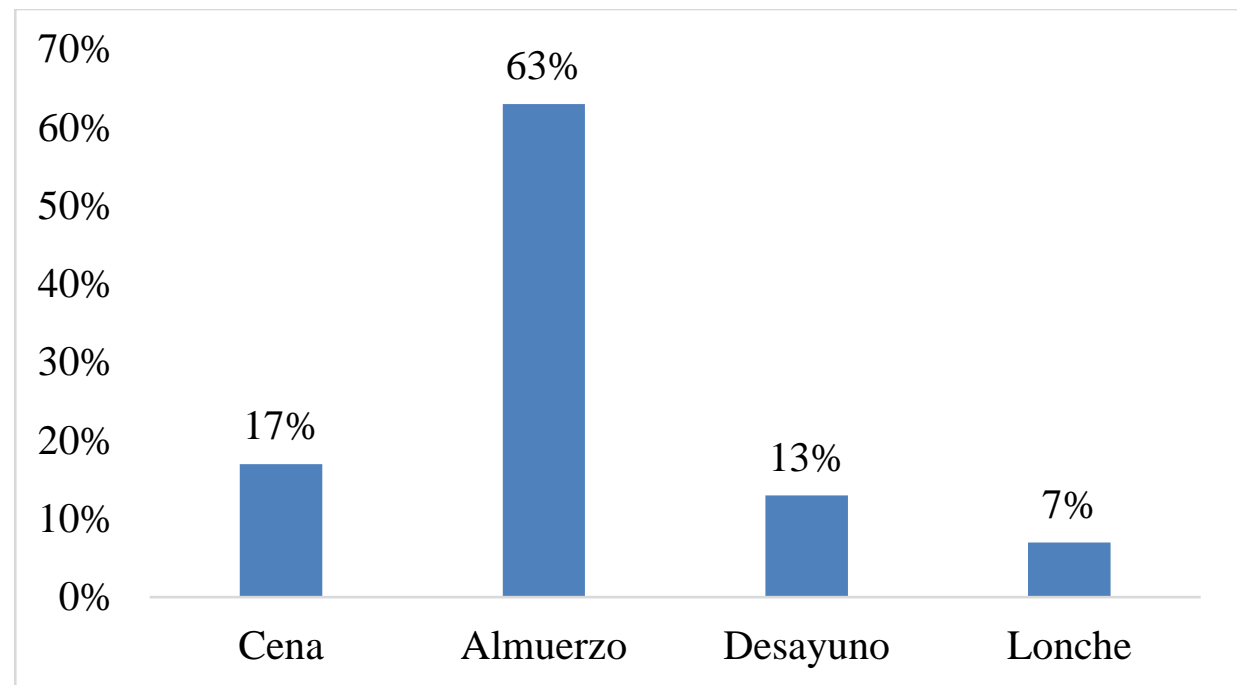

Ilustración 6. Pregunta general 2: ¿Qué comidas consume fuera de casa? Adaptado de encuesta aplicada.

Se puede concluir que el $63 \%$ de los encuestados prefieren almorzar fuera de casa, el $17 \%$ cenar, el $13 \%$ desayunar y el $7 \%$ tomar lonche. Para efectos del proyecto solo se considerará los servicios de almuerzo y cena por ser los de mayor aceptación dentro del público objetivo.

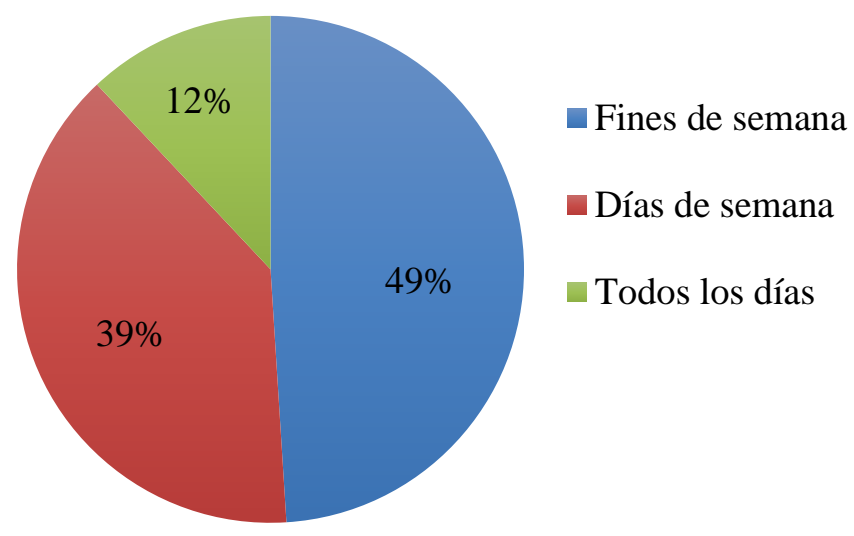

Ilustración 7. Pregunta general 3: Por lo general, ¿qué días suele ir a comer fuera de casa? Adaptado de encuesta aplicada.

Se puede observar que el $49 \%$ de los participantes suele comer fuera de casa los fines de semana, el 39\% los días de semana y el 12\% todos los días. 


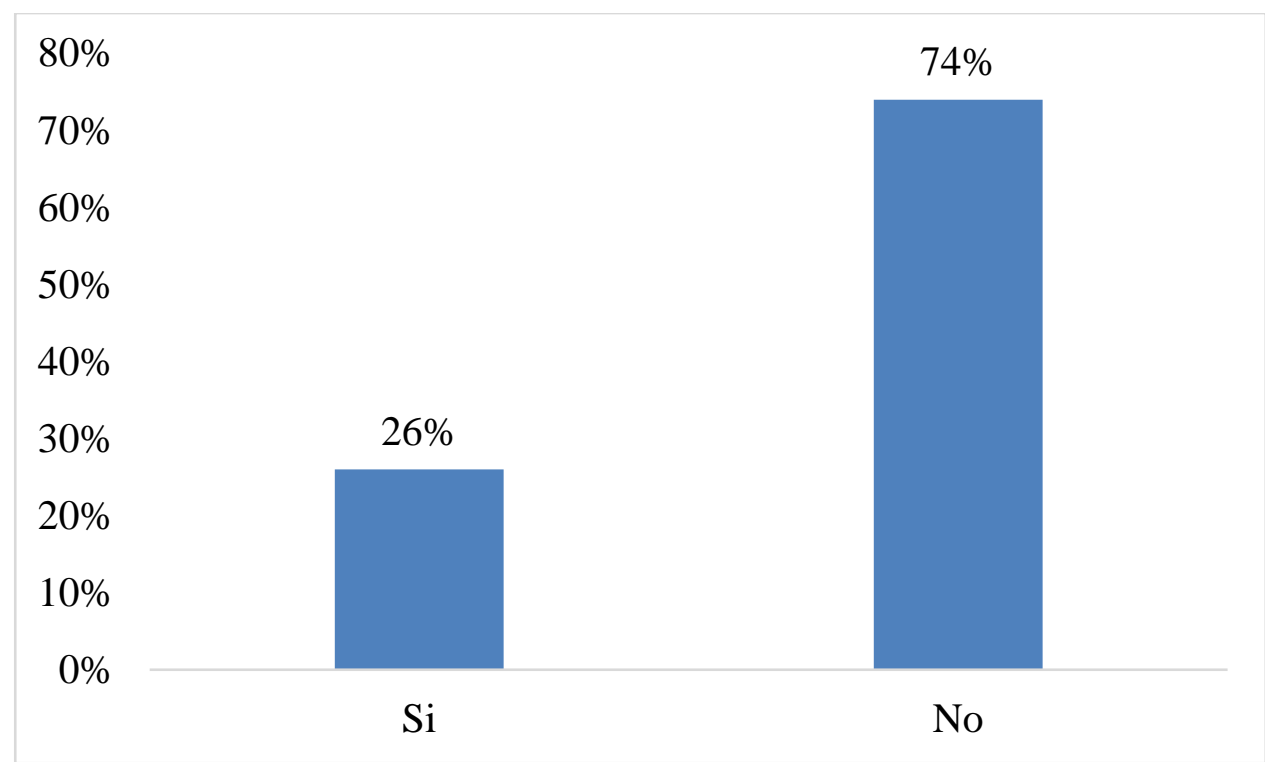

Ilustración 8. Pregunta general 4: ¿Suele desayunar fuera de casa? Adaptado de encuesta aplicada.

El 74\% de los encuestados no suelen desayunar fuera de casa y el $26 \%$ si lo hace. Por esta razón sólo se está considerando atender los productos de almuerzo y cena.

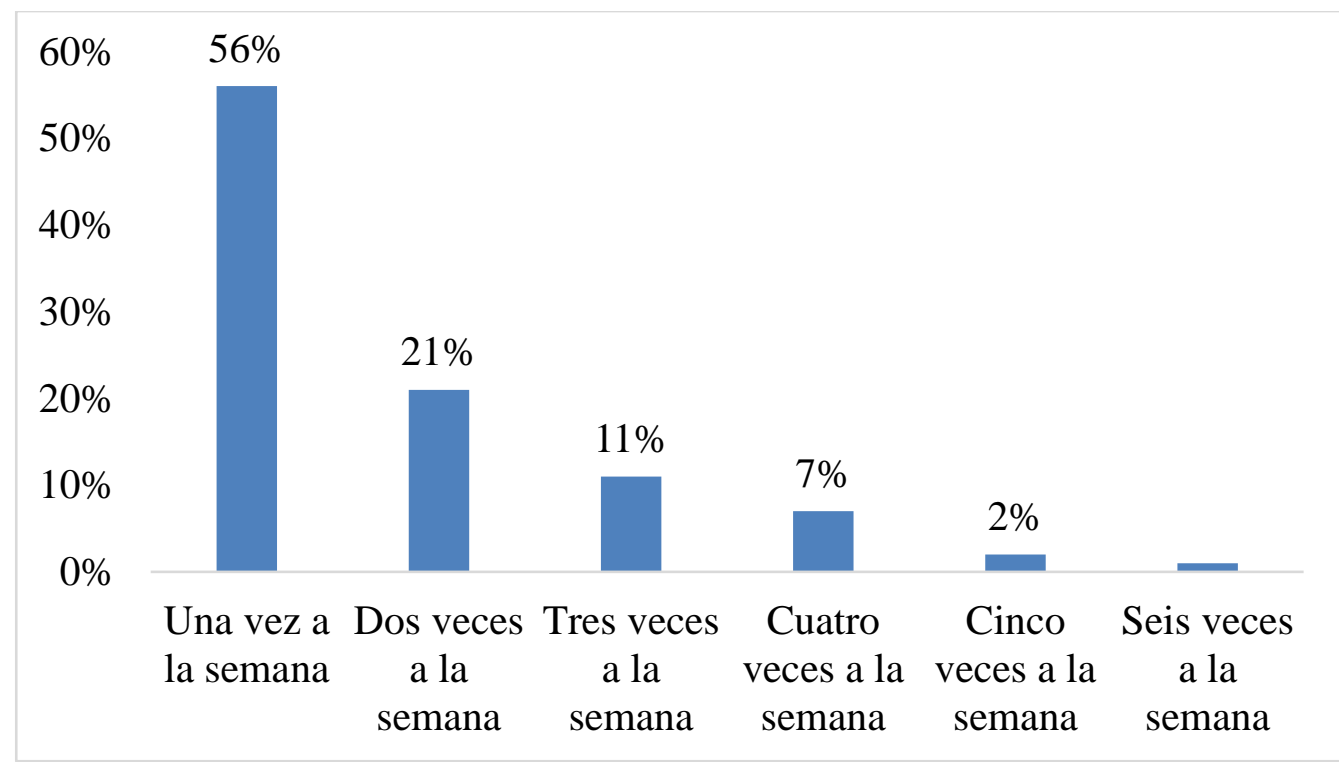

Ilustración 9. Pregunta general 5: ¿Cuántas veces por semana suele desayunar fuera de casa? Adaptado de encuesta aplicada.

Se puede concluir que el $56 \%$ de los encuestados desayuna fuera de casa una vez a la semana, el $21 \%$ lo hace dos veces a la semana, el $11 \%$ tres veces a la semana, $7 \%$ cuatro veces a la semana, $2 \%$ cinco veces a la semana. 


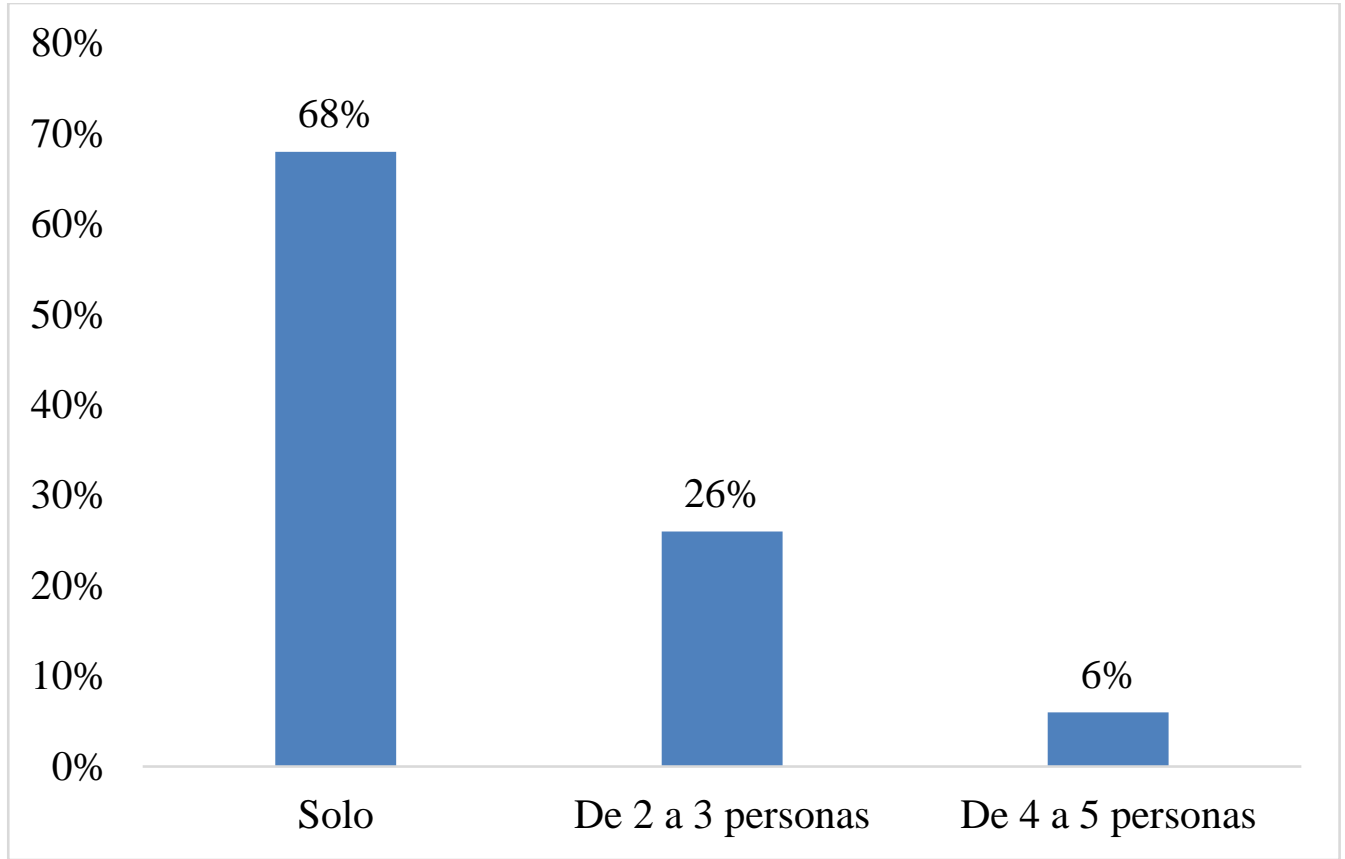

Ilustración 10. Pregunta general 6: ¿Con cuántas personas suele desayunar fuera de casa?

Según el gráfico, se puede apreciar que el 68\% de los encuestados suelen desayunar solos fuera de casa, el $26 \%$ desayunan con 2 y 3 personas y el $6 \%$ lo hace con cuatro y cinco personas.

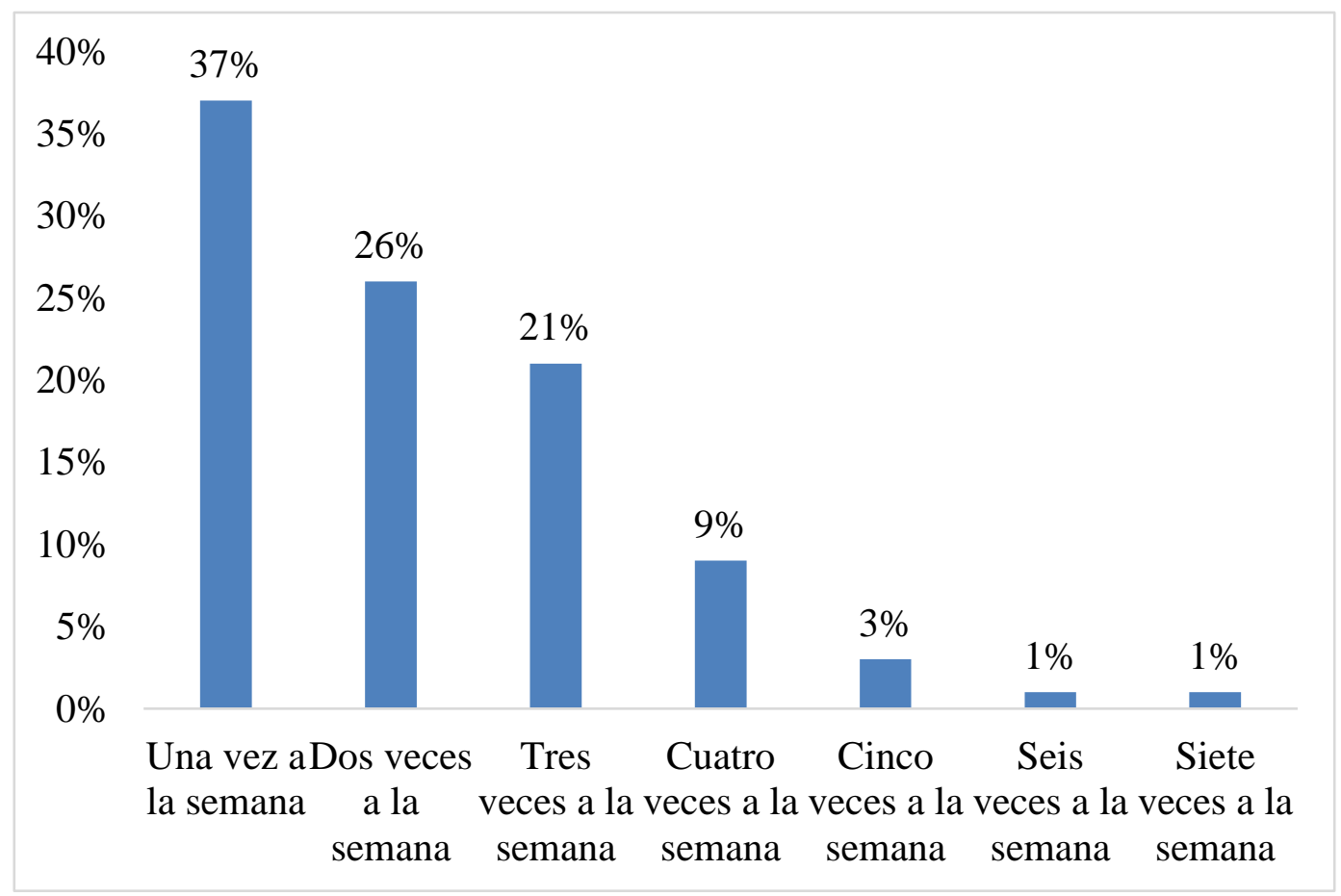

Ilustración 11. Pregunta general 7: ¿Cuántas veces por semana suele almorzar fuera de casa? 
Se puede concluir que el $37 \%$ de los encuestados suele almorzar fuera de casa, el $26 \%$ lo hace dos veces por semana, el $21 \%$ tres veces a la semana, el $9 \%$ cuatro veces a la semana, el $3 \%$ cinco veces a la semana. Estos resultados favorecen al proyecto puesto que son clientes potenciales que podrían consumir en el restaurante.

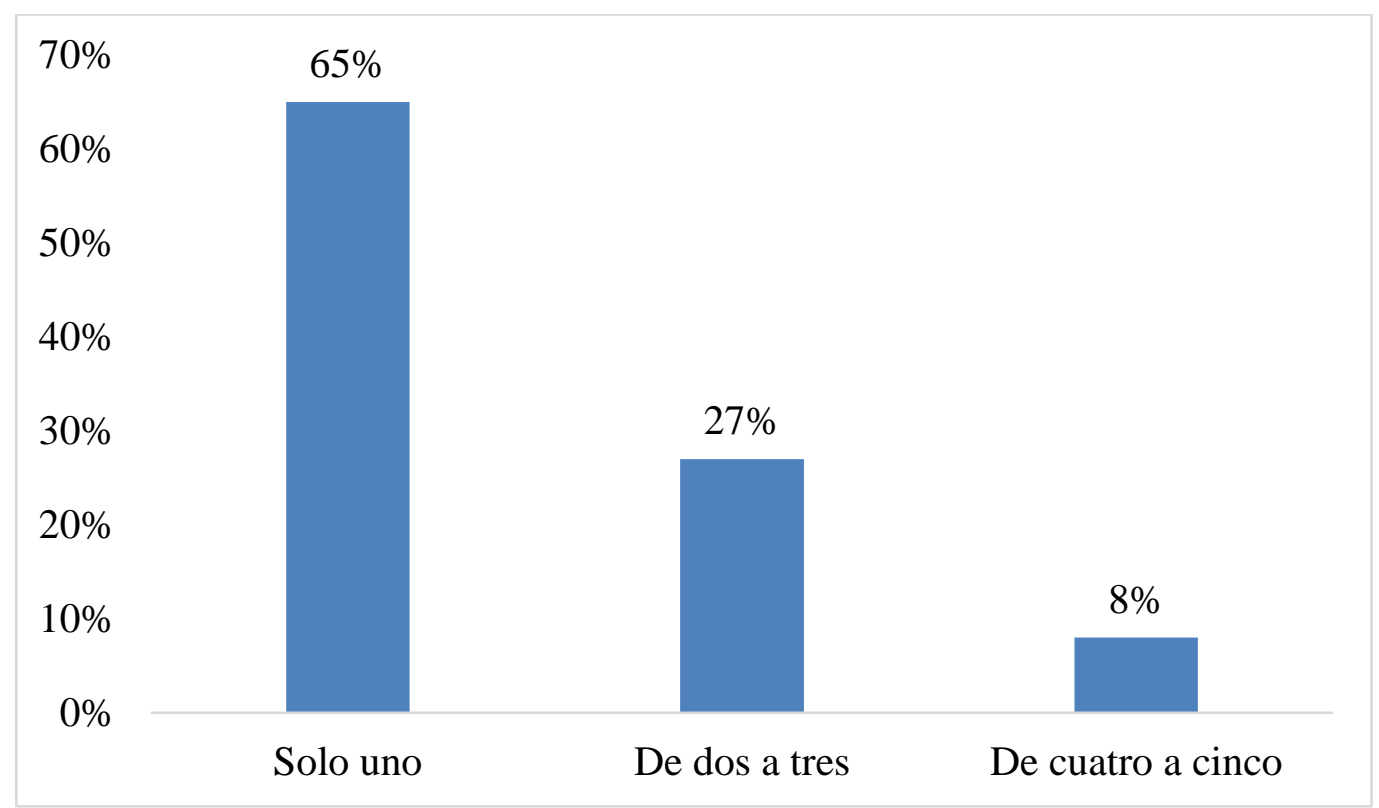

Ilustración 12. Pregunta general 8: ¿Con cuántas personas suele almorzar fuera de casa? Adaptado de encuesta aplicada.

El $65 \%$ de los encuestados suele almorzar solo fuera de casa, el $27 \%$ almuerza de dos a tres personas y el $8 \%$ de cuatro a cinco.

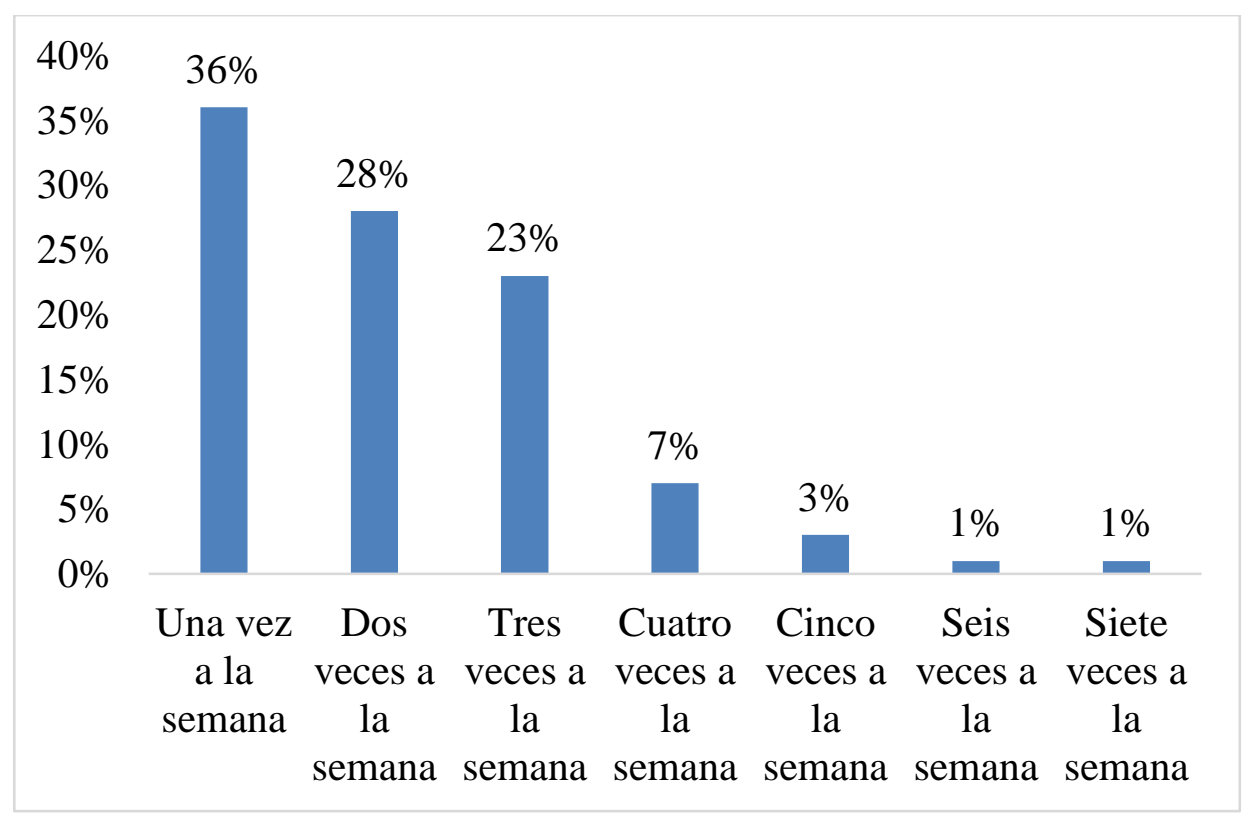

Ilustración 13. Pregunta general 9: ¿Cuántas veces por semana suele cenar fuera de casa? Adaptado de encuesta aplicada. 
El 36\% de los encuestados suele cenar fuera de casa al menos una vez a la semana, el $28 \%$ lo hace de dos a tres veces a la semana, el $23 \%$ tres veces a la semana.

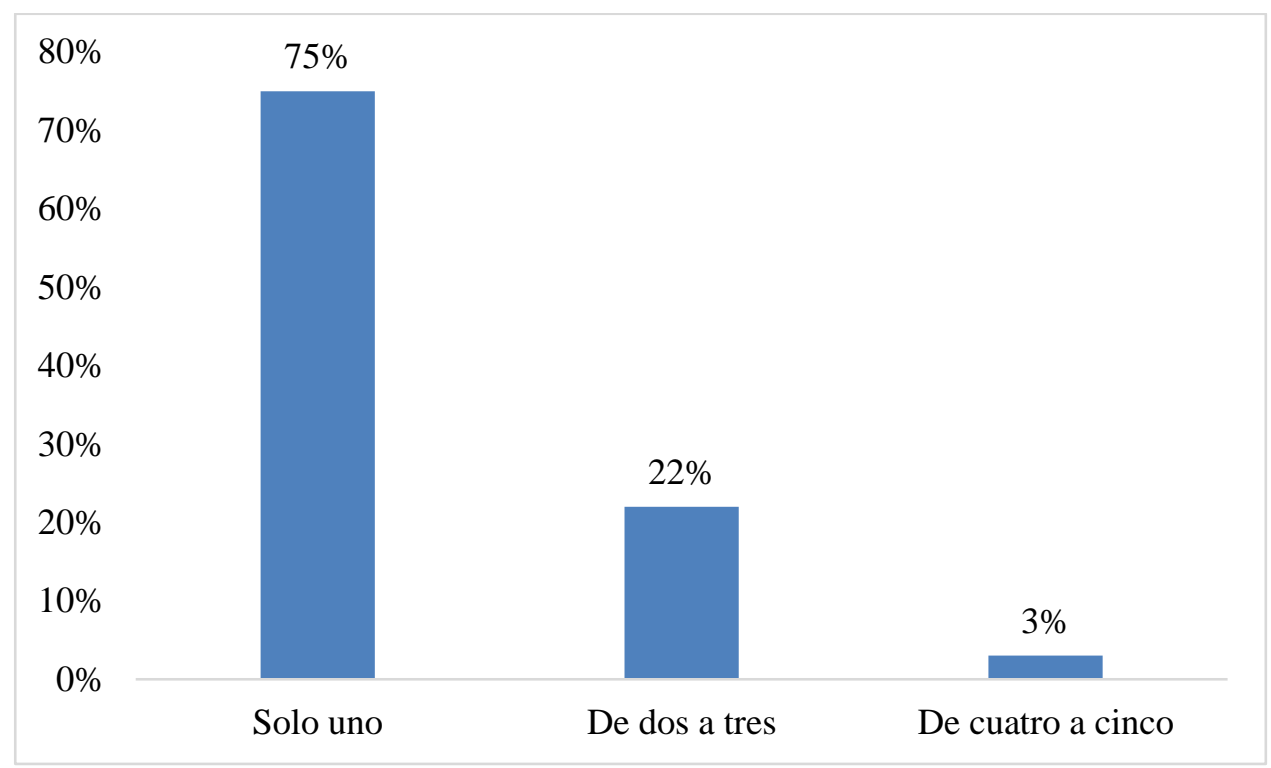

Ilustración 14. Pregunta general 10: ¿Con cuántas personas suele cenar fuera de casa? Adaptado de encuesta aplicada.

El gráfico nos muestra que el $75 \%$ de los encuestados suele cenar fuera de casa solos, el $22 \%$ lo hace de dos a tres personas y el $3 \%$ de cuatro a cinco personas.

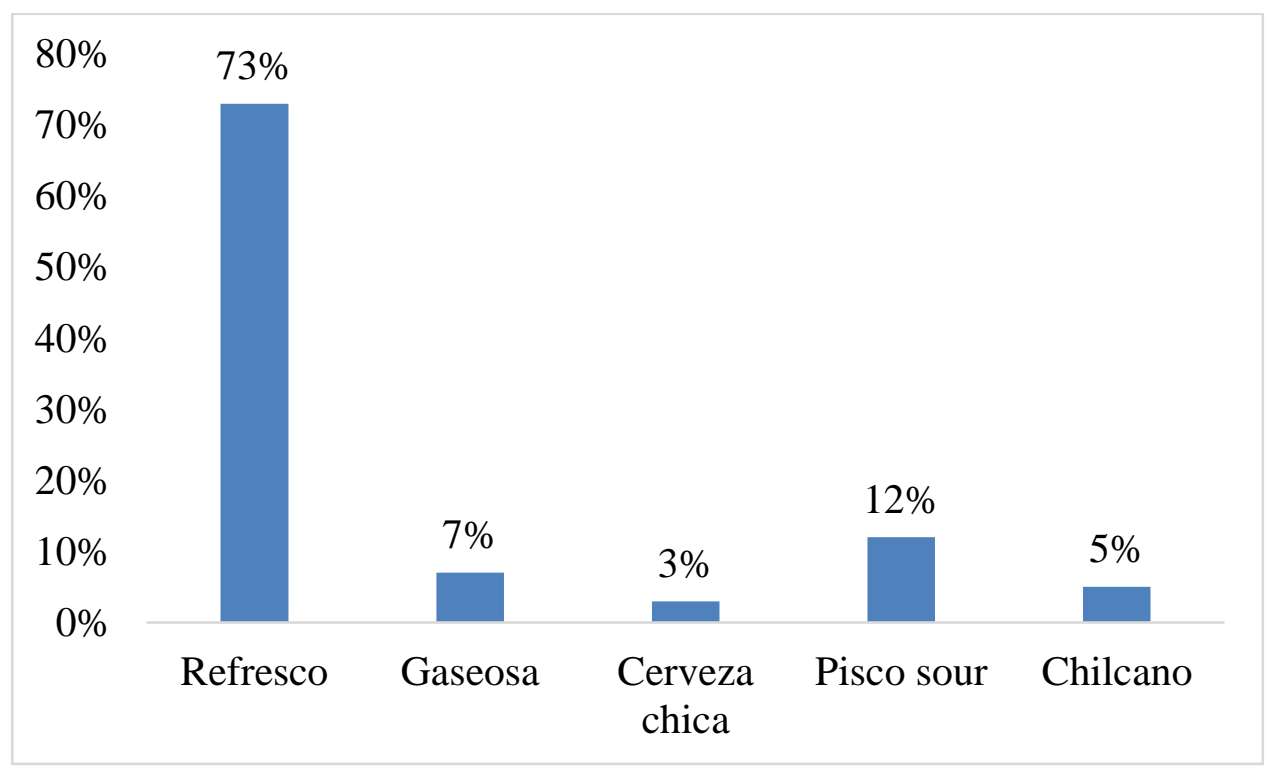

Ilustración 15. Pregunta general 11: ¿Con qué sueles acompañar su almuerzo o cena? Adaptado de encuesta aplicada.

El 73\% de los participantes suele acompañar su almuerzo con refresco, el 7\% con gaseosa, el $3 \%$ con cerveza, el $12 \%$ prefieren pisco sour y el $5 \%$ chilcano. 


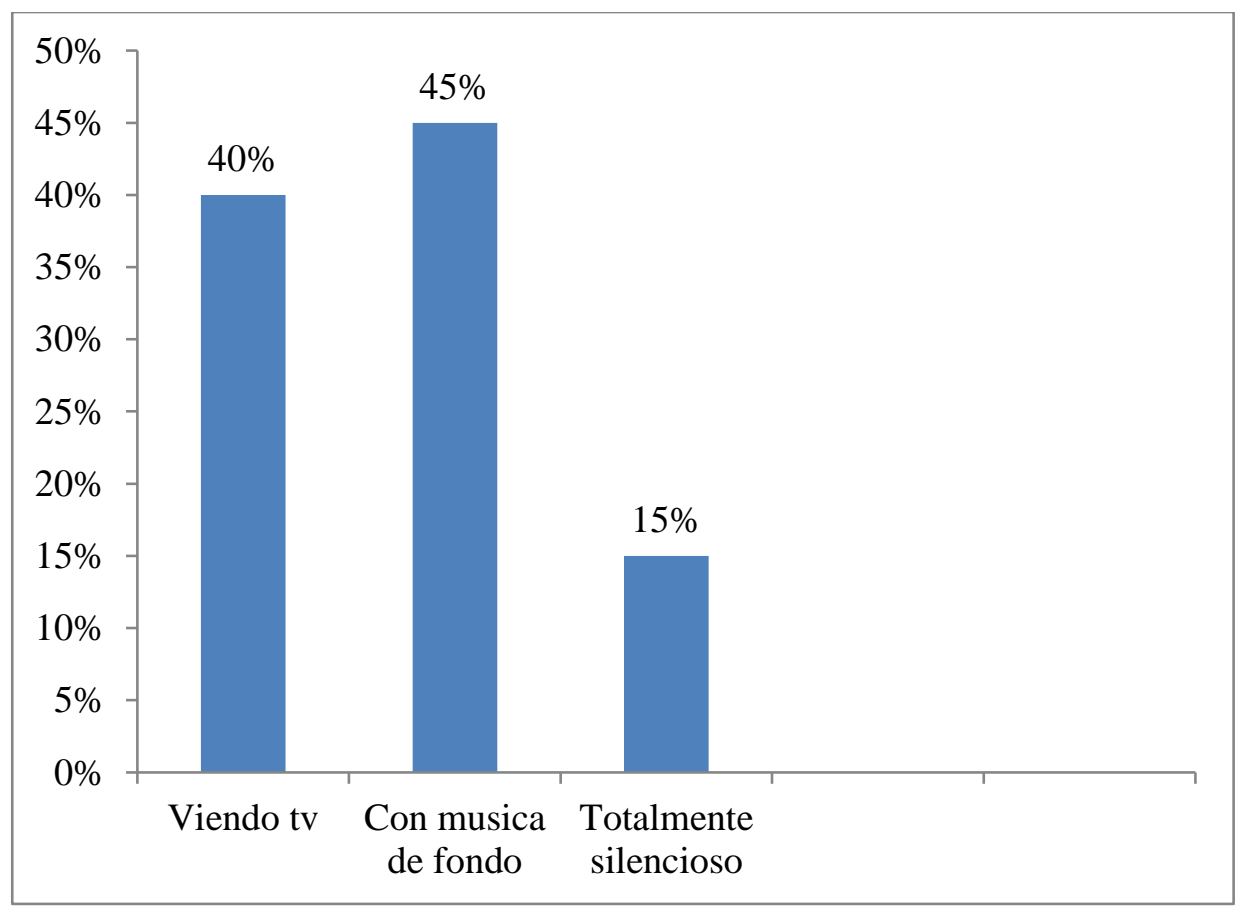

Ilustración 16. Pregunta 12. ¿Por qué motivo suele ir a comer fuera de casa?

Adaptado de encuesta aplicada.

Se puede concluir que el $26 \%$ de los encuestados suelen comer fuera de casa por aniversarios o cumpleaños, el $25 \%$ por encuentro con amigos, el $23 \%$ por disfrute/ocio, el $20 \%$ en forma cotidiana, el $6 \%$ por reuniones de trabajo.

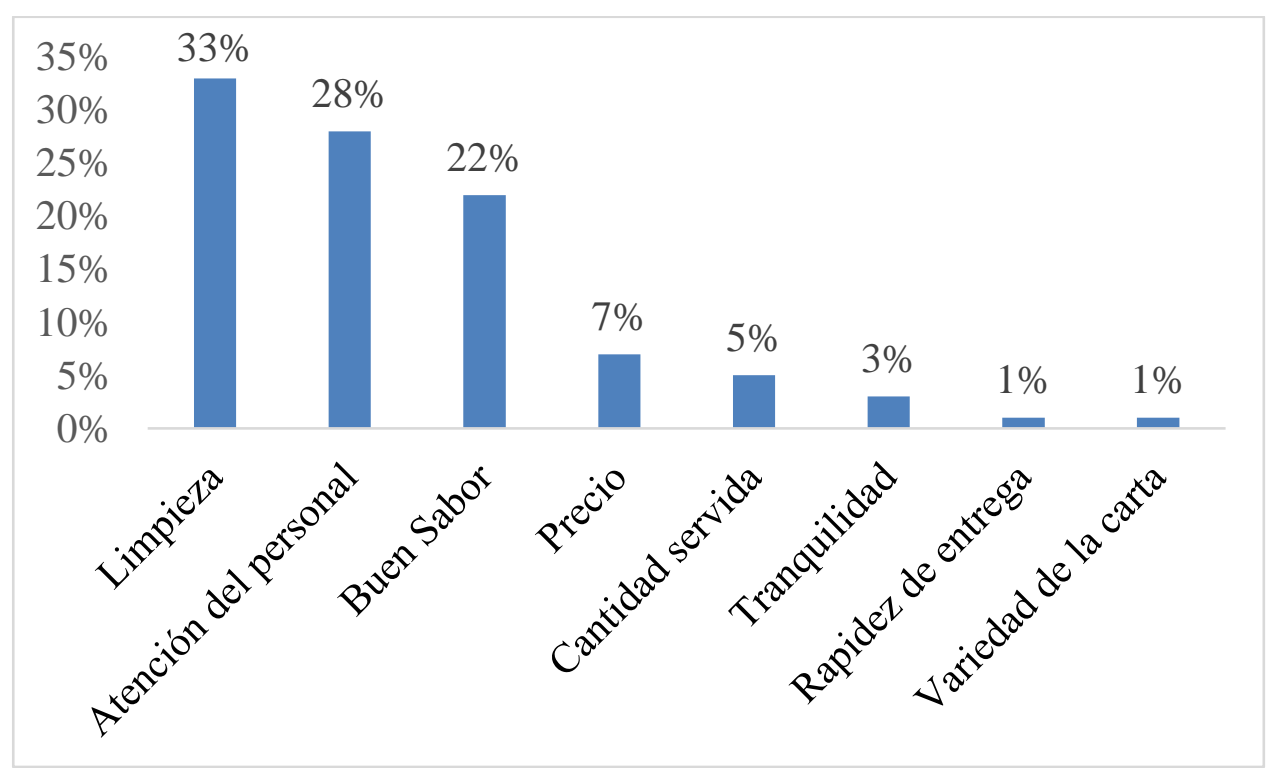

Ilustración 17. Pregunta general 13: Clasifique los distintos atributos de restaurantes por orden de importancia. 1 es muy importante y 8 es menos importante. Adaptado de encuesta aplicada.

Se puede observar, que para los encuestados el atributo que más valoran en un restaurante es la limpieza con un $33 \%$, la tranquilidad con un $28 \%$, el buen sabor con un $22 \%$, 
precio $7 \%$ y cantidad servida $5 \%$ estos cinco atributos son los más importantes y confirma lo que concluyeron los participantes en el focus group.

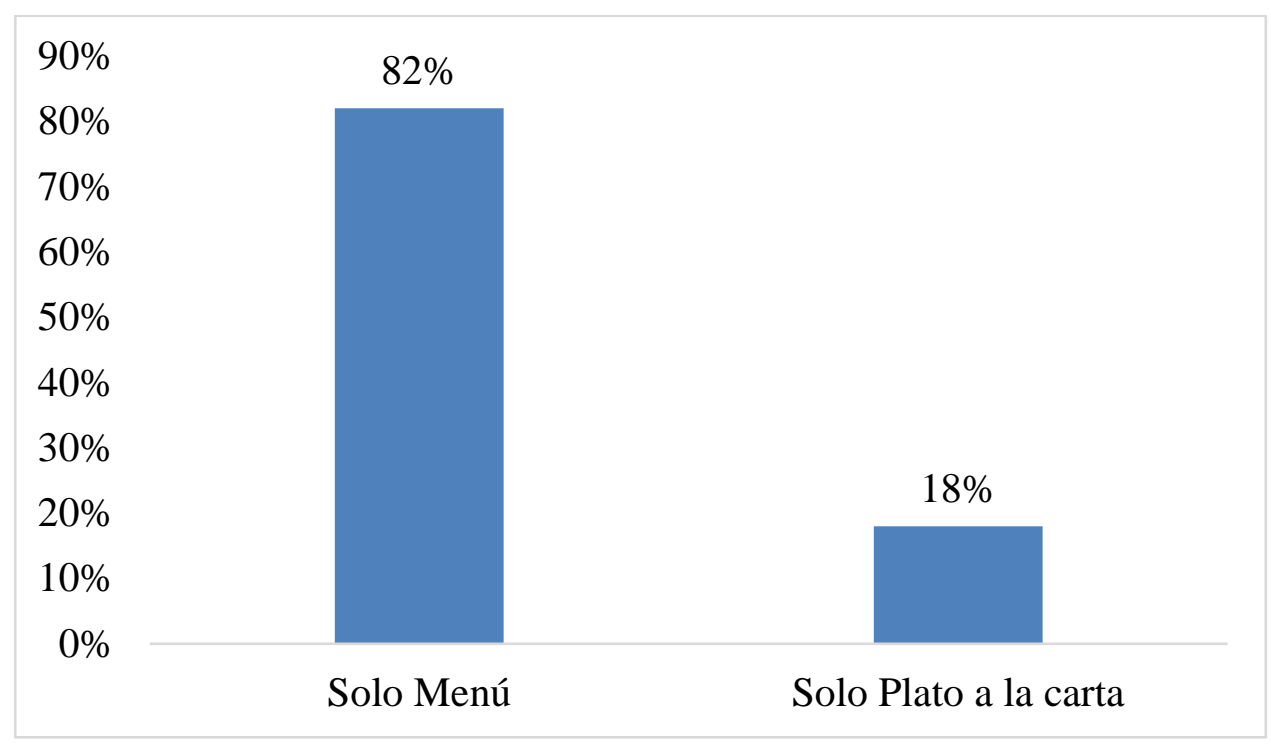

Ilustración 18. Pregunta general 14: Cuando sale a comer fuera de casa ¿Ud. prefiere pedir menú o plato a la carta? Adaptado de encuesta aplicada.

El $82 \%$ de los encuestados prefiere comer menú, si es que sale a comer fuera de casa y solo el $18 \%$ plato a la carta.

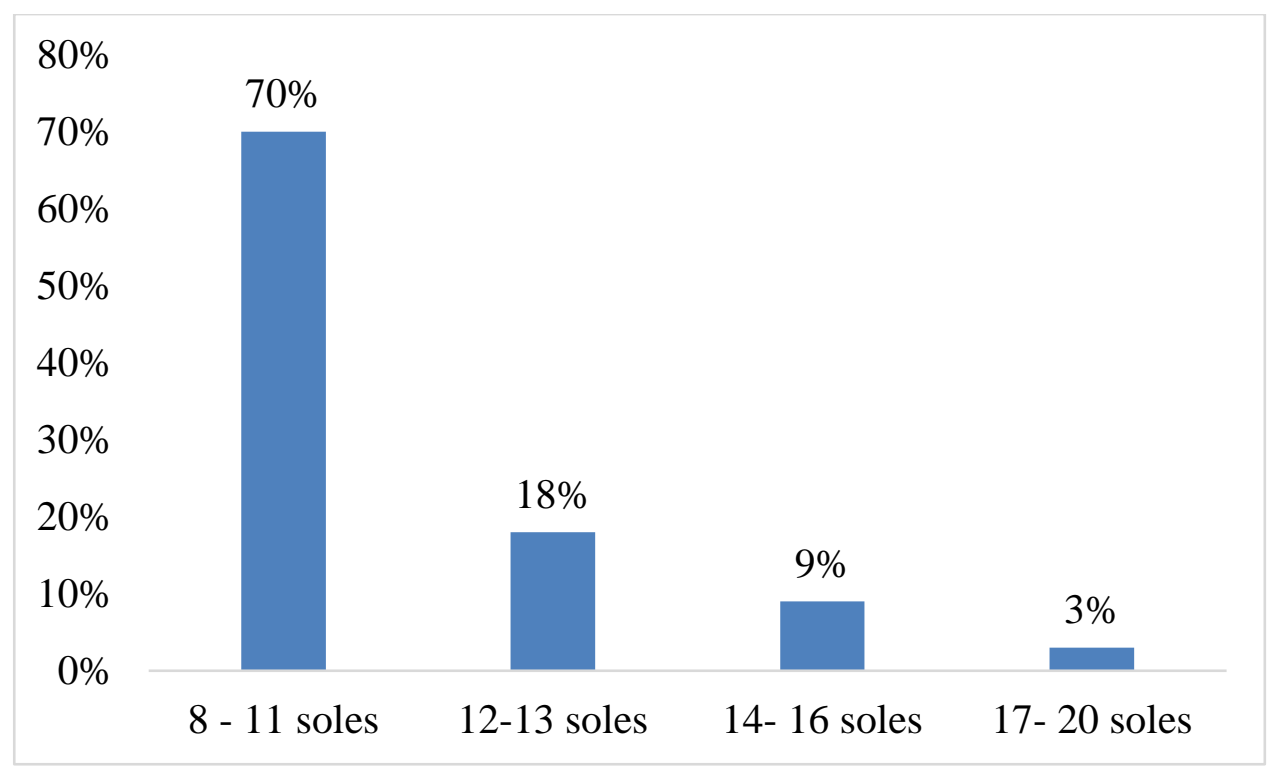

Ilustración 19. Pregunta general 15: ¿Cuánto está dispuesto a pagar por un menú? Adaptado de encuesta aplicada.

El 70\% de los participantes están dispuestos a pagar entre 8 y 11 soles por menú, el $18 \%$ entre 12 y 13 soles, el $9 \%$ entre 14 y 16 soles y el $3 \%$ entre 17 y 20 soles. Se puede concluir, que es una respuesta coherente para el público objetivo al que está dirigido el 
proyecto. Cabe mencionar que el menú más barato en la zona de nuestra competencia directa es de $\mathrm{S} / 10$.

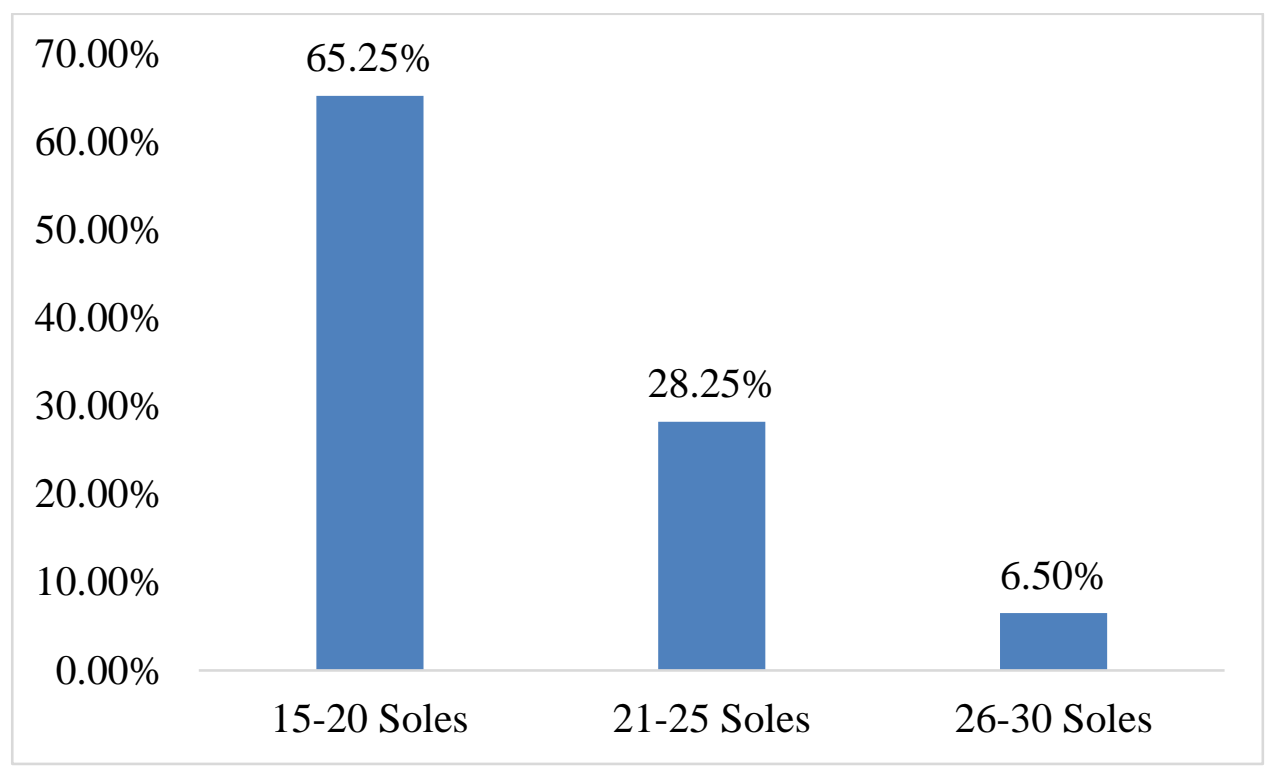

Ilustración 20. Pregunta general 16: ¿Cuánto está dispuesto a pagar por un plato a la carta? Adaptado de encuesta aplicada.

El $65.25 \%$ de los encuestados está dispuesto a pagar por un plato a la carta entre $15 \mathrm{y}$ 20 soles, el $28.25 \%$ entre 21 y 25 soles y el $6.5 \%$ entre 26 y 30 soles.

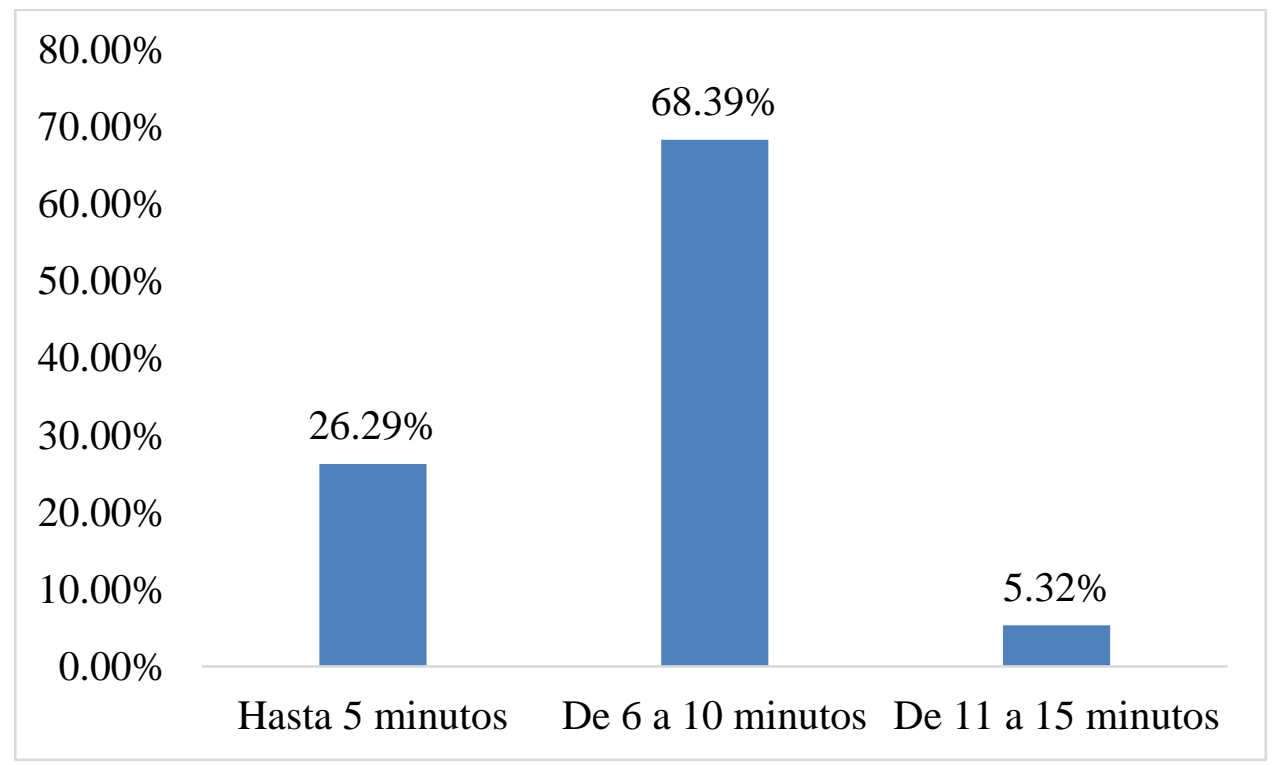

Ilustración 21. Pregunta general 17: ¿Cuánto tiempo está dispuesto a esperar por un menú? Adaptado de encuesta aplicada.

En el gráfico se puede concluir que el $68.39 \%$ de los encuestados prefiere esperar de 6 a 10 minutos, el $26.29 \%$ hasta 5 minutos y el $5.32 \%$ entre 11 y 15 minutos. Los comensales no desean esperar más de 10 minutos por un menú, puesto que la mayoría trabaja o estudia y tienen un horario definido para salir a comer. 


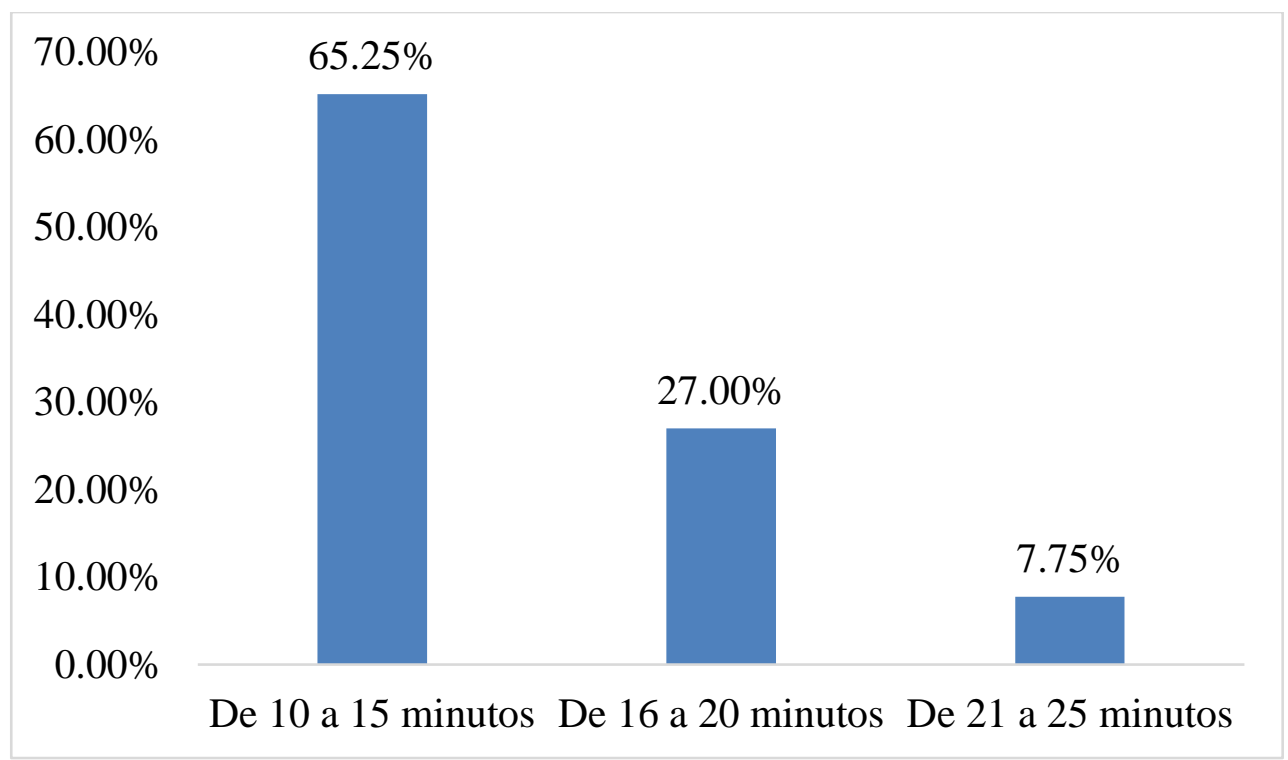

Ilustración 22. Pregunta general 18: ¿Cuánto tiempo está dispuesto a esperar por un plato a la carta? Adaptado de encuesta aplicada.

El $65.25 \%$ de los encuestados prefiere esperar por un plato a la carta de 10 a 15 minutos, el $27 \%$ de 16 a 20 minutos y el $7.75 \%$ de 21 a 25 minutos.

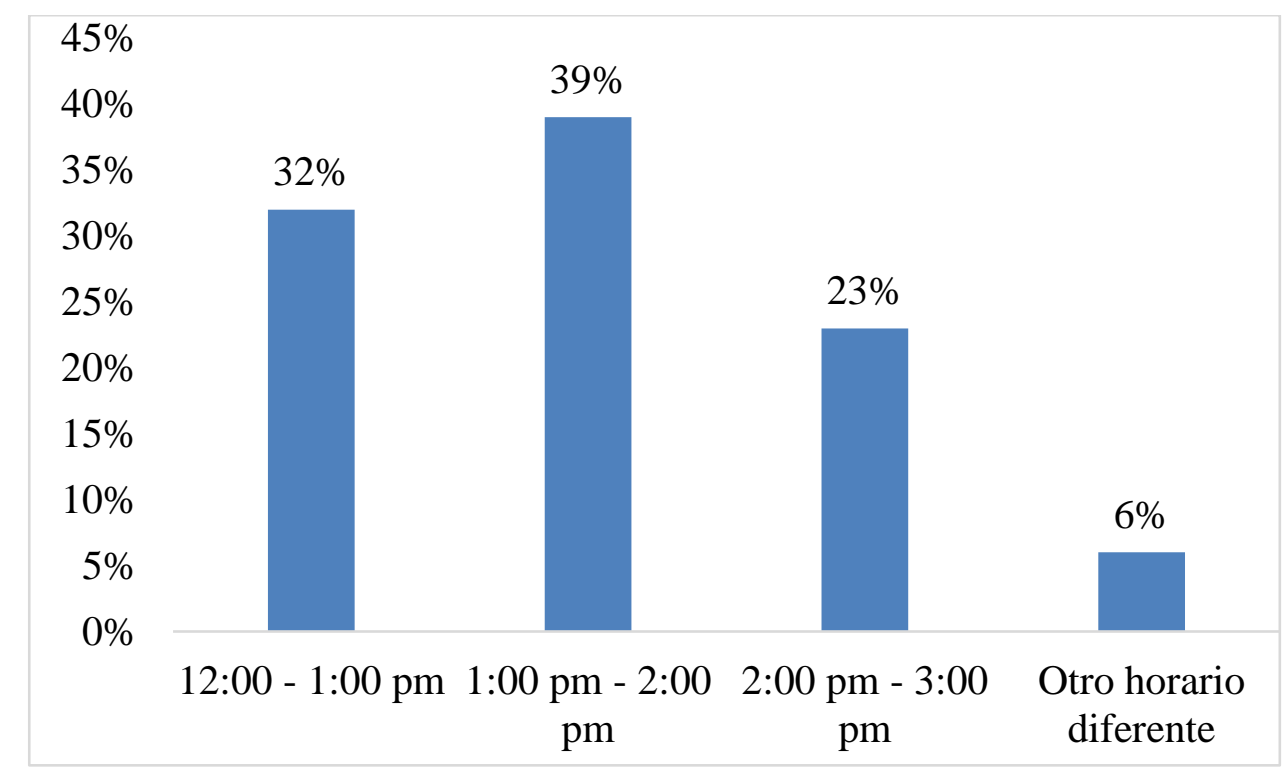

Ilustración 23. Pregunta general 18.1: ¿Cuál es su horario habitual de almuerzo? Adaptado de encuesta aplicada.

Se observa que el horario de 1:00 pm a 2:00 pm es el preferido por el público, esto indica que más del 90\% almuerza en los intervalos de 12:00 - 1:00 pm. 


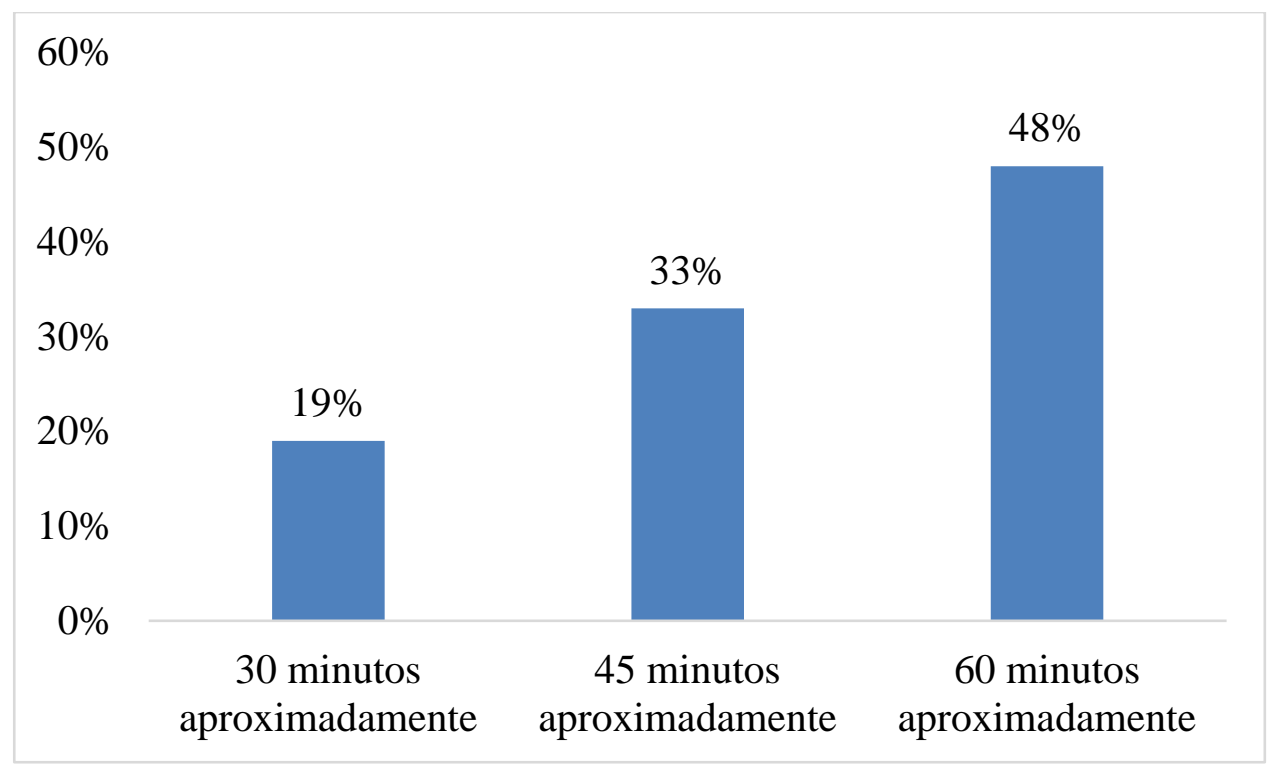

Ilustración 24. Pregunta general 18.2: ¿Cuál es el tiempo que demora en almorzar? Adaptado de encuesta aplicada.

Se observa que cerca del $50 \%$ se demoras 60 minutos aproximadamente en almorzar.

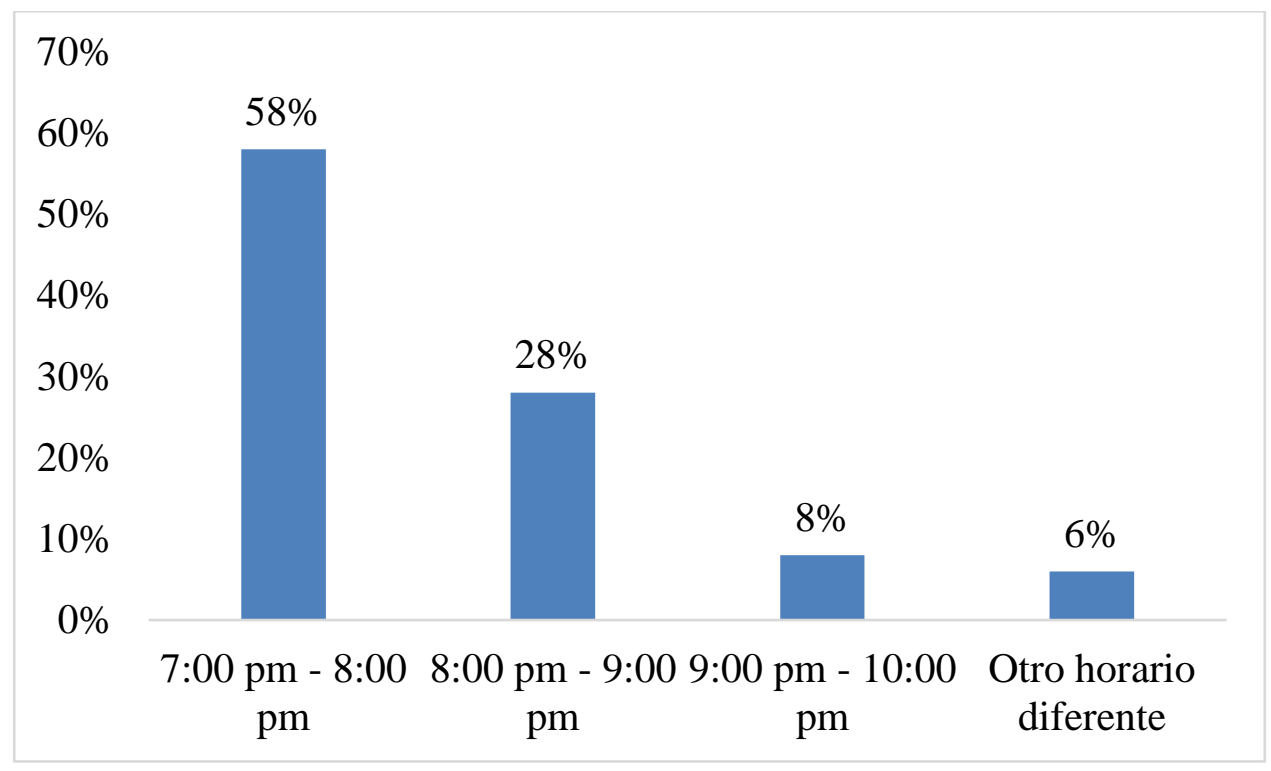

Ilustración 25. Pregunta general 18.3: ¿Cuál es su horario habitual de cena? Adaptado de encuesta aplicada.

Se observa que más del 50\% cena de 7:00 pm a 8:00 pm, además de esto se puede observar que más del 90\% cena en el intervalo de 7:00 pm a 10:00 pm. 


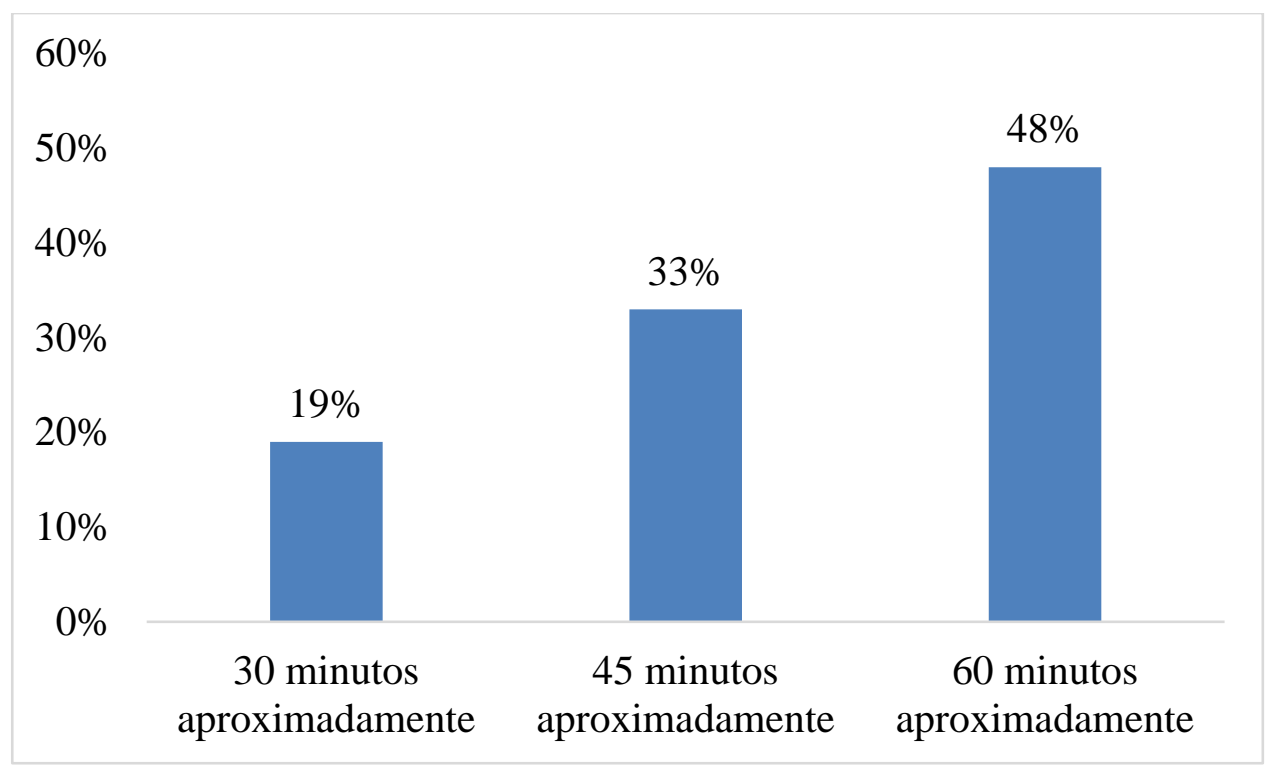

Ilustración 26. Pregunta general 18.4: ¿Cuál es el tiempo que demora en cenar? Adaptado de encuesta aplicada.

Se observa que cerda del 50\% demorara aproximadamente 60 minutos en cenar.

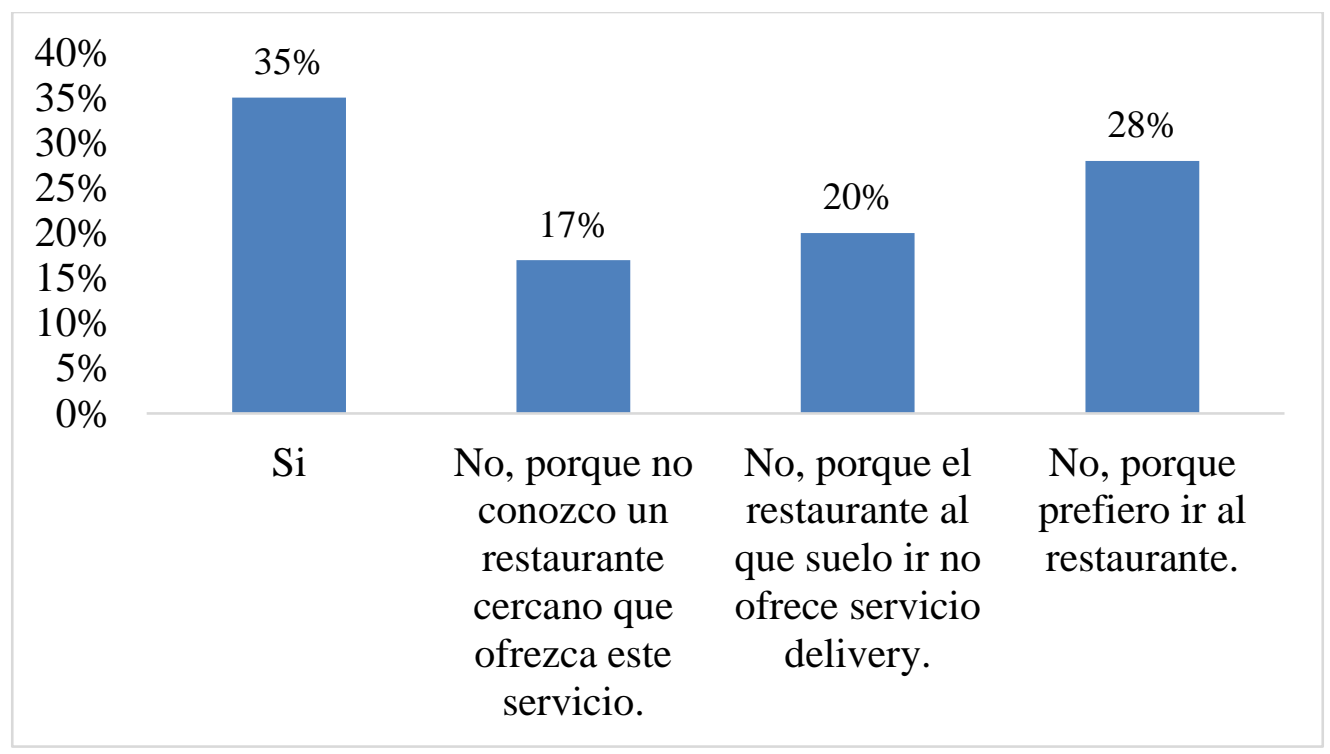

Ilustración 27. Pregunta general 19: ¿Suele pedir delivery? De ser negativa la respuesta, indique el motivo. Adaptado de encuesta aplicada.

El $35 \%$ de los encuestados suele pedir delivery y el $65 \%$ no lo hace porque por

diferentes razones. El mercado de delivery puede incrementarse si es que se logra fidelizar al comensal. 


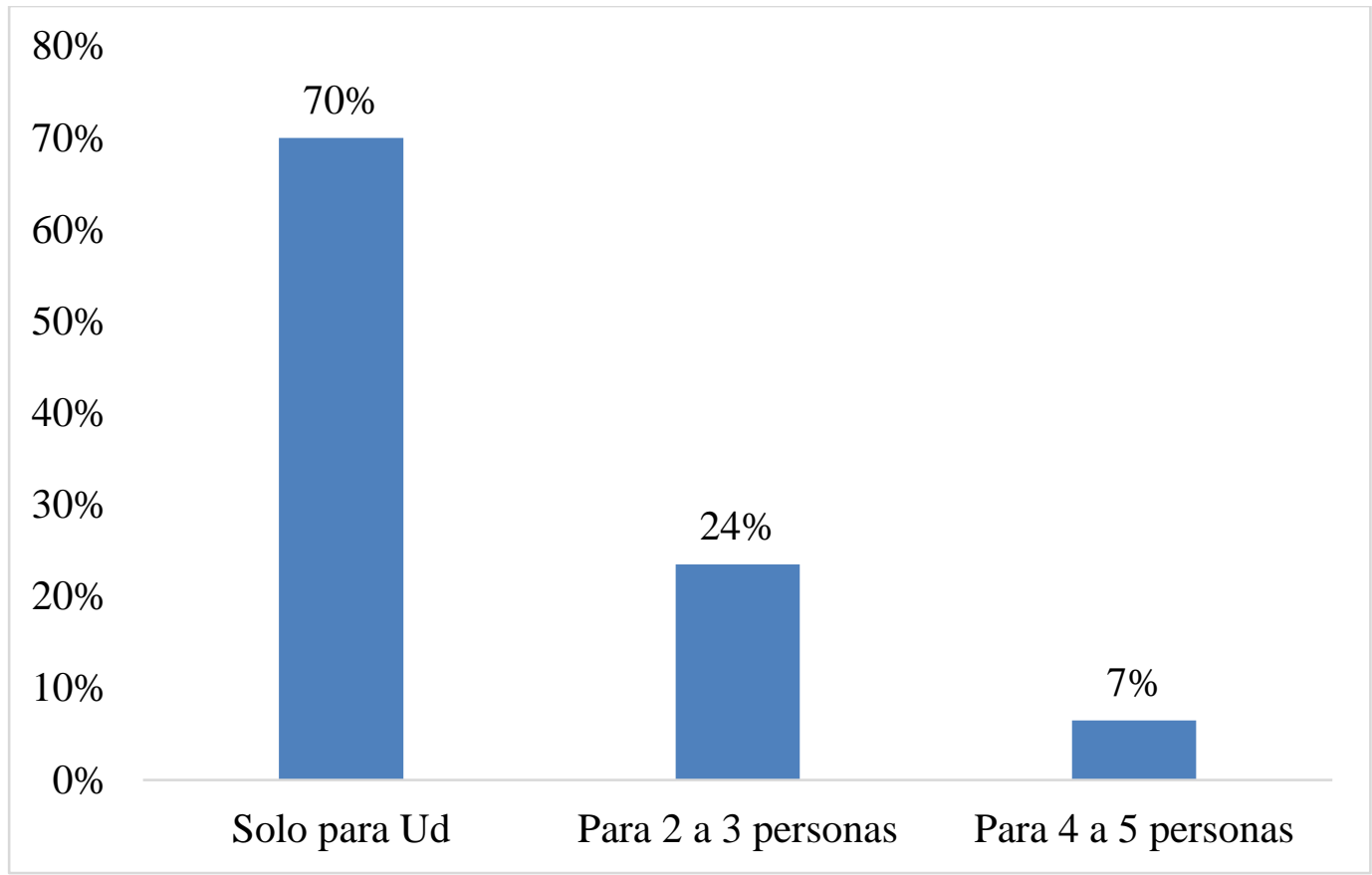

Ilustración 28. Pregunta general 20: Cuando pide un servicio delivery ¿para cuántas personas lo solicita? Adaptado de encuesta aplicada.

Cuando las personas solicitan un servicio delivery, el 70\% lo piden solo para ellos, el $24 \%$ para 2 o 3 personas y el $7 \%$ para 4 o 5 personas.

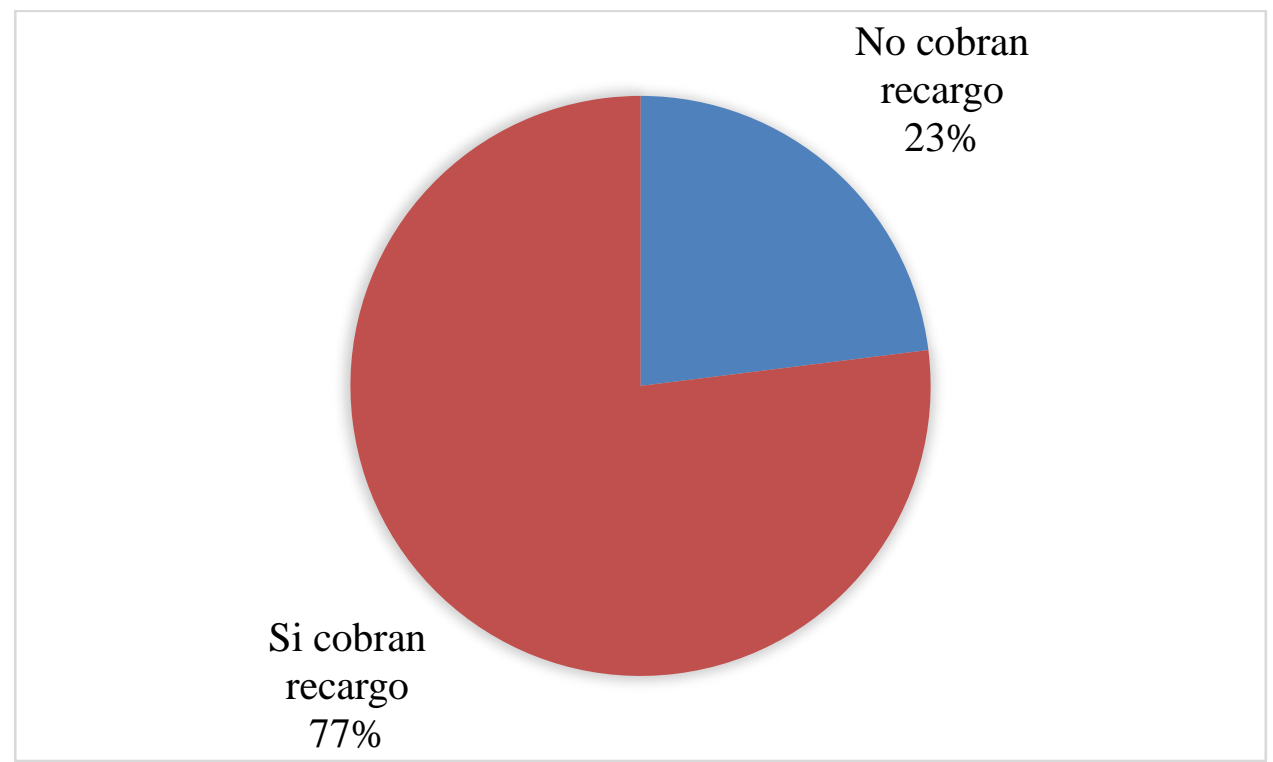

Ilustración 29. Pregunta general 21: Le cobran algún recargo adicional por el servicio de delivery? Adaptado de encuesta aplicada.

Según el gráfico, se puede concluir que el $77 \%$ de los restaurantes cobran un recargo por el servicio de delivery y el $23 \%$ no cobran por este servicio adicional, siendo un punto favorable, puesto que para el proyecto no está planificado cobrar este servicio y este sería un punto a favor del proyecto. 


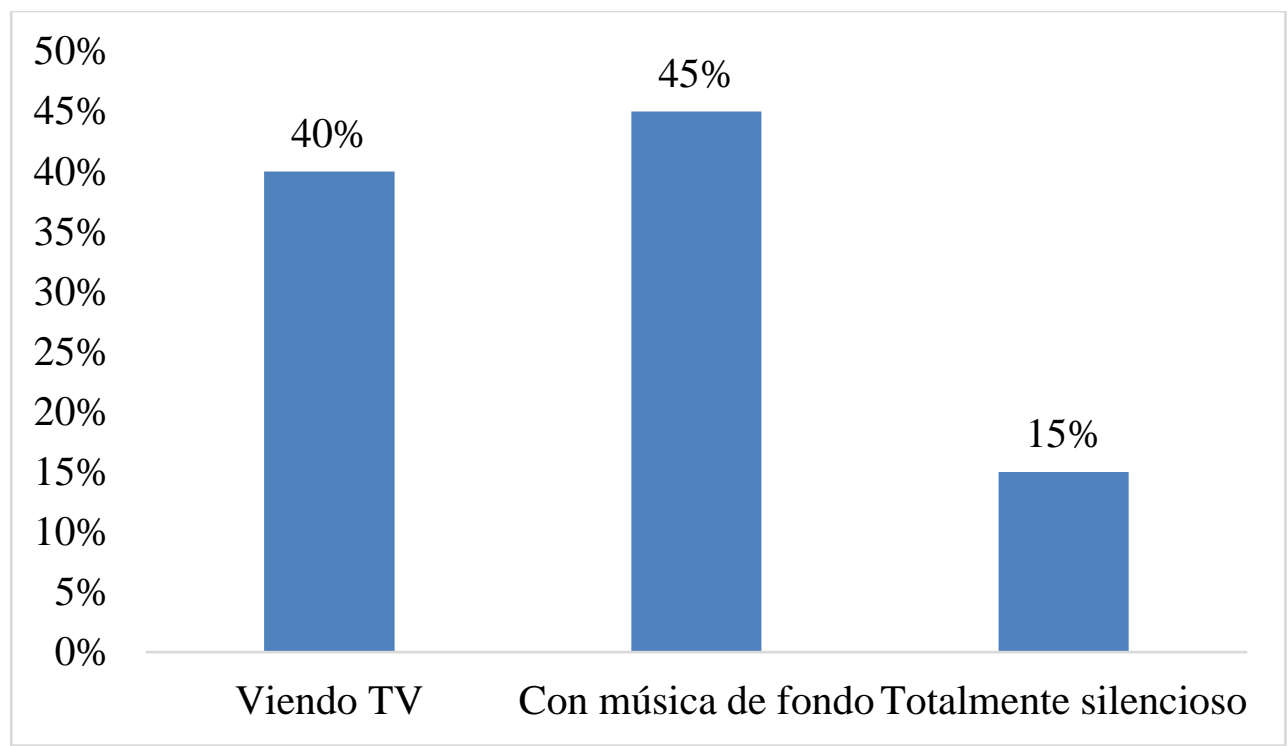

Ilustración 30. Pregunta general 22: ¿Qué ambiente prefiere para almorzar? Adaptado de encuesta aplicada.

El 45\% de los encuestados prefiere un ambiente con música de fondo, el $40 \%$ de los encuestados prefiere un ambiente donde se pueda ver televisión, el 15\% lo prefiere en silencio.

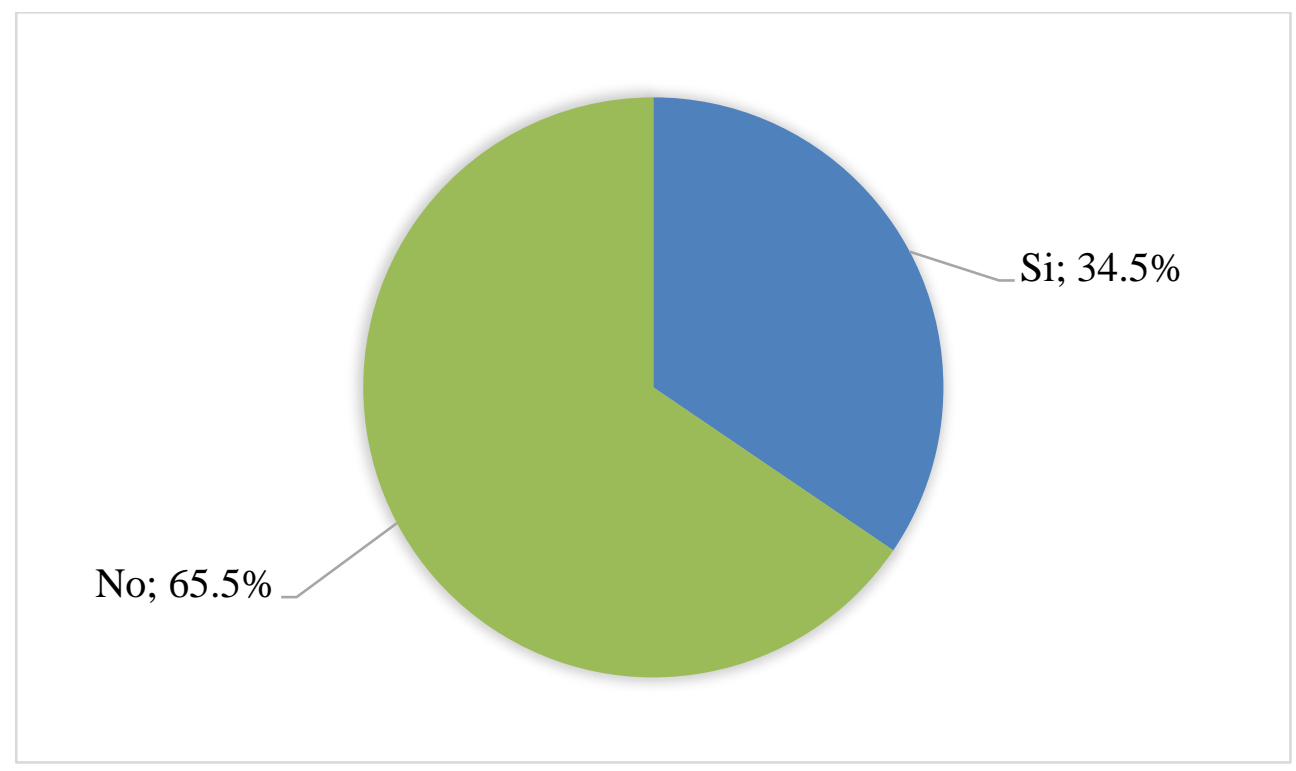

Ilustración 31. Pregunta general 23: ¿Ud. tiene algún restaurante preferido en esta zona? (Territorio III de Villa El Salvador). Adaptado de encuesta aplicada.

El $65.5 \%$ de los encuestados no tiene un restaurante preferido en Villa el Salvador, este resultado favorece al proyecto, puesto que se puede aplicar una estrategia de fidelización a través de un buen servicio al cliente. 


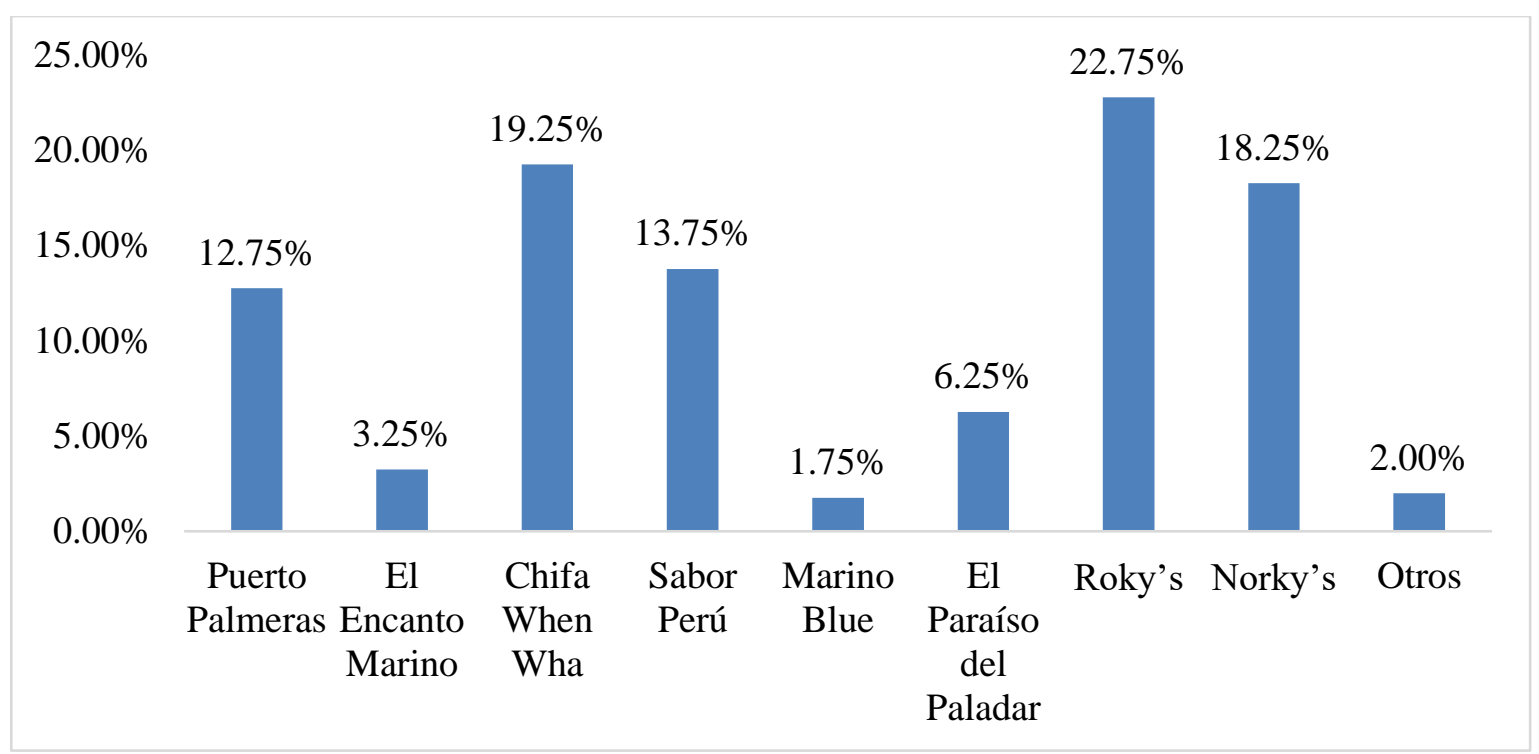

Ilustración 32. Pregunta general 24: Si en la pregunta anterior su respuesta ha sido positiva, ¿cuál es? Adaptado de encuesta aplicada.

El $21 \%$ de los encuestados indican que su preferencia se inclina hacia el restaurante "Rokys", el 19\% "When Wha”, el 18\% "Norkys" y el 17\% "Sabor Peru”. Esto indica que las cadenas de pollerías tienen una buena preferencia en el sector.

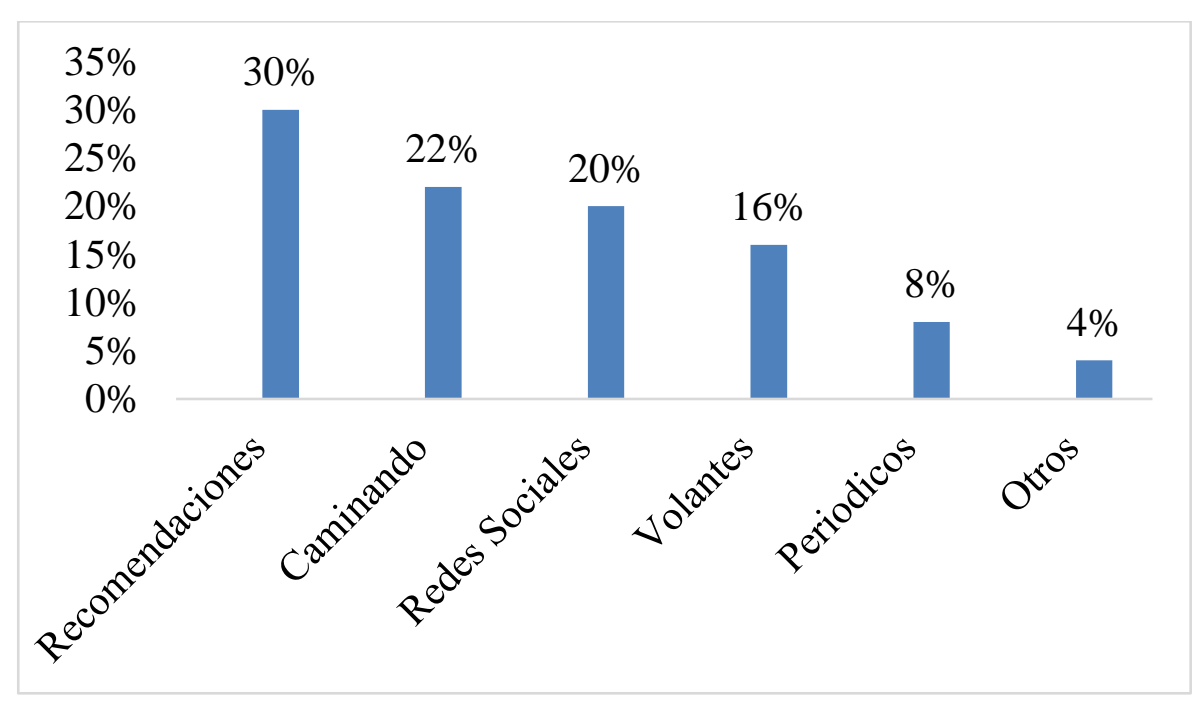

Ilustración 33. Pregunta general 25: ¿Cómo suele enterarse sobre nuevos restaurantes? Adaptado de encuesta aplicada.

La mayoría de los encuestados suelen enterarse sobre nuevos restaurantes por recomendaciones, cuando caminan, por redes sociales, volantes, periódicos. Por lo tanto, a las personas que asistan por primera vez al restaurante deben tener una buena impresión de la misma para que sea recomendado. 


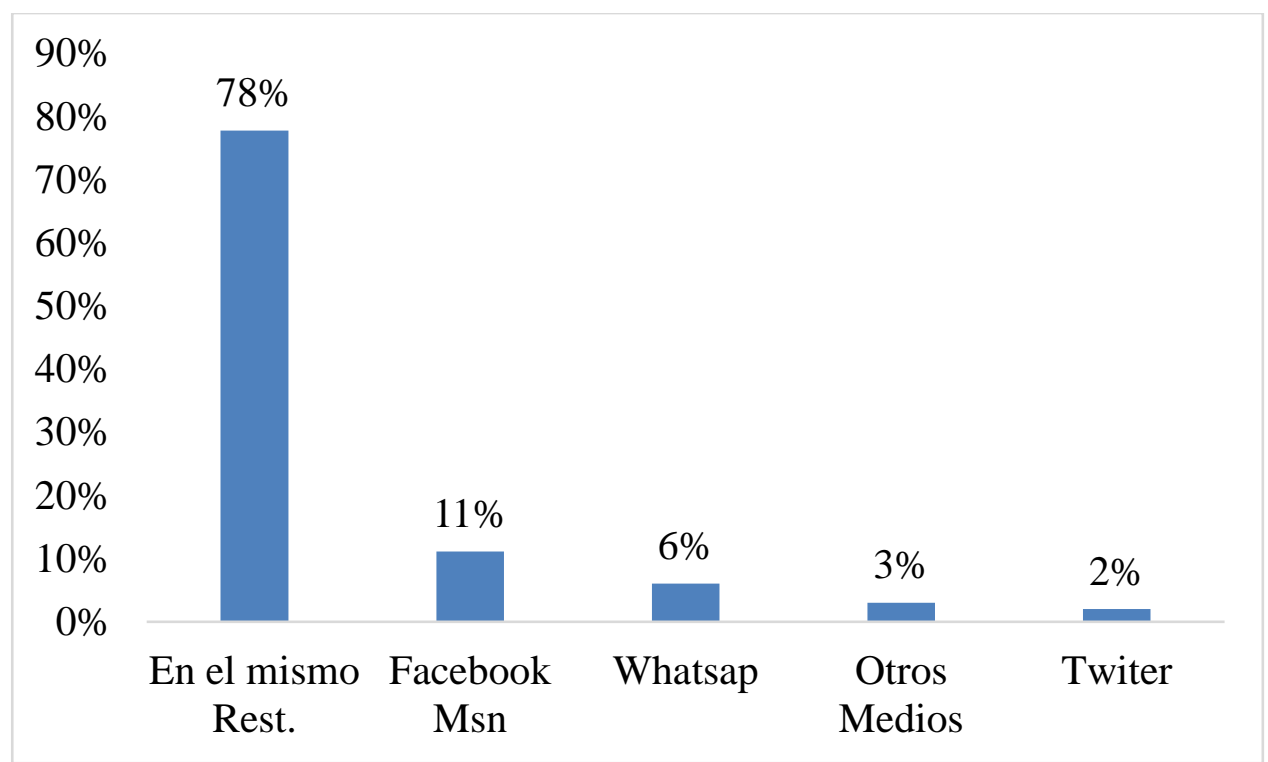

Ilustración 34. Pregunta general 26: ¿Cómo suele enterarse del menú o carta del día de un restaurante? Adaptado de encuesta aplicada.

El 78\% de los encuestados indicaron que suelen enterarse del menú o carta del día por medio del mismo restaurante, el 11\% se entera por el Facebook, el 6\% por WhatsApp, el 3\% por otros medios.

\section{c) Preguntas de Valor}

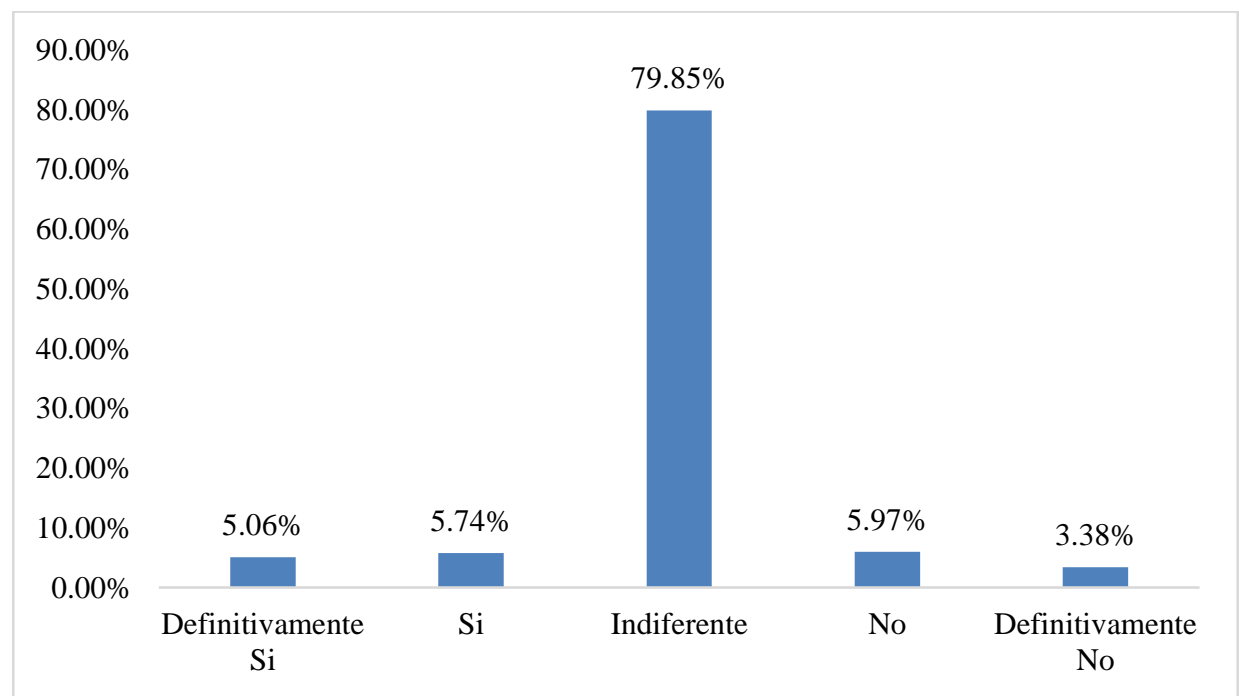

Ilustración 35. Pregunta sobre propuesta de valor 1: ¿Ud. Iría a este restaurante? Adaptado de encuesta aplicada.

Después de haber mencionado las características que tendría el nuevo restaurante (atributos, precios y condición de delivery), el 5.06\% de los encuestados indicaron que definitivamente sí asistiría; el 5.74\%, sí asistiría; el 79.85\% es indiferente; el 5.97\%, no lo haría; y el 3.38\%, definitivamente no asistiría. 


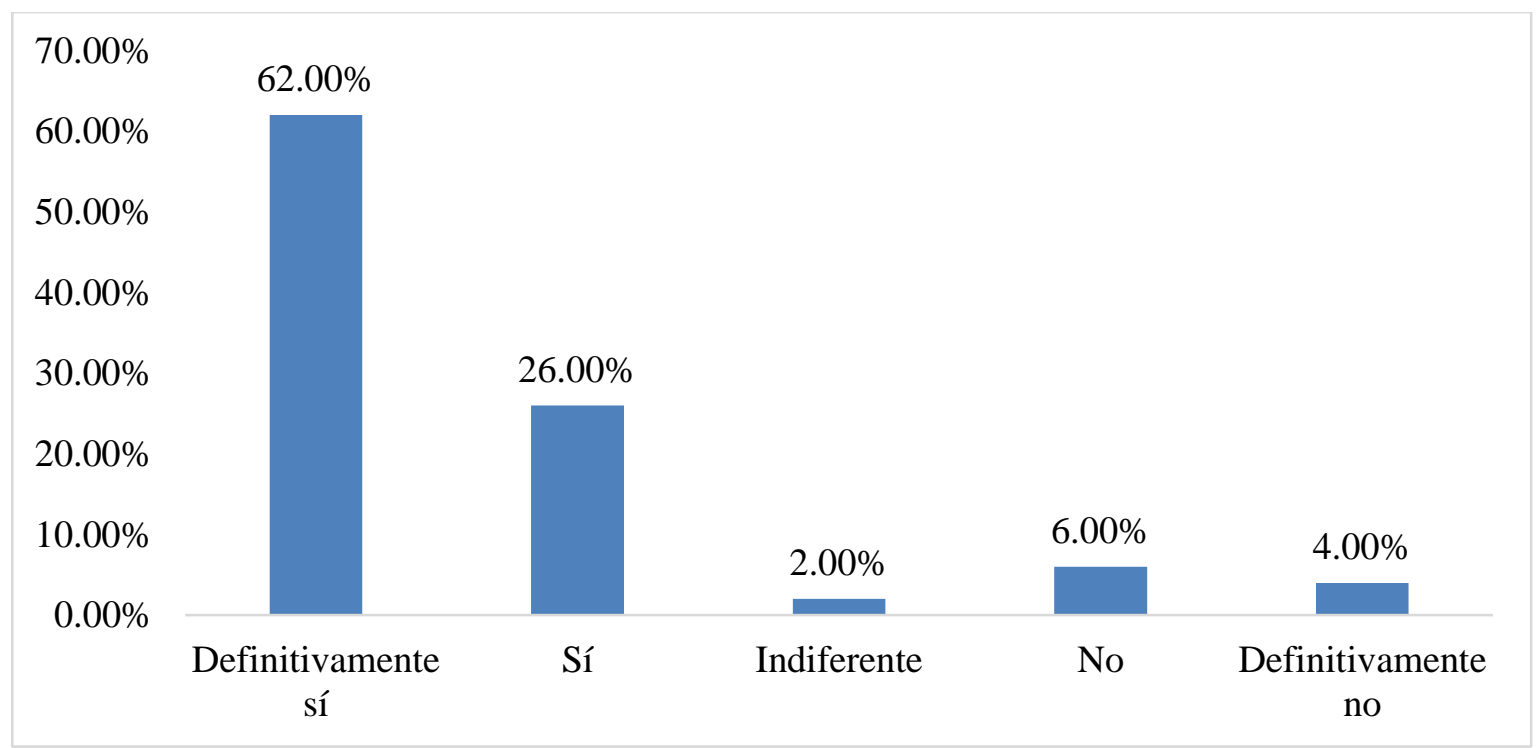

Ilustración 36. Pregunta sobre propuesta de valor 2. ¿Ud. pediría delivery de este restaurante? Adaptado de encuesta aplicada.

El $62 \%$ de los encuestados indicaron que definitivamente sí pediría el servicio de delivery, Esta respuesta es favorable para el proyecto, puesto que más del 60\% está dispuesto a utilizar este servicio.

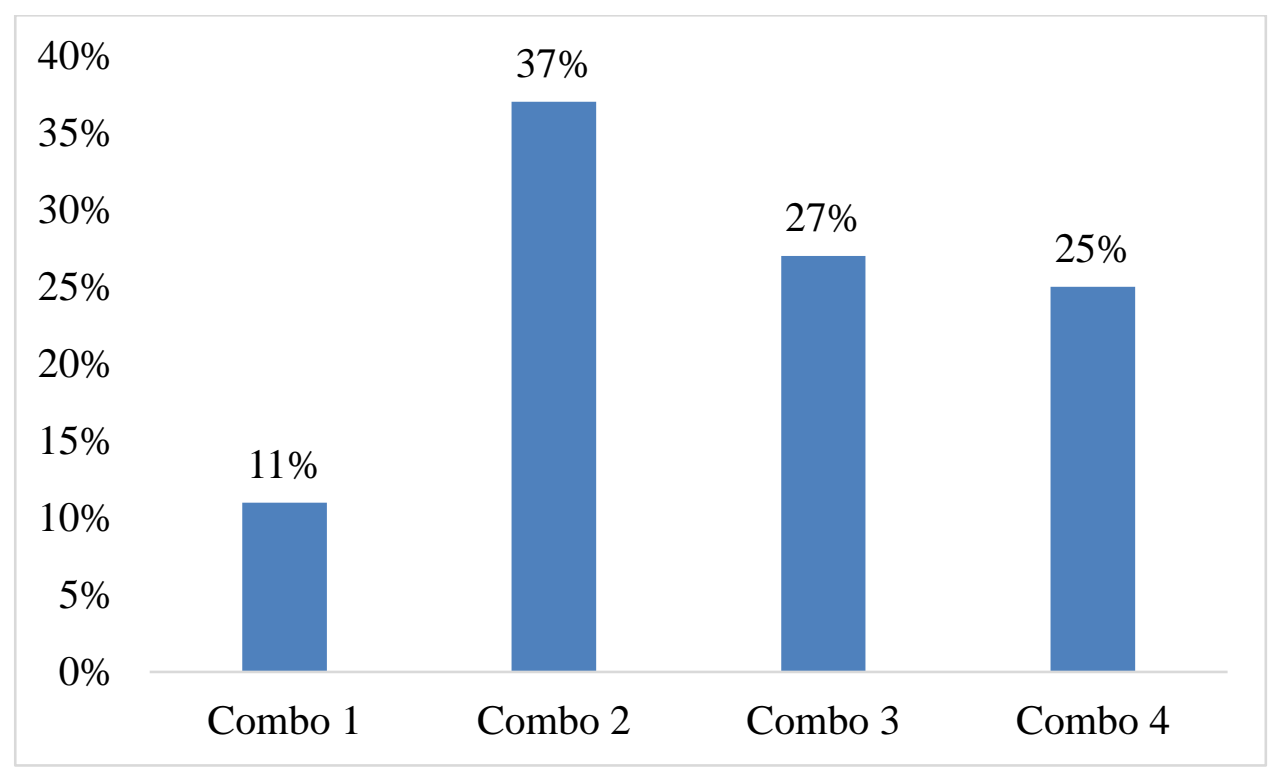

Ilustración 37. Pregunta sobre propuesta de valor 3: ¿Qué desayunos le gustaría encontrar? Adaptado de encuesta aplicada.

El 37\% de los encuestados les gustaría encontrar el combo 2 que está conformado por Jugo de papaya/piña/naranja + Infusión o café + pan con huevo, palta o pollo. El 27\% prefiere el combo 3 , el $25 \%$ el combo 4 y el $11 \%$ el combo 1. 


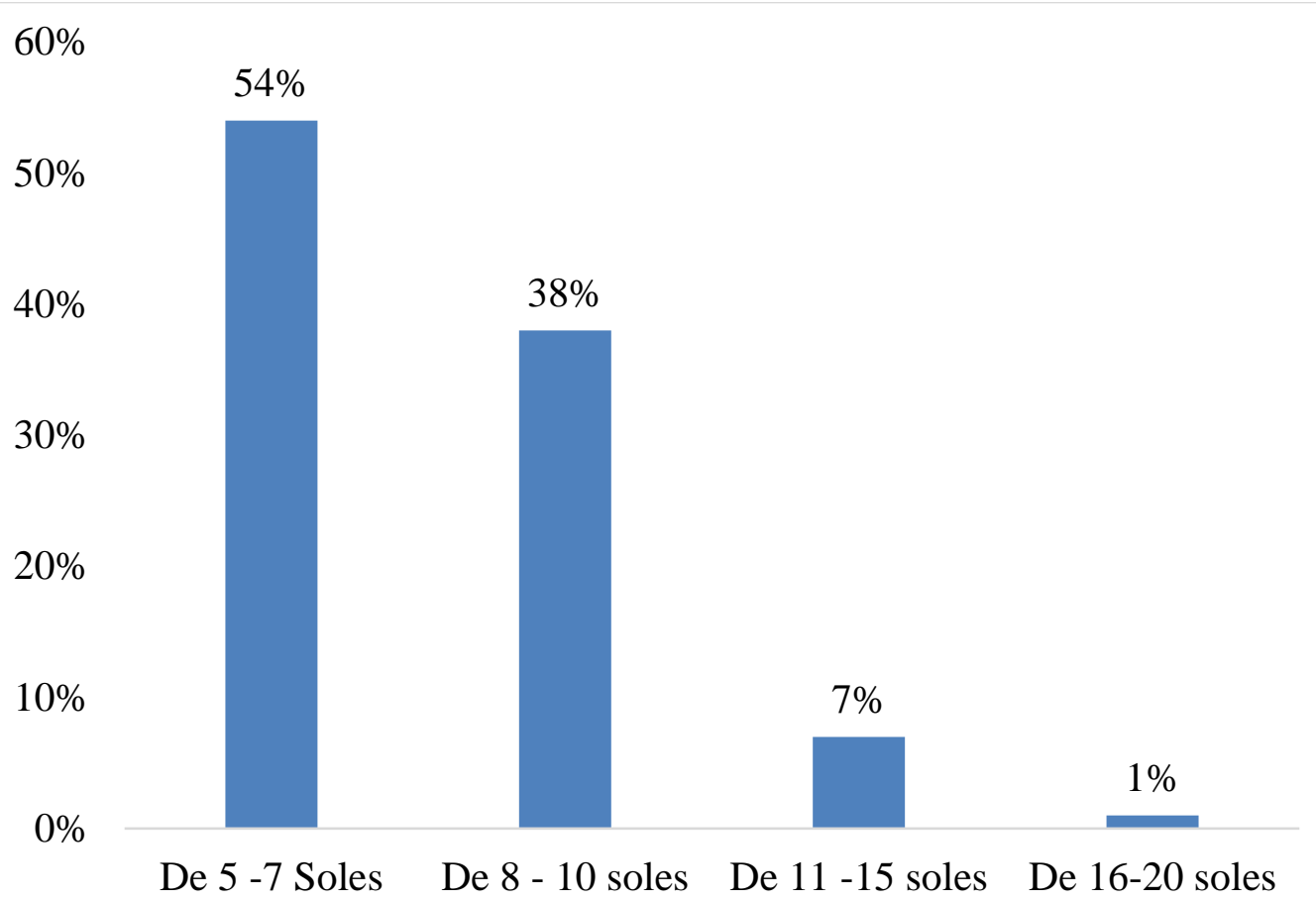

Ilustración 38. Pregunta sobre propuesta de valor 4: ¿Cuánto estaría dispuesto a pagar por un desayuno en este restaurante? Adaptado de encuesta aplicada.

El 54\% de los encuestados estaría dispuesto a pagar por un desayuno entre 5 y 7 soles, el $38 \%$ entre 8 y 10 soles, el $7 \%$ entre 11 y 15 soles, el $1 \%$ entre 16 y 20 soles.

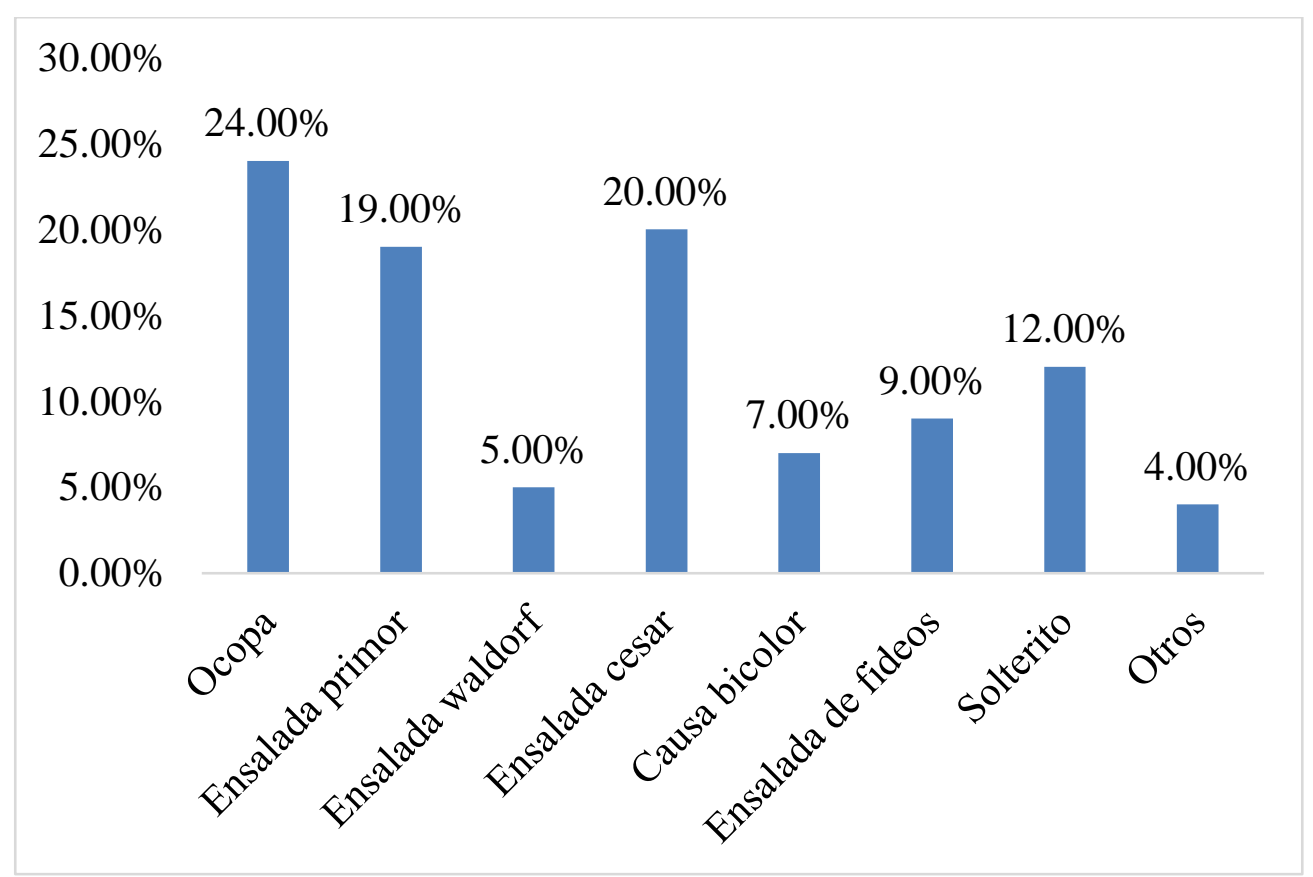

Ilustración 39. Pregunta sobre propuesta de valor 5: ¿Cuál de estas entradas le gustaría encontrar en el restaurante? Adaptado de encuesta aplicada.

El 24\% de los encuestados prefiere encontrar como entradas Ocopa, el 19\% ensalada primor, $20 \%$ prefiere ensalada cesar. Son las tres entradas que tiene más acogida entre los encuestados. 


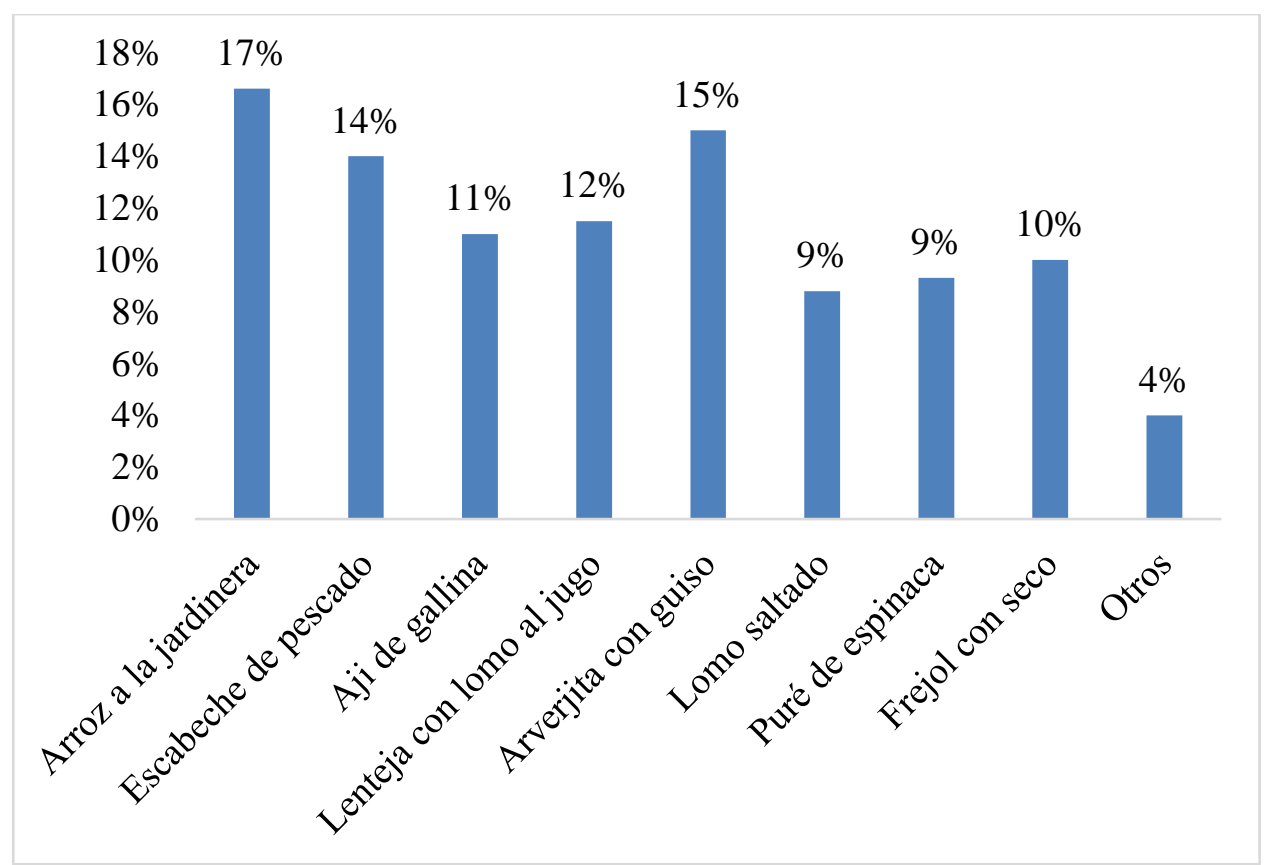

Ilustración 40. Pregunta sobre propuesta de valor 6: ¿Qué tipo de plato de fondo desearía encontrar? Adaptado de encuesta aplicada.

El 17\% de los encuestados prefieren como platos de fondo arroz a la jardinera, el $15 \%$ alverjita con guiso, el 14\% escabeche de pescado, esos son los tres platos que prefieren los comensales y ratifica lo que indicaron en el focus group, puesto que se inclinan a la comida criolla.

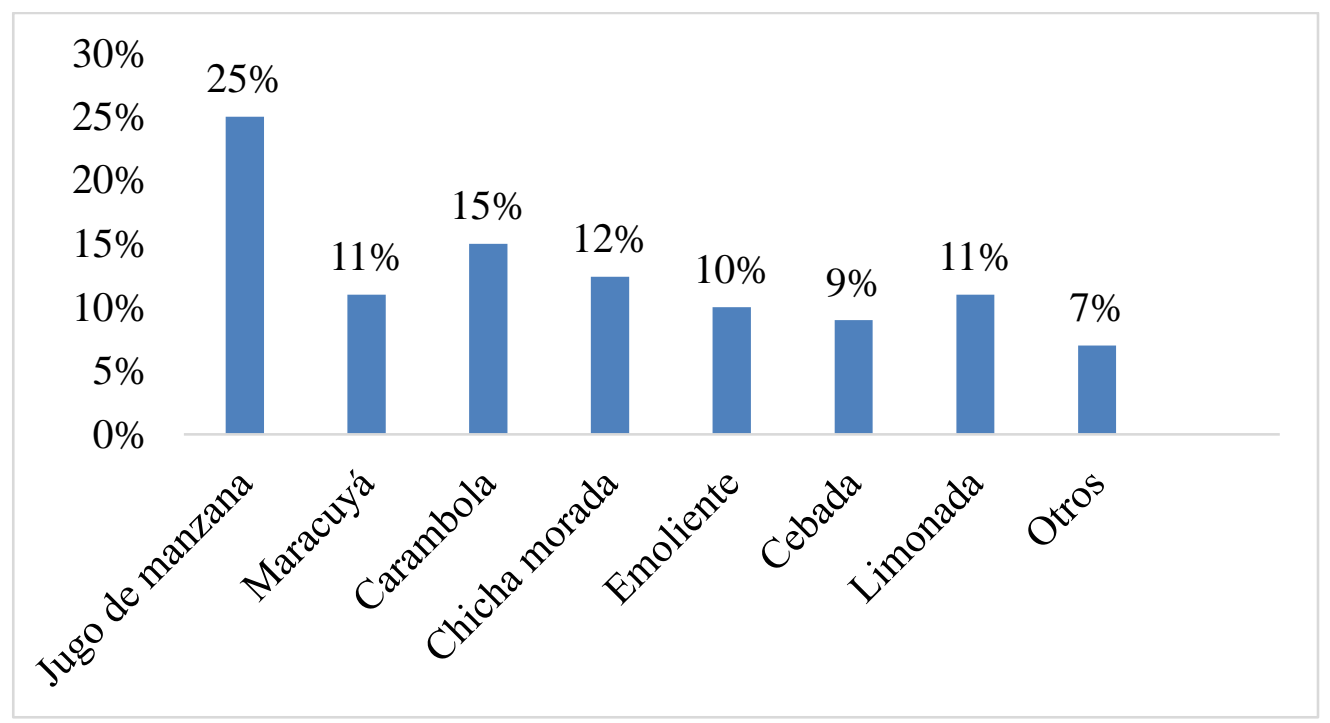

Ilustración 41. Pregunta sobre propuesta de valor 7: ¿Qué tipo de refresco le gustaría encontrar? Adaptado de encuesta aplicada.

El 25\% de los encuestados prefieren chicha morada, el 15\% prefiere carambola, el 12\% chicha morada, esos fueron las bebidas más apreciadas por el público objetivo. 


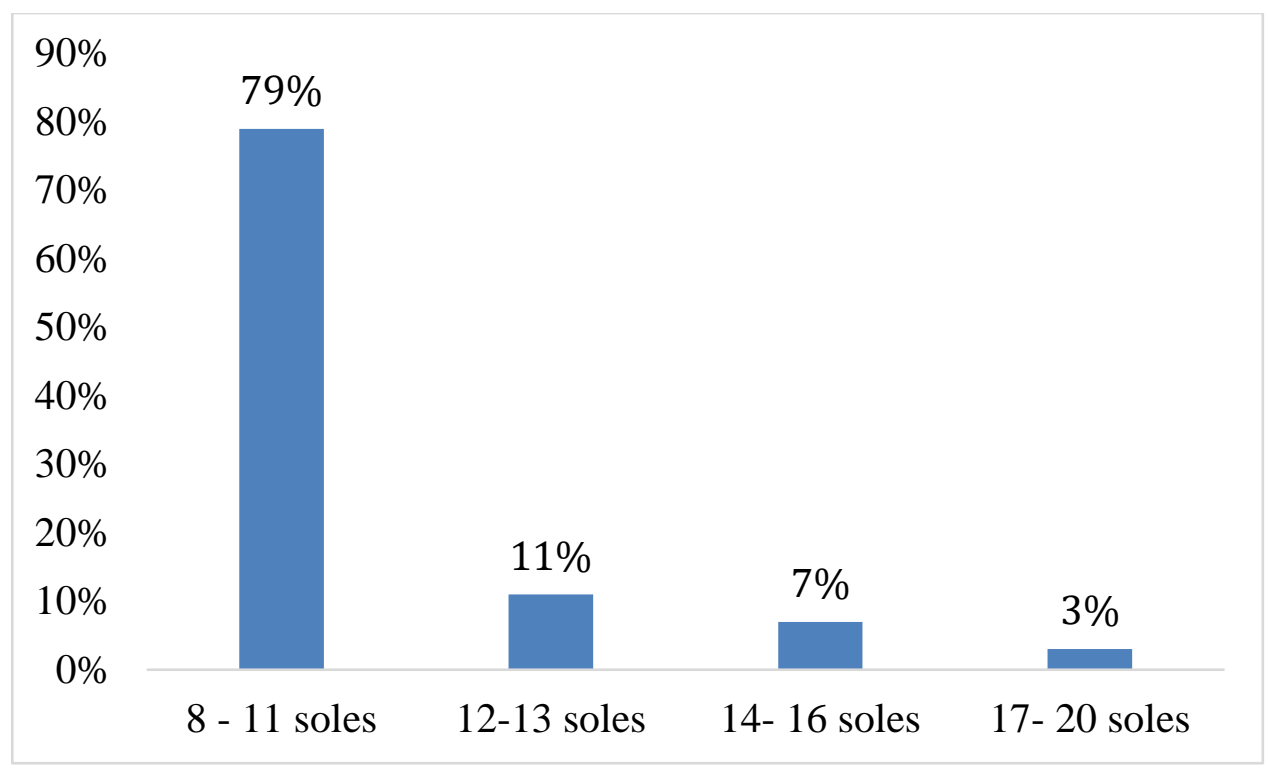

Ilustración 42. Pregunta sobre propuesta de valor 8: ¿Cuánto estaría dispuesto a pagar por menú de este restaurante? Adaptado de encuesta aplicada.

El 79\% de los encuestados están dispuestos a pagar por un menú de este proyecto de 8 a 11 soles, el $11 \%$ entre 12 a 13 soles, el 6\% entre 14 y 16 soles, el 3\% de 17 a 20 soles.

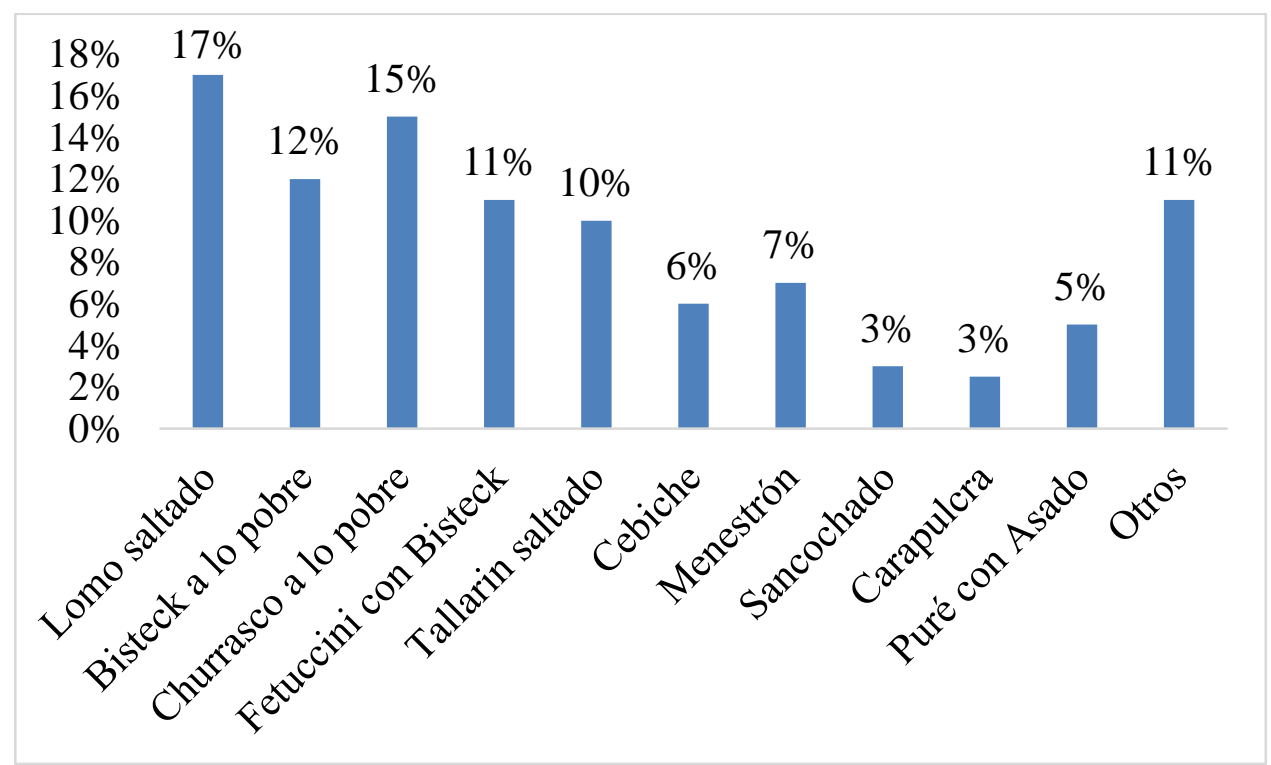

Ilustración 43. Pregunta sobre propuesta de valor 9: ¿Qué platos a la carta le gustaría encontrar? Adaptado de encuesta aplicada.

Según el gráfico, se puede concluir que el $17 \%$ de los encuestados prefiere lomo saltado, el $15 \%$ churrasco a lo pobre, el $12 \%$ bisteck a la pobre. Se puede concluir que son los platos con mayor preferencia. 


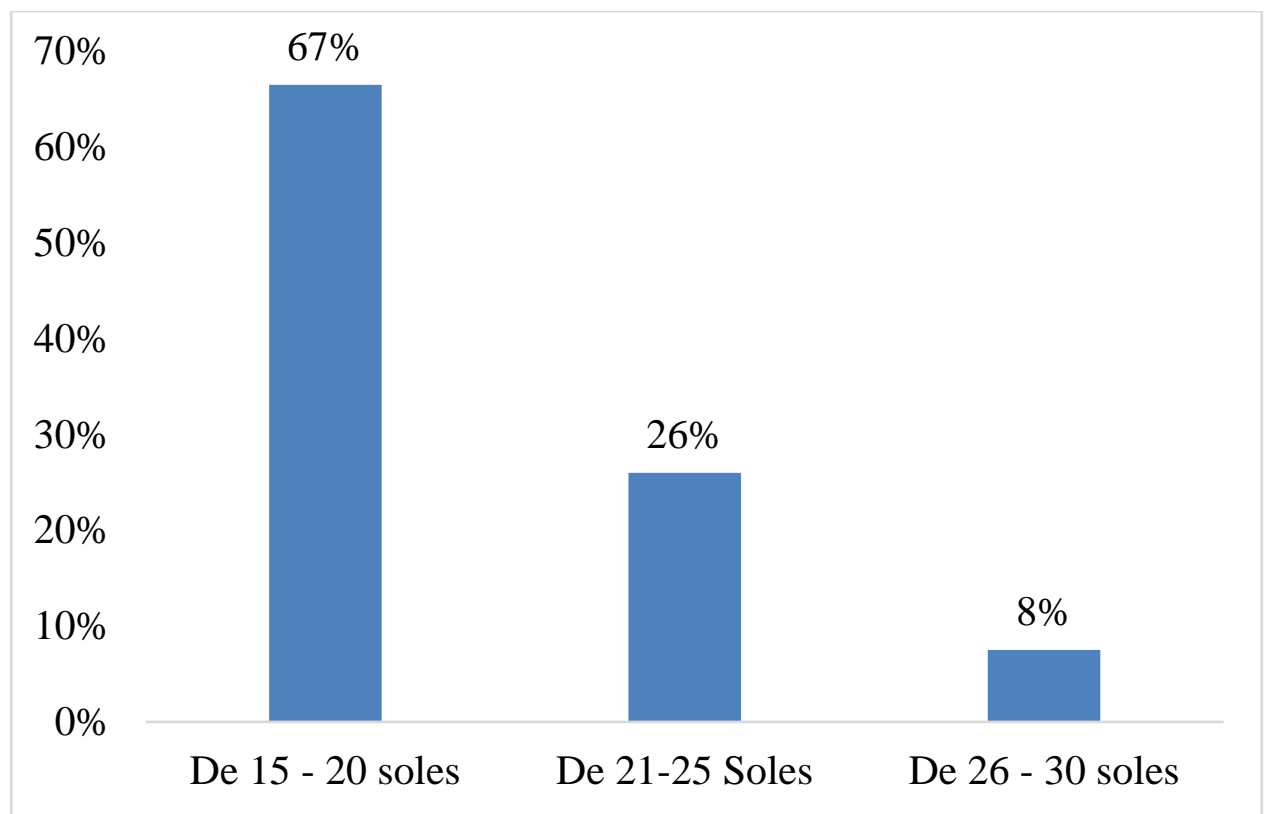

Ilustración 44. Pregunta sobre propuesta de valor 10: ¿Cuánto estaría dispuesto a pagar por un plato a la carta de este restaurante? Adaptado de encuesta aplicada.

El $67 \%$ de los encuestados estarían dispuestos a pagar de 15 a 20 soles, por un plato a la carta, el $26 \%$ de 21 a 25 soles, el $8 \%$ de 26 a 30 soles.

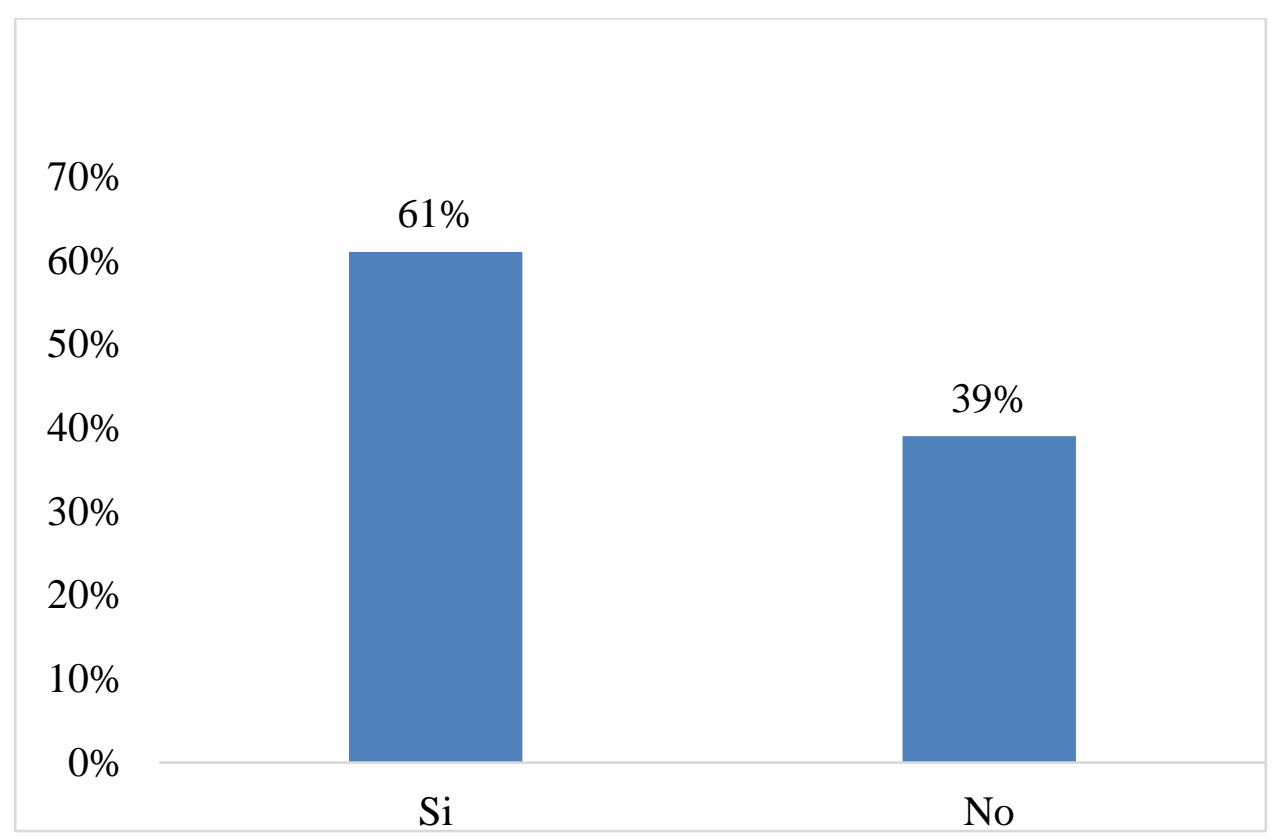

Ilustración 45. Pregunta sobre propuesta de valor 11: ¿Le gustaría encontrar bebidas alcohólicas los fines de semana? Adaptado de encuesta aplicada.

El $61 \%$ de los encuestados prefieren que se ofrezca bebidas alcohólicas y el 39\% no prefiere las bebidas alcohólicas. Para efectos del proyecto, solo se venderán bebidas alcohólicas los fines de semana. 


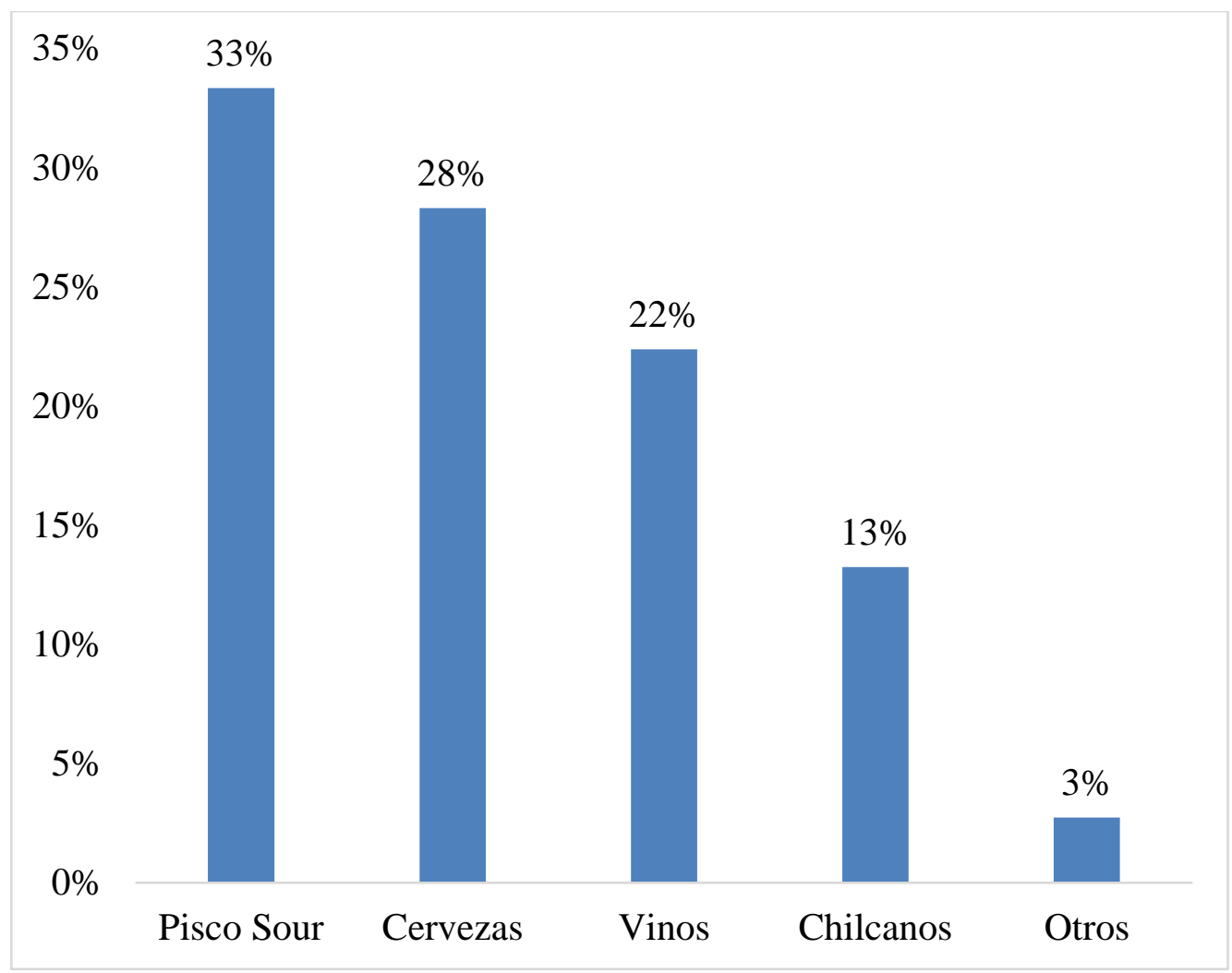

Ilustración 46. Pregunta sobre propuesta de valor 12: ¿Qué bebidas alcohólicas le gustaría encontrar? Adaptado de encuesta aplicada.

El 33\% de los encuestados prefiere encontrar como bebidas alcohólicas pisco sour, el $28 \%$ cervezas, el $22 \%$ vinos, el $13 \%$ chilcanos.

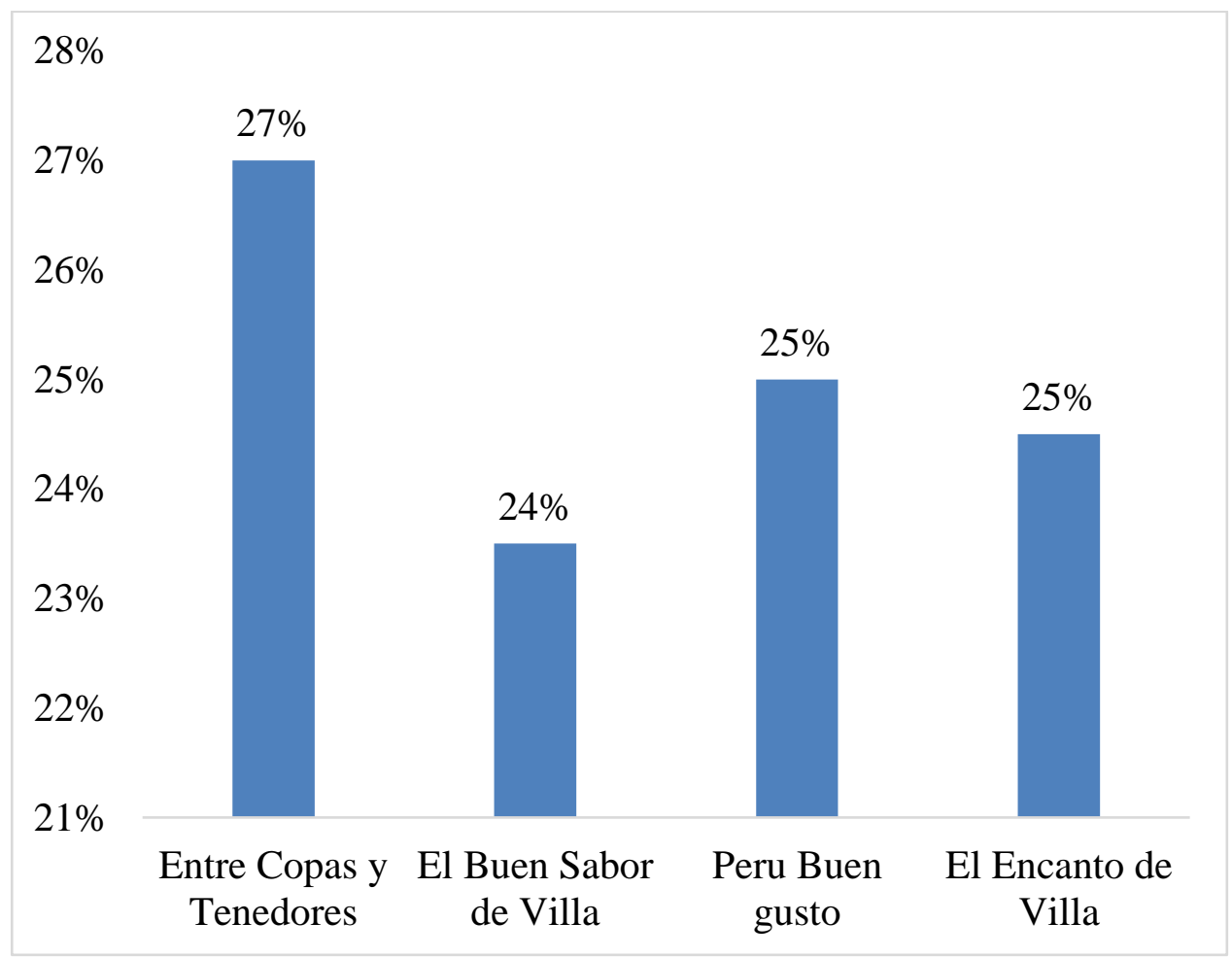

Ilustración 47. Pregunta sobre propuesta de valor 13: ¿Qué nombre le gustaría que tenga este restaurante? Adaptado de encuesta aplicada. 
E1 27\% de los encuestados prefiere que el restaurante lleve como nombre "Entre Copas y tenedores", el 25\%, "Perú buen Gusto", "El Encanto de Villa" y el 24\% "E1 Buen Sabor de Villa".

\begin{tabular}{|l|l|}
\hline $70 \%$ & $65 \%$ \\
$60 \%$ & \\
$50 \%$ & \\
$40 \%$ & $35 \%$ \\
$30 \%$ & \\
$20 \%$ & \\
$10 \%$ & \\
$0 \%$ & POS \\
\hline
\end{tabular}

Ilustración 48. Pregunta sobre propuesta de valor 14: ¿Qué metodo de pago prefiere utilizar? Adaptado de encuesta aplicada.

El 35\% de los encuestados prefiere utilizar el POS al momento de pagar, mientras que el $65 \%$ prefiere pagar en efectivo.

\subsection{Conclusiones Y Recomendaciones Del Estudio Cualitativo Y Cuantitativo}

Luego de haber realizado el estudio cualitativo y cuantitativo, se pueden tener las siguientes conclusiones:

- La comida criolla es la preferida por el público, esta preferencia está marcada tanto en las encuestas realizadas como en los focus group llevados a cabo, además de esto las entrevistas realizadas a los expertos ratifican esta preferencia del consumidor peruano.

- Es importante el buen servicio y la calidad de atención para que los comensales deseen volver al restaurante; para lograr esto es necesario una adecuada gestión de insumos y costos que aseguren la calidad y la rapidez en la atención. 
- Los precios bajos para menús y platos a las cartas son los que más resaltan tanto en las encuestas como en los focus group realizados, esto va de la mano con la propuesta que se está realizando al implementar este negocio.

- La propuesta de valor planteada es atractiva para el público, este se ve reflejado en las encuestas, en donde más del $60 \%$ de los encuestados afirmaron que asistirían a este nuevo restaurante; a su vez, los focus group también reflejan esta inclinación hacia esta nueva propuesta.

Las recomendaciones para el plan de negocios son:

- Es recomendable ofrecer descuentos y promociones que sirvan para atraer y retener a potenciales clientes.

- La calidad de servicio es fundamental para la nueva propuesta que se plantea, esta se debe asegurar ya que los focus group y las encuestas reflejan que no sólo el precio y el sabor de la comida son características importantes para los consumidores.

- Es importante aprovechar e incentivar el uso de las redes sociales para promocionar los platos y ofertas que ofrece este proyecto.

- Ya que los menús son los platos más solicitados por los clientes, es recomendable que este sea variado para así poder ofrecer diversos productos al público, de tal manera que la monotonía en los platos no desanime al cliente en asistir a este restaurante. 


\subsection{Perfil Del Consumidor Tipo Y Sus Variantes}

Tabla 12

Perfil del Consumidor Tipo y sus Variantes

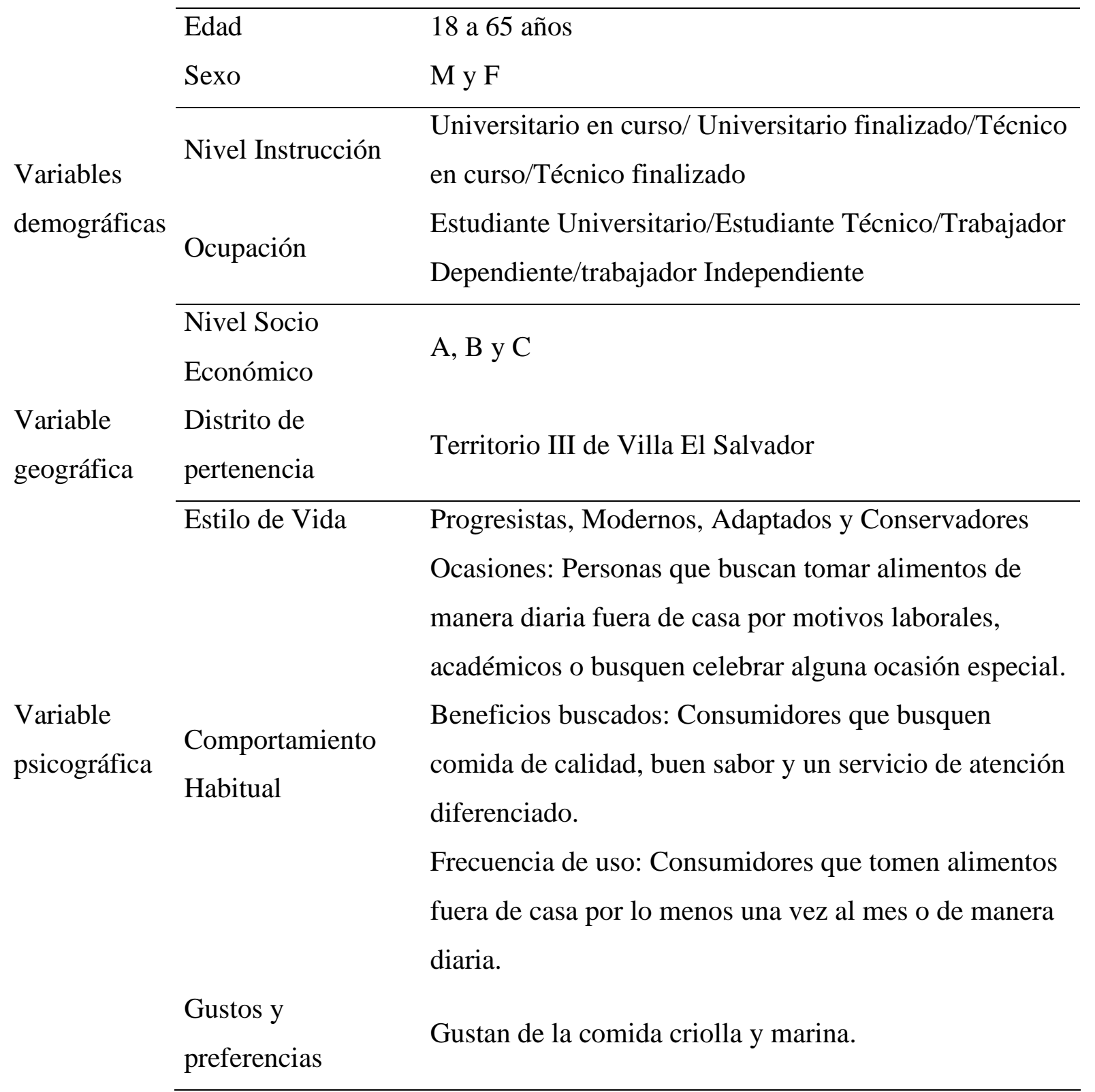

Nota Fuente. Elaboración propia 


\section{Capítulo IV. Proyección Del Mercado Objetivo}

\subsection{El Ámbito de la Proyección}

Los diferentes métodos de proyección de mercado objetivo se clasifican en métodos cualitativos y métodos cuantitativos.

\subsubsection{Métodos Cualitativos}

Estos métodos son utilizados cuando la data estadística con la que se cuenta para el análisis es insuficiente, estas técnicas se basan en el criterio de las personas entrevistas. Los métodos cualitativos son: Método Delphi, Investigación de Mercados, Consenso de un Panel, Pronóstico Visionario y Analogía Histórica.

\subsubsection{Métodos Cuantitativos}

Los métodos cuantitativos se clasifican en series de tiempo y causales.

\subsubsection{Series de tiempo}

Estos métodos se utilizan cuando la información histórica puede cuantificarse en estadísticas descriptivas y ser utilizadas para pronóstico, manteniendo márgenes de error discretos. Las series de tiempo pueden seguir cuatro patrones distintos: Estacionalidad, tendencia, estacionalidad y ciclo. Los métodos de proyección cuantitativa de series de tiempo son: Método de Promedios Móviles, Métodos de Suavización Exponencial y Descomposición de Series de Tiempo.

\subsubsection{Causales}

El propósito de los modelos causales es descubrir la forma en la que las variables independientes se relacionan y así poder utilizar esta relación para predecir valores futuros de la variable dependiente. Los modelos que se utilizan son: Modelos de Regresión, Modelos Econométricos y Encuestas de intenciones de compra y anticipaciones. (Hanke \& Reitsch, 2013).

Para el presente proyecto, se utilizó el método causal de regresión lineal, debido a que este modelo es el que mejor se adapta a la proyección. El ámbito de la proyección se ciñe a 
Lima Metropolitana, la cual tiene 9 millones 904 mil 727 habitantes, según datos del INEI al 30 de junio de 2015. El restaurante está ubicado en la zona sur de Lima Metropolitana, específicamente en el distrito de Villa El Salvador. En el 2015, en este distrito habitaban 463 mil 14 personas. Asimismo, se está considerando a los funcionarios que laboran en la Municipalidad del distrito de Villa El Salvador, personal de la Comisaría y a los estudiantes de la Universidad Autónoma, aledaña al restaurante.

Tabla 13

Población histórica de Villa el Salvador (en número de personas)

\begin{tabular}{lll}
\hline Año & X & Población $(\mathrm{y})$ \\
\hline 2000 & -7.5 & 332,001 \\
2001 & -6.5 & 341,185 \\
2002 & -5.5 & 350,307 \\
2003 & -4.5 & 359,344 \\
2004 & -3.5 & 268,373 \\
2005 & -2.5 & 377,067 \\
2006 & -1.5 & 385,609 \\
2007 & -0.5 & 393,893 \\
2008 & 0.5 & 402,075 \\
2009 & 1.5 & 410,313 \\
2010 & 2.5 & 418,768 \\
2011 & 3.5 & 427,466 \\
2012 & 4.5 & 436,289 \\
2013 & 5.5 & 445,189 \\
2014 & 6.5 & 454,114 \\
2015 & 7.5 & 463,014 \\
\hline A & & \\
\hline
\end{tabular}

Nota. Adaptado de INEI (2015)

\subsection{Selección del Método de Proyección}

Para calcular el número de personas que viven, estudian o laboran en el Territorio III de Villa El Salvador, se utilizó el método de proyección cuantitativo causal de regresión, el cual busca encontrar la relación existente entre variables independientes y dependientes a 
través de regresiones y correlaciones, las mismas que permiten derivar una ecuación mediante la cual se pueda estimar una variable dependiente con la información de las variables independientes. (Hanke \& Reitsch, 2013).

Considerando el modelo de regresión lineal mencionado de la forma $\mathrm{Y}=\mathrm{A}+\mathrm{Bx}$, donde A es el punto de corte en el eje vertical y B es la pendiente de la recta generada, se obtuvo que:

$$
\begin{array}{ll}
\mathrm{A}= & 391,562.94 \\
\mathrm{~B}= & 9,667.54 \\
\mathrm{r} 2= & 78.20 \%
\end{array}
$$

El coeficiente R2 que es más de 78\% afirma que el pronóstico realizado es aceptable. En función a los parámetros calculados, se procede a calcular la población proyectada para el distrito de Villa El Salvador para los próximos cinco años que dura este proyecto.

Tabla 14

Población Proyectada (en número de personas)

\begin{tabular}{cccccc}
\hline & $\mathbf{2 0 1 9}$ & $\mathbf{2 0 2 0}$ & $\mathbf{2 0 2 1}$ & $\mathbf{2 0 2 2}$ & $\mathbf{2 0 2 3}$ \\
\hline Población & 502,740 & 512,407 & 522,075 & 531,742 & 541,410 \\
Municipalidad & 104 & 104 & 104 & 104 & 104 \\
Comisaría & 503 & 512 & 522 & 532 & 541 \\
Estudian & 4,500 & 4,635 & 4,774 & 4,917 & 5,065 \\
\hline Total & 507,846 & 517,659 & 527,475 & 537,295 & 547,120 \\
\hline $\begin{array}{l}\text { Nota. Adaptado de INEI, Memoria de Municipalidad de Villa El Salvador y Censo } \\
\text { Nacional de Comisarías 2015. }\end{array}$ & & &
\end{tabular}

\subsubsection{Mercado Potencial}

Este mercado está conformado por el conjunto de personas que podrían necesitar el bien o servicio y cumplen con los criterios de segmentación. Para calcular el mercado potencial, se utilizó la proyección poblacional de la tabla anterior y se realizó la 
segmentación geográfica (Territorio III), demográfica (18 a 65 años) y socioeconómica (NSE A, B y C).

Tabla 15

Distribución de la población por Territorios (En porcentaje)

\begin{tabular}{cc}
\hline TERRITORIO & PORCENTAJE \\
\hline Territorio I & $14.35 \%$ \\
Territorio II & $9.89 \%$ \\
Territorio III & $\mathbf{7 . 9 3 \%}$ \\
Territorio IV & $15.28 \%$ \\
Territorio V & $12.73 \%$ \\
Territorio VI & $8.39 \%$ \\
Territorio VII & $9.45 \%$ \\
Territorio VIII & $15.19 \%$ \\
Territorio IX & $6.79 \%$ \\
\hline TOTAL & $100.00 \%$
\end{tabular}

Nota. Adaptado de respuesta enviada por Villa El Salvador mediante DOC. $\mathrm{N}^{\circ} 4510$ 2019.

Tabla 16

Población quinquenal en Villa El Salvador (en número de personas)

\begin{tabular}{lllllllllll}
\hline $15-19$ & $20-24$ & $25-29$ & $30-34$ & $35-39$ & $40-44$ & $45-49$ & $50-54$ & $55-59$ & $60-64$ & $65-69$ \\
\hline 43,542 & 43,978 & 39,083 & 39,683 & 35,687 & 26,825 & 22,964 & 19,250 & 16,555 & 13,001 & 8,311 \\
\hline 17,417 & 43,978 & 39,083 & 39,683 & 35,687 & 26,825 & 22,964 & 19,250 & 16,555 & 13,001 & 1,662 \\
\hline
\end{tabular}

Nota. Adaptado de INEI

Tabla 17

Distribución de la población por Estrato Socioeconómico (En porcentaje)

\begin{tabular}{ccccccc}
\hline Distrito & A & B & C & D & E & Total \\
\hline Villa El Salvador & $\mathbf{0 . 0 0 \%}$ & $\mathbf{1 0 . 4 0 \%}$ & $\mathbf{4 5 . 8 0 \%}$ & $32.10 \%$ & $11.70 \%$ & $100.00 \%$ \\
\hline Nota. Adaptado de APEIM 2017 & & & &
\end{tabular}


Tabla 18

Mercado Potencial (en número de personas)

\begin{tabular}{lccccc}
\hline & 2019 & 2020 & 2021 & 2022 & 2023 \\
\hline Mercado Potencial & 15,694 & 16,012 & 16,332 & 16,653 & 16,975
\end{tabular}

Nota. Población proyectada de Villa El Salvador segmentada geográfica (7.93\%), demográfica $(62.72 \%)$ y socioeconómicamente $(56.20 \%)$.

\subsubsection{Mercado Disponible}

Este mercado está conformado por los consumidores del mercado potencial que tienen la necesidad de adquirir el bien o servicio del proyecto; es decir, son aquellas personas que consumen el almuerzo o cena fuera de su casa por diferentes razones. El $80.00 \%$ de los encuestados, manifestaron que almuerzan o cenan fuera de casa.

Tabla 19

Mercado Disponible (en número de personas)

\begin{tabular}{lccccc}
\hline & 2019 & 2020 & 2021 & 2022 & 2023 \\
\hline Mercado Disponible & 12,555 & 12,810 & 13,065 & 13,322 & 13,580 \\
\hline Nota Fuente. Elaboración propia - Estudio de Mercado & &
\end{tabular}

\subsubsection{Mercado Efectivo}

Este mercado está conformado por los consumidores del mercado disponible que tienen la intención de compra y están en la capacidad de hacerlo.

Para determinar el mercado efectivo, se utiliza el porcentaje de encuestados que prefieren comida criolla y marina $(72.20 \%=66.5 \%+5.7 \%)$ y están dispuestas a pagar por lo menos entre 8 y 11 soles $(79.0 \%)$.

\section{Tabla 20}

Mercado Efectivo (en número de personas)

\begin{tabular}{lccccc}
\hline & 2019 & 2020 & 2021 & 2022 & 2023 \\
\hline Mercado Efectivo & 7,161 & 7,306 & 7,452 & 7,599 & 7,746 \\
\hline
\end{tabular}




\subsubsection{Mercado Objetivo}

Este mercado está conformado por los consumidores del mercado efectivo que está dispuesto a consumir la propuesta de valor. De la pregunta $\mathrm{N}^{\circ} 27$ de la encuesta, se obtuvo que el 5.06\% definitivamente sí iría y el 5.74\% sí iría. Según McDaniel y Roger Gates, una estimación razonable pero conservadora sería de 70\% de los que "definitivamente sí iría" y $35 \%$ de los que "sí iría".

De esta manera, el mercado objetivo está compuesto por los trabajadores de las zonas agropecuarias, comerciales e industriales del distrito, trabajadores públicos de la Municipalidad y comisaría cercana, estudiantes de la universidad Autónoma del Perú y los habitantes del Territorio III de Villa El Salvador.

Tabla 21

Mercado Objetivo (en número de personas)

\begin{tabular}{lccccc}
\hline & 2019 & 2020 & 2021 & 2022 & 2023 \\
\hline Mercado Objetivo & 398 & 406 & 414 & 422 & 430 \\
\hline Nota Fuente. Elaboración propia & - Estudio de Mercado
\end{tabular}




\section{Capítulo V. Plan de Marketing}

\subsection{Estrategias de Marketing}

Según Kotler y Armstrong (2012), las compañías que ofrecen servicios siguen estrategias de marketing tradicionales; sin embargo, como los servicios difieren de los productos tangibles, es necesario enfoques de marketing adicionales. El servicio es creado por los empleados del front office y los clientes; por lo tanto, las empresas entienden la cadena servicio - utilidades que vincula a estos dos agentes. Esta cadena consiste en cinco eslabones:

1. Calidad interna del servicio

2. Empleados de servicio satisfechos y productivos

3. Mayor valor del servicio

4. Clientes satisfechos y leales

5. Utilidades y crecimiento saludables

\subsubsection{Estrategia de producto}

Según Kotler y Keller (2016), la estrategia de producto requiere de decisiones coordinadas sobre el producto, marcas, empaque y etiquetado.

Con respecto a la estrategia de producto, se tomó como referencia la matriz de expansión de producto y mercados, Matriz Ansoff (1957): 
Tabla 22

Matriz de Expansión de Productos

\begin{tabular}{lll}
\hline & Productos Existentes & Productos Nuevos \\
\hline Mercados Existentes & Penetración del Mercado & Desarrollo de Productos \\
Mercados Nuevos & Desarrollo del Mercado & Diversificación \\
& &
\end{tabular}

Nota. Adaptado de Dirección de Marketing por Kotler y Keller (2016)

Dado que la propuesta de valor de este proyecto no se brinda y por ende, no existe el mercado que la consuma, la estrategia de producto es la de desarrollo de mercado. El producto básico por entregarse son los distintos platos de comida criolla, marina y bebidas que satisfacen la necesidad de alimentación de los clientes, acompañado de un servicio diferenciado.

Los ingredientes a utilizarse son frescos, los perecibles son comprados en la mañana del día laborable y los no perecibles son monitoreados frecuentemente por el encargado de cocina con el fin de garantizar que su frecuencia de rotación sea la apropiada.

Con respecto a los servicios complementarios, el local de Entre Copas y Tenedores está ambientado con frases de tipografía artística, las cuales hacen alusión a la comida peruana dentro de un ambiente pintoresco y colorido en donde resaltan imágenes de platos peruanos. Una de las características que tendrá este restaurante es su variedad y calidad de la carta que será renovada semanalmente. 
A continuación, los productos ofertados:

Tabla 23

Menú de semana 1

\begin{tabular}{|c|c|c|c|c|c|c|}
\hline Día & Sopa & Entrada & Plato 1 & Plato 2 & Plato 3 & Refresco \\
\hline \multirow{3}{*}{ Lunes } & & & Arroz a la & Escabeche de & & \\
\hline & Verduras & Ocopa & jardinera & pescado & Puré con asado & Chicha \\
\hline & & Ensalada & & & & \\
\hline \multirow[t]{2}{*}{ Martes } & Gallina & Primor & Adobo de pollo & Cau cau criollo & Frejol con seco & Emoliente \\
\hline & & Ensalada & & Pollo al & Pescado al & \\
\hline \multirow[t]{2}{*}{ Miércoles } & De pollo & Waldorf & Picante de res & horno/ajiaco & limón & Cebada \\
\hline & & Ensalada & Chuleta de & & & \\
\hline \multirow[t]{2}{*}{ Jueves } & Patasca & César & cerdo & Ají de gallina & Bisteck/pobre & Limonada \\
\hline & & & Arroz con & Lenteja/lomo al & Estofado & \\
\hline \multirow[t]{2}{*}{ Viernes } & Choros & Ceviche & mariscos & jugo & olla/pallares & Manzana \\
\hline & & & Pachamanca de & Churrasco con & & \\
\hline Sábado & Menestrón & Causa & pollo & arroz & Lomo saltado & Carambola \\
\hline
\end{tabular}

Nota Fuente. Elaboración propia 
Tabla 24

Menú de semana 2

\begin{tabular}{|c|c|c|c|c|c|c|}
\hline Día & Sopa & Entrada & Plato 1 & Plato 2 & Plato 3 & Refresco \\
\hline & & & Pescado a la & Arroz con & Pescado & \\
\hline \multirow[t]{2}{*}{ Lunes } & Aristud & Ensalada fideos & chorrillana & cerdo & entomatado & Chicha \\
\hline & & & Pepián de & Fetuccini a la & Tallarín rojo / & \\
\hline \multirow[t]{2}{*}{ Martes } & Aguadito & Solterito & pavo & crema & pollo & Emoliente \\
\hline & & & Ceviche de & Olluquito / & Suprema de & \\
\hline \multirow[t]{2}{*}{ Miércoles } & Crema/arverja & Ensalada rusa & pollo & pollo & pollo & Cebada \\
\hline & & & Picante a la & Pollo punto & Seco a la & \\
\hline \multirow[t]{2}{*}{ Jueves } & Chupe/habas & Palta a la reyna & norteña & cuy & limeña & Limonada \\
\hline & & & Dieta de & Arverjita/guiso & Chicharrón de & \\
\hline \multirow[t]{2}{*}{ Viernes } & Chupe/pescado & Ceviche & pollo & res & pescado & Manzana \\
\hline & Sopa a la & & & & & \\
\hline Sábado & minuta & Ensalada/aceituna & Pollo al vino & Picante de res & Puré con asado & Carambola \\
\hline
\end{tabular}

Nota Fuente. Elaboración propia 
Tabla 25

Menú de semana 3

\begin{tabular}{|c|c|c|c|c|c|c|}
\hline Día & Sopa & Entrada & Plato 1 & Plato 2 & Plato 3 & Refresco \\
\hline Lunes & $\begin{array}{l}\text { Sopa a la } \\
\text { minuta }\end{array}$ & $\begin{array}{l}\text { Pastel de } \\
\text { acelga }\end{array}$ & $\begin{array}{l}\text { Arroz con } \\
\text { pollo }\end{array}$ & $\begin{array}{c}\text { Puré de } \\
\text { espinaca con } \\
\text { pollo }\end{array}$ & $\begin{array}{l}\text { Carne mechada } \\
\text { con frijoles }\end{array}$ & Chicha \\
\hline Martes & Sancochado & $\begin{array}{c}\text { Salpicón de } \\
\text { verduras }\end{array}$ & $\begin{array}{l}\text { Friccase de } \\
\text { pollo }\end{array}$ & $\begin{array}{l}\text { Pechuga de } \\
\text { pavo en salsa } \\
\text { waldorf }\end{array}$ & $\begin{array}{c}\text { Guiso de trigo } \\
\text { con res }\end{array}$ & Emoliente \\
\hline Miércoles & $\begin{array}{c}\text { Consome } \\
\text { de res }\end{array}$ & $\begin{array}{c}\text { Choclo con } \\
\text { queso }\end{array}$ & $\begin{array}{c}\text { Tallarín verde } \\
\text { con pollo }\end{array}$ & Cerdo adobado & $\begin{array}{c}\text { Churrasco con } \\
\text { arroz }\end{array}$ & Cebada \\
\hline Jueves & $\begin{array}{l}\text { Crema de } \\
\text { zapallo }\end{array}$ & $\begin{array}{c}\text { Brocheta de } \\
\text { pollo }\end{array}$ & Pollo arverjado & $\begin{array}{l}\text { Arroz a la } \\
\text { cubana }\end{array}$ & $\begin{array}{l}\text { Pollo con } \\
\text { verduras }\end{array}$ & Limonada \\
\hline Viernes & $\begin{array}{c}\text { Chilcano de } \\
\text { pescado }\end{array}$ & Ceviche & $\begin{array}{c}\text { Pavita con } \\
\text { arroz jardinera }\end{array}$ & $\begin{array}{c}\text { Hígado } \\
\text { encebollado }\end{array}$ & $\begin{array}{l}\text { Pescado } \\
\text { apanado }\end{array}$ & Manzana \\
\hline & Sopa de & Huevo en & Pachamanca de & Lenteja/lomo al & & \\
\hline Sábado & verduras & salsa golf & pollo & jugo & Olluquito / pollo & Carambola \\
\hline
\end{tabular}

Nota Fuente. Elaboración propia 
Tabla 26

Menú de semana 4

\begin{tabular}{|c|c|c|c|c|c|c|}
\hline Día & Sopa & Entrada & Plato 1 & Plato 2 & Plato 3 & Refresco \\
\hline & & Ensalada & Pescado & Arroz con & Estofado a la & \\
\hline \multirow[t]{2}{*}{ Lunes } & Aristud & fideos & chorrillana & cerdo & olla/pallares & Chicha \\
\hline & & & Pepian de & Fetuccini a la & & \\
\hline \multirow[t]{2}{*}{ Martes } & Aguadito & Solterito & pavo & crema & Frejol con seco & Emoliente \\
\hline & & & Suprema de & Olluquito / & & \\
\hline \multirow[t]{2}{*}{ Miércoles } & Crema/arverja & Ensalada rusa & pollo & pollo & Ceviche de pollo & Cebada \\
\hline & & Palta a la & Picante a la & Pollo punto & & \\
\hline \multirow[t]{2}{*}{ Jueves } & Chupe/habas & reyna & norteña & cuy & Seco a la limeña & Limonada \\
\hline & Aguadito de & & Dieta de & Arverjita/guiso & & \\
\hline \multirow[t]{2}{*}{ Viernes } & pescado & Ceviche & pollo & res & Huevera frita & Manzana \\
\hline & & Salpicón de & & & & \\
\hline Sábado & Sopa criolla & verduras & Pollo al vino & Picante de res & Puré con asado & Carambola \\
\hline
\end{tabular}

Nota Fuente. Elaboración propia

Tabla 27

Platos extras preferidos en encuesta

\begin{tabular}{c}
\hline Platos \\
Lomo Saltado \\
Bisteck a lo Pobre \\
Churrasco a lo Pobre \\
Fetuccini con bisteck \\
Tallarín saltado \\
\hline Nota Fuente. Elaboración propia
\end{tabular}


Tabla 28

Bebidas a comercializar

$\frac{\text { Bebidas }}{\text { Gaseosas de } 500 \mathrm{ml}}$
Cervezas $335 \mathrm{ml}$
Nota Fuente. Elaboración propia

Con respecto al servicio de delivery, el mismo que se realiza sin costo adicional a zonas aledañas al restaurante, la comida es entregada en táperes de plástico y con cubiertos descartables.

\subsubsection{Estrategia de precio}

Según Kotler y Keller (2016), la estrategia de fijación de precios cambia según el ciclo de vida del producto. Para fijar los precios en etapa de introducción, es posible utilizar dos estrategias:

1. Capturar el nivel más alto del mercado: Las empresas fijan precios de introducción altos con el objetivo de obtener la mayor utilidad posible de cada capa. Se puede utilizar esta estrategia bajo ciertas condiciones: (a) La imagen y calidad del producto justifica el precio y hay compradores dispuestos a pagarlo; (b) Los costos de producción de un volumen más pequeño no eliminan los beneficios; y (c) No debe ser fácil para los competidores penetrar el mercado y quitarle participación.

2. Penetrar en el mercado: Las empresas fijan un precio inicial bajo para penetrar el mercado con rapidez y profundidad, el volumen alto de ventas permite abaratar costos y seguir reduciendo el precio. Se puede utilizar esta estrategia bajo ciertas condiciones: (a) El mercado es muy sensible al precio; (b) Los costos de producción y distribución disminuyen conforme aumentan las ventas; (c) Los precios bajos cobrados deben ser una barrera de entrada para nuevos competidores. 
3. La estrategia de precio utilizada por Entre Copas y Tenedores es la de precios bajos para penetrar en el mercado. El menú costará S/ 11; los platos a la carta, S/ 18; y las bebidas, entre S/ 3 - S/ 5. Todos los precios son congruentes con la investigación cualitativa y cuantitativa realizada previamente, permite cubrir costos y marginar, y está dentro del rango de precios cobrado por la competencia.

\subsubsection{Estrategia de distribución y plaza}

Según Kotler y Keller (2016), las estrategias de distribución se clasifican en: (a) Canal de distribución directo: No tiene niveles de intermediarios, la empresa vende directamente a los consumidores; (b) Canal de distribución indirecto: Incluye uno o más intermediarios.

Por otro lado, las estrategias de plaza se clasifican en: (a) Único sitio: Solo existe un punto de venta porque la empresa necesita generar economías de escala que le permite mejorar los resultados económicos; (b) Múltiples sitios: Velando por la comodidad del cliente, se inaugura más de un punto de venta y se establece rutas de transporte que faciliten el acceso.

Entre Copas y Tenedores utiliza una estrategia de distribución directa porque no hay intermediarios involucrados en el proceso de poner el producto a disposición del cliente; ya que el consumidor se acerca al restaurante o se le ofrece un servicio propio de delivery. Por otro lado, con respecto a la estrategia de plaza, la disponibilidad del servicio es en un único sitio porque solo se cuenta con un local, el mismo que está ubicado en Villa El Salvador.

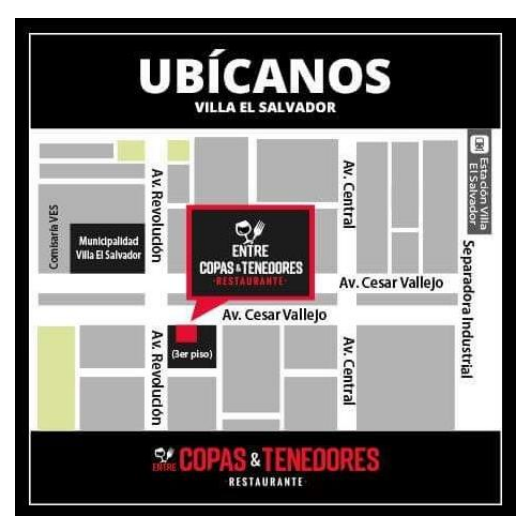

Ilustración 49. Volante con el plano de ubicación del local 


\subsubsection{Estrategia de promoción y publicidad}

La estrategia publicitaria que utiliza la compañía para lograr sus objetivos de publicidad consta de dos pilares: crear mensajes publicitarios que capten la atención y se comuniquen adecuadamente y seleccionar los medios de comunicación publicitarios (vehículos que se utilizan para entregar los mensajes publicitarios al público previsto). (Kotler, 2012).

El objetivo principal de la promoción y publicidad implementada por Entre Copas y Tenedores es dar a conocer, posicionar la marca, retener y fidelizar a los nuevos comensales. La publicidad se realiza a través de las siguientes herramientas:

\section{a) Entrega de Volantes}

Una semana antes de la apertura del local, se entregan volantes para dar a conocer la novedad del restaurante. Posteriormente, el personal en horas de baja concurrencia (4:00 pm - 06:00 pm), reparte volantes. En estos volantes se brinda información sobre la ubicación, los platos de comida y número de contacto para el servicio de delivery.

Esta distribución se realiza alrededor del Territorio III de Villa el Salvador y a las afueras de las empresas de las zonas económicas aledañas.

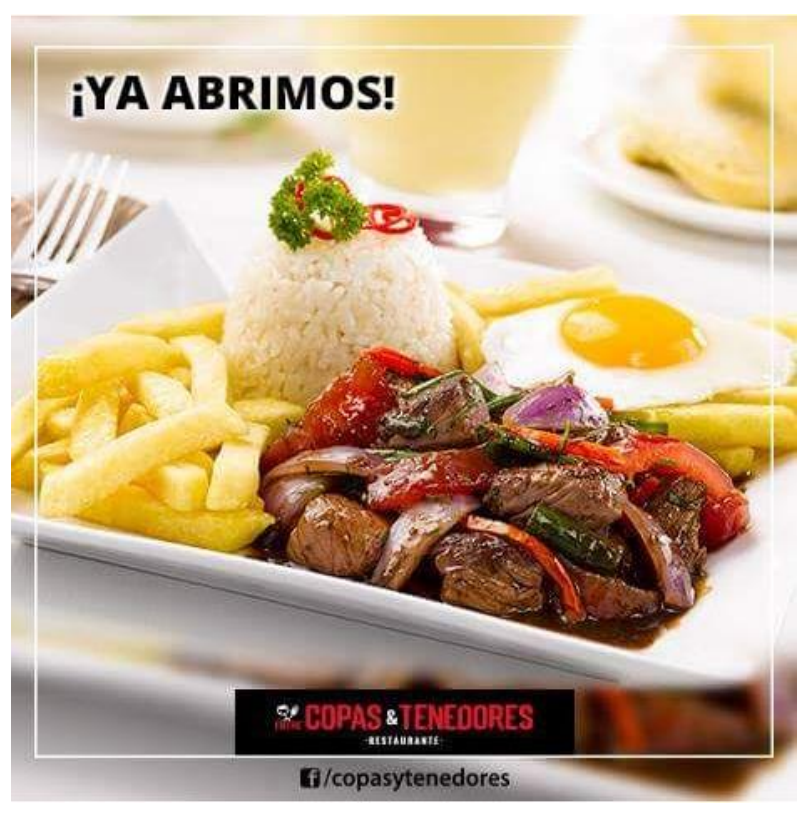

Ilustración 50. Volante sobre la apertura del local 


\section{b) Campaña en redes sociales}

Se realiza una campaña de publicidad en redes sociales que permita dar a conocer y llegar a más personas, esto permite tener reconocimiento y mayor presencia en el mercado.

En Facebook, el contenido es variado, allí se publican videos, se actualizan los platos, se dan a conocer las promociones, eventos, fechas especiales y recetas de platos fáciles de preparar.

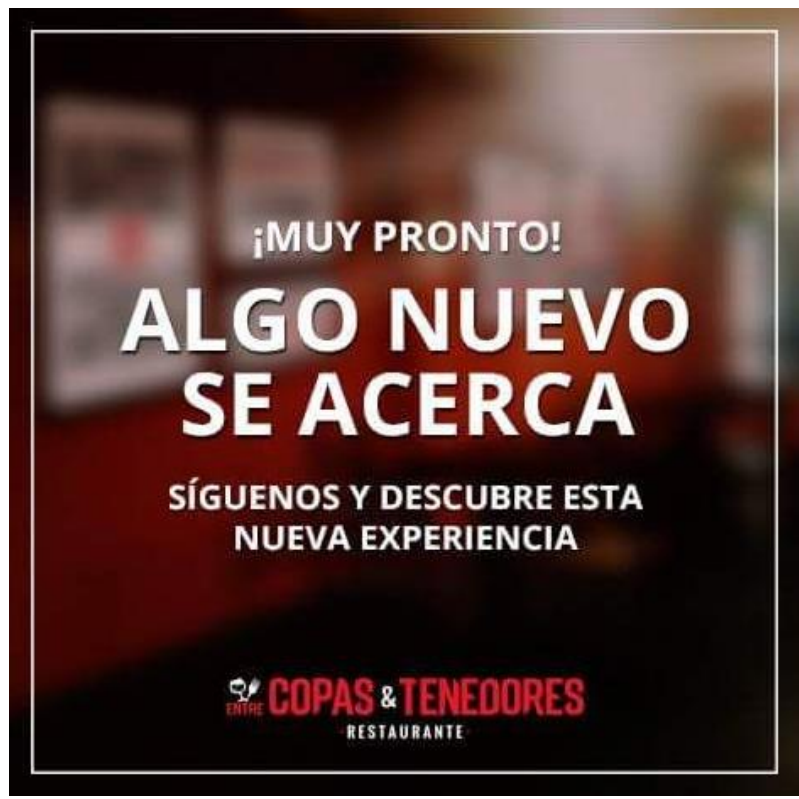

Ilustración 51. Publicidad previa a eventos especiales

- $\quad$ En WhatsApp, se envían los platos a la carta y menús del día. En la primera visita, se le pregunta al comensal si quisiera recibir la carta virtualmente. De ser afirmativa su respuesta, se le toma sus datos personales. 


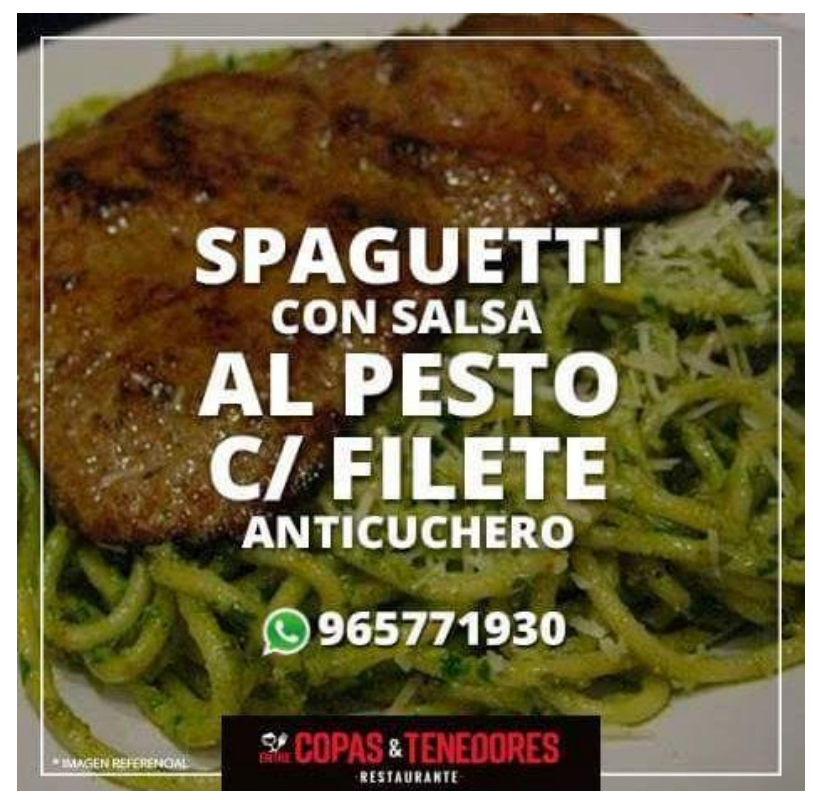

Ilustración 52. Platos del día

En cuanto a la promoción, $11 \%$ de los encuestados respondieron que a través de Facebook y el $78 \%$ en el mismo restaurante.

\section{c) Entrega de merchandising}

A los visitantes, se les entregan publicidad relacionada al local como llaveros, lapiceros y calendarios con información relativa al restaurante.

d) Servicio y comunicación del personal de contacto:

El personal del restaurante se encuentra en la capacidad de responder las dudas y consultar de los consumidores sobre la variedad de los platos y al mismo tiempo ofrecer otras alternativas adicionales.

Para la implementación de estas estrategias de promoción y publicidad, tomamos como referencia los resultados de las preguntas 25 y 26 aplicadas en la encuesta. Con respecto a cómo suelen enterarse sobre nuevos restaurantes, la mayoría de encuestados respondió que por recomendaciones y caminando, razón por la cual se cuida del servicio brindado y de la comunicación por parte del personal de contacto así como la entrega de volantes. Por otro lado, con respecto a la pregunta cómo suele enterarse del menú o carta de un restaurante, los encuestados respondieron que en el mismo restaurante $78 \%$ y solo el $11 \%$ 
a través de redes sociales. Esto brinda la oportunidad de digitalizar el negocio, implementando promociones mediante redes sociales debido a que la competencia aledaña a la zona del proyecto no ofrece este tipo de promociones, con excepción de las cadenas Norky's o Rocky's.

\subsubsection{Estrategia de personas}

Entre los puestos de trabajo más demandantes de los negocios de servicios se encuentran los de contacto directo con los clientes. Estos empleados son el vínculo entre el interior y el exterior de la organización, y se espera que sean rápidos y eficientes al desempeñar tareas operativas, así como corteses y útiles al tratar con los consumidores. Por lo tanto, detrás de la mayoría de las empresas de servicios exitosas de la actualidad hay un firme compromiso por administrar los recursos humanos de manera efectiva, lo cual incluye reclutamiento, selección, capacitación, motivación, y conservación de los empleados. Es importante lograr un compromiso emocional con la estrategia básica de la empresa, así como promover un servicio de excelencia, sensibilidad, espíritu de equipo, respeto mutuo, honestidad e integridad. Los gerentes deben enseñar y enfocarse en "el qué”, “el por qué” y el "cómo”, en vez de otros aspectos específicos del puesto. (Lovelock, 2015).

El reclutamiento y selección de personal es realizado por el administrador, quien evalúa habilidades cognitivas y blandas, valores y experiencia en el sector. Se pide que los colaboradores conozcan los ingredientes de los platos ofrecidos con el fin de estar en la capacidad de orientar al consumidor. Además, debe de estar con la indumentaria correctamente identificada para atender al cliente. Semanalmente, se realizan reuniones de retroalimentación y revisión de uniformes. 


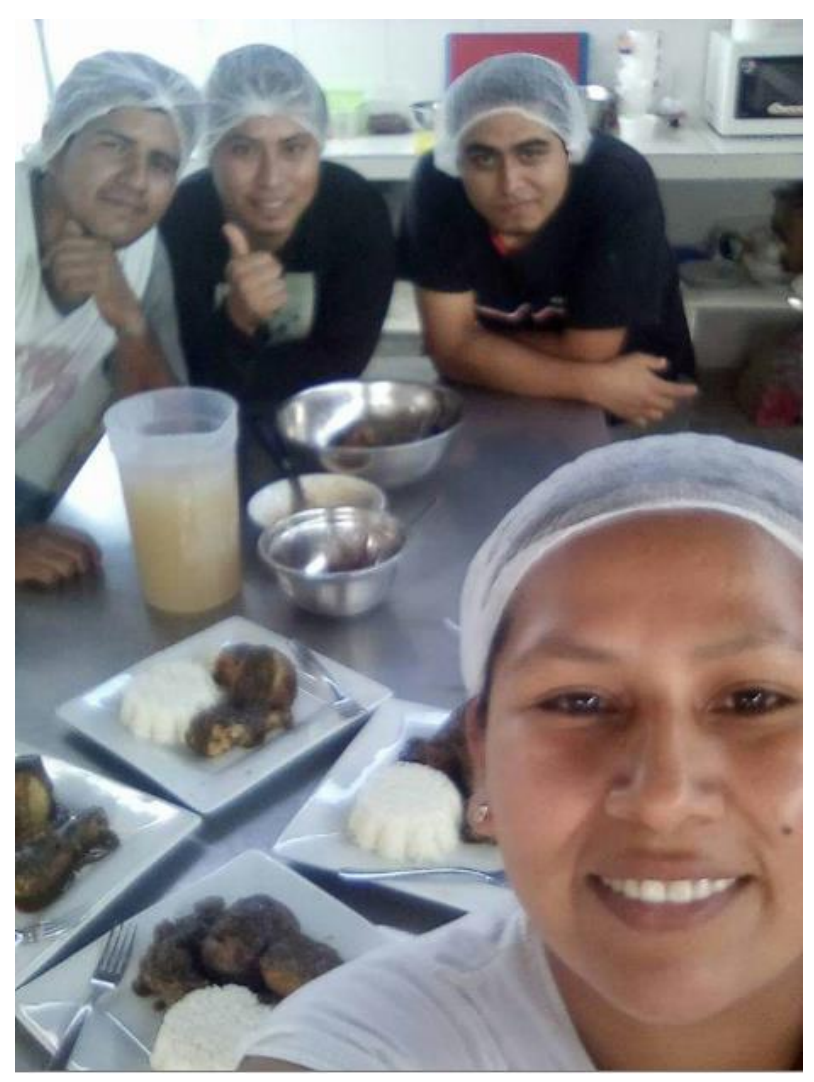

Ilustración 53. Personal correctamente uniformado

\subsubsection{Estrategia de procesos.}

El diseño de procesos de servicio no sólo tiene implicaciones para los clientes, sino también para el costo, la velocidad y la productividad con los que se logra el resultado deseado. Una reingeniería implica analizar y rediseñar los procesos para lograr un desempeño mejor y más rápido, identificando el tiempo que toma cada paso en el proceso, además del tiempo muerto entre cada paso. Sin embargo, eso no necesariamente implica que los procesos estuvieran mal diseñados desde un principio, sino que es probable que los cambios en la tecnología, las necesidades de los clientes, las características adicionales de servicio y las nuevas ofertas hayan provocado que los procesos existentes se vuelvan obsoletos. (Lovelock, 2015).

Según (Heizer, 2004), el objetivo de una estrategia de procesos es poder transformar los recursos en bienes y servicios y así satisfacer a los clientes, la estrategia de enfoque repetitivo, proceso de producción orientado al producto que usa módulos. Los módulos 
(que pueden ser carne, queso, salsa, tomates o cebollas) se combinan para conseguir un producto casi a medida. De esta forma, la empresa obtiene tanto la ventaja económica del modelo continuo, como de la personalización.

A continuación, se detallará los procesos que serán el reflejo de todas las actividades dirigidas al cliente, con el fin de crear una estructura sólida y que asegure un rol y desempeño adecuado para lograr todos los objetivos de la empresa. 


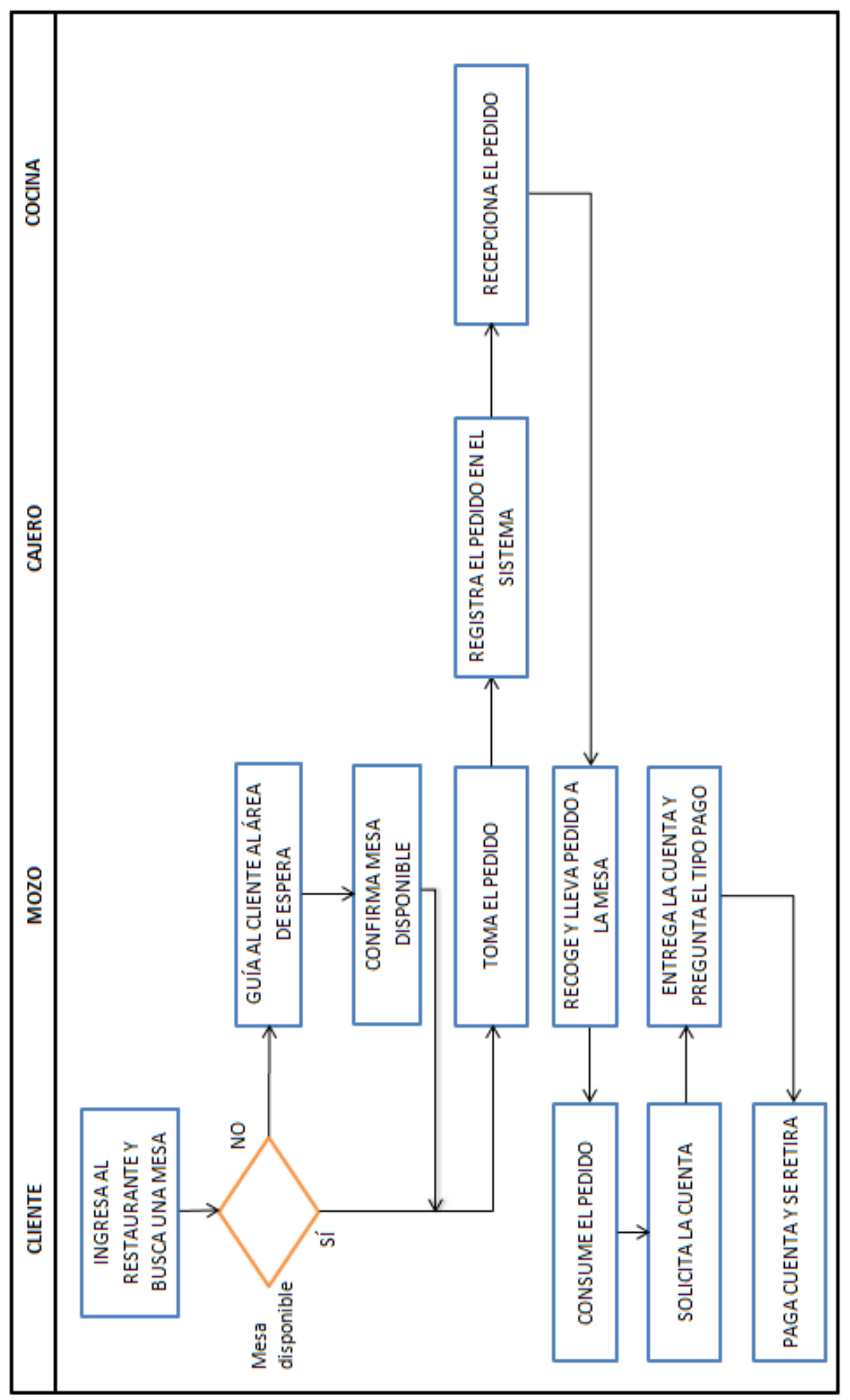

Ilustración 54. Atención al cliente en el punto de venta 


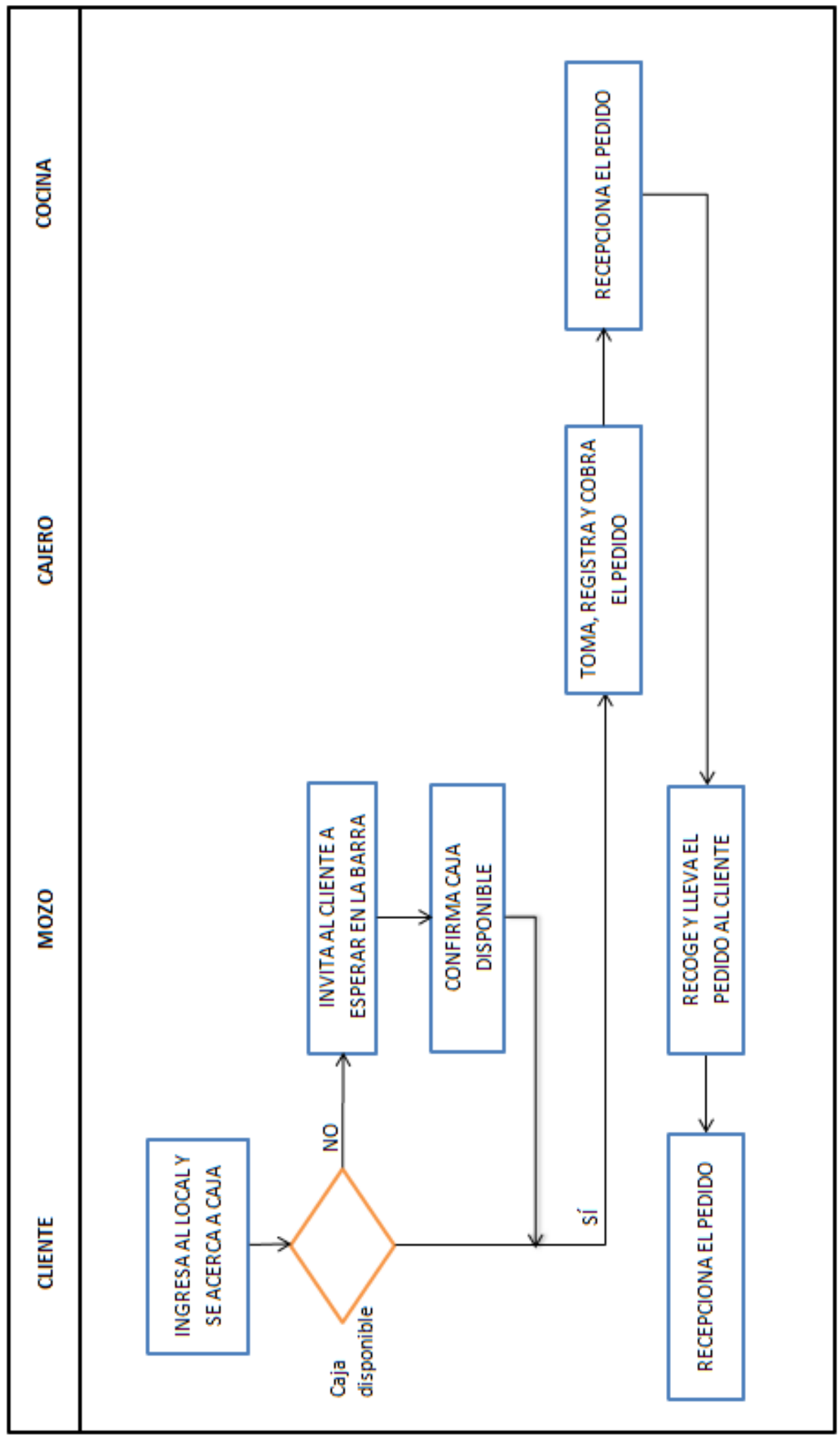

Ilustración 55. Atención al cliente "Comida para llevar" 


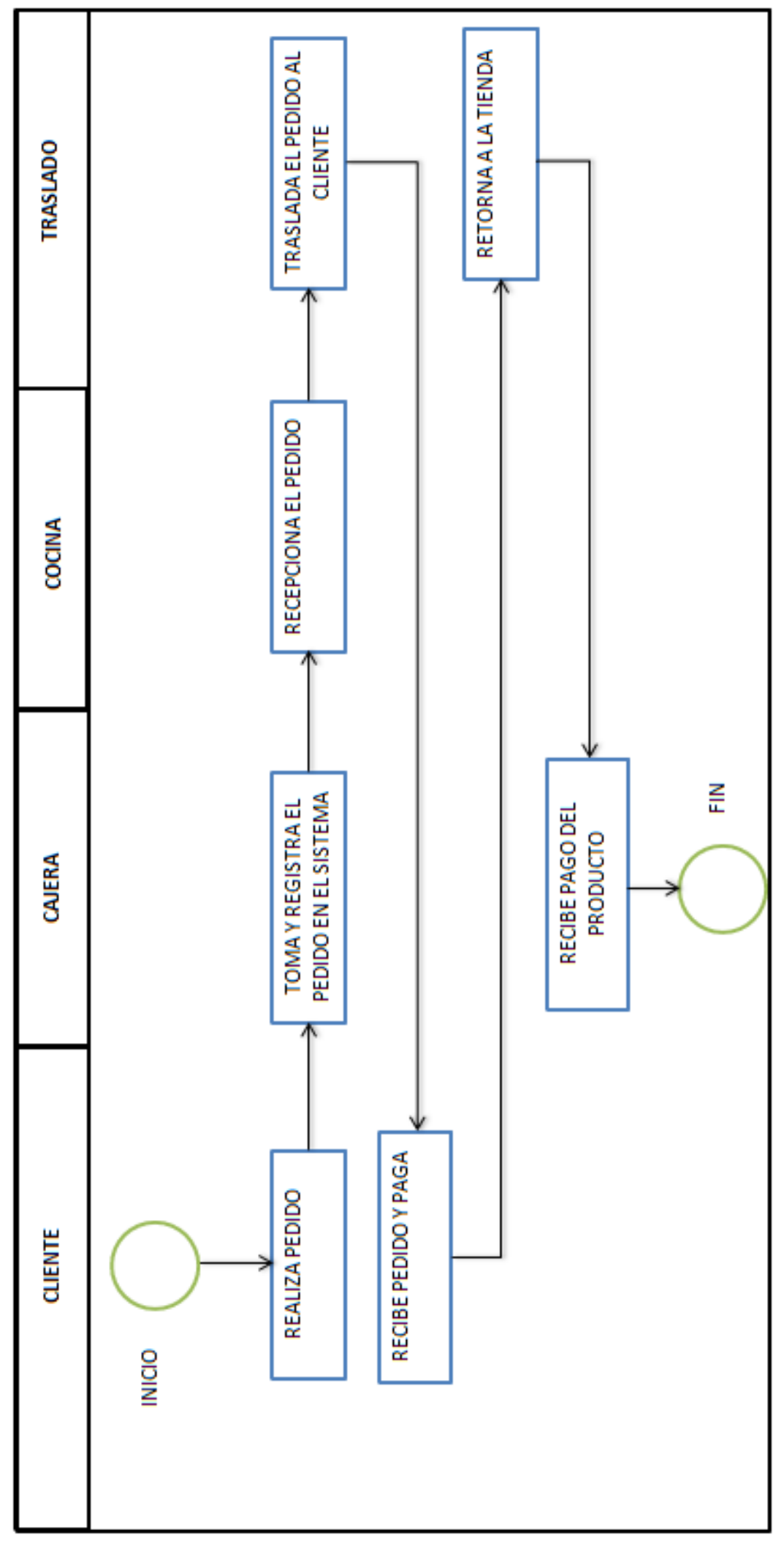

Ilustración 56. Atención al cliente delivery 


\subsubsection{Estrategia de presencia física}

El entorno físico de servicio que los clientes experimentan tiene un papel fundamental en la creación de la experiencia del servicio y en el incremento (o la disminución) de la satisfacción del consumidor, sobre todo en los servicios de alto contacto de procesamiento hacia las personas. La presencia física ayuda a moldear los sentimientos y las reacciones adecuadas en los clientes y los empleados. La apariencia y conducta del personal de servicio y de los clientes puede reforzar o deteriorar la impresión creada por un entorno de servicio, las empresas deberían de reclutar empleados para desempeñar papeles específicos, vestirlos con uniformes que sean consistentes con el panorama de servicio donde trabajan, y guían su discurso y sus movimientos. (Lovelock, 2015).

El local tiene las siguientes características:

- $\quad$ La infraestructura es consistente con el concepto del restaurante, está ambientado con frases de tipografía artística que hacen alusión a la popularidad y buena sazón de la comida peruana para que el cliente se distraiga y tome fotografías.

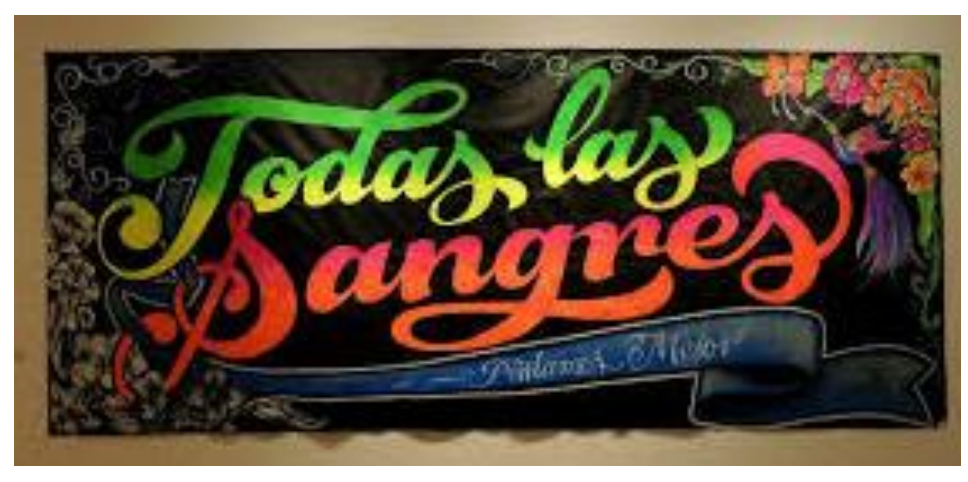

Ilustración 57 Cuadro del local 


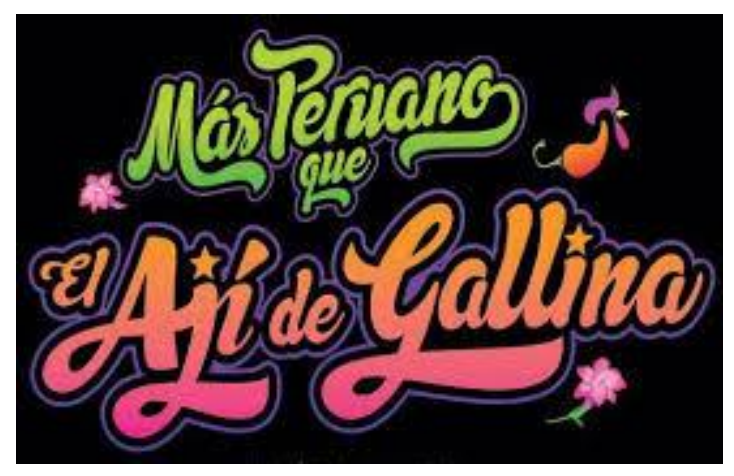

Ilustración 58 Propuesta de Individual

- $\quad$ El local cuenta con 14 mesas y 56 sillas de madera, las cuales son confortables para que los clientes disfruten de todo el tiempo que permanezcan en el local.

- $\quad$ Los servicios higiénicos para hombres y mujeres están a una distancia prudente y debidamente señalizados con el propósito de no incomodar y guiar a los comensales.

- $\quad$ El personal está correctamente vestido con el uniforme de la empresa y se realiza una revisión semanal de la presentación de los colaboradores.

- Se cuenta solo con tres estacionamientos.

- $\quad$ En la caja, se encuentra el personal dedicado a recibir el pago del consumo y las opiniones del cliente.

\subsection{Estrategia de Ventas}

Johnston y Marshall comentan que "la estrategia de ventas son todas las actividades, procesos y decisiones que abarcan la función de la administración de ventas de una empresa" (2009, p.10).

\subsubsection{Plan de Ventas}

El plan o programa de ventas debe tomar en consideración las variables externas que encara la empresa con relación a su entorno, esto con el objetivo de maximizar las ganancias del negocio (Johnston \& Marshall, 2009). 
Se utilizan las siguientes estrategias para asegurar las ventas:

- Ofrecer descuentos presentando cupones y anuncios entregados por el restaurante.

- Realizar concursos y sorteos a través de redes sociales.

\subsubsection{Política de servicios y garantías}

Lovelock y Wirtz sostienen que "la garantía de servicio es una de las formas en que las organizaciones muy enfocadas en el cliente institucionalizan un manejo profesional de las quejas y una recuperación efectiva del servicio" (2015, p.359).

Entre Copas y Tenedores posee políticas de higiene y salubridad que aseguran la calidad de los productos e insumos utilizados, estas son:

- Realizar limpieza de los artefactos para la preparación de los alimentos como son: la refrigeradora, cocina y licuadoras, acabada la jornada diaria.

- Realizar fumigaciones una vez al año para evitar cualquier tipo de plagas.

- Efectuar la limpieza de las mesas y sillas una vez el cliente se haya retirado.

- Limpieza y aseguramiento de provisiones de los servicios higiénicos una vez se haya finalizado la jornada diaria.

Las políticas relacionadas con la calidad del servicio son las siguientes:

- Brindarles información a los clientes de forma precisa y oportuna con respecto al contenido de los productos de menú y platos a la carta.

- Ofrecer a los clientes un servicio que supere sus expectativas en relación con lo pagado por ellos.

- Asegurar que se cumpla con el tiempo máximo de espera deseado por los clientes, 10 minutos para menú y 15 minutos para platos a la carta.

- Atender y responder las solicitudes e inquietudes de los clientes de forma rápida y eficaz. 


\section{Capítulo VI. Pronóstico de Ventas}

\subsection{Fundamentos y Supuestos}

Según Johnston y Marshall (2009) es "una estimación de las que pueden realizarse, en moneda corriente o unidades, para un periodo futuro especificado" (p.133).

En la encuesta, se evaluó qué alimentos suelen consumir los consumidores fuera de casa. Por lo tanto, los ingresos de Entre Copas y Tenedores se proyectó diversificando las ventas según los porcentajes de la siguiente tabla:

Tabla 29

Consumo de alimentos fuera de casa (en porcentaje)

\begin{tabular}{ccc}
\hline Ítems & $\%$ & Nuevo \% \\
\hline Almuerzos & $63 \%$ & $79 \%$ \\
Cenan & $17 \%$ & $21 \%$ \\
Desayunan & $13 \%$ & \\
Lonche & $7 \%$ & \\
\hline Total & $\mathbf{1 0 0 \%}$ & $\mathbf{8 0 \%}$
\end{tabular}

Nota Fuente. Elaboración propia

\subsubsection{Pronósticos de ventas de almuerzos}

Para proyectar el número de almuerzos a vender, el mercado objetivo calculado en el capítulo IV fue multiplicado por el porcentaje escalado de personas que manifestaron consumir el almuerzo fuera de casa.

Tabla 30

Mercado Objetivo de almuerzos (en número de personas)

\begin{tabular}{lccccc}
\hline & 2019 & 2020 & 2021 & 2022 & 2023 \\
\hline Total & 313 & 319 & 326 & 332 & 339
\end{tabular}

Nota Fuente. Elaboración propia 
Asimismo, se consultó la frecuencia de la necesidad de almorzar fuera de casa.

Debido a que el restaurante atiende de lunes a sábado, excluyendo domingos y feriados, la frecuencia de demanda proyectada de un cliente promedio es 95 veces al año.

\section{Tabla 31}

Frecuencia promedio de visitas a almorzar anuales

\begin{tabular}{cccc}
\hline $\begin{array}{c}\text { Veces a la } \\
\text { Semana }\end{array}$ & $\%$ & Nuevo \% & Veces al año \\
\hline 1 & $48 \%$ & $50 \%$ & 25.00 \\
2 & $24 \%$ & $25 \%$ & 25.00 \\
3 & $16 \%$ & $17 \%$ & 25.00 \\
4 & $3 \%$ & $3 \%$ & 6.25 \\
5 & $3 \%$ & $3 \%$ & 7.81 \\
6 & $2 \%$ & $2 \%$ & 6.25 \\
7 & $4 \%$ & & \\
\hline Total & $\mathbf{1 0 0 \%}$ & $\mathbf{1 0 0 \%}$ & $\mathbf{9 5 . 3 1}$ \\
\hline
\end{tabular}

Nota Fuente. Encuesta aplicada

Además, se preguntó con cuántas personas almuerza el encuestado.

Tabla 32

Ventas promedio por visita en almuerzos (en número)

\begin{tabular}{cccc}
\hline & Promedio & $\%$ & Factor \\
\hline Solo 1 & 1 & $78 \%$ & 0.78 \\
De 2 a 3 & 2.5 & $16 \%$ & 0.40 \\
de 4 a 5 & 4.5 & $6 \%$ & 0.27 \\
\hline Total & & $\mathbf{1 0 0 \%}$ & $\mathbf{1 . 4 5}$
\end{tabular}

Nota Fuente. Encuesta aplicada 
Sobre las preferencias por tipo de comida pedida y modalidad de entrega, se obtuvieron los siguientes resultados:

Tabla 33

Tipo de plato solicitado (en porcentaje)

\begin{tabular}{lr}
\hline Tipo de Plato & \\
\hline Menú & $82.00 \%$ \\
Extras & $18.00 \%$ \\
\hline Total & $\mathbf{1 0 0 . 0 0 \%}$
\end{tabular}

Nota Fuente. Encuesta aplicada

Tabla 34

Modalidad de entrega (en porcentaje)

\begin{tabular}{lr}
\hline Modalidad de entrega & \\
\hline Mesa & $65.00 \%$ \\
Delivery & $35.00 \%$ \\
\hline Total & $\mathbf{1 0 0 . 0 0 \%}$ \\
\hline
\end{tabular}

Nota Fuente. Encuesta aplicada

En las siguientes tablas, se muestran el número de almuerzos a venderse por tipo y precios.

Tabla 35

Número de almuerzos a comercializar anuales (en unidades y por tipo)

\begin{tabular}{cccccc}
\hline & 2019 & 2020 & 2021 & 2022 & 2023 \\
\hline Menú & 23,064 & 23,531 & 24,001 & 24,473 & 24,947 \\
Extras & 5,063 & 5,165 & 5,268 & 5,372 & 5,476 \\
Delivery Menú & 15,145 & 15,452 & 15,760 & 16,070 & 16,382 \\
\hline Total & $\mathbf{4 3 , 2 7 1}$ & $\mathbf{4 4 , 1 4 9}$ & $\mathbf{4 5 , 0 3 0}$ & $\mathbf{4 5 , 9 1 5}$ & $\mathbf{4 6 , 8 0 5}$
\end{tabular}

Nota Fuente. Elaboración propia 
Tabla 36

Precio (en soles)

\begin{tabular}{cc}
\hline Precio & S/ \\
\hline Menú & 11 \\
Extra & 18 \\
Delivery & 11
\end{tabular}

Nota Fuente. Encuesta aplicada

Además, se consultó sobre la preferencia por platos extras:

Tabla 37

Preferencias de los consumidores (en \%)

\begin{tabular}{ccc}
\hline Plato Extra & $\%$ & Nuevo \% \\
\hline Lomo Saltado & $17 \%$ & $26 \%$ \\
Bisteck a lo Pobre & $12 \%$ & $18 \%$ \\
Churrasco a lo Pobre & $15 \%$ & $23 \%$ \\
Fetuccini con bisteck & $11 \%$ & $17 \%$ \\
Tallarín saltado & $10 \%$ & $15 \%$ \\
Otros & $35 \%$ & \\
\hline Total & $\mathbf{1 0 0 \%}$ & $\mathbf{1 0 0 \%}$ \\
\hline
\end{tabular}

Nota Fuente. Encuesta aplicada

Con los resultados de la tabla anterior y la de número de almuerzos (en unidades por tipo), se pronosticó los números de platos extras vendidos por tipo. 
Tabla 38

Número de platos extras en almuerzo (en unidades)

\begin{tabular}{cccccc}
\hline & 2019 & 2020 & 2021 & 2022 & 2023 \\
\hline Lomo Saltado & 1,324 & 1,351 & 1,378 & 1,405 & 1,432 \\
Bisteck a lo Pobre & 935 & 954 & 973 & 992 & 1,011 \\
Churrasco a lo Pobre & 1,168 & 1,192 & 1,216 & 1,240 & 1,264 \\
Fetuccini con bisteck & 857 & 874 & 892 & 909 & 927 \\
Tallarín saltado & 779 & 795 & 811 & 826 & 842 \\
\hline Extras & $\mathbf{5 , 0 6 3}$ & $\mathbf{5 , 1 6 5}$ & $\mathbf{5 , 2 6 8}$ & $\mathbf{5 , 3 7 2}$ & $\mathbf{5 , 4 7 6}$
\end{tabular}

Nota Fuente. Elaboración propia

Los ingresos generados por los almuerzos en sus diferentes modalidades se muestran a continuación:

Tabla 39

Ingresos por almuerzos con IGV (en soles)

\begin{tabular}{cccccc}
\hline & 2019 & 2020 & 2021 & 2022 & 2023 \\
\hline Menú & 253,700 & 258,844 & 264,010 & 269,200 & 274,415 \\
Extras & 91,130 & 92,977 & 94,833 & 96,697 & 98,570 \\
Delivery & 166,595 & 169,972 & 173,365 & 176,773 & 180,197 \\
\hline Total & $\mathbf{5 1 1 , 4 2 5}$ & $\mathbf{5 2 1 , 7 9 3}$ & $\mathbf{5 3 2 , 2 0 8}$ & $\mathbf{5 4 2 , 6 7 1}$ & $\mathbf{5 5 3 , 1 8 3}$
\end{tabular}

Nota Fuente. Elaboración propia

Tabla 40

Ingresos por almuerzos sin IGV (en soles)

\begin{tabular}{cccccc}
\hline & 2019 & 2020 & 2021 & 2022 & 2023 \\
\hline Menú & 215,000 & 219,359 & 223,737 & 228,136 & 232,555 \\
Extras & 77,228 & 78,794 & 80,367 & 81,947 & 83,534 \\
Delivery & 141,182 & 144,044 & 146,919 & 149,808 & 152,710 \\
\hline Total & $\mathbf{4 3 3 , 4 1 1}$ & $\mathbf{4 4 2 , 1 9 8}$ & $\mathbf{4 5 1 , 0 2 4}$ & $\mathbf{4 5 9 , 8 9 0}$ & $\mathbf{4 6 8 , 7 9 9}$
\end{tabular}

Nota Fuente. Elaboración propia 


\subsubsection{Pronósticos de ventas por cenas}

Gracias a la encuesta, se sabe que el $17 \%$ de los entrevistados cena fuera de casa. De esta manera, el mercado de objetivo de cenas es el siguiente:

\begin{tabular}{|c|c|c|c|c|c|}
\hline \multicolumn{6}{|c|}{ Mercado Objetivo de cenas (en número de personas) } \\
\hline & 2019 & 2020 & 2021 & 2022 & 2023 \\
\hline Total & 84 & 86 & 88 & 90 & 91 \\
\hline
\end{tabular}

Nota Fuente. Elaboración propia

Asimismo, se consultó la frecuencia de la necesidad de cenar fuera de casa. Debido a que el restaurante atiende de lunes a sábado, la frecuencia de demanda proyectada de un cliente promedio es 97 veces al año.

Tabla 42

Frecuencia de visitas a cenar anualmente

\begin{tabular}{cccc}
\hline Veces x semana & $\%$ & Nuevo \% & Veces al año \\
\hline 1 & $46 \%$ & $47 \%$ & 23.47 \\
2 & $28 \%$ & $29 \%$ & 28.57 \\
3 & $13 \%$ & $13 \%$ & 19.90 \\
4 & $7 \%$ & $7 \%$ & 14.29 \\
5 & $3 \%$ & $3 \%$ & 7.65 \\
6 & $1 \%$ & $1 \%$ & 3.06 \\
7 & $1 \%$ & & \\
\hline Total & $\mathbf{9 9 \%}$ & $\mathbf{1 0 0 \%}$ & $\mathbf{9 6 . 9 4}$ \\
\hline
\end{tabular}

Nota Fuente. Encuesta aplicada 
También, se preguntó con cuántas personas cena el encuestado.

Tabla 43

Ventas promedio por visita en cenas

\begin{tabular}{cccc}
\hline & Promedio & $\%$ & Factor \\
\hline Solo 1 & 1 & $75 \%$ & 0.75 \\
De 2 a 3 & 2.5 & $22 \%$ & 0.55 \\
de 4 a 5 & 4.5 & $3 \%$ & 0.14 \\
\hline Total & & $\mathbf{1 0 0 \%}$ & $\mathbf{1 . 4 4}$
\end{tabular}

Nota Fuente. Encuesta aplicada

A continuación, se muestra el número de platos extras por tipo que se venden por el servicio de cena durante los cinco años de vida útil del proyecto.

Tabla 44

Número de cenas anuales (en unidades por tipo)

\begin{tabular}{cccccc}
\hline & 2019 & 2020 & 2021 & 2022 & 2023 \\
\hline Lomo Saltado & 3,074 & 3,136 & 3,199 & 3,262 & 3,325 \\
Bisteck a lo Pobre & 2,170 & 2,214 & 2,258 & 2,302 & 2,347 \\
Churrasco a lo Pobre & 2,712 & 2,767 & 2,822 & 2,878 & 2,934 \\
Fetuccini con bisteck & 1,989 & 2,029 & 2,070 & 2,110 & 2,151 \\
Tallarín saltado & 1,808 & 1,845 & 1,882 & 1,919 & 1,956 \\
\hline Total & $\mathbf{1 1 , 7 5 3}$ & $\mathbf{1 1 , 9 9 1}$ & $\mathbf{1 2 , 2 3 0}$ & $\mathbf{1 2 , 4 7 1}$ & $\mathbf{1 2 , 7 1 2}$
\end{tabular}

Nota Fuente. Encuesta aplicada 
En las siguientes tablas, se muestran los ingresos de cenas, considerando un precio promedio por plato extra de S/ 18.

\section{Tabla 45}

Ingresos por cenas y por tipo de cena con $I G V$ (en soles)

\begin{tabular}{cccccc}
\hline & 2019 & 2020 & 2021 & 2022 & 2023 \\
\hline Lomo Saltado & 55,329 & 56,450 & 57,577 & 58,709 & 59,846 \\
Bisteck a lo Pobre & 39,055 & 39,847 & 40,643 & 41,442 & 42,244 \\
Churrasco a lo Pobre & 48,819 & 49,809 & 50,803 & 51,802 & 52,805 \\
Fetuccini con bisteck & 35,801 & 36,527 & 37,256 & 37,988 & 38,724 \\
Tallarín saltado & 32,546 & 33,206 & 33,869 & 34,535 & 35,204 \\
\hline Total & $\mathbf{2 1 1 , 5 5 0}$ & $\mathbf{2 1 5 , 8 3 9}$ & $\mathbf{2 2 0 , 1 4 7}$ & $\mathbf{2 2 4 , 4 7 5}$ & $\mathbf{2 2 8 , 8 2 3}$ \\
\hline
\end{tabular}

Nota Fuente. Encuesta aplicada

Tabla 46

Ingresos por cenas y por tipo de cena sin IGV (en soles)

\begin{tabular}{cccccc}
\hline & 2019 & 2020 & 2021 & 2022 & 2023 \\
\hline Lomo Saltado & 46,889 & 47,839 & 48,794 & 49,753 & 50,717 \\
Bisteck a lo Pobre & 33,098 & 33,769 & 34,443 & 35,120 & 35,800 \\
Churrasco a lo Pobre & 41,372 & 42,211 & 43,054 & 43,900 & 44,750 \\
Fetuccini con bisteck & 30,340 & 30,955 & 31,573 & 32,193 & 32,817 \\
Tallarín saltado & 27,582 & 28,141 & 28,702 & 29,267 & 29,834 \\
\hline Total & $\mathbf{1 7 9 , 2 8 0}$ & $\mathbf{1 8 2 , 9 1 4}$ & $\mathbf{1 8 6 , 5 6 5}$ & $\mathbf{1 9 0 , 2 3 3}$ & $\mathbf{1 9 3 , 9 1 8}$
\end{tabular}

Nota Fuente. Encuesta aplicada

\subsubsection{Ingreso por venta de bebidas}

Todos los platos se venden con un refresco sin costo adicional. De cualquier forma, se le preguntó a los encuestados, con qué bebida le gustaría consumir la comida comprada, se obtuvieron los siguientes resultados. 
Tabla 47

Preferencia de bebidas

\begin{tabular}{ccc}
\hline Bebidas & \% & Nuevo \% \\
\hline Refresco & $73.00 \%$ & $87.95 \%$ \\
Gaseosa & $7.00 \%$ & $8.43 \%$ \\
Cerveza chica & $3.00 \%$ & $3.61 \%$ \\
Pisco Sour & $12.00 \%$ & \\
Chilcano & $5.00 \%$ & \\
\hline Total & $\mathbf{1 0 0 . 0 0 \%}$ & $\mathbf{1 0 0 . 0 0 \%}$
\end{tabular}

Nota Fuente. Encuesta aplicada

En el restaurante, únicamente se vende como bebida extra gaseosas de $500 \mathrm{ml}$ a $\mathrm{S} / 3$ y cervezas de $335 \mathrm{ml}$ a $\mathrm{S} / 5$. Los refrescos no tienen ningún costo adicional.

Estos porcentajes se le multiplican al número de platos proyectados. Luego, se multiplica por el precio propuesto de cada bebida y de esta manera, se conocen los ingresos por la venta de bebidas.

Tabla 48

Ingresos consolidados de bebidas con IGV(en soles)

\begin{tabular}{cccccc}
\hline Ítems & 2019 & 2020 & 2021 & 2022 & 2023 \\
\hline Gaseosa & 13,922 & 14,204 & 14,488 & 14,772 & 15,058 \\
Cerveza & 9,944 & 10,146 & 10,348 & 10,552 & 10,756 \\
\hline Total & $\mathbf{2 3 , 8 6 6}$ & $\mathbf{2 4 , 3 5 0}$ & $\mathbf{2 4 , 8 3 6}$ & $\mathbf{2 5 , 3 2 4}$ & $\mathbf{2 5 , 8 1 5}$
\end{tabular}

Nota Fuente. Encuesta aplicada

Tabla 49

Ingresos consolidados de bebidas sin IGV(en soles)

\begin{tabular}{cccccc}
\hline Ítems & 2019 & 2020 & 2021 & 2022 & 2023 \\
\hline Gaseosa & $\mathbf{1 1 , 7 9 8}$ & $\mathbf{1 2 , 0 3 7}$ & $\mathbf{1 2 , 2 7 8}$ & $\mathbf{1 2 , 5 1 9}$ & $\mathbf{1 2 , 7 6 1}$ \\
Cerveza & $\mathbf{8 , 4 2 7}$ & $\mathbf{8 , 5 9 8}$ & $\mathbf{8 , 7 7 0}$ & $\mathbf{8 , 9 4 2}$ & $\mathbf{9 , 1 1 5}$ \\
\hline Total & $\mathbf{2 0 , 2 2 5}$ & $\mathbf{2 0 , 6 3 5}$ & $\mathbf{2 1 , 0 4 7}$ & $\mathbf{2 1 , 4 6 1}$ & $\mathbf{2 1 , 8 7 7}$
\end{tabular}

Nota Fuente. Encuesta aplicada 
Finalmente, se muestran los ingresos consolidados del proyecto.

Tabla 50

Ingresos consolidados por tipo con IGV (en soles)

\begin{tabular}{cccccc}
\hline Ítems & 2019 & 2020 & 2021 & 2022 & 2023 \\
\hline Menú & 253,700 & 258,844 & 264,010 & 269,200 & 274,415 \\
Delivery Menú & 166,595 & 169,972 & 173,365 & 176,773 & 180,197 \\
Almuerzo Extras & 91,130 & 92,977 & 94,833 & 96,697 & 98,570 \\
Cena Extras & 211,550 & 215,839 & 220,147 & 224,475 & 228,823 \\
Bebidas & 23,866 & 24,350 & 24,836 & 25,324 & 25,815 \\
\hline Total & $\mathbf{7 4 8 , 8 6 0}$ & $\mathbf{7 6 4 , 0 0 2}$ & $\mathbf{7 7 9 , 2 1 2}$ & $\mathbf{7 9 4 , 4 9 2}$ & $\mathbf{8 0 9 , 8 4 3}$
\end{tabular}

Nota Fuente. Encuesta aplicada

Tabla 51

Ingresos consolidados por tipo sin IGV (en soles)

\begin{tabular}{cccccc}
\hline Ítems & 2019 & 2020 & 2021 & 2022 & 2023 \\
\hline Menú & 215,000 & 219,359 & 223,737 & 228,136 & 232,555 \\
Delivery Menú & 141,182 & 144,044 & 146,919 & 149,808 & 152,710 \\
Almuerzo Extras & 77,228 & 78,794 & 80,367 & 81,947 & 83,534 \\
Cena Extras & 179,280 & 182,914 & 186,565 & 190,233 & 193,918 \\
Bebidas & 20,225 & 20,635 & 21,047 & 21,461 & 21,877 \\
\hline Total & $\mathbf{6 3 4 , 6 2 7}$ & $\mathbf{6 4 7 , 4 5 9}$ & $\mathbf{6 6 0 , 3 4 9}$ & $\mathbf{6 7 3 , 2 9 8}$ & $\mathbf{6 8 6 , 3 0 8}$
\end{tabular}

\subsection{Justificación}

Las ventas se proyectan en base a las respuestas de la encuesta realizada y las proyecciones de mercado objetivo del apartado 4.2.4. Mercado Objetivo.

\subsection{Análisis De Los Riesgos Y Aspectos Críticos Que Impactan En El Pronóstico}

Las características del bien o servicio, el grupo de clientes, la zona geográfica y el periodo pueden afectar el pronóstico de ventas. (Johnston \& Marshall, 2009).

Algunos factores que pueden afectar el pronóstico son: 
- El contexto económico actual: En caso haya una desaceleración económica, puede generar que la población contraiga sus ingresos y la demanda se vea afectada.

- Aparición de nuevos competidores: En caso de que se abran otros restaurantes en el distrito, puede traer consigo una disminución en la proyección de ventas al quitar participación de mercado.

- Promociones: Las promociones pueden traer consigo un efecto positivo al ofrecer al consumidor una alternativa adicional, generando así el aumento en el pronóstico de ventas.

- Pandemia - riesgos biológicos: De existir algún riesgo biológico, el Estado podría decretar cuarentena a nivel nacional, permitiendo que los restaurantes atiendan con capacidad limitada o nula. 


\section{Capítulo VII. Ingeniería del Proyecto}

\subsection{Estudio de ingeniería}

El estudio de ingeniería del proyecto debe llegar a determinar la función de producción óptima para la utilización eficiente y eficaz de los recursos disponibles para la producción del bien o servicio deseado. Para ello, deberán analizarse las distintas alternativas y condiciones en que se pueden combinar los factores productivos, identificando, a través de la cuantificación y proyección en el tiempo de los montos de inversiones de capital, los costos y los ingresos de operación asociados con cada una de las alternativas de producción. (Sapag, 2008).

Este estudio tiene como objetivo poder determinar la adquisición de los recursos, describir los procesos para soportar las operaciones y poder determinar la distribución óptima para cumplir con los estándares de calidad deseado.

\subsubsection{Modelamiento y selección de procesos productivos}

El proceso de producción es el procedimiento técnico que se utiliza en el proyecto para obtener los bienes y servicios a partir de insumos, y se identifica como la transformación de una serie de materias primas para convertirla en artículos mediante una determinada función de manufactura. Cualquier proceso productivo, por complicado que sea, puede ser representado por medio de un diagrama para su análisis. Por Ejemplo; Diagrama de bloques, Diagrama de flujo del proceso, Cursograma analítico, Diagrama de hilos y diagrama de recorrido, Iconograma y el Diagrama sinóptico. (Baca, 2010).

Se muestra el proceso de producción de la línea del producto a ofrecer, el cual transforma una serie de insumos en un producto final a través de una combinación de mano de obra, herramientas, métodos y procedimientos de operación, además del proceso de atención del restaurante. 


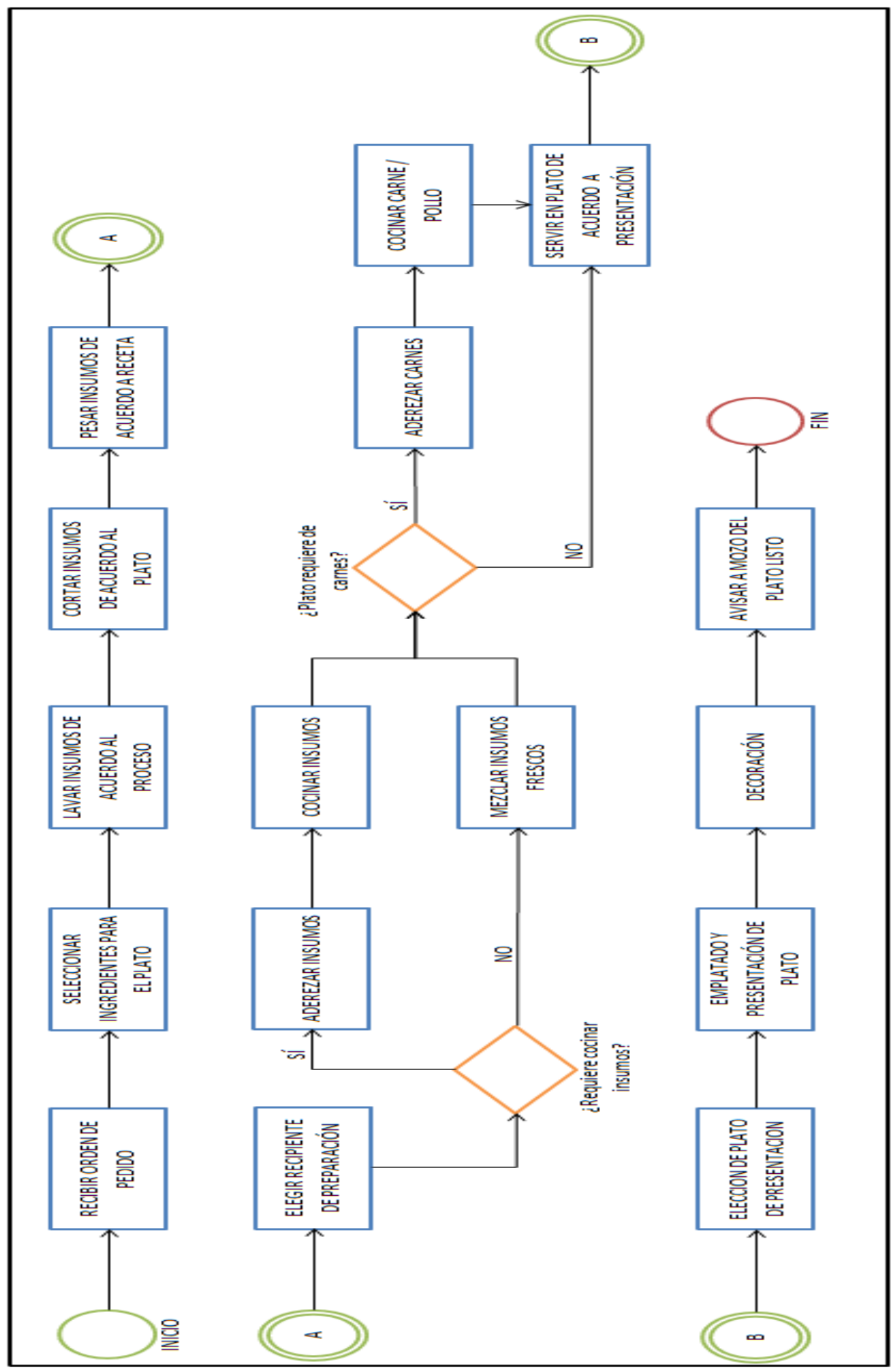

Ilustración 59. Flujo de la preparación del Menú y/o Platos a la Carta 


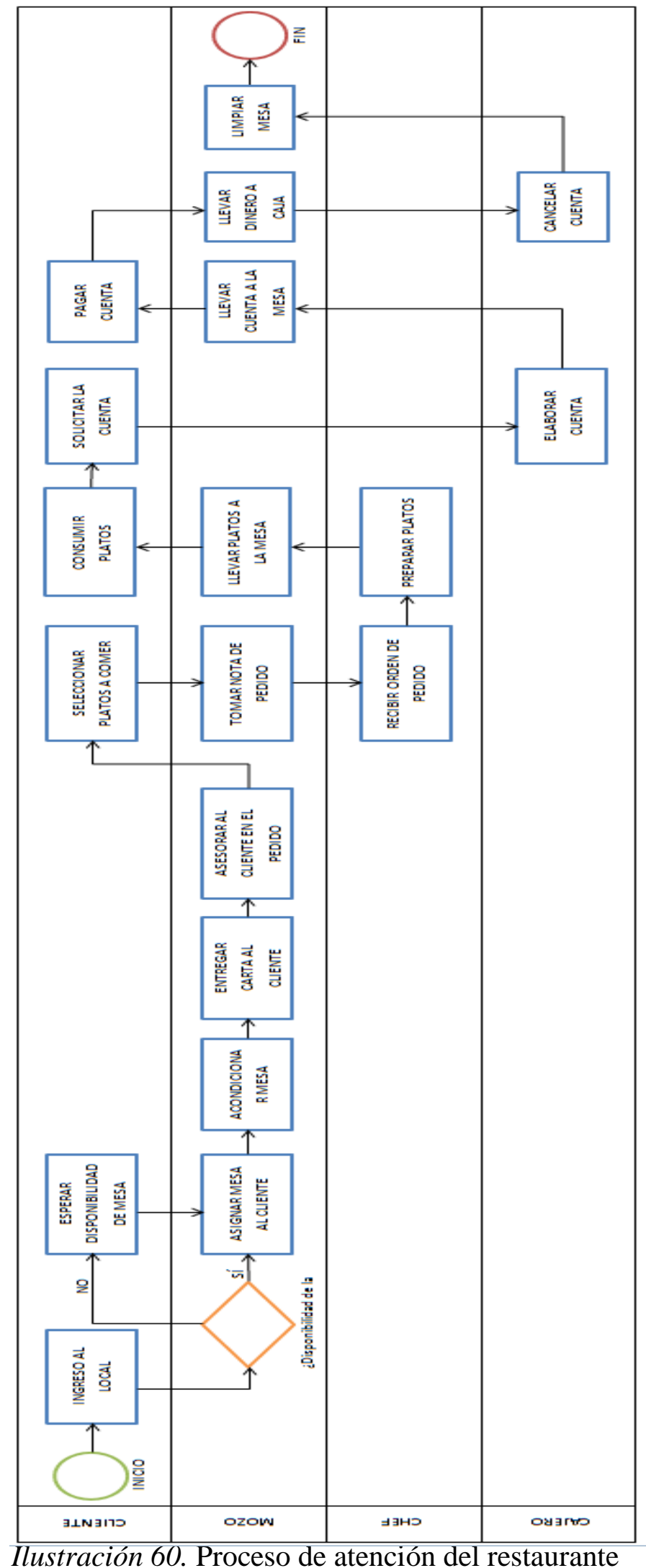

\subsubsection{Selección del equipamiento}

En el momento de elegir la tecnología de fabricación, se entenderá por tal al conjunto de conocimientos técnicos, equipos y procesos que se emplean para desarrollar una 
determinada función, se debe de tener en cuenta los resultados de la investigación de mercado, pues esto dictará las normas de calidad y la cantidad que se requieren, factores que influyen en la decisión. Otro aspecto importante que se debe considerar es la flexibilidad de los procesos y de los equipos para procesar varias clases de insumos, lo cual ayudará a evitar los tiempos muertos y a diversificar fácilmente la producción en un momento dado. Otro factor primordial, analizado a detalle más adelante, es la adquisición de equipo y maquinaria, factor en el que se consideran muchos aspectos para obtener la mejor opción. (Baca, 2010).

A continuación, se detalla el equipamiento que tendrá el establecimiento para que pueda tener un adecuado funcionamiento del proceso productivo:

\section{Tabla 52}

Dotación de equipamiento y mobiliario

\begin{tabular}{|c|c|c|c|c|c|c|c|}
\hline Producto & Unidad & Marca & Modelo & $\begin{array}{l}\text { Capacidad/Dime } \\
\text { nsión / Potencia }\end{array}$ & Cantidad & $\begin{array}{c}\text { Precio } \\
\text { unitario } \\
\text { (soles) }\end{array}$ & Proveedor \\
\hline Congeladora & Pza & Indurama & CI-309BL & $310 \mathrm{~L}$ & 2 & 1,399 & HIRAOKA \\
\hline Refrigeradora & Pza & Miray & $\begin{array}{c}\text { ERT32G2 } \\
\text { KSQS }\end{array}$ & $420 \mathrm{~L}$ & 1 & 1,199 & HIRAOKA \\
\hline $\begin{array}{c}\text { Cocina } \\
\text { Industrial }\end{array}$ & Pza & Fadicc & - & 6 Hornillas & 1 & 600 & MAKRO \\
\hline $\begin{array}{c}\text { Horno } \\
\text { Microonda }\end{array}$ & Pza & Samsung & $\begin{array}{c}\text { AMW83K } \\
\text { /XPE }\end{array}$ & $23 \mathrm{~L}$ & 2 & 219 & HIRAOKA \\
\hline Licuadora & Pza & Philips & HR3652 & $2 \mathrm{~L}$ & 2 & 499 & HIRAOKA \\
\hline Mesa trabajo & Pza & Aro & - & $70 \times 160 \mathrm{~cm}$ & 1 & 1,000 & MAKRO \\
\hline $\begin{array}{c}\text { Escurridora de } \\
\text { Platos }\end{array}$ & Pza & Aro & - & $1 \mathrm{~m}$ & 1 & 220 & MAKRO \\
\hline $\begin{array}{l}\text { Campana } \\
\text { Extractora }\end{array}$ & Pza & Sole & $\begin{array}{c}\text { TURE73C } \\
\text { O }\end{array}$ & - & 1 & 499 & HIRAOKA \\
\hline
\end{tabular}




\begin{tabular}{|c|c|c|c|c|c|c|c|}
\hline $\begin{array}{l}\text { Barra para } \\
\text { restaurante }\end{array}$ & Pza & Aro & & $2 \mathrm{~m}$ & 1 & 1,000 & MAKRO \\
\hline $\begin{array}{l}\text { Estantes para } \\
\text { Almacén }\end{array}$ & Pza & Aro & - & 4 niveles & 2 & 300 & MAKRO \\
\hline $\begin{array}{l}\text { Exhibidoras } \\
\text { de Bebidas }\end{array}$ & Pza & Aro & BC Cooler & $250 \mathrm{~L}$ & 1 & 1,549 & MAKRO \\
\hline Televisor & Pza & Samsung & $\begin{array}{c}\text { UN40J520 } \\
0\end{array}$ & $40 "$ & 2 & 1,399 & HIRAOKA \\
\hline Equipo sonido & Pza & LG & RMS & 480Watts & 1 & 449 & HIRAOKA \\
\hline $\begin{array}{c}\text { Hervidor + } \\
\text { Cafetera }\end{array}$ & Pza & Thomas & $\begin{array}{c}4512 \mathrm{MN} / \\
\mathrm{TH} 130\end{array}$ & $2 \mathrm{~L} / 5$ tazas & 1 & 149 & HIRAOKA \\
\hline $\begin{array}{l}\text { Balanza de } \\
\text { Cocina }\end{array}$ & Pza & Aro & Electronic & $5 \mathrm{~kg}$ & 1 & 25 & MAKRO \\
\hline Mesa & Pza & Aro & cuadrada & 4 personas & 14 & 150 & MAKRO \\
\hline Silla & Pza & Aro & - & - & 52 & 20 & MAKRO \\
\hline Bancos altos & Pza & Aro & - & - & 4 & 50 & MAKRO \\
\hline Vajillas & Pza & Aro & Tendido & $10.5^{\prime \prime}$ & 48 & 3 & MAKRO \\
\hline Ollas & Pza & Aro & - & & 4 & 100 & MAKRO \\
\hline Set Utensilios & Pza & $\mathrm{M} \& \mathrm{~K}$ & - & - & 4 & 200 & MAKRO \\
\hline Cubiertos & Pza & Facusa & Blister & - & 60 & 9 & MAKRO \\
\hline Vasos & Pza & Cristar & Lexington & $8.5 \mathrm{oz}$ & 48 & 68 & MAKRO \\
\hline Jarras & Pza & Luminarc & $\begin{array}{c}\text { Jarra con } \\
\text { Tapa }\end{array}$ & $1 \mathrm{~L}$ & 10 & 12 & MAKRO \\
\hline Ventilador & Pza & Miray & VMT-411 & $60 \mathrm{Watts}$ & 4 & 199 & HIRAOKA \\
\hline
\end{tabular}

Nota Fuente. Elaboración propia. Adaptado de catálogo MAKRO.

\subsubsection{Layout}

Una buena distribución de la planta es la que proporciona condiciones de trabajo aceptables y permite la operación más económica, a la vez que mantiene las condiciones 
óptimas de seguridad y bienestar para los trabajadores. Los objetivos y principios básicos de una distribución de la planta son los siguientes: Integración total, Mínima distancia de recorrido, Utilización del espacio cúbico, Seguridad y bienestar para el trabajador y Flexibilidad. (Baca, 2010).

El establecimiento tiene un espacio de $200 \mathrm{~m}^{2}$, a continuación, se muestra el layout propuesto por el proyecto para atender a los comensales. 


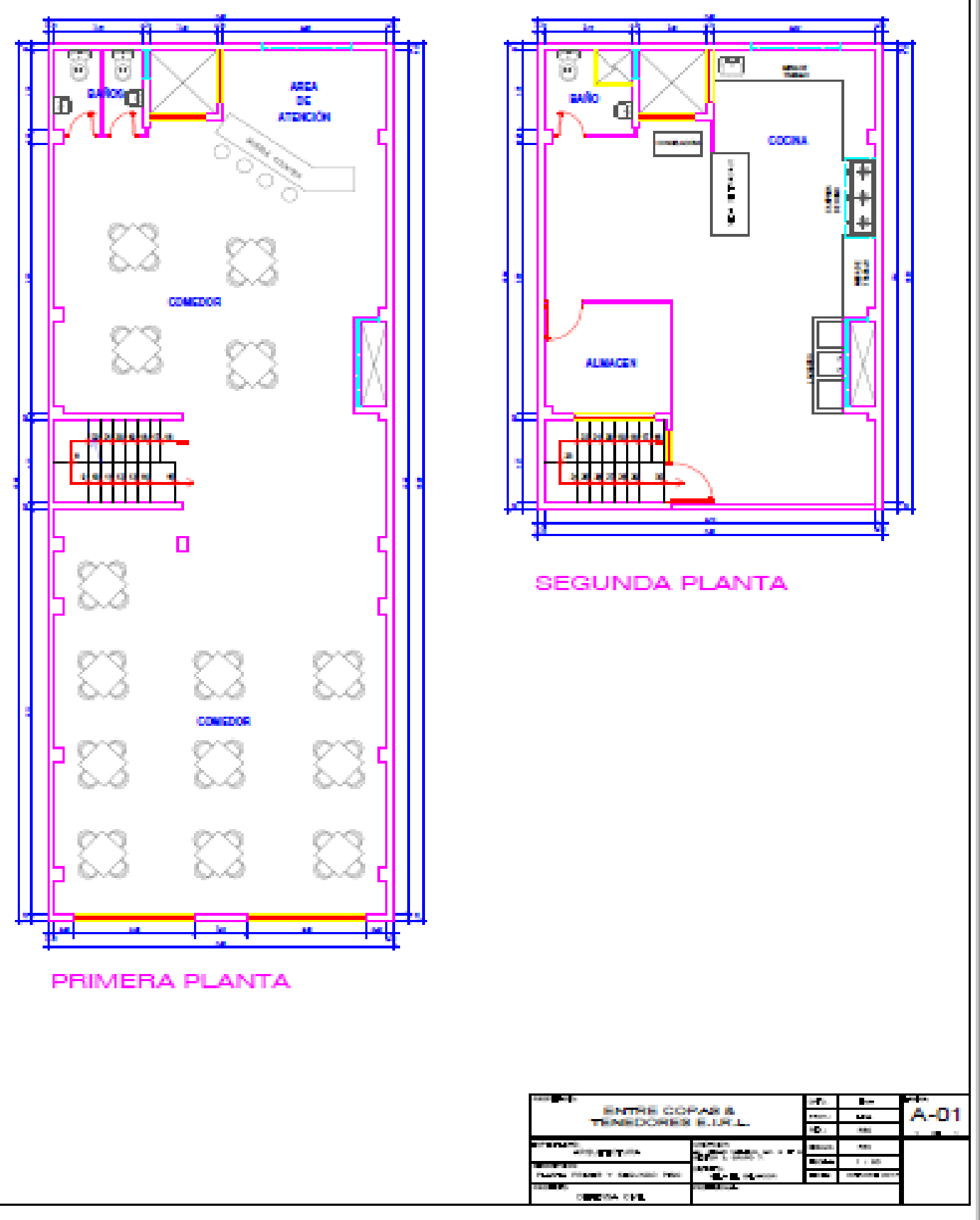

Ilustración 61. Layout propuesto

\subsubsection{Distribución de equipos y maquinarias}

Conocidas la cantidad de equipos y su distribución física más adecuada, se pueden determinar los requerimientos de espacios para su instalación, así como los de los lugares para bodegaje, salas de descanso o alimentación para el personal, vías de tránsito, salas de espera, baños, estacionamientos, casetas de vigilancia, etcétera. 
Además de la inversión necesaria en construcción soportante de los ítems anteriores, el proyecto por lo general presenta una gran variedad de obras físicas, muchas de las cuales son omitidas por falta de prolijidad en el análisis, como la reparación de caminos, la construcción de vías de acceso interiores (peatonales y de vehículos), cercos, casetas de control de accesos, estacionamientos para clientes, jardines, bodegas para materiales de aseo, techumbre en lugares de carga de vehículos, sala cuna para los hijos de los trabajadores (si correspondiera), comedores, etcétera. (Sapag, 2008).

Según lo mostrado en el layout, el establecimiento se divide en 2 pisos, el primero que consta de $130 \mathrm{~m}^{2}$ se atenderá a los clientes y este contará de 2 baños de $3 \mathrm{~m}^{2}$ para los clientes, además estará la barra de atención de pedidos y los mostradores de bebidas de $5 \mathrm{~m}^{2}$. El segundo piso consta de $70 \mathrm{~m}^{2}$ allí se realiza la preparación de los alimentos, ésta tiene un área de $15 \mathrm{~m}^{2}$, además cuenta con un almacén de $6 \mathrm{~m}^{2}$ y un baño de servicios de $3 \mathrm{~m}^{2}$.

La distribución de los equipos dentro del área de la cocina es como sigue:

- La congeladora se encuentra alejada de la cocina, pero cerca de la mesa de trabajo para la rapidez de suministro de carnes.

- El refrigerador se encuentra al costado de la congeladora para tener una buena distribución y rapidez de suministro de verduras y productos en cremas.

- La zona de lavado se encuentra al frente de la mesa de trabajo y al costado de la cocina para poder lavar los equipos de cocina y los platos para el emplatado.

- La cocina industrial se encuentra debajo de la campana de succión y al frente de la mesa de trabajo, para una rapidez en la preparación de la comida.

- El Horno microondas se encuentra al costado de la mesa de trabajo para poder calentar y/o cocinar productos ligeros y rápidos. 

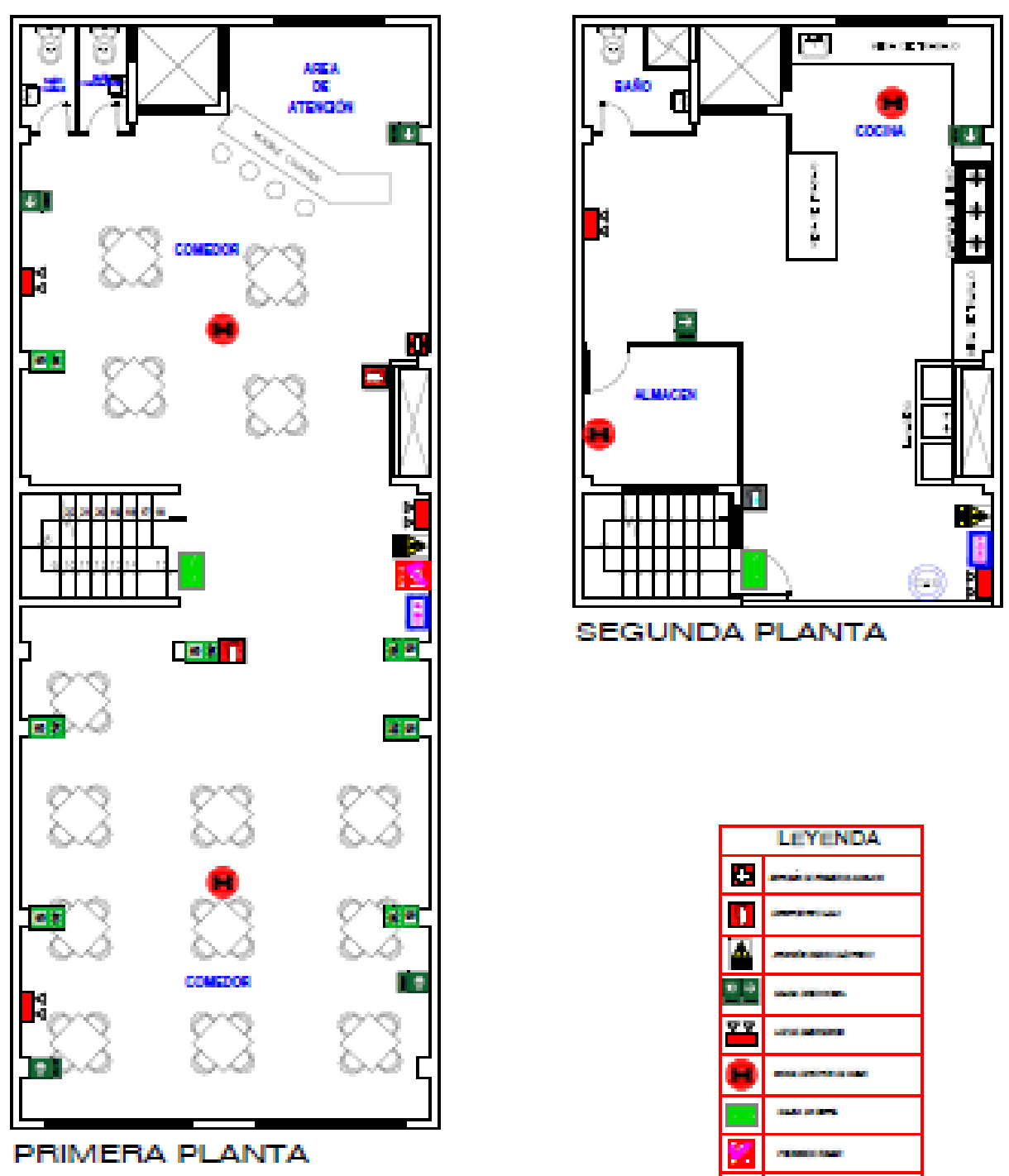

SEGUNDA PLANTA
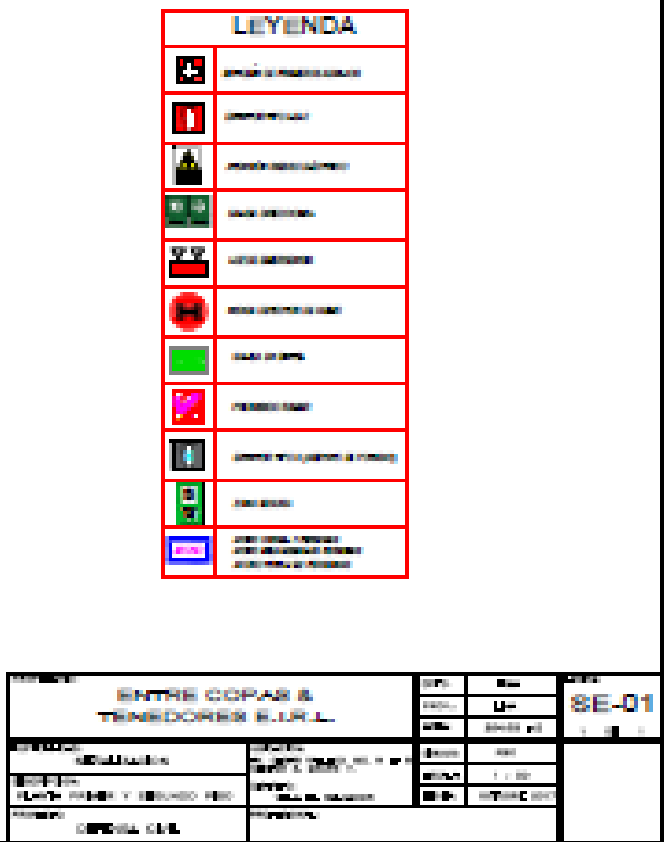

Ilustración 62. Distribución de equipos

\subsection{Determinación del tamaño}

El tamaño de un proyecto muestra su relación con el número de unidades a producir, el número de consultas médicas que atender, la cantidad de empresas a las que prestar 
servicios contables o el número de cursos a dictar en un periodo de tiempo. El estudio del tamaño de un proyecto es fundamental para determinar el monto de las inversiones y el nivel de operación que, a su vez, permitirá cuantificar los costos de funcionamiento y los ingresos proyectados. Varios elementos se conjugan para la definición del tamaño: la demanda esperada, la disponibilidad de los insumos, la localización del proyecto y el valor de los equipos. (Sapag, 2011).

Según el layout presentado en el punto 7.1.3, el restaurante es un establecimiento de dos pisos con un área de $133.16 \mathrm{~m}^{2}$. Se inicia operaciones con 14 mesas y 56 sillas; sin embargo, el local tiene capacidad para 18 mesas y 72 sillas. Además, el aforo es de 92 personas distribuidas en ambas plantas, incluyendo al personal y clientela.

En la hora del almuerzo, cuando hay más demanda, se calcula poder albergar a 168 personas en tres turnos desde el mediodía hasta las 3:00 pm, con un tiempo promedio de rotación de una hora.

\subsubsection{Proyección de crecimiento}

La proyección de crecimiento en ventas y en capacidad de atención se debe analizar en conjunto. Para el presente proyecto no se realizan reinversiones debido a que las catorce mesas iniciales son suficientes para los cinco años de vida útil. Lo único que se considera es la renovación de menaje y utensilios cada dos años.

\subsubsection{Recursos}

Los recursos son distintos medios utilizados para conseguir un objetivo o satisfacer una necesidad. Los recursos pueden ser: (a) Humanos: Fuente de trabajo originario de las personas para llevar a cabo una actividad; (b) Materiales: Bienes tangibles de los que dispone una empresa para lograr sus objetivos como materia prima, instalaciones, herramientas, etc.; y (c) Naturales: Aquellos extraídos de la naturaleza para ser transformados en beneficio de la sociedad. (Ramírez Elbar, 2004) 
El presente proyecto emplea once personas en total: un administrador, un asistente logístico, dos cocineros, dos asistentes de cocina, un cajero y cuatro mozos.

Adicionalmente, los recursos tecnológicos que se utilizan han sido mencionados en el apartado 7.1.4. Por otro lado, los recursos financieros utilizados son mencionados en el capítulo IX, donde se realiza la planificación financiera.

\subsubsection{Tecnología}

Según Sapag y Sapag (2007), la tecnología se define como la combinación de mano de obra, maquinaria, métodos y procedimientos de operación dentro de un proceso productivo que ayuda a transformar insumos en productos de manera más eficiente.

Los procesos productivos del presente proyecto son mecánicos apoyados en las siguientes tecnologías que facilitan su desarrollo:

- Controlador digital: Esta tecnología se encuentra presente en las refrigeradoras y congeladoras que permite regular la temperatura de los equipos.

- Sistema de refrigeración por convección forzada: Se añade una fuerza externa como un ventilador, el cual permite que el aire fluya al interior de todo el equipo de manera uniforme.

- Condensador dinámico de alta eficiencia: El cual permite que el gas cumpla su función refrigerante al interior del equipo gracias al proceso de condensación.

\subsubsection{Flexibilidad}

La flexibilidad del negocio está dada en función del pronóstico de ventas y su capacidad de respuesta frente a nuevos requerimientos. En el capítulo VI, se observa que Entre Copas y Tenedores experimenta una tasa de crecimiento promedio anual de demanda cercana a 2.0\% desde el 2019 hasta el 2023.

Actualmente, el local cuenta con catorce mesas, las mismas que tienen cuatro sillas alrededor y se estima una rotación de aproximadamente 60 minutos desde el mediodía hasta 
las 3:00 pm. Como consecuencia, se tiene la capacidad de atender a 168 personas por día, cubriendo la demanda inicial.

\subsubsection{Selección del tamaño ideal}

En la hora del almuerzo, en la cual hay mayor demanda, se proyecta una demanda promedio de 90 personas, distribuidas en tres turnos de una hora cada uno. Por lo tanto, por hora, se debe atender 30 personas en salón con 56 sillas disponibles y un aforo de 92 personas.

Teniendo en cuenta estas condiciones, el tamaño ideal de la planta es de $200 \mathrm{~m}^{2}$, la misma que permite aumentar el número de mesas hasta 18 y tener espacios de trabajo adecuados.

\subsection{Estudio de localización}

Según Sapag y Sapag (2007), el estudio de la localización tiene por objetivo elegir aquella ubicación que permita las mayores ganancias entre las alternativas que se consideren factibles. El enfoque de este estudio no es netamente económico, se debe tomar en consideración distintos factores, tales como: técnicos, legales, tributarios, sociales, emocionales, etc., que puedan impactar en la rentabilidad del proyecto. El análisis de la ubicación se debe realizar en dos etapas: macrolocalización y, dentro de esta, la de microlocalización definitiva. Para la selección de una macrolocalización, se consideran aspectos muy distintos a los de la microlocalización; por ejemplo: políticas impositivas, influencias climáticas, normativa vigente, etc. El análisis de microlocalización sólo indicará cuál es la mejor alternativa de instalación dentro de la macrozona elegida.

Para el presente proyecto, se define como macrolocalización el distrito de Villa el Salvador; debido a que: (a) Según el reporte del INEI, Villa El Salvador el distrito más poblado de Lima Sur; (b) Se encuentra el Parque Industrial, y la zonas comerciales y agropecuarias que generan un gran flujo de trabajadores al distrito. 
Además, con respecto a la microlocalización, se eligió el territorio III del distrito de Villa El Salvador, específicamente en la Av. César Vallejo Mz. N Lt. № 9; debido a los siguientes factores: (a) Se encuentra ubicado en una zona céntrica, frente a la Municipalidad de Villa El Salvador; (b) De los locales observados, este es el que cuenta con un mayor espacio (200 m2); (c) Se encuentra ubicado frente a la comisaría de Villa El Salvador, por lo que se tiene mayor seguridad; (d) Hay una estación del tren bastante cercana al lugar elegido; y (e) El costo del alquiler es coherente o a nivel del mercado, igual a S/ 4,500 mensuales.

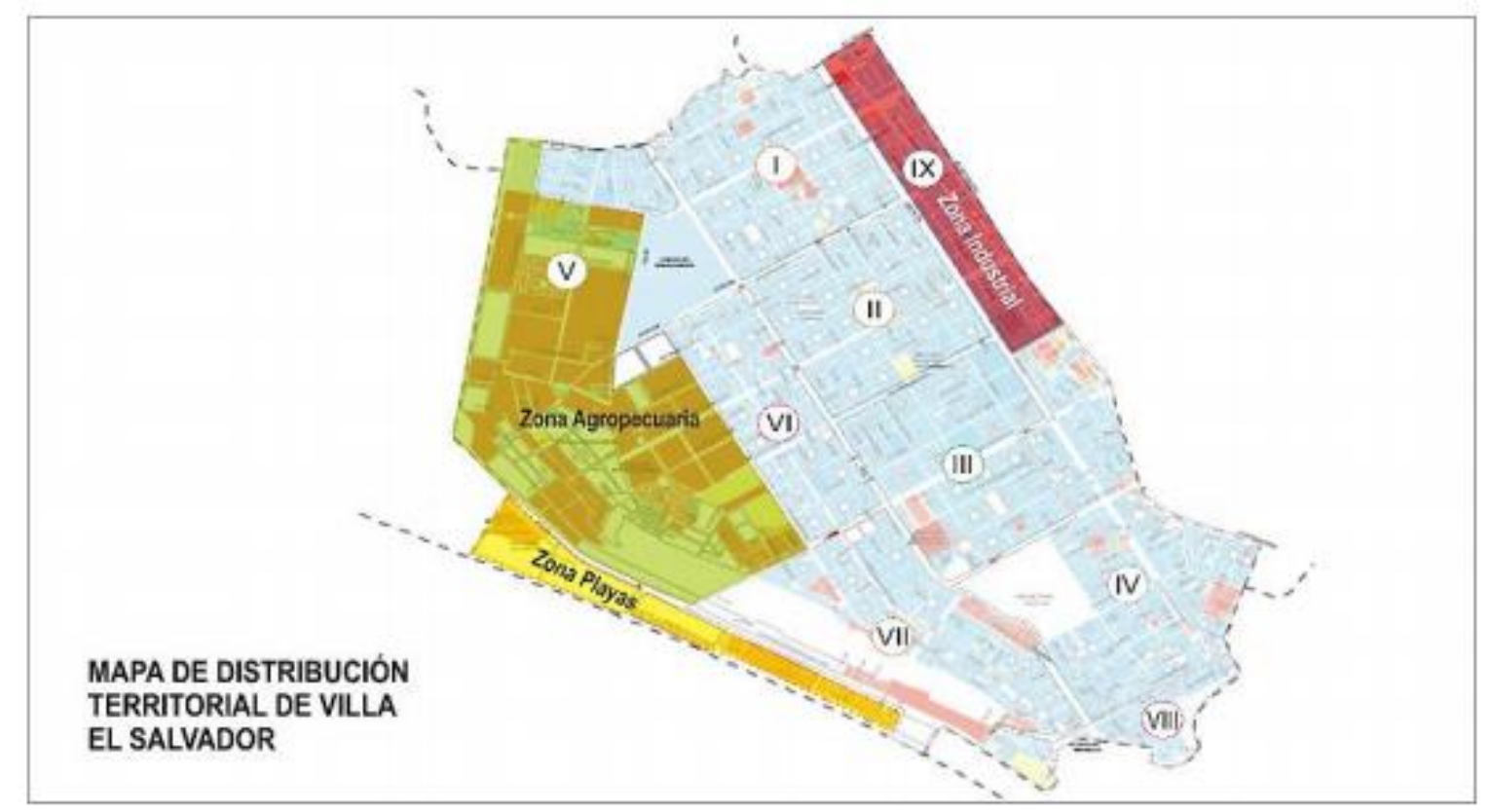

Ilustración 63. Mapa de Distribución Territorial de Villa El Salvador

\subsubsection{Definición de factores locacionales}

Según Sapag (2011), los factores locacionales principales son los siguientes:

- Mercado que se desea atender.

- Transporte y accesibilidad de los usuarios.

- Regulaciones legales de la zona.

- Aspectos técnicos. 
- Aspectos ambientales.

- Costos y disponibilidad de terrenos o edificaciones adecuados a las características del proyecto.

En el presente proyecto se tuvo en cuenta la cercanía al público objetivo (mercado atendido) que son los trabajadores de las distintas zonas económicas y la población del territorio III del distrito de Villa El Salvador. El local está ubicado frente a la municipalidad del distrito de manera equidistante a zona industrial, comercial y agropecuaria.

Otro punto que se tiene en consideración son los costos que tiene el alquiler del local, este costo es independiente al nivel de ventas que tiene el negocio. La disponibilidad del local también juega un papel importante dentro del negocio debido a que en el distrito de Villa El Salvador existe una amplia oferta de locales comerciales en zonas concurridas.

Las consideraciones legales en el distrito permiten la apertura del local de forma ordenada mediante la solicitud de licencia de funcionamiento que brinda la municipalidad de Villa El Salvador.

\subsubsection{Consideraciones legales}

De acuerdo a Sapag (2011), "Por la viabilidad legal de un proyecto se determina la existencia o la inexistencia de normas que pudieran restringir la realización del negocio o condicionar su materialización al cumplimiento de algunos requisitos mínimos para poder implementarlo" (p. 172).

Los documentos necesarios para la apertura del local son los siguientes:

- Licencia de funcionamiento: Es necesario tramitar este documento con la municipalidad el distrito para poder iniciar las operaciones de manera formal, esto se hace mediante un formato que ofrece la municipalidad de Villa El Salvador en su página web.

- Condiciones de seguridad dictadas por Defensa Civil, esta inspección y otorgación de la licencia es realizada por la municipalidad correspondiente. 
- Cumplir con la norma sanitaria para el funcionamiento de restaurantes y servicios afines dictada por la Dirección General de Salud Ambiental (DIGESA), publicada con la Resolución Ministerial N³ 363 - 2005 / MINSA. Esta norma tiene como objetivo: (a) Asegurar la calidad sanitaria e inocuidad de los alimentos y bebidas en todas sus etapas; (b) Establecer los requisitos sanitarios operativos y las buenas prácticas de manipulación; y (c) Establecer las condiciones higiénicas sanitarias y de infraestructura mínimas.

\subsubsection{Identificación del marco legal}

Según Baca (2010), el marco legal "son una serie de códigos de la más diversa índole, como el fiscal, sanitario, civil y penal que repercuten de alguna manera sobre un proyecto y, por tanto, deben tomarse en cuenta, ya que toda actividad empresarial y lucrativa se encuentra incorporada a determinado marco jurídico”. (p.103).

En primer lugar, al ser el negocio una persona jurídica, se procede a inscribir el nombre en la Superintendencia Nacional de los Registros Públicos (SUNARP). Una vez entregado el asiento registral se procede a crear e inscribir el RUC en la SUNAT. Luego, se obtienen las autorizaciones adicionales correspondientes (licencia de funcionamiento, permisos de la municipalidad, etc). A continuación, se obtienen los comprobantes de pago a utilizar. Finalmente, se legalizan los libros contables que pueden ser físicos y/o electrónicos.

Asimismo, Entre Copas y Tenedores se acoge al Régimen MYPE Tributario de pequeña empresa, debido a que es una persona jurídica y los ingresos no superan las 1700 UIT en ninguno de los ejercicios proyectados. A continuación, las condiciones de este régimen:

- Comprobantes que puede emitir: Factura, boleta y todos los demás permitidos.

- DJ anual - Renta: Sí, se declara de manera anual.

- Pago de Tributos Mensuales: (a) Impuesto a la Renta: Si no superan las 300 UIT de ingresos netos anuales: pagarán el $1 \%$ de los ingresos netos obtenidos en el mes. Si 
en cualquier mes superan las 300 UIT de ingresos netos anuales pagarán 1.5\% o coeficiente; e (b) IGV: 18\% sobre la venta realizada.

- Restricción por tipo de actividad: No tiene.

- Trabajadores: De a uno a cien trabajadores. A quienes se les debe pagar, 15 días de vacaciones, una gratificación al año y 15 días de CTS al año.

- Valor de Activos Fijos: Sin límite

- Pago de Impuesto a la Renta en función de las utilidades: Sí

\subsubsection{Ordenamiento jurídico de la empresa}

Según la Ley General de Sociedades, en el Perú, se pueden constituir los siguientes tipos de sociedades:

- Sociedad Comercial de Responsabilidad Limitada

- Sociedad Anónima Cerrada

- Sociedad Anónima

La razón social de la empresa será “Sociedad de Responsabilidad Limitada”, la cual tiene las siguientes características:

- La cantidad de socios puede ser desde dos hasta 20 personas.

- El capital de la empresa está conformado por los aportes de los socios integrantes en participaciones iguales de por lo menos $25 \%$.

- La administración de la empresa es encargada, por los socios, a uno o más gerentes. No existe Junta de Accionistas.

- Los miembros de una sociedad de responsabilidad limitada son gerente (representa a los socios y puede ser uno de estos) y sub-gerente (remplaza al gerente en caso de ausencia). 


\subsection{Determinación de la localización óptima}

La localización más apropiada será la que permita asegurar el cumplimiento de los objetivos para el proyecto, permitiendo alcanzar la mayor participación posible en la población objetivo y también maximizar la rentabilidad del negocio (Sapag, 2011).

Para el presente proyecto se optó por alquilar el inmueble ubicado en la avenida César Vallejo muy cercano a la avenida Revolución, esto debido al siguiente análisis realizado:

Tabla 53

Determinación de la localización óptima

\begin{tabular}{|c|c|c|c|c|c|c|c|}
\hline Factores & Peso & $\begin{array}{l}\text { Local 1: Calle } \\
\text { Los Crisoles }\end{array}$ & $\begin{array}{c}\text { Nota } \\
\text { Local } \\
1\end{array}$ & $\begin{array}{l}\text { Local 2: Av. } \\
\text { César Vallejo }\end{array}$ & $\begin{array}{c}\text { Nota } \\
\text { Local } \\
2\end{array}$ & $\begin{array}{l}\text { Local 3: } \\
\text { Velasco } \\
\text { Alvarado }\end{array}$ & $\begin{array}{c}\text { Nota } \\
\text { Local } \\
3\end{array}$ \\
\hline Ubicación & $25 \%$ & $\begin{array}{c}\text { Calle Los } \\
\text { Crisoles, Parque } \\
\text { Industrial, Villa } \\
\text { El Salvador Villa } \\
\text { El Salvador, } \\
\text { Lima, Lima }\end{array}$ & 2 & $\begin{array}{c}\text { Av. César } \\
\text { Vallejo Mz. N } \\
\text { Lt. } N^{\circ} 9\end{array}$ & 3 & $\begin{array}{c}\text { Calle } \\
\text { Velasco } \\
\text { Alvarado } \\
\text { S/n Villa } \\
\text { El } \\
\text { Salvador, } \\
\text { Lima, } \\
\text { Lima }\end{array}$ & 1 \\
\hline Tamaño & $30 \%$ & $110 \mathrm{~m} 2$ & 1 & $200 \mathrm{~m} 2$ & 3 & $130 \mathrm{~m} 2$ & 2 \\
\hline Precio & $20 \%$ & 1900 & 3 & 2000 & 2 & 4026 & 1 \\
\hline $\begin{array}{l}\text { Lugares } \\
\text { Aledaños }\end{array}$ & $25 \%$ & Parque Industrial & 2 & $\begin{array}{c}\text { Municipalidad } \\
\text { de VES y } \\
\text { Estación VES } \\
\text { del Tren }\end{array}$ & 3 & $\begin{array}{c}\text { Zona } \\
\text { Residencial }\end{array}$ & 1 \\
\hline $\begin{array}{c}\text { Nota } \\
\text { Ponderada } \\
\end{array}$ & $100 \%$ & & 1.9 & & 2.8 & & 1.3 \\
\hline
\end{tabular}

Nota Fuente. Elaboración propia - Estudio de campo realizado

Dado que el local de la Av. César Vallejo obtuvo mayor nota como consecuencia de su mejor ubicación, mayor tamaño, menor precio y su cercanía a lugares concurridos, es elegido para que sea el local donde se instala Entre Copas y Tenedores. 


\section{Capítulo VIII. Aspectos Organizacionales}

\subsection{Caracterización de la cultura organizacional deseada}

Según Chiavenato (2009), la cultura organizacional es el conjunto de hábitos establecidos por las normas, valores, actitudes y expectativas que comparten todos los miembros de la organización; es decir, constituye la forma institucionalizada de pensar y actuar en una empresa.

Entre Copas y Tenedores posee una cultura organizacional basada en el buen servicio al cliente; es decir, aúnan sus valores y actitudes con el objetivo de asegurar su entera satisfacción. Además de esto, busca generar la excelencia en la calidad de los platos y en los procesos, generando el compromiso para los trabajadores con el cumplimiento de los objetivos organizacionales.

\subsubsection{Visión}

Según Chiavenato (2009), la visión es la imagen que la empresa tiene sobre sí misma proyectada en el tiempo y en el espacio, tomando en consideración los recursos que tiene a su disposición, el tipo de relaciones que desea tener con sus stakeholders, sus objetivos estratégicos, oportunidades y desafíos; es decir todas las condiciones en las que opera. En resumen, la visión es todo aquello que se pretende ser, considerando lo que es hoy.

La visión de Entre Copas y Tenedores es: "Ser el restaurante líder de comida criolla y marina de Villa El Salvador, ofreciendo un servicio de calidad que garantice la satisfacción de nuestros clientes".

\subsubsection{Misión}

Según Chiavenato (2009), la misión representa la razón de ser de una organización. La misión de la empresa debe responder a tres preguntas básicas: ¿Quiénes somos? ¿Qué hacemos? y ¿por qué lo hacemos? La misión incluye los objetivos esenciales de la empresa y los deseos de la misma de atender a la sociedad, del mercado y del cliente. Es importante 
que todos los miembros de la organización conozcan la misión para que sepan a dónde se dirigen y qué camino deben seguir.

La misión de Entre Copas y Tenedores es: "Somos un restaurante de comida peruana que ofrece a sus clientes productos de calidad a través de un servicio diferenciado y responsabilidad social. Estamos comprometidos a satisfacer las expectativas de nuestros clientes, agregando valor a la sociedad y nuestros colaboradores.”

\subsubsection{Principios}

Según Chiavenato (2009), los principios constituyen las creencias y actitudes que orientan el comportamiento individual de las empresas dentro de una organización. Los principios organizacionales se derivan de algunos supuestos básicos, los mismos que son el núcleo de la cultura empresarial y representan dirección, integridad y autodisciplina en las personas.

Los principios de Entre Copas y Tenedores son:

- Calidad: Se verifica que todos los ingredientes mantengan la calidad desde la compra hasta su preparación en el restaurante.

- Servicio: El cliente es lo más importante y el objetivo es alcanzar el máximo nivel de satisfacción.

- Limpieza: Los trabajadores velan por la limpieza de todo el restaurante, siendo esta una de las características más valoradas por los clientes.

- Innovación: Este principio permite que el restaurante se adapte a los cambios de gustos y preferencias de los clientes.

\subsection{Formulación de Estrategias del Negocio}

Según Kotler y Keller (2016), existen tres estrategias genéricas para el planeamiento estratégico. Estas son: i) Liderazgo general de costos, ii) Diferenciación y iii) Enfoque. 
Para este proyecto, se plantea la estrategia de diferenciación, dado que al consumidor se le ofrece una propuesta de valor distinta a la existente en la zona. Este plan de negocio ofrece platos de comida criolla, marina y bebidas en un ambiente pintoresco, colorido y atractivo visualmente, con cuadros de tipografía artística relacionadas a la popularidad y preferencia por la comida peruana; con atención cordial, esmerada y altos estándares de higiene.

\subsection{Determinación de las ventajas competitivas críticas}

Según Robbins \& Coulter (2014), la ventaja competitiva es "aquello que distingue a una organización respecto de las demás; su sello distintivo, permitiendo hacer algo que el resto no puede o hacerlo mejor que las demás” (p.248).

Las ventajas competitivas principales frente a los competidores que se ubican en el distrito son las siguientes:

- Atención de forma personalizada y cordial por parte del personal, en la cual se le informe al cliente sobre las recomendaciones y beneficios de los platos preparados. Se busca brindar especial atención a las necesidades que tiene el comensal; por ejemplo, estar atento a si desea más bebida o algún acompañamiento como granos de maíz tostados, salsa picante, etc.

- Ambientación pintoresca del local con tipografía estilo Elliot Túpac, en el cual se resalta la preferencia y popularidad de la comida peruana.

- Ubicación céntrica frente a la Municipalidad, vigilada por Serenazgo, con pistas accesibles y disponibilidad de tres estacionamientos.

\subsection{Diseño de la estructura organizacional deseada}

La estructura organizacional es la distribución de los puestos y tareas dentro de la organización de manera que haya un reparto razonable y coherente de las funciones de tal 
forma que estas se acoplen y encajen entre sí para poder alcanzar los objetivos generales y específicos del negocio. (Chiavenato, 2009).

La estructura organizacional del negocio es la siguiente:

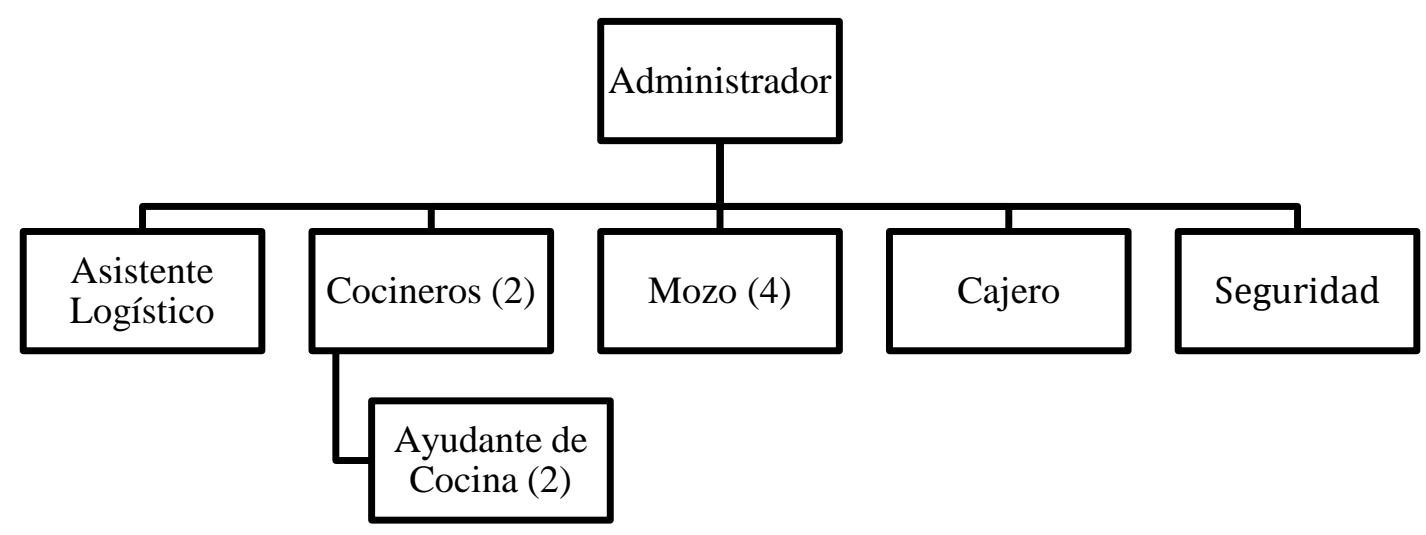

Ilustración 64. Organigrama del negocio

De acuerdo a la entrevista realizada a los expertos; como es el caso del dueño del restaurante, un mozo tiene la capacidad de atender un plato (persona) en 1.5 minutos. De acuerdo a los horarios de atención y al número de mesas que existen, se necesitan 4 mozos en total, dos por turno (almuerzo y cena) y esto se determina dividiendo tiempo total de atención de mesas entre el número de platos y se calcula de la siguiente manera: 
Tabla 54

Cálculo de número de Mozos, turno Almuerzo

\begin{tabular}{cccccccc}
\hline $\begin{array}{c}\text { Horario } \\
\text { Almuerzo }\end{array}$ & $\begin{array}{c}\mathrm{N}^{\circ} \text { Platos } \\
\text { (promedio) }\end{array}$ & $\mathrm{N}^{\circ}$ Mesas & $\begin{array}{c}\text { Platos por } \\
\text { mesa } \\
\text { promedio) }\end{array}$ & $\begin{array}{c}\text { Capacidad } \\
\text { atención } \\
\text { Mozo x } \\
\text { plato (min) }\end{array}$ & $\begin{array}{c}\text { Capacidad } \\
\text { total } \\
\text { atención } \\
\text { mozo por } \\
\text { mesa (min) }\end{array}$ & $\begin{array}{c}\text { Tiempo } \\
\text { total } \\
\text { atencion } \\
\text { mesas } \\
\text { (min) }\end{array}$ & $\begin{array}{c}\text { Número de } \\
\text { Mozos } \\
\text { necesarios } \\
\text { por turno }\end{array}$ \\
\hline 12:00 - 13:00 & 30 & 14 & 2 & 1.5 & 3.2 & 45.00 & $\mathbf{2}$ \\
13:00 - 14:00 & 35 & 14 & 3 & 1.5 & 3.8 & 52.50 & $\mathbf{2}$ \\
14:00 - 15:00 & 25 & 14 & 2 & 1.5 & 2.7 & 37.50 & $\mathbf{2}$ \\
\hline
\end{tabular}

Nota Fuente. Elaboración propia

Tabla 55

Cálculo de número de Mozos, turno Cena

\begin{tabular}{cccccccc}
\hline Horario Cena & $\begin{array}{c}\mathrm{N}^{\circ} \text { Platos } \\
\text { (promedio) }\end{array}$ & $\mathrm{N}^{\circ}$ Mesas & $\begin{array}{c}\text { Platos por } \\
\text { mesa } \\
\text { (promedio) }\end{array}$ & $\begin{array}{c}\text { Capacidad } \\
\text { atención } \\
\text { Mozo x } \\
\text { plato (min) }\end{array}$ & $\begin{array}{c}\text { Capacidad } \\
\text { total } \\
\text { atención } \\
\text { mozo por } \\
\text { mesa (min) }\end{array}$ & $\begin{array}{c}\text { Tiempo } \\
\text { total } \\
\text { atencion } \\
\text { mesas } \\
\text { (min) }\end{array}$ & $\begin{array}{c}\text { Número de } \\
\text { Mozos } \\
\text { necesarios } \\
\text { por turno }\end{array}$ \\
\hline 19:00- 20:00 & 14 & 14 & 1 & 1.5 & 1.6 & 21.00 & $\mathbf{2}$ \\
20:00- 21:00 & 14 & 14 & 1 & 1.5 & 1.6 & 21.00 & $\mathbf{2}$ \\
21:00-22:00 & 12 & 14 & 1 & 1.5 & 1.1 & 21.00 & $\mathbf{2}$ \\
\hline
\end{tabular}

Nota Fuente. Elaboración propia

De acuerdo a la entrevista realizada al dueño del restaurante, el chef y el ayudante de cocina tienen la capacidad de preparar un menú en 3 minutos y un plato a la carta en 8 minutos, esto trabajando los dos a la par. De acuerdo a los horarios de atención y a los tipos de platos servidos, se determinó que se necesita un cocinero y un ayudante de cocina en cada turno, el cálculo se realizó diviendo el tiempo total de la capacidad del cocinero y el ayudante entre los 60 minutos que dura cada horario según el turno. El cálculo se detalla a continuación: 
Tabla 56

Cálculo de número de Personal de Cocina, turno Almuerzo

\begin{tabular}{|c|c|c|c|c|c|c|c|}
\hline $\begin{array}{c}\text { Horario } \\
\text { Almuerzo }\end{array}$ & $\begin{array}{l}\mathrm{N}^{\circ} \text { Platos } \\
\text { de Menú } \\
\text { (promedio) }\end{array}$ & $\begin{array}{l}\mathrm{N}^{\circ} \text { Platos a } \\
\text { la carta } \\
\text { (promedio) }\end{array}$ & $\begin{array}{c}\mathrm{N}^{\circ} \\
\text { Platos } \\
\text { por hora } \\
\text { total }\end{array}$ & $\begin{array}{c}\text { Capacidad } \\
\text { Preparación } \\
\text { Menu (3 } \\
\text { min c/u) }\end{array}$ & $\begin{array}{c}\text { Capacidad } \\
\text { preparación } \\
\text { Carta }(8 \\
\operatorname{min~c} / \mathrm{u})\end{array}$ & $\begin{array}{c}\text { Tiempo } \\
\text { total de } \\
\text { capacidad } \\
\text { cocinero } \\
\text { más } \\
\text { ayudante }\end{array}$ & $\begin{array}{l}\text { Personal } \\
\text { necesario } \\
\text { en cocina } \\
\text { por turno }\end{array}$ \\
\hline $\begin{array}{c}12: 00- \\
13: 00\end{array}$ & 20 & 10 & 30 & 60 & 80 & 140 & 2 \\
\hline $\begin{array}{c}13: 00- \\
14: 00\end{array}$ & 30 & 5 & 35 & 90 & 40 & 130 & 2 \\
\hline $\begin{array}{c}14: 00- \\
15: 00\end{array}$ & 20 & 5 & 25 & 60 & 40 & 100 & 2 \\
\hline
\end{tabular}

Nota Fuente. Elaboración propia

\section{Tabla 57}

Cálculo de número de Personal de Cocina, turno Cena

\begin{tabular}{cccccccc}
\hline $\begin{array}{c}\text { Horario } \\
\text { Cena }\end{array}$ & $\begin{array}{c}\mathrm{N}^{\circ} \text { Platos } \\
\text { de Menú } \\
\text { (promedio) }\end{array}$ & $\begin{array}{c}\mathrm{N}^{\circ} \text { Platos a } \\
\text { la carta } \\
\text { (promedio) }\end{array}$ & $\begin{array}{c}\mathrm{N}^{\circ} \text { Platos } \\
\text { por hora } \\
\text { total }\end{array}$ & $\begin{array}{c}\text { Capacidad } \\
\text { Preparación } \\
\text { Menu }(3 \\
\text { min c/u) }\end{array}$ & $\begin{array}{c}\text { Capacidad } \\
\text { preparación } \\
\text { Carta }(8 \text { min } \\
\text { c/u) }\end{array}$ & $\begin{array}{c}\text { Tiempo } \\
\text { total de } \\
\text { capacidad } \\
\text { cocinero } \\
\text { más } \\
\text { ayudante }\end{array}$ & $\begin{array}{c}\text { Personal } \\
\text { necesario cocina } \\
\text { por turno }\end{array}$ \\
\hline $\begin{array}{c}19: 00- \\
20: 00\end{array}$ & 0 & 14 & 14 & 0 & 112 & 112 & $\mathbf{2}$ \\
$\begin{array}{c}20: 00- \\
21: 00\end{array}$ & 0 & 14 & 14 & 0 & 112 & 112 & $\mathbf{2}$ \\
$\begin{array}{c}21: 00- \\
22: 00\end{array}$ & 0 & 12 & 14 & 0 & 96 & 96 & $\mathbf{2}$ \\
\hline
\end{tabular}

Nota Fuente. Elaboración propia

\subsection{Diseño de los perfiles de puesto clave}

El diseño del puesto incluye la asignación de las metas y tareas que deben llevar a cabo los empleados. Los gerentes pueden cambiar conscientemente el diseño del puesto para mejorar la productividad o la motivación del trabajador. Sin embargo, los gerentes también pueden influir inconscientemente en el diseño del puesto mediante la introducción de nuevas tecnologías, lo que puede cambiar la forma en que se desempeñan los puestos y la naturaleza de los mismos. (Daft, 2011).

Cada puesto exige ciertas competencias de su ocupante para que lo desempeñe bien. Esas competencias varían conforme al puesto, el nivel jerárquico y el área de actuación. 
Exigen que el ocupante sepa manejar los recursos, las relaciones interpersonales, la

información, los sistemas y la tecnología con diferentes grados de intensidad. (Chiavenato,

2009). A continuación, la descripción de los puestos:

\section{Tabla 58}

\section{Perfil del Administrador}

\section{ADMINISTRADOR(A)}

\section{Responsabilidad del Puesto}

Supervisar y asegurar el correcto funcionamiento del establecimiento en su totalidad siguiendo los estándares y políticas de la marca. Manejo de personal a cargo.

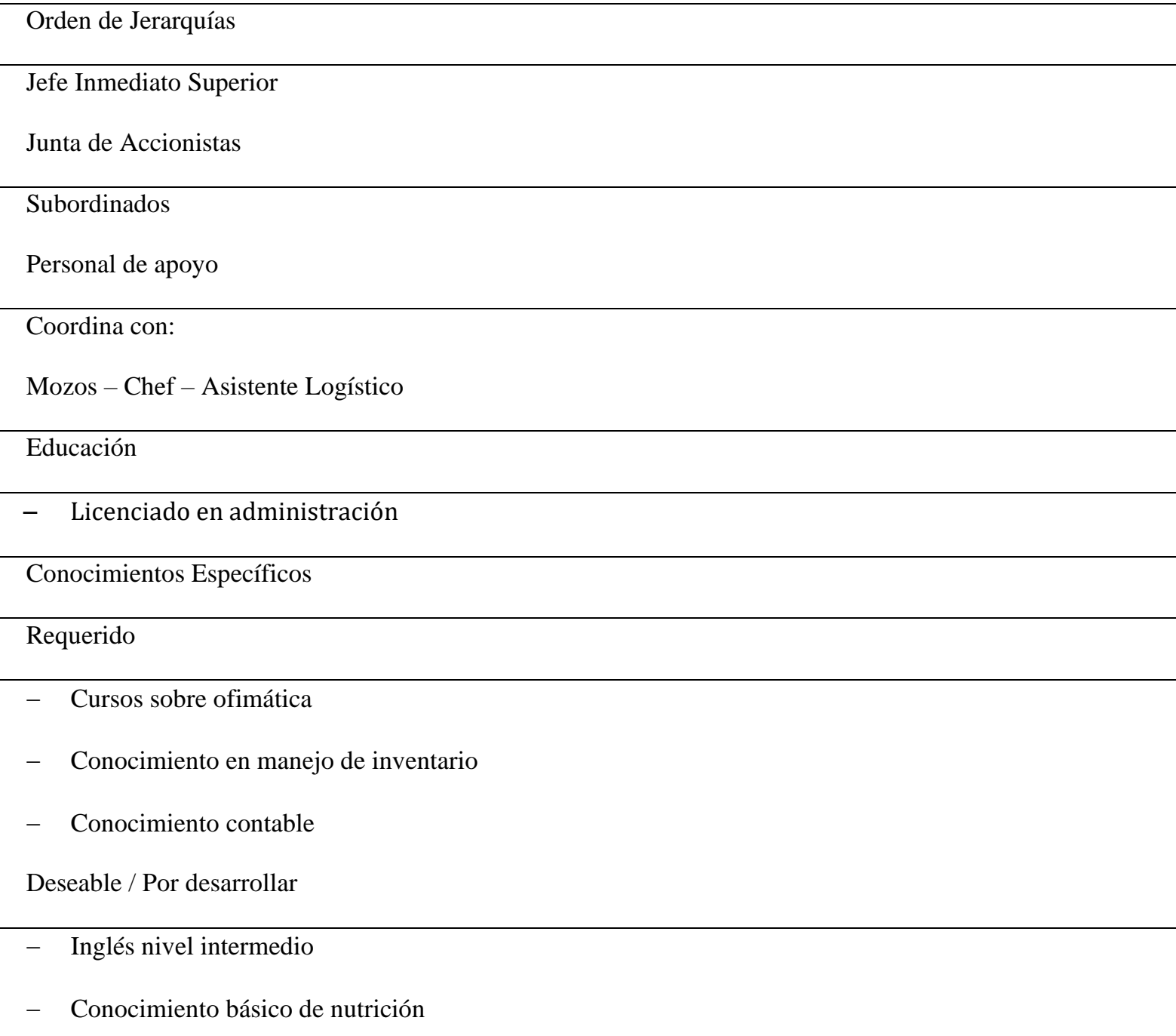

Competencia o Habilidades Específicas

Habilidades: 


\section{Generales}

- Liderazgo

- Enfoque al cliente

- Trabajo en equipo

- Capacidad de trabajo bajo presión

- Capacidad innovadora

- Excelente nivel de comunicación

\begin{tabular}{lll}
\hline Edad & Años de Experiencia & Idioma \\
\hline Mayor de 25 años & demostrada cono de experiencia \\
& algún establecimiento o jefe de comida. Castellano
\end{tabular}

\section{Funciones del Cargo}

- Administrar el presupuesto del establecimiento.

- Solicitar equipamiento de cocina sea necesario.

- Elaborar y adecuar el cronograma de trabajo de los colaboradores del establecimiento

- Supervisar la compra de inventarios

- Estar dispuesto a proveer asistencia en horarios de mucho trabajo.

\section{Nota Fuente. Elaboración propia}

\section{Tabla 59}

\section{Perfil del Cocinero}

\section{COCINERO}

\section{Responsabilidad del Puesto}

Supervisar, planificar, controlar y asegurar la preparación de los platos requeridos por los clientes de acuerdo a las recetas establecidas, a los estándares de calidad y en los tiempos establecidos de preparación en conjunto con su equipo de trabajo.

Experiencia en manejo de personal a cargo.

Orden de Jerarquías

Jefe Inmediato Superior 
Administrador

Subordinados

Ayudantes de cocina

Coordina con:

Administrador

Educación

- Chef titulado

Conocimientos Específicos

Requerido

- Cursos sobre costeo de platos

- Manejo de inventario

Deseable / Por desarrollar

- Inglés nivel intermedio

Competencia o Habilidades Específicas

Edad Años de Experiencia Idioma

Mínimo 2 años de experiencia

Mayor de 23 años demostrada como líder de cocina y preparando platos de comida

saludable.

\section{Funciones del Cargo}

- Planear y supervisar el mise en place.

- Garantizar la elaboración y presentación correcta de los platos de comida.

- Asegurar que el equipo de cocina cuente con los implementos e insumos necesarios.

- Implementar buenas prácticas de manipulación de alimentos.

- Supervisar y asegurar que las áreas de trabajo y equipos se mantengan en óptimas condiciones limpias y funcionando de acuerdo a los estándares de calidad.

- Controlar estrictamente los inventarios y costos de los platos.

- Implementar nuevos platos innovadores en la carta.

- Planificar el trabajo de su equipo de cocina de acuerdo a las cargas de trabajo.

Nota Fuente. Elaboración propia 
Tabla 60

Perfil del Asistente de Cocina

ASISTENTE DE COCINA

Responsabilidad del Puesto

Asistir al chef ejecutivo al momento de preparar los alimentos.

Orden de Jerarquías

Jefe Inmediato Superior

Cocinero

Subordinados

Ninguno

Coordina con:

Cocinero

Educación

- Estudiante de Gastronomía

\section{Conocimientos Específicos}

Requerido

- Conocimiento de preparación de comida criolla y marina. (Limpiar, pelar, cortar insumos).

\section{Deseable / Por desarrollar}

Costeo de insumos.

Competencia o Habilidades Específicas

- Trabajo en equipo

- Comunicación

- Profesionalismo

\begin{tabular}{lll}
\hline Edad & Años de Experiencia & Idioma \\
\hline & Mínimo 6 meses de experiencia & \\
Mayor de 18 años & demostrada como asistente de & Castellano \\
& chef.
\end{tabular}


Funciones del Cargo

- Ayudar al cocinero en la preparación de alimentos

- Preparar los platos para servir

- Mantener limpia la cocina y zona de trabajo.

- $\quad$ Escurrir y lavar los platos y colocarlos en el sitio adecuado.

- Desempaquetar y almacenar los productos en congeladoras y otras áreas de almacenaje.

- Controlar el inventario de insumos.

\section{Nota Fuente. Elaboración propia}

\section{Tabla 61}

\section{Perfil del Mozo}

\section{MOZO}

Responsabilidad del Puesto

Asegurar una atención personalizada a todos los clientes de acuerdo a los parámetros de atención, calidad e higiene establecidos por la empresa.

Orden de Jerarquías

Jefe Inmediato Superior

Administrador

Subordinados

No aplica

Coordina con:

Asistente logístico

\section{Educación}

- Secundaria completa

Conocimientos Específicos

Requerido

- Manejo de comandas 
Deseable / Por desarrollar

- Inglés nivel básico

Competencia o Habilidades Específicas

\begin{tabular}{lll}
\hline Edad & Años de Experiencia & Idioma \\
\hline Mayor de 18 años & Mínimo 6 meses de experiencia & Castellano \\
& demostrada en atención al cliente & \\
\hline
\end{tabular}

Funciones del Cargo

- Tomar el pedido solicitado por los clientes en el formato establecido.

- Asesorar al cliente en la elección de los platos a la carta.

- Establecer una relación efectiva con el cliente y mantenerla durante todo el servicio.

- Promover el consumo de la carta entre los clientes del establecimiento.

- Asegurar el óptimo montaje de las mesas (limpieza / menaje adecuado).

- Solicitar a cocina los pedidos de los clientes de acuerdo a los procedimientos establecidos.

- Identificar las principales necesidades de los clientes durante su estancia en el establecimiento.

- Solicitar la cuenta en la caja y presentarla al cliente en el momento requerido

- Apoyar al administrador en las tareas requeridas.

Nota Fuente. Elaboración propia

Tabla 62

Perfil del Cajero

\section{CAJERO}

Responsabilidad del Puesto

Asegurar el correcto cobro de cuentas, atender con calidad y buen servicio a los comensales. Manejo de caja registradora y diversos procedimientos de formas de pago. Llevar el control de cada comandas.

Orden de Jerarquías

Jefe Inmediato Superior

Administrador

Coordina con:

Administrador - Mozos 


\section{Educación}

- Secundaria completa

Conocimientos Específicos

\section{Requerido}

- Identificar legitimidad del dinero

- Saber usar las diferentes formar de pago

- Cursos sobre office

- Hacer reportes y encuadre de caja

Deseable / Por desarrollar

- Inglés nivel básico

- Habilidad social

- Conocimiento básico de computación

Competencia o Habilidades Específicas

Habilidades:

Generales

- Enfoque al cliente

- Trabajo en equipo

- Capacidad de trabajo bajo presión

- Capacidad innovadora

- Excelente nivel de comunicación

Edad Años de Experiencia Idioma

\begin{tabular}{lll}
\hline Mayor de 20 años & No necesaria & Castellano
\end{tabular}

Funciones del Cargo

- Registrar la cobranza de los productos adquiridos por el cliente.

- Saludar cordialmente.

- Estar dispuesta y atenta a dar un buen servicio al cliente.

- Mirar a los ojos cuando se hable al cliente.

- Preguntar ticket, efectivo o crédito.

Nota Fuente. Elaboración propia 
Tabla 63

Perfil del Asistente Logístico

ASISTENTE LOGISTICO

Responsabilidad del Puesto

Asegurar la compra y abastecimiento de los insumos y utensilios necesarios para la preparación de los

platos así como también asegurar eficiencia en la gestión de los inventarios.

Orden de Jerarquías

Jefe Inmediato Superior

Administrador

Coordina con:

Administrador - Mozos

Educación

- Estudiante de aministración de empresas, restaurantes o afines.

Conocimientos Específicos

Requerido

- Identificar el adecuado estado de los insumos.

- Estar al tanto de precios y ofertas de insumos.

- Hacer reportes de inventarios.

Deseable / Por desarrollar

- Optimización de inventarios.

- Habilidad social

- Conocimiento básico de computación

Competencia o Habilidades Específicas

Habilidades:

Generales

- Trabajo en equipo

- Capacidad de trabajo bajo presión

- Iniciativa y autonomía

- Adecuado nivel de comunicación 


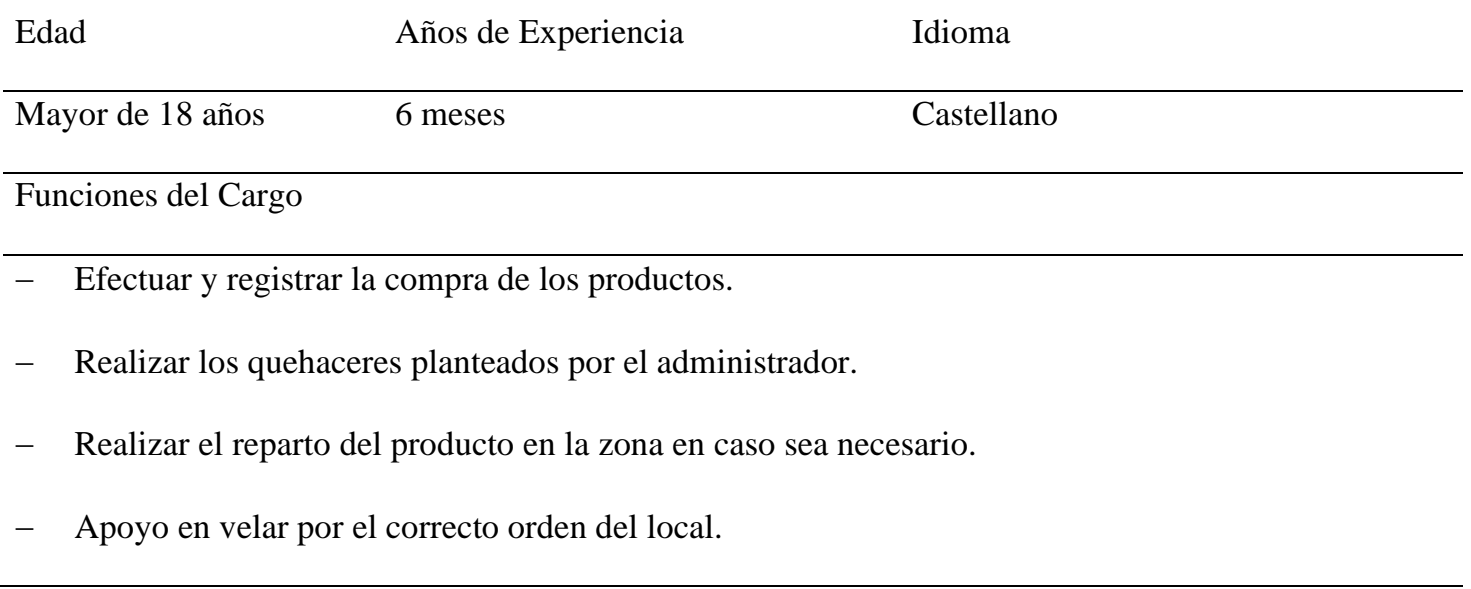

Nota Fuente. Elaboración propia

\subsection{Remuneraciones, compensaciones e incentivos}

En la mayoría de las organizaciones, el principal componente de la remuneración total es la remuneración básica, la paga fija que el trabajador recibe de manera regular en forma de sueldo mensual o de salario por hora. En la jerga económica el salario es el pago monetario que el trabajador recibe por vender su fuerza de trabajo. Aun cuando en otros periodos de la historia habían existido trabajadores asalariados, no fue sino hasta el advenimiento del capitalismo que el salario se convirtió en la forma dominante de pagar por la mano de obra. (Chiavenato, 2009)

Los procesos para recompensar a las personas constituyen los elementos fundamentales para incentivar y motivar a los trabajadores de la organización, siempre que los objetivos organizacionales sean alcanzados y los objetivos individuales sean satisfechos. Por tal razón, los procesos para ofrecer recompensas destacan entre los principales procesos administrativos del área de recursos humanos dentro de las organizaciones. Las organizaciones desarrollan sistemas de recompensas que provocan un efecto directo en su capacidad para atraer, retener y motivar a los trabajadores. Por una parte, las recompensas buscan incentivar la contribución de las personas para alcanzar los objetivos y la rentabilidad de la organización. (Chiavenato, 2009). 
A continuación, se detalla la remuneración y el gasto que la empresa paga por cada trabajador operativo y administrativo:

Tabla 64

Remuneración personal administrativo

\begin{tabular}{|c|c|c|c|c|c|c|c|c|c|c|}
\hline Puesto & $\begin{array}{c}\text { Rem. } \\
\text { Mensual }\end{array}$ & $\begin{array}{l}\text { Rem. } \\
\text { Anual }\end{array}$ & Vacacione & sGratificaciones & $\begin{array}{l}\text { Sub. } \\
\text { Total }\end{array}$ & Essalud & $\begin{array}{l}\text { CTS (1 } \\
\text { al año) }\end{array}$ & $\begin{array}{c}\text { CT } \\
\text { Unitario }\end{array}$ & $\begin{array}{c}\text { No de } \\
\text { Empleados }\end{array}$ & $\begin{array}{l}\text { Costo } \\
\text { Total }\end{array}$ \\
\hline Administrador & 3,500 & 38,500 & 1,750 & 3,500 & 43,750 & 3,938 & 1,896 & 49,583 & 1 & 49,583 \\
\hline Asistente Logístico & 1,200 & 13,200 & 600 & 1,200 & 15,000 & 1,350 & 650 & 17,000 & 1 & 17,000 \\
\hline Cocineros & 2,400 & 26,400 & 1,200 & 2,400 & 30,000 & 2,700 & 1,300 & 34,000 & 2 & 68,000 \\
\hline $\begin{array}{l}\text { Ayudante de } \\
\text { cocina }\end{array}$ & 1,200 & 13,200 & 600 & 1,200 & 15,000 & 1,350 & 650 & 17,000 & 2 & 34,000 \\
\hline Mozo & 1,200 & 13,200 & 600 & 1,200 & 15,000 & 1,350 & 650 & 17,000 & 4 & 68,000 \\
\hline Cajero & 1,200 & 13,200 & 600 & 1,200 & 15,000 & 1,350 & 650 & 17,000 & 1 & 17,000 \\
\hline Seguridad & 1,000 & 11,000 & 500 & 1,000 & 12,500 & 1,125 & 542 & 14,167 & 1 & 14,167 \\
\hline Total & 11,700 & 128,700 & 5,850 & 11,700 & 146,250 & 13,163 & 6,338 & 165,750 & 12 & 267,750 \\
\hline
\end{tabular}

\subsection{Política de recursos humanos}

Según Chiavenato (2009) las principales políticas e instrumentos adoptados por las empresas investigadas en términos de porcentajes:

- Educación: programas de capacitación y desarrollo ejecutados por instituciones contratadas

- Política de remuneración asociada con los resultados de la empresa

- Vacaciones

- Horarios de Trabajo

- Administración del clima organizacional

- Política de valoración de la calidad de vida

- Política de identificación, desarrollo y retención de talentos

- Evaluación estructurada del desempeño

- Política de remuneración asociada con las habilidades y competencias A continuación, se muestra la política de recursos humanos el cual debe de ser respetado y acatado por todos los colaboradores de "Entre Copas y Tenedores". 


\section{a. Educación}

La empresa capacita a sus trabajadores de acuerdo al perfil, funciones y/o competencias, negocia acuerdos con cadenas de supermercados mayoristas para capacitar a su personal operativo. Ejemplo: Nuevas tendencias culinarias, nuevas medidas de higiene, etc.

\section{b. Jornada Laboral y Asistencia del personal}

El artículo $25^{\circ}$ de la constitución política del Perú señala que la jornada ordinaria de trabajo es de ocho horas diarias o cuarenta y ocho horas semanales, como máximo. En caso de jornadas acumulativas o atípicas, el promedio de horas trabajadas en el periodo correspondiente no puede superar dicho máximo.

- Todo el personal deberá registrar la hora de ingreso y salida, es personal e intransferible.

- Cuando el colaborador haya registrado su hora de ingreso se dará por iniciada la jornada laboral efectiva.

- El refrigerio no forma parte de la jornada laboral, el tiempo por ley es de $45 \mathrm{~min}$.

- Se constituye como faltas laborales las inasistencias injustificadas, tardanzas, cumplimiento de funciones y/o cualquier tipo de agresiones físicas o morales.

- El descanso semanal obligatorio será de manera rotativa, esto se trabaja mediante un cronograma de turnos, para que todo el personal pueda rotar.

\section{c. Horarios de trabajo}

Los horarios de trabajo estarán sujetos a las programaciones de la semana de acuerdo a las horas de trabajo exigidas por ley. Es importante mencionar que el restaurante atenderá al público de lunes a sábado de 12:00 hasta las 10:00 p.m., sin embargo, los horarios de trabajo abarcan desde las 7:00 a.m. hasta las 11:00 p.m., y se distribuyen de la siguiente manera:

\section{Tabla 65}

Horario del personal 


\begin{tabular}{ccc}
\hline Personal & Desde & Hasta \\
\hline Administrador & 12:00 p.m. & 9:00 p.m. \\
Asistente logístico & 6:00 a.m. & 3:00 p.m. \\
Cocinero 1 & 7:00 a.m. & 4:00 p.m. \\
Cocinero 2 & 1:00 p.m. & 10:00 p.m. \\
Ayudante de cocina 1 & 7:00 a.m. & 4:00 p.m. \\
Ayudante de cocina 2 & 1:00 p.m. & 10:00 p.m. \\
Mozo 1 & 10:00 a.m. & 7:00 p.m. \\
Mozo 2 & 11:00 a.m. & 8:00 p.m. \\
Mozo 3 & 2:00 p.m. & 11:00 p.m. \\
Mozo 4 & 2:00 p.m. & 11:00 p.m. \\
Seguridad & 1:00 p.m. & $10: 00$ p.m. \\
Cajero & 12:00 p.m. & 9:00 p.m. \\
\hline
\end{tabular}

Nota Fuente. Elaboración propia

- $\quad$ Se puede compensar horas, siempre que exista un acuerdo entre el empleador y el empleado y conste por escrito.

\section{d. Vacaciones}

- $\quad$ Todos los colaboradores deben gozar de vacaciones dentro de los doce meses siguientes a los que adquieren el derecho vacacional.

- $\quad$ El periodo vacacional se contabiliza desde el primer día en que el trabajador deja de asistir al centro de labores hasta el día anterior a la fecha en que el colaborador se reincorpora a sus labores. El período vacacional incluye los descansos semanales obligatorios, feriados o días no laborales que estén comprendidos en el período de vacaciones.

- Ningún colaborador podrá exceder de 15 días calendario, de acuerdo al régimen de la empresa.

Todos los colaboradores van a tener un goce mínimo de 7 días calendario de vacaciones continuas para asegurar un periodo adecuado de descanso físico adecuado.

- Los colaboradores deben programar las fechas de vacaciones con 15 días hábiles de 
anticipación en coordinación con el administrador del establecimiento.

\section{e. Beneficios}

- $\quad$ Según Ley

\section{f. Política de identificación, desarrollo y retención de talentos}

Todas las personas tienen las mismas oportunidades de empleo y respetando las leyes laborales vigentes, en "Entre Copas y Tenedores" no existe discriminación alguna por raza, religión, color, racionalidad, edad, estado civil o por cualquier otra causa. Esta política se aplica en el proceso de reclutamiento selección y contratación de todos los colaboradores.

La empresa gestiona estrategia del talento, enfocándonos en un plan de desarrollo individual, donde se desarrollan metas laborales y personales a corto, mediano y largo plazo. 


\section{Capítulo IX. Planificación Financiera}

\subsection{La Inversión}

El plan de inversiones se presentará en forma desagregada: por etapas de negocio, por activos y capital de trabajo y, finalmente, indicando las reinversiones necesarias a lo largo del horizonte de vida del proyecto. (Arbaiza, 2013).

\subsubsection{La Inversión pre-operativa}

Una correcta estimación de la inversión inicial para la ejecución del negocio requiere del cálculo de los siguientes componentes:

a) El capital fijo, compuesto por los activos fijos (tangibles e intangibles) y por los gastos pre-operativos.

b) El capital de trabajo

Estos datos son fundamentales en la elaboración de presupuestos y para el análisis económico y financiero del negocio; por ello, se saben conocer con claridad los conceptos financieros señalados a continuación. (Arbaiza, 2013).

Para el presente plan de inversiones pre operativo se estimó los activos tangibles, para la parte de producción y administración, y activos intangibles, para la parte de producción. En esta distribución se consideran las maquinarias y equipos, muebles y enseres, y utensilios y herramientas, además los activos de la parte administrativa donde se hace referencia a la inversión de apertura, trámites y documentos de constitución de la empresa, algunos puntos resaltantes como la marcha blanca, pago de alquileres y garantía por adelantado y los equipos de cómputo. 
Tabla 66

Inversión en Activos Fijos de Producción (en soles)

\begin{tabular}{cc}
\hline Descripción & Inversión \\
\hline Maquinarias y equipos & 21,905 \\
Muebles y enseres & 3,908 \\
Utensilios y herramientas & 4,564 \\
\hline Total & $\mathbf{3 0 , 3 7 7}$
\end{tabular}

$\overline{\text { Nota Fuente. Elaboración propia - Proveedores varios }}$

Tabla 67

Inversión en Activos Fijos de Administración (en soles)

\begin{tabular}{cc}
\hline Descripción & Inversión \\
\hline Maquinarias y equipos & 9,400 \\
Muebles y enseres & 22,946 \\
Equipo de computo & 4,490 \\
\hline Total & $\mathbf{3 6 , 8 3 6}$
\end{tabular}

Nota Fuente. Elaboración propia - Proveedores varios

\section{Tabla 68}

Inversión Total en Activos Fijos (en soles)

\begin{tabular}{cc}
\hline Total Activo Fijo (c/ IGV) & 67,213 \\
Total Activo Fijo (sin IGV) & 56,960 \\
\hline
\end{tabular}

Nota Fuente. Elaboración propia

La inversión en soles en activo fijo, se considera como activo fijo a aquellos bienes que posee la empresa que no están destinados para la comercialización y que permitirán generar a la empresa ingresos futuros. El detalle de estos activos se presenta en el anexo 9. 
Además, se detalla la inversión en activos intangibles:

\section{Tabla 69}

Inversión en Intangibles (en soles)

\begin{tabular}{cc}
\hline Descripción & Inversión \\
\hline Constitución de la empresa & $2,320.09$ \\
Alquiler del local (un mes más garantía) & $9,000.00$ \\
Marketing pre operativo & $5,000.00$ \\
Software & $1,500.00$ \\
POS & 270.00 \\
Servicios (un mes de agua y luz) & 200.00 \\
\hline Total Intangible (con IGV) & $\mathbf{1 8 , 2 9 0 . 0 9}$ \\
\hline Total Intangible (sin IGV) & $\mathbf{1 7 , 0 1 4 . 9 0}$
\end{tabular}

Nota Fuente. Elaboración propia - Proveedores varios

\subsubsection{La Inversión en capital de trabajo}

Los activos corrientes, que generalmente se conocen como capital de trabajo, representan la parte de la inversión que pasa de una forma a otra en la conducción ordinaria del negocio. Esta idea incluye la transición continua del efectivo a los inventarios, a las cuentas por cobrar y, de nuevo, al efectivo. Como sustitutos del efectivo, los valores negociables se consideran parte del capital de trabajo. (Gitman, 2012).

Se consideró como capital de trabajo una semana de insumos, un mes de envases de delivery y un mes de útiles de limpieza. Esta conclusión se obtuvo de la entrevista a un administrador de restaurantes. 
Tabla 70

Cálculo del Capital de Trabajo (en soles)

\begin{tabular}{lcccccc}
\hline \multicolumn{1}{c}{ Capital de Trabajo } & $\mathbf{0}$ & $\mathbf{2 0 1 9}$ & $\mathbf{2 0 2 0}$ & $\mathbf{2 0 2 1}$ & $\mathbf{2 0 2 2}$ & $\mathbf{2 0 2 3}$ \\
\hline Insumos (una semana) & 4,738 & 4,738 & 4,833 & 4,930 & 5,026 & 5,124 \\
Útiles de limpieza & 2,045 & 2,045 & 2,086 & 2,128 & 2,170 & 2,211 \\
Envase de delivery & 252 & 252 & 258 & 263 & 268 & 273 \\
\hline Total & 7,035 & 7,035 & 7,177 & 7,320 & 7,464 & 7,608 \\
\hline Var. Capital de Trabajo & & - & 142 & 143 & 144 & 144 \\
\hline
\end{tabular}

Nota Fuente. Elaboración propia

\subsubsection{Costo del proyecto}

Cuando una empresa se constituye, normalmente incurre en una suma cuantiosa de costos cuyo objeto es poner en funcionamiento su administración. Por ejemplo, la escritura notarial, el registro de la misma, los honorarios de profesionales contratados para constituir la sociedad, la impresión de acciones, libros y registros, así como los permisos y demás trámites gubernamentales. Un negocio puede adquirir activos intangibles de otras compañías o desarrollarlos por sí mismo. Cuando un activo intangible se adquiere por medio de una compra, es necesario estimar el valor de los activos no monetarios dados a cambio. Además, el costo de adquisición de los activos fijos es también aplicables al concepto de intangibles. Los costos de activos fijos especifican que las inversiones en inmuebles, maquinaria y equipo deben evaluarse al costo de adquisición, al de construcción o, en su caso, a su valor equivalente. El costo de adquisición incluye el precio neto pagado por los bienes, más todos los gastos necesarios para tener el activo en el lugar y las condiciones que permitan su funcionamiento, como los derechos y gastos de importación, fletes, seguros, gastos de instalación o acondicionamiento necesarios para que el activo comience a operar. (Gitman, 2012). 
Para este proyecto, el $72.63 \%$ de la inversión es destinada a activos fijos tangibles para producción y administración; el 19.76\%, a activos intangibles; y el 7.60\%, a capital de trabajo.

\section{Tabla 71}

Inversión Total (en soles)

\begin{tabular}{ccc}
\hline Ítems & Total $(\mathrm{S} /)$ & $\%$ \\
\hline Activo Fijo Tangible & 67,213 & $72.63 \%$ \\
Activo Fijo Intangible & 18,290 & $19.76 \%$ \\
Capital de Trabajo & 7,035 & $7.60 \%$ \\
\hline Total & 92,538 & $100.00 \%$
\end{tabular}

Nota Fuente. Elaboración propia

La inversión total requerida para iniciar el proyecto en mención es S/ 92,538, monto financiado por aportes de capital de socios.

\subsubsection{Inversiones futuras.}

No se consideran inversiones futuras, dado que el local incluye suficiente espacio para cubrir las ventas proyectadas.

\subsection{Financiamiento.}

\subsubsection{Endeudamiento y condiciones.}

Gitman y Zutter explican que el endeudamiento o capital de deuda son "todos los préstamos en los que incurre una empresa, incluyendo los bonos, y que se reembolsan de acuerdo con un programa fijo de pagos.” (2012, p. 248). Estos pagos están sujetos a determinadas condiciones pactadas entre la empresa y el prestamista.

El presente proyecto no es bancable, dado que no existe ninguna relación comercial con el banco previa. Por lo tanto, toda la inversión es financiada con aporte social. 
Tabla 72

Financiamiento (en soles y en \%)

\begin{tabular}{ccc}
\hline Ítems & Total (S/) & $\%$ \\
\hline Capital Propio & 92,538 & $100.00 \%$ \\
Préstamo & - & $0.00 \%$ \\
\hline Total & $\mathbf{9 2 , 5 3 8}$ & $\mathbf{1 0 0 \%}$ \\
\hline
\end{tabular}

Nota Fuente. Elaboración propia

\subsubsection{Capital y costo de oportunidad}

Gitman y Zutter señalan que el costo de oportunidad o costo de capital "representa el costo de financiamiento de una compañía y es la tasa mínima de rendimiento que debe ganar un proyecto para incrementar el valor de la empresa". (2012, p.333).

En el presente proyecto, se utilizó el modelo CAPM para determinar la tasa de retorno exigida por el accionista. Dadas las condiciones de mercado y de la industria donde se desempeña Entre Copas y Tenedores, la tasa de retorno exigida por el accionista es igual a $17.38 \%$.

Tabla 73

Datos relevantes

\begin{tabular}{cc}
\hline Beta Apalancada & 0.6830 \\
Beta Desapalancada & 0.6830 \\
Tasa Impositiva Perú (IR) & $29.50 \%$ \\
Razón de Capital (E/(D+E) & $100.00 \%$ \\
Razón de Endeudamiento & \\
(D/(D+E) & $0.00 \%$ \\
Tasa Rf USA (2010-2019) & $3.54 \%$ \\
Rendimiento S\&P500 (2010- & $11.62 \%$ \\
2019) & $\mathbf{9 . 0 6 \%}$ \\
\hline COK Nominal USA
\end{tabular}

Nota Fuente. Elaboración propia 
Tabla 74

COK del proyecto

\begin{tabular}{cc}
\hline COK & $\%$ \\
\hline COK Nominal USA & $9.06 \%$ \\
Riesgo País Perú & $1.68 \%$ \\
Inflación USA & $1.90 \%$ \\
Inflación de Perú & $2.19 \%$ \\
Riesgo de Proyecto & $5 \%$ \\
Nuevo & \\
\hline COK apalancado Perú & $17.38 \%$ \\
\hline
\end{tabular}

Nota Fuente. Elaboración propia

Para el cálculo del costo de oportunidad del inversionista, se ha considerado el COK nominal de USA y se le añadió el riesgo país Perú para una inversión en dólares en Perú. Luego, se multiplicó por el ratio de inflaciones Perú / USA y se le añadió 5pbs por riesgo de proyecto nuevo.

\subsubsection{Costo de capital promedio ponderado}

Gitman y Zutter sostienen que "refleja el costo futuro promedio esperado de los fondos a largo plazo; se calcula ponderando el costo de cada tipo específico de capital de acuerdo con su proporción en la estructura de capital de la compañía”. (2012, p. 344).

Para determinar el costo de capital promedio ponderado, se utilizó la fórmula del WACC, considerando que los accionistas realizan aportes del 100\% de la inversión inicial requerida. 
Tabla 75

Cálculo del WACC (en \%)

\begin{tabular}{cc}
\hline COK apalancado Perú & $17.38 \%$ \\
Costo Deuda (Kd) & $0.00 \%$ \\
Razón de Capital (E/(D+E) & $100.00 \%$ \\
Razón de Endeudamiento & \\
(D/(D+E) & $0.00 \%$ \\
Tasa Impositiva Perú (IR) & $29.50 \%$ \\
\hline WACC & $\mathbf{1 7 . 3 8 \%}$ \\
\hline
\end{tabular}

Nota Fuente. Elaboración propia

\subsection{Presupuestos Base}

El presupuesto es una metodología que consiste en evaluar periodo a periodo, o bien en determinados periodos, las áreas, programas y los gastos de la empresa. Estos gastos deben de evaluarse detalladamente con el objetivo de que el proyecto sea lo más real posible.

\subsubsection{Presupuesto de ventas}

El presupuesto de ventas detallado por tipo de producto se muestra a continuación:

\section{Tabla 76}

Ingresos por tipo con $I G V$ (en soles)

\begin{tabular}{cccccc}
\hline & 2019 & 2020 & 2021 & 2022 & 2023 \\
\hline Menú & 253,700 & 258,844 & 264,010 & 269,200 & 274,415 \\
Delivery Menú & 166,595 & 169,972 & 173,365 & 176,773 & 180,197 \\
Almuerzo Extras & 91,130 & 92,977 & 94,833 & 96,697 & 98,570 \\
Cena Extras & 211,550 & 215,839 & 220,147 & 224,475 & 228,823 \\
Bebidas & 23,866 & 24,350 & 24,836 & 25,324 & 25,815 \\
\hline Total & $\mathbf{7 4 8 , 8 6 0}$ & $\mathbf{7 6 4 , 0 0 2}$ & $\mathbf{7 7 9 , 2 1 2}$ & $\mathbf{7 9 4 , 4 9 2}$ & $\mathbf{8 0 9 , 8 4 3}$
\end{tabular}

Nota Fuente. Elaboración propia 
Tabla 77

Ingresos por tipo $\sin I G V$ (en soles)

\begin{tabular}{cccccc}
\hline & 2019 & 2020 & 2021 & 2022 & 2023 \\
\hline Menú & 215,000 & 219,359 & 223,737 & 228,136 & 232,555 \\
Delivery Menú & 141,182 & 144,044 & 146,919 & 149,808 & 152,710 \\
Almuerzo Extras & 77,228 & 78,794 & 80,367 & 81,947 & 83,534 \\
Cena Extras & 179,280 & 182,914 & 186,565 & 190,233 & 193,918 \\
Bebidas & 20,225 & 20,635 & 21,047 & 21,461 & 21,877 \\
\hline Total & $\mathbf{6 3 4 , 6 2 7}$ & $\mathbf{6 4 7 , 4 5 9}$ & $\mathbf{6 6 0 , 3 4 9}$ & $\mathbf{6 7 3 , 2 9 8}$ & $\mathbf{6 8 6 , 3 0 8}$
\end{tabular}

Nota Fuente. Elaboración propia

\subsubsection{Presupuesto de costos de producción}

En las siguientes tablas se muestra el costeo por tipo de producto.

Tabla 78

Costeo por tipo con IGV (en soles)

\begin{tabular}{cccccc}
\hline & 2019 & 2020 & 2021 & 2022 & 2023 \\
\hline Almuerzo & 116,155 & 118,504 & 120,863 & 123,233 & 125,614 \\
Extras & 95,076 & 96,999 & 98,930 & 100,870 & 102,819 \\
Bebidas & 16,176 & 16,504 & 16,833 & 17,164 & 17,497 \\
& & & & & \\
\hline Total & $\mathbf{2 2 7 , 4 0 7}$ & $\mathbf{2 3 2 , 0 0 6}$ & $\mathbf{2 3 6 , 6 2 6}$ & $\mathbf{2 4 1 , 2 6 7}$ & $\mathbf{2 4 5 , 9 2 9}$
\end{tabular}

Nota Fuente. Elaboración propia 
Tabla 79

Costeo por tipo sin IGV (en soles)

\begin{tabular}{lccccc}
\hline & 2019 & 2020 & 2021 & 2022 & 2023 \\
\hline Almuerzo & 98,436 & 100,427 & 102,426 & 104,435 & 106,453 \\
Extras & 80,573 & 82,202 & 83,839 & 85,483 & 87,135 \\
Bebidas & 13,708 & 13,986 & 14,265 & 14,546 & 14,828 \\
\hline Total & $\mathbf{1 9 2 , 7 1 8}$ & $\mathbf{1 9 6 , 6 1 5}$ & $\mathbf{2 0 0 , 5 3 0}$ & $\mathbf{2 0 4 , 4 6 3}$ & $\mathbf{2 0 8 , 4 1 5}$
\end{tabular}

Nota Fuente. Elaboración propia

\subsubsection{Presupuesto de costo de ventas}

Según Stickney, Weil, Schipper, Francis y Avolio (2013), el presupuesto de costo de ventas comprende los cargos asociados directamente a la fabricación del producto o del servicio que se proyecta vender u ofrecer en un determinado periodo de tiempo. Los costos asociados son: costo de materia prima, mano de obra y gastos de fabricación.

El presupuesto de costo de ventas detallado por tipo de plato se encuentra en el anexo 10 .

\subsubsection{Presupuesto de gastos administrativos}

Según Stickney et al. (2013), los gastos administrativos son todos aquellos cargos en los que se incurre con el fin de administrar todas las actividades de una empresa y no son identificables con las operaciones de venta; por ejemplo: alquileres de oficinas, amortización, sueldos de personal interno y externo, pago de servicios, entre otros.

Los gastos administrativos están conformados por planilla, servicios y útiles de limpieza y oficina. 
Tabla 80

Pago de Planillas (en soles)

\begin{tabular}{ccccccccccc}
\hline Puesto & $\begin{array}{c}\text { Rem. } \\
\text { Mensual }\end{array}$ & $\begin{array}{c}\text { Rem. } \\
\text { Anual }\end{array}$ & Vacaciones Gratificaciones & $\begin{array}{c}\text { Sub. } \\
\text { Total }\end{array}$ & Essalud & $\begin{array}{c}\text { CTS (1 } \\
\text { al año) }\end{array}$ & $\begin{array}{c}\text { CT } \\
\text { Unitario }\end{array}$ & $\begin{array}{c}\text { No de } \\
\text { Empleados }\end{array}$ & $\begin{array}{c}\text { Costo } \\
\text { Total }\end{array}$ \\
\hline Administrador & 3,500 & 38,500 & 1,750 & 3,500 & 43,750 & 3,938 & 1,896 & 49,583 & 1 & 49,583 \\
Asistente Logístico & 1,200 & 13,200 & 600 & 1,200 & 15,000 & 1,350 & 650 & 17,000 & 1 & 17,000 \\
Cocineros & 2,400 & 26,400 & 1,200 & 2,400 & 30,000 & 2,700 & 1,300 & 34,000 & 2 & 68,000 \\
Ayudante de & 1,200 & 13,200 & 600 & 1,200 & 15,000 & 1,350 & 650 & 17,000 & 2 & 34,000 \\
cocina & & & & & & & & & & \\
Mozo & 1,200 & 13,200 & 600 & 1,200 & 15,000 & 1,350 & 650 & 17,000 & 4 & 68,000 \\
Cajero & 1,200 & 13,200 & 600 & 1,200 & 15,000 & 1,350 & 650 & 17,000 & 1 & 17,000 \\
Seguridad & 1,000 & 11,000 & $\mathbf{5 0 0}$ & 1,000 & 12,500 & 1,125 & 542 & 14,167 & 1 & 14,167 \\
\hline Total & $\mathbf{1 1 , 7 0 0}$ & $\mathbf{1 2 8 , 7 0 0}$ & $\mathbf{5 , 8 5 0}$ & $\mathbf{1 1 , 7 0 0}$ & $\mathbf{1 4 6 , 2 5 0}$ & $\mathbf{1 3 , 1 6 3}$ & $\mathbf{6 , 3 3 8}$ & $\mathbf{1 6 5 , 7 5 0}$ & $\mathbf{1 2}$ & $\mathbf{2 6 7 , 7 5 0}$ \\
\hline
\end{tabular}

Nota Fuente. Elaboración propia

Tabla 81

Pago de Servicios (en soles)

\begin{tabular}{cccc}
\hline Servicio & Mensual & Anual c/IGV & Anual S/ IGV \\
\hline Luz & 300 & 3,600 & 3,051 \\
Agua & 400 & 4,800 & 4,068 \\
Alquiler & 4,500 & 54,000 & 54,000 \\
Gas & 2,200 & 26,400 & 22,373 \\
Trío Movistar & 200 & 2,400 & 2,034 \\
Mantenimiento de cámaras & 250 & 500 & 424 \\
Arbitrios & 250 & 3,000 & 3,000 \\
\hline Total & $\mathbf{8 , 1 0 0}$ & $\mathbf{9 1 , 7 0 0}$ & $\mathbf{8 8 , 9 4 9}$
\end{tabular}

Nota Fuente. Elaboración propia - Provedores Servicios Básicos

Tabla 82

Útiles de limpieza y oficina anuales (en soles)

\begin{tabular}{lccccc}
\hline & $\mathbf{2 0 1 9}$ & $\mathbf{2 0 2 0}$ & $\mathbf{2 0 2 1}$ & $\mathbf{2 0 2 2}$ & $\mathbf{2 0 2 3}$ \\
\hline Útiles de Limpieza & 24,359 & 24,852 & 25,347 & 25,844 & 26,343 \\
Útiles de oficina & 180 & 184 & 187 & 191 & 195 \\
\hline Total con IGV & $\mathbf{2 4 , 5 3 9}$ & $\mathbf{2 5 , 0 3 6}$ & $\mathbf{2 5 , 5 3 4}$ & $\mathbf{2 6 , 0 3 5}$ & $\mathbf{2 6 , 5 3 8}$ \\
\hline Total con IGV & $\mathbf{2 0 , 7 9 6}$ & $\mathbf{2 1 , 2 1 7}$ & $\mathbf{2 1 , 6 3 9}$ & $\mathbf{2 2 , 0 6 3}$ & $\mathbf{2 2 , 4 9 0}$ \\
\hline
\end{tabular}

Nota Fuente. Elaboración propia 


\subsubsection{Presupuesto de marketing y ventas}

Según Stickney et al. (2013), los gastos de marketing y ventas son todos aquellos relacionados a la venta, distribución, comercialización y publicidad de los productos o servicios ofertados por la empresa; por ejemplo: sueldos y comisiones de vendedores, publicidad, flete sobre ventas, entre otros.

Para el presente proyecto, se está considerando el $4 \%$ de los ingresos que servirá para la elaboración de los gastos de marketing del proyecto. Cada envase de delivery cuesta 0.20 (con IGV). Además, la comisión del POS es de 3.44\%, la misma que es asumida por el restaurante.

\section{Tabla 83}

Presupuesto proyectado de gastos de ventas (en soles)

\begin{tabular}{cccccc}
\hline & $\mathbf{2 0 1 9}$ & $\mathbf{2 0 2 0}$ & $\mathbf{2 0 2 1}$ & $\mathbf{2 0 2 2}$ & $\mathbf{2 0 2 3}$ \\
\hline Marketing & 25,385 & 25,898 & 26,414 & 26,932 & 27,452 \\
Envases & 2,781 & 2,833 & 2,890 & 2,946 & 3,004 \\
Comisión & 1,179 & 1,203 & 1,227 & 1,251 & 1,275 \\
POS & & & & & \\
\hline Total & $\mathbf{2 9 , 3 4 5}$ & $\mathbf{2 9 , 9 3 4}$ & $\mathbf{3 0 , 5 3 0}$ & $\mathbf{3 1 , 1 2 9}$ & $\mathbf{3 1 , 7 3 1}$ \\
\hline
\end{tabular}

Nota Fuente. Elaboración propia

Los detalles relacionados al gasto de marketing se detallan en el anexo 11, en el cual se especifica en que herramientas de publicidad se destina aproximadamente el $4 \%$ de los ingresos.

\subsubsection{Presupuesto de gastos financieros}

Según Stickney et al. (2013), los gastos financieros se generan a partir de los préstamos tomados por la empresa; es decir, de su decisión de obtener capital a través de financiamiento de terceros; por ejemplo: préstamos, descuentos por pronto pago, bonos emitidos, entre otros.

Para el presente caso, no tenemos gastos financieros, ya que no se tomó deuda bancaria. 


\subsection{Presupuestos de Resultados}

\subsubsection{Estado de Ganancias y Pérdidas}

Tabla 84

Estado de Ganancias y Pérdidas proyectado (en soles)

\begin{tabular}{|c|c|c|c|c|c|}
\hline \multicolumn{6}{|c|}{ ESTADO DE GANANCIAS Y PÉRDIDAS AL 31 DE DICIEMBRE DE 20XX } \\
\hline & 2019 & 2020 & 2021 & 2022 & 2023 \\
\hline Ventas & 634,627 & 647,459 & 660,349 & 673,298 & 686,308 \\
\hline Costo de Ventas & $-196,733$ & $-200,630$ & $-204,626$ & $-208,641$ & $-212,674$ \\
\hline Utilidad Bruta & 437,894 & 446,829 & 455,723 & 464,657 & 473,634 \\
\hline Gastos Administrativos & $-390,331$ & $-392,550$ & $-394,814$ & $-397,089$ & $-399,374$ \\
\hline Planilla & $-267,750$ & $-267,750$ & $-267,750$ & $-267,750$ & $-267,750$ \\
\hline Servicios & $-88,949$ & $-90,748$ & $-92,554$ & $-94,369$ & $-96,193$ \\
\hline Útiles de Aseo & $-22,529$ & $-22,950$ & $-23,407$ & $-23,867$ & $-24,328$ \\
\hline Depreciación & $-7,700$ & $-7,700$ & $-7,700$ & $-7,700$ & $-7,700$ \\
\hline Amortización & $-3,403$ & $-3,403$ & $-3,403$ & $-3,403$ & $-3,403$ \\
\hline Gastos de ventas & $-29,345$ & $-29,934$ & $-30,530$ & $-31,129$ & $-31,731$ \\
\hline Marketing & $-25,385$ & $-25,898$ & $-26,414$ & $-26,932$ & $-27,452$ \\
\hline Envases & $-2,781$ & $-2,833$ & $-2,890$ & $-2,946$ & $-3,004$ \\
\hline Comisión POS & $-1,179$ & $-1,203$ & $-1,227$ & $-1,251$ & $-1,275$ \\
\hline Utilidad Operativa & 18,218 & 24,345 & 30,378 & 36,439 & 42,529 \\
\hline Gastos Financieros & 0 & 0 & 0 & 0 & 0 \\
\hline Ingresos Financieros & 0 & 0 & 0 & 0 & 0 \\
\hline $\begin{array}{l}\text { Utilidad Antes de } \\
\text { Impuestos }\end{array}$ & 18,218 & 24,345 & 30,378 & 36,439 & 42,529 \\
\hline Impuesto a la Renta & $-5,374$ & $-7,182$ & $-8,962$ & $-10,750$ & $-12,546$ \\
\hline Utilidad Neta & 12,844 & 17,163 & 21,417 & 25,690 & 29,983 \\
\hline
\end{tabular}

Nota Fuente. Elaboración propia

\subsubsection{Estado de Situación Financiera proyectado}

Según Stickney et al. (2013), el Balance General proyectado, también conocido como Estado de Situación Financiera proyectado, es aquel que muestra la situación económica - financiera de un negocio a una fecha determinada. El Balance General proyectado incluye:

1. Activos: Recursos propios con el potencial de proporcionar futuros beneficios económicos a la empresa. 
2. Pasivos: Deudas adquiridas con terceros como entidades financieras, proveedores, empleados, gobierno, entre otros.

3. Patrimonio: Muestra los montos de fondos que han sido invertidos por los accionistas con el fin de ganar derechos de titularidad sobre los activos de la empresa.

\section{Tabla 85}

Estado de Situación Financiera proyectada (en soles)

\begin{tabular}{|c|c|c|c|c|c|}
\hline & 2019 & 2020 & 2021 & 2022 & 2023 \\
\hline ACTIVO CORRIENTE & 51,446 & 76,438 & 109,196 & 141,665 & 182,991 \\
\hline Efectivo & 45,484 & 70,356 & 102,993 & 135,340 & 176,545 \\
\hline Inventarios & 5,962 & 6,082 & 6,203 & 6,324 & 6,446 \\
\hline Cuentas por cobrar & - & - & - & - & - \\
\hline \multicolumn{6}{|l|}{ IGV x cobrar } \\
\hline ACTIVO NO CORRIENTE & 62,872 & 56,334 & 45,231 & 38,693 & 27,590 \\
\hline IME & 56,960 & 61,524 & 61,524 & 66,088 & 66,088 \\
\hline Depreciación & $-7,700$ & $-15,399$ & $-23,099$ & $-30,799$ & $-38,498$ \\
\hline Intangibles & 17,015 & 17,015 & 17,015 & 17,015 & 17,015 \\
\hline Amortización & $-3,403$ & $-6,806$ & $-10,209$ & $-13,612$ & $-17,015$ \\
\hline TOTAL ACTIVO & 114,318 & 132,772 & 154,427 & 180,357 & 210,581 \\
\hline PASIVO CORRIENTE & 8,936 & 10,227 & 10,465 & 10,705 & 10,946 \\
\hline Cuentas por Pagar & 8,936 & 10,227 & 10,465 & 10,705 & 10,946 \\
\hline CTS por pagar & 853 & 853 & 853 & 853 & 853 \\
\hline IGV por pagar & 3,406 & 4,546 & 4,637 & 4,728 & 4,819 \\
\hline Impuesto a la Renta & 448 & 598 & 747 & 896 & 1,046 \\
\hline Vacaciones por pagar & - & - & - & - & - \\
\hline ESSALUD por pagar & 1,772 & 1,772 & 1,772 & 1,772 & 1,772 \\
\hline ONP por pagar & 2,457 & 2,457 & 2,457 & 2,457 & 2,457 \\
\hline Obligación Financiera & - & - & - & - & \\
\hline PASIVO NO CORRIENTE & - & - & - & - & - \\
\hline Obligación Financiera & - & - & - & & \\
\hline TOTAL PASIVO & 8,936 & 10,227 & 10,465 & 10,705 & 10,946 \\
\hline TOTAL PATRIMONIO & 105,382 & 122,545 & 143,962 & 169,652 & 199,635 \\
\hline Capital social & 92,538 & 92,538 & 92,538 & 92,538 & 92,538 \\
\hline Reserva legal & 1,284 & 3,001 & 5,142 & 7,711 & 10,710 \\
\hline Utilidades acumuladas & 11,560 & 27,006 & 46,281 & 69,402 & 96,387 \\
\hline $\begin{array}{l}\text { TOTAL PASIVO + } \\
\text { PATRIMONIO }\end{array}$ & 114,318 & 132,772 & 154,427 & 180,357 & 210,581 \\
\hline
\end{tabular}

Nota Fuente. Elaboración propia

\subsubsection{Flujo de caja proyectado}

Según Stickney et al. (2013), el Flujo de Caja proyecta el efectivo que será generado como consecuencia de las actividades operativas, de inversión y financieras durante un periodo de tiempo específico. 
A continuación, se muestra el Flujo de Caja Libre para el Inversionista a través del método indirecto.

Tabla 86

Flujo de Caja Libre para el Accionista (en soles)

\begin{tabular}{|c|c|c|c|c|c|c|c|}
\hline & 2018 & 2019 & 2020 & 2021 & 2022 & 2023 & Perpetuidad \\
\hline Utilidad Neta & & 12,844 & 17,163 & 21,417 & 25,690 & 29,983 & \\
\hline (+) Depreciación & & 7,700 & 7,700 & 7,700 & 7,700 & 7,700 & \\
\hline (+) Amortización & & 3,403 & 3,403 & 3,403 & 3,403 & 3,403 & \\
\hline FGO (Flujo Generado por Operaciones) & - & 23,947 & 28,266 & 32,519 & 36,792 & 41,086 & \\
\hline Inv. Capital de Trabajo & 7,035 & & & & & & \\
\hline (-) Var. $\mathrm{CxC}$ & & $-12,601$ & - & - & - & - & \\
\hline (-) Var. Inventarios & & - & 120 & 121 & 121 & 122 & \\
\hline (+) Var. CxP & & 8,936 & 1,291 & 239 & 240 & 241 & \\
\hline FCO (Operating Cash Flow) & $-7,035$ & 45,484 & 29,436 & 32,637 & 36,911 & 41,205 & \\
\hline Activo Fijo & 67,213 & & 4,564 & & 4,564 & & \\
\hline Activo Intangible & 18,290 & & & & & & \\
\hline Recuperación del Activo & - & - & - & - & - & - & \\
\hline FCFF (Free Cash Flow to the Firm) & $-92,538$ & 45,484 & 24,872 & 32,637 & 32,347 & 41,205 & - \\
\hline (+) Préstamo & - & - & - & - & - & - & \\
\hline (-) Amortizaciones & - & - & - & - & - & - & \\
\hline FCFE (Free Cash Flow to Equity) & $-92,538$ & 45,484 & 24,872 & 32,637 & 32,347 & 41,205 & 109,949 \\
\hline
\end{tabular}

Nota Fuente. Elaboración propia 
Además, se presenta el flujo de caja a través del método directo.

Tabla 87

Flujo de Caja Método Directo

Flujo de Operativo Método Directo (en nuevos soles)

\begin{tabular}{lcccccc}
\hline & 2018 & 2019 & 2020 & 2021 & 2022 & 2023 \\
\hline Capital de trabajo & $-7,035$ & $-7,035$ & $-7,177$ & $-7,320$ & $-7,464$ & $-7,608$ \\
Ventas & & 748,860 & 764,002 & 779,212 & 794,492 & 809,843 \\
Costo de Ventas & & $-227,407$ & $-232,006$ & $-236,626$ & $-241,267$ & $-245,929$ \\
Planilla & & $-262,668$ & $-267,750$ & $-267,750$ & $-267,750$ & $-267,750$ \\
Envase delivery & & $-3,029$ & $-3,090$ & $-3,152$ & $-3,214$ & $-3,276$ \\
Utiles de limpieza & $-24,539$ & $-25,036$ & $-25,534$ & $-26,035$ & $-26,538$ \\
Marketing & & $-29,954$ & $-30,560$ & $-31,168$ & $-31,780$ & $-32,394$ \\
Comisión POS & & $-1,391$ & $-1,419$ & $-1,447$ & $-1,476$ & $-1,504$ \\
IGV por pagar & & $-37,466$ & $-53,414$ & $-55,549$ & $-56,640$ & $-57,735$ \\
Servicios & & $-104,960$ & $-107,082$ & $-109,214$ & $-111,356$ & $-113,507$ \\
Intereses por pagar & & - & - & - & - & - \\
Impuesto a la Renta & & $-4,927$ & $-7,031$ & $-8,813$ & $-10,601$ & $-12,396$ \\
\hline Flujo Operativo & $\mathbf{- 7 , 0 3 5}$ & $\mathbf{3 8 , 4 4 9}$ & $\mathbf{6 7 , 8 8 5}$ & $\mathbf{1 0 0 , 5 2 2}$ & $\mathbf{1 3 7 , 4 3 3}$ & $\mathbf{1 7 8 , 6 3 8}$ \\
\hline
\end{tabular}

Flujo de Inversiones (en nuevos soles)

\begin{tabular}{lcccccc}
\hline & 2018 & 2019 & 2020 & 2021 & 2022 & 2023 \\
\hline Activo Fijo & 67,213 & & 4,564 & & 4,564 \\
Activo Intangible & 18,290 & & & & & \\
\hline Flujo de Inversiones & $\mathbf{- 8 5 , 5 0 3}$ & $\mathbf{- 8 5 , 5 0 3}$ & $\mathbf{- 9 0 , 0 6 7}$ & $\mathbf{- 9 0 , 0 6 7}$ & $\mathbf{- 9 4 , 6 3 1}$ & $\mathbf{- 9 4 , 6 3 1}$ \\
\hline
\end{tabular}

Flujo de Caja Financiero (en nuevos soles)

\begin{tabular}{lcccccc}
\hline & 2018 & 2019 & 2020 & 2021 & 2022 & 2023 \\
\hline Deuda & - & - & - & - & - & - \\
Amortizaciones & - & - & - & - & - & - \\
Aporte Social & 92,538 & & & & & \\
\hline Flujo Financiero & $\mathbf{9 2 , 5 3 8}$ & $\mathbf{9 2 , 5 3 8}$ & $\mathbf{9 2 , 5 3 8}$ & $\mathbf{9 2 , 5 3 8}$ & $\mathbf{9 2 , 5 3 8}$ & $\mathbf{9 2 , 5 3 8}$ \\
\hline
\end{tabular}

Flujo de caja consolidado (en nuevos soles)

\begin{tabular}{lcccccc}
\hline & 2018 & 2019 & 2020 & 2021 & 2022 & 2023 \\
\hline Flujo de Caja Consolidado & - & $\mathbf{4 5 , 4 8 4}$ & $\mathbf{7 0 , 3 5 6}$ & $\mathbf{1 0 2 , 9 9 3}$ & $\mathbf{1 3 5 , 3 4 0}$ & $\mathbf{1 7 6 , 5 4 5}$ \\
\hline
\end{tabular}

Nota Fuente. Elaboración propia 


\section{Capítulo X. Evaluación Económica Financiera}

\subsection{Evaluación Financiera}

El proyecto tendrá un horizonte de cinco años, teniendo como año 0 el 2018 y serán utilizados indicadores financieros para poder evaluar la viabilidad del proyecto.

\subsubsection{TIR}

Gitman y Zutter indican que la tasa interna de retorno es "la tasa de descuento que iguala el VPN de una oportunidad de inversión con \$0; es la tasa de rendimiento que ganará la empresa si invierte en el proyecto y recibe las entradas de efectivo esperadas" (2012, p. 372).

A partir del flujo de caja libre para el accionista mostrado en el inciso 9.4.3., se ha calculado que la TIR para el presente proyecto es de $26.74 \%$ y de $37.48 \%$, incluyendo el flujo de perpetuidad, que es el último flujo del año 5 descontado a la TIR. Esta TIR mide la rentabilidad del proyecto de inversión. Debido a que esta rentabilidad supera al costo de oportunidad del inversionista se puede determinar que el proyecto es económicamente viable.

\subsubsection{VAN}

Gitman y Zutter señalan que el VAN o Valor Presente Neto “indica la cantidad de dinero que se espera como creación de riqueza de un proyecto de inversión” (2012, p.382). Para el presente proyecto, se han determinado los siguientes VAN, concluyendo que el proyecto es viable:

\section{Tabla 88}

Cálculo de VAN

\begin{tabular}{ll}
\hline VAN & S/ 17,023 \\
\hline VAN incluyendo perpetuidad & S/ 52,841 \\
\hline
\end{tabular}

Nota Fuente. Elaboración propia 


\subsubsection{Periodo de Recuperación de la Inversión Descontado}

Se descuenta el flujo de caja libre para el accionista a la tasa WACC y se acumula hasta recuperar la inversión inicial, es decir hasta que dé 0 .

Tabla 89

Flujo de Caja Libre para el Accionista Descontado

\begin{tabular}{|c|c|c|c|c|c|c|c|}
\hline & 0 & 1 & 2 & 3 & 4 & 5 & 6 \\
\hline $\begin{array}{l}\text { Flujo de Caja Libre para } \\
\text { Accionista }\end{array}$ & $-92,538$ & 45,484 & 24,872 & 32,637 & 32,347 & 41,205 & 109,949 \\
\hline $\begin{array}{l}\text { Flujo de Caja Libre para } \\
\text { Accionista Descontado }\end{array}$ & $-92,538$ & 38,750 & 18,053 & 20,182 & 17,041 & 18,494 & 42,042 \\
\hline $\begin{array}{l}\text { Flujo de Caja Libre para } \\
\text { Accionista Descontado } \\
\text { Acumulado }\end{array}$ & & $-53,788$ & $-35,735$ & $-15,554$ & 1,488 & 19,982 & 62,023 \\
\hline
\end{tabular}

Nota Fuente. Elaboración propia

Se calculó los siguientes que el periodo de recuperación de inversión descontado es de 3 años y 11 meses.

\subsubsection{ROE}

Según Gitman y Zutter (2012), el indicador de Return On Equity mide el rendimiento obtenido sobre la inversión de los accionistas comunes de la empresa. La manera de cálculo es la siguiente: $\mathrm{ROE}=$ Utilidad Neta / Patrimonio Neto.

Tabla 90

Cálculo del ROE (en \%)

\begin{tabular}{lccccc}
\hline & 2019 & 2020 & 2021 & 2022 & 2023 \\
\hline Utilidad Neta & 12,844 & 17,163 & 21,417 & 25,690 & 29,983 \\
Patrimonio & 105,382 & 122,545 & 143,962 & 169,652 & 199,635 \\
& & & & & \\
\hline ROE (\%) & $\mathbf{1 2 . 1 9 \%}$ & $\mathbf{1 4 . 0 1 \%}$ & $\mathbf{1 4 . 8 8 \%}$ & $\mathbf{1 5 . 1 4 \%}$ & $\mathbf{1 5 . 0 2 \%}$
\end{tabular}

Nota Fuente. Elaboración propia

\subsubsection{Ratios}

Según Gitman y Zutter (2012), los ratios financieros son razones que permiten analizar y supervisar el desempeño de la empresa. Estas razones se clasifican en: de liquidez, actividad, endeudamiento, rentabilidad y mercado. Las razones de liquidez, 
actividad y endeudamiento miden el riesgo del negocio; las de rentabilidad, el rendimiento y las de mercado, tanto el riesgo como rendimiento.

Tabla 91

Ratios de la empresa (en \%)

\begin{tabular}{lccccc}
\hline RATIOS & $\mathbf{2 0 1 9}$ & $\mathbf{2 0 2 0}$ & $\mathbf{2 0 2 1}$ & $\mathbf{2 0 2 2}$ & $\mathbf{2 0 2 3}$ \\
\hline LIQUIDEZ (AC/PC) & 5.76 & 7.47 & 10.43 & 13.23 & 16.72 \\
SOLVENCIA (A/P) & 12.79 & 12.98 & 14.76 & 16.85 & 19.24 \\
ROA (UN/A) & $11.24 \%$ & $12.93 \%$ & $13.87 \%$ & $14.24 \%$ & $14.24 \%$ \\
ROE (UN/E) & $12.19 \%$ & $14.01 \%$ & $14.88 \%$ & $15.14 \%$ & $15.02 \%$ \\
D/E & $8.48 \%$ & $8.35 \%$ & $7.27 \%$ & $6.31 \%$ & $5.48 \%$ \\
\hline
\end{tabular}

Nota Fuente. Elaboración propia

\subsection{Análisis de Riesgo}

\subsubsection{Análisis de punto de equilibrio}

El punto de equilibrio nos permite conocer la cantidad mínima para que los ingresos cubran los gastos fijos y variables; es decir, no se gane ni pierda.

\section{Tabla 92}

Punto de equilibrio (en unidades)

\begin{tabular}{lcc}
\hline Menús & & VS \\
\hline Precio & 11 & \\
Costo de Ventas & 220,675 & \\
CF ponderado & $\mathbf{2 7 , 7 2 3}$ & $\mathbf{3 8 , 2 0 9}$ \\
\hline Punto de Equilibrio & & VS \\
\hline Extras & 18 & \\
\hline Precio & 7 & \\
Costo de Ventas & 158,921 & \\
CF ponderado & $\mathbf{1 4 , 9 2 3}$ & $\mathbf{1 6 , 8 1 6}$ \\
\hline Punto de Equilibrio &
\end{tabular}

Nota Fuente. Elaboración propia 


\subsubsection{Análisis de sensibilidad}

Se denomina análisis de sensibilidad (AS) al procedimiento por medio del cual se puede determinar cuánto se afecta (cuán sensible es) la TIR ante cambios en determinadas variables del proyecto. (Baca, 2010)

Para el proyecto en mención se ha considerado el análisis de las variables precio de menú y costos de insumos.

Tabla 93

Sensibilidad al precio del menú

\begin{tabular}{lcccc}
\hline Precio de Menú & $\mathbf{1 0}$ & $\mathbf{1 0 . 5 0}$ & $\mathbf{1 1 . 5 0}$ & $\mathbf{1 2}$ \\
\hline TIR & $-12.28 \%$ & $9.13 \%$ & $42.60 \%$ & $57.46 \%$ \\
VAN & $-45,044$ & $-14,010$ & 48,057 & 79,091 \\
\hline
\end{tabular}

Nota Fuente. Elaboración propia

Tabla 94

Sensibilidad al costo de venta

\begin{tabular}{lrrrr}
\hline Costos de insumos & \multicolumn{1}{c}{$\mathbf{- 1 0 . 0 0 \%}$} & \multicolumn{1}{l}{$\mathbf{- 5 . 0 0 \%}$} & \multicolumn{1}{c}{$\mathbf{5 . 0 0 \%}$} & \multicolumn{1}{c}{$\mathbf{1 0 . 0 0 \%}$} \\
\hline VAN & $46.95 \%$ & $37.08 \%$ & $15.74 \%$ & $3.68 \%$ \\
TIR & $\mathrm{S} / .56,812$ & $\mathrm{~S} / .36,918$ & $\mathrm{~S} / .-2,871$ & $\mathrm{~S} / .-22,766$ \\
\hline
\end{tabular}

Nota Fuente. Elaboración propia

\subsubsection{Identificación de riesgos del proyecto}

Se identificaron los eventos que potencialmente representan un riesgo y pueden impactar en los resultados del proyecto de manera específica y medible. Los riesgos identificados son los siguientes:

- Cambios regulatorios y legislativos de la Municipalidad de Villa El Salvador.

- Estimaciones inexactas del precio del producto.

- Desabastecimiento de Insumos por desastres naturales. 
- Estimaciones inexactas de costos.

- Aparición de nuevos competidores.

- Cambios continuos en el precio de los insumos.

- Bajo rendimiento de los equipos de cocina.

- Falta de fidelidad del cliente.

- Alta rotación de personal.

- Falta de capacidad financiera a largo plazo.

- Uso inadecuado de las redes sociales.

- Regulaciones de licencias de defensa civil.

- Regulaciones de licencias de Higiene y seguridad.

- Complicaciones virales o biológicas que restrinjan el servicio en restaurantes.

\section{Análisis cualitativo de los riesgos}

Para la evaluación cualitativa se utiliza la matriz de riesgos, que permite clasificar las consecuencias para el objetivo del proyecto. Para determinar el impacto y probabilidad se utiliza una escala de "0 a 1", el cruce determina su clasificación cualitativa.

A continuación, se muestra la Matriz de evaluación de riesgos.

\section{Tabla 95}

Matriz de la evaluación de riesgos

\begin{tabular}{cccccc}
\hline \multirow{2}{*}{ Nivel de impacto } & \multicolumn{5}{c}{ Probabilidad } \\
\cline { 3 - 6 } & & 0.20 & Media & Alta & Muy Alta \\
\hline BAJO & 0.20 & 0.04 & 0.50 & 0.80 & 0.90 \\
MEDIO & 0.50 & 0.10 & 0.25 & 0.16 & 0.18 \\
ALTO & 0.80 & 0.16 & 0.40 & 0.40 & 0.45 \\
MUY ALTO & 0.90 & 0.18 & 0.45 & 0.72 & 0.72 \\
\hline
\end{tabular}

Nota Fuente. Elaboración propia 
Tabla 96

Escala de probabilidad

\begin{tabular}{ccl} 
ESCALA & NIVEL & \multicolumn{1}{c}{ PROBABILIDAD } \\
\hline 0.20 & BAJA & $\begin{array}{l}\text { No hay evidencia de que haya ocurrido, pero en condiciones } \\
\text { especiales se puede llegar a materializar el riesgo } \\
\text { Hay evidencia de ocurrencia bajo condiciones especiales } \\
\text { Hay evidencia de que ha ocurrido varias veces, sin embargo, en } \\
\text { condiciones especiales puede no materializarse el riesgo } \\
\text { Hay evidencias de ocurrencias y es casi seguro que se materialice el } \\
\text { riesgo }\end{array}$ \\
\hline
\end{tabular}

Nota Fuente. Elaboración propia

Tabla 97

Escala de impacto

\begin{tabular}{ccl} 
ESCALA & NIVEL & \multicolumn{1}{c}{ IMPACTO } \\
\hline 0.20 & BAJO & Si llegara a presentarse su impacto sería mínimo \\
0.50 & MEDIO & Si llegara a presentarse tendría mediana consecuencia \\
0.80 & ALTO & Si llegara a presentarse, tendría alta consecuencia \\
0.90 & MUY ALTO & Si llegara a presentarse, las consecuencias serían catastróficas \\
\hline
\end{tabular}

Nota Fuente. Elaboración propia

Después de haber identificado los riesgos del proyecto, pasamos a analizarlos

mediante escalas de probabilidad e impacto, pudiendo identificar en la tabla 94, el nivel de riesgo.

La estrategia de Respuesta que normalmente abordan las amenazas o los riesgos que pueden tener impactos negativos sobre los objetivos del proyecto en caso de materializarse, son: Evitar, transferir, mitigar y aceptar. Estas se clasificaron por la tabla 97, que nos permite por medio de la tolerancia de riesgo la prioridad de enfoque que debemos tener para minimizar los riesgos que representan al proyecto. 
Tabla 98

Tolerancia de riesgo

\begin{tabular}{|c|c|c|c|c|c|c|}
\hline RIESGO & \multicolumn{2}{|c|}{ ESCALA } & \multicolumn{2}{|c|}{ TOLERANCIA AL RIESGO } & $\begin{array}{c}\text { ESTRATEGIA } \\
\text { DE } \\
\text { RESPUESTA } \\
\end{array}$ & PRIORIDAD \\
\hline $\begin{array}{l}\text { MUY } \\
\text { ALTO }\end{array}$ & 1 & 0.7 & INTOLERABLE & $\begin{array}{l}\text { No se debe comenzar ni } \\
\text { continuar hasta que se } \\
\text { reduzca el riesgo }\end{array}$ & $\begin{array}{l}\text { TRANSFERIR } \\
\text { MITIGAR }\end{array}$ & INMEDIATA \\
\hline ALTO & 0.69 & 0.24 & IMPORTANTE & $\begin{array}{l}\text { No debe comenzarse el } \\
\text { trabajo hasta que no haya } \\
\text { riesgo, remediarse el } \\
\text { problema de forma } \\
\text { urgente }\end{array}$ & $\begin{array}{l}\text { TRANSFERIR } \\
\text { MITIGAR }\end{array}$ & ALTA \\
\hline MEDIO & 0.23 & 0.1 & MODERADO & $\begin{array}{c}\text { Se debe hacer el esfuerzo } \\
\text { para reducir el riesgo }\end{array}$ & $\begin{array}{l}\text { MITIGAR } \\
\text { ACEPTAR }\end{array}$ & MEDIA/ALTA \\
\hline BAJO & 0.1 & 0.001 & TOLERABLE & $\begin{array}{l}\text { No se necesita mejorar la } \\
\text { acción preventiva. Se } \\
\text { requiere comprobaciones } \\
\text { periódicas para asegurar } \\
\text { que se mantiene la } \\
\text { eficacia de la medida de } \\
\text { control }\end{array}$ & $\begin{array}{l}\text { MITIGAR } \\
\text { ACEPTAR }\end{array}$ & BAJA \\
\hline
\end{tabular}

Nota Fuente. Elaboración propia 
Tabla 99

Evaluación, Análisis y Estrategia de respuesta

\begin{tabular}{|c|c|c|c|c|c|c|c|}
\hline & RIESGOS & PROB. & IMPACTO & ESCALA & $\begin{array}{l}\text { NIVEL DE } \\
\text { RIESGO }\end{array}$ & $\begin{array}{c}\text { ESTRATEGIA } \\
\text { DE } \\
\text { RESPUESTA }\end{array}$ & PRIORIDAD \\
\hline $\mathrm{R} 1$ & $\begin{array}{l}\text { Cambios } \\
\text { regulatorios y } \\
\text { legislativos de la } \\
\text { municipalidad }\end{array}$ & 0.2 & 0.5 & 0.1 & BAJO & $\begin{array}{l}\text { MITIGAR } \\
\text { ACEPTAR }\end{array}$ & BAJA \\
\hline $\mathrm{R} 2$ & $\begin{array}{l}\text { Estimaciones } \\
\text { inexactas del precio } \\
\text { del producto }\end{array}$ & 0.2 & 0.8 & 0.16 & MEDIO & $\begin{array}{l}\text { MITIGAR } \\
\text { ACEPTAR }\end{array}$ & MEDIA/ALTA \\
\hline R3 & $\begin{array}{l}\text { Desabastecimiento } \\
\text { de Insumos }\end{array}$ & 0.8 & 0.9 & 0.72 & MUY ALTO & $\begin{array}{l}\text { TRANSFERIR } \\
\text { MITIGAR }\end{array}$ & INMEDIATA \\
\hline $\mathrm{R} 4$ & $\begin{array}{l}\text { Estimaciones } \\
\text { inexactas de costos }\end{array}$ & 0.5 & 0.8 & 0.4 & IMPORTANTE & $\begin{array}{l}\text { TRANSFERIR } \\
\text { MITIGAR }\end{array}$ & ALTA \\
\hline R5 & $\begin{array}{l}\text { Aparición de } \\
\text { nuevos } \\
\text { competidores }\end{array}$ & 0.8 & 0.8 & 0.64 & IMPORTANTE & $\begin{array}{l}\text { TRANSFERIR } \\
\text { MITIGAR }\end{array}$ & ALTA \\
\hline R6 & $\begin{array}{l}\text { Cambios continuos } \\
\text { en el precio de los } \\
\text { insumos }\end{array}$ & 0.8 & 0.8 & 0.64 & IMPORTANTE & $\begin{array}{l}\text { TRANSFERIR } \\
\text { MITIGAR }\end{array}$ & ALTA \\
\hline $\mathrm{R} 7$ & $\begin{array}{l}\text { Bajo rendimiento de } \\
\text { los equipos de } \\
\text { cocina }\end{array}$ & 0.8 & 0.9 & 0.72 & MUY ALTO & $\begin{array}{l}\text { TRANSFERIR } \\
\text { MITIGAR }\end{array}$ & INMEDIATA \\
\hline $\mathrm{R} 8$ & $\begin{array}{l}\text { Falta de fidelidad } \\
\text { del cliente }\end{array}$ & 0.8 & 0.8 & 0.64 & IMPORTANTE & $\begin{array}{l}\text { TRANSFERIR } \\
\text { MITIGAR }\end{array}$ & ALTA \\
\hline R9 & $\begin{array}{l}\text { Alta rotación de } \\
\text { personal }\end{array}$ & 0.8 & 0.5 & 0.4 & IMPORTANTE & $\begin{array}{l}\text { TRANSFERIR } \\
\text { MITIGAR }\end{array}$ & ALTA \\
\hline $\mathrm{R} 10$ & $\begin{array}{l}\text { Falta de capacidad } \\
\text { financiera a largo } \\
\text { plazo }\end{array}$ & 0.2 & 0.8 & 0.16 & MEDIO & $\begin{array}{l}\text { MITIGAR } \\
\text { ACEPTAR }\end{array}$ & MEDIA/ALTA \\
\hline R11 & $\begin{array}{l}\text { Uso inadecuado de } \\
\text { las redes sociales } \\
\text { Regulaciones de }\end{array}$ & 0.2 & 0.5 & 0.1 & BAJO & $\begin{array}{l}\text { MITIGAR } \\
\text { ACEPTAR }\end{array}$ & BAJA \\
\hline $\mathrm{R} 12$ & $\begin{array}{l}\text { licencias de defensa } \\
\text { civil } \\
\text { Regulaciones de }\end{array}$ & 0.8 & 0.5 & 0.4 & IMPORTANTE & $\begin{array}{l}\text { TRANSFERIR } \\
\text { MITIGAR }\end{array}$ & ALTA \\
\hline $\mathrm{R} 13$ & $\begin{array}{l}\text { licencias de Higiene } \\
\text { y seguridad }\end{array}$ & 0.8 & 0.5 & 0.4 & IMPORTANTE & $\begin{array}{l}\text { TRANSFERIR } \\
\text { MITIGAR }\end{array}$ & ALTA \\
\hline
\end{tabular}




\section{Conclusiones y Recomendaciones}

\section{Conclusiones}

- Con respecto a la investigación de mercado, se puede concluir que la mayoría de los encuestados prefiere almorzar comida criolla. Para eso se cuenta con una carta variada en la cual el precio de los menús es de $\mathrm{S} / 11$, mientras que el precio de los platos extras es de S/ 18 c/u. Estos precios son coherentes con las respuestas presentadas tanto el estudio cualitativo como el cuantitativo.

- La comida criolla tiene la mayor preferencia por parte del consumidor peruano, esto es validado gracias a los diferentes Focus Group y entrevistas llevadas a cabo, así como también demostrado en los resultados de las encuestas.

- La estrategia que se busca implementar es la de diferenciación y está basada en tres pilares: Calidad y buen sabor de los productos, servicio personalizado y ambientación llamativa y pintoresca.

- Según el análisis financiero, se puede concluir que el presente proyecto es económicamente viable, dado que tiene una TIR mayor al COK $(26.74 \%$ VS 17.38\%). Además, el VAN es positivo, igual a S/ 17,023.31.

\section{Recomendaciones}

- Se debe poner mucho énfasis en la limpieza del local mediante constante capacitación a los mozos y demás personal.

- Al no existir una marcada preferencia de los consumidores a un determinado restaurante, se debe trabajar dentro del Plan de Marketing las estrategias que 
permitan posicionar este nuevo restaurante en la mente de los consumidores como uno de buena calidad y servicio a precios módicos.

- Se debe incrementar y promocionar el servicio de delivery debido a que existe un enorme potencial de crecimiento al estar el negocio dentro de la zona comercial y cerca de la zona industrial del distrito; esto permitirá que la rentabilidad del proyecto se incremente aún más.

- Es recomendable establecer alianzas con proveedores de insumos básicos para la preparación de los platos, esto es posible debido a que dentro del distrito existen grandes mercados y centros de abastos.

- Las redes sociales del restaurante deben ser dinámicas para así poder mostrar a los posibles comensales la variedad de platos, la calidad del servicio, la ambientación, etc y así poder crear una comunidad virtual de clientes que puedan ir promocionando la existencia y atractivos de este negocio. 
Anexos

\section{Anexo 1: Fichas Técnicas de Focus Group TÉCNICAS EMPLEADAS FOCUS GROUP $\mathbf{N}^{\circ} 1$}

Localización Distrito de Villa el Salvador

Universo muestral Hombres y mujeres de 18 años a más que vivan, laboren y/o estudien en el distrito de Villa el Salvador, que lleven un estilo de vida progresistas, modernas, adaptados o conservadoras y pertenezcan al NSE A, B y C.

Técnica de reclutamiento Por conveniencia

Objetivos del estudio Recoger información cualitativa sobre el sector gastronómico en Villa el Salvador para el desarrollo de uno nuevo restaurante.

Temas estudiados

a) Conocimiento de preferencias gastronómicas.

b) Valoración de los atributos de un restaurante.

c) Importancia del ambiente del local.

d) Conocimiento de precios a pagar.

e) Frecuencia de consumo.

f) Opiniones de la propuesta de valor.

\begin{tabular}{ll}
\hline Duración & 60 minutos \\
\hline Fecha de estudio & Miércoles 02 de agosto de 2017 a las 19:00 \\
\hline Segmento de edad del & Grupos de 3 a 10 personas \\
público evaluado & De 18 a 65 años.
\end{tabular}




\section{TÉCNICAS EMPLEADAS FOCUS GROUP N $\mathbf{N}^{\circ} 2$}

\begin{tabular}{|c|c|}
\hline Localización & Distrito de Villa el Salvador \\
\hline Universo muestral & $\begin{array}{l}\text { Hombres y mujeres de } 18 \text { años a más que vivan, } \\
\text { laboren y/o estudien en el distrito de Villa el } \\
\text { Salvador, que lleven un estilo de vida progresistas, } \\
\text { modernas, adaptados o conservadoras y pertenezcan } \\
\text { al NSE A, B y C. }\end{array}$ \\
\hline Técnica de reclutamiento & Por conveniencia \\
\hline Objetivos del estudio & $\begin{array}{l}\text { Recoger información cualitativa sobre el sector } \\
\text { gastronómico en Villa el Salvador para el desarrollo } \\
\text { de uno nuevo restaurante. }\end{array}$ \\
\hline Temas estudiados & $\begin{array}{l}\text { a) Conocimiento de preferencias gastronómicas. } \\
\text { b) Valoración de los atributos de un restaurante. } \\
\text { c) Importancia del ambiente del local. } \\
\text { d) Conocimiento de precios a pagar. } \\
\text { e) Frecuencia de consumo. } \\
\text { f) Opiniones de la propuesta de valor. }\end{array}$ \\
\hline Duración & 60 minutos \\
\hline Fecha de estudio & Jueves 03 de agosto de 2017 a las 15:00 \\
\hline $\begin{array}{l}\text { Segmento de edad del } \\
\text { público evaluado }\end{array}$ & $\begin{array}{l}\text { Grupos de } 3 \text { a } 10 \text { personas } \\
\text { De } 18 \text { a } 65 \text { años. }\end{array}$ \\
\hline
\end{tabular}




\section{TÉCNICAS EMPLEADAS FOCUS GROUP N 3}

\begin{tabular}{|c|c|}
\hline Localización & Distrito de Villa el Salvador \\
\hline Universo muestral & $\begin{array}{l}\text { Hombres y mujeres de } 18 \text { años a más que vivan, } \\
\text { laboren y/o estudien en el distrito de Villa el } \\
\text { Salvador, que lleven un estilo de vida progresistas, } \\
\text { modernas, adaptados o conservadoras y pertenezcan } \\
\text { al NSE A, B y C. }\end{array}$ \\
\hline Técnica de reclutamiento & Por conveniencia \\
\hline Objetivos del estudio & $\begin{array}{l}\text { Recoger información cualitativa sobre el sector } \\
\text { gastronómico en Villa el Salvador para el desarrollo } \\
\text { de uno nuevo restaurante. }\end{array}$ \\
\hline Temas estudiados & $\begin{array}{l}\text { a) Conocimiento de preferencias gastronómicas. } \\
\text { b) Valoración de los atributos de un restaurante. } \\
\text { c) Importancia del ambiente del local. } \\
\text { d) Conocimiento de precios a pagar. } \\
\text { e) Frecuencia de consumo. } \\
\text { f) Opiniones de la propuesta de valor. }\end{array}$ \\
\hline Duración & 60 minutos \\
\hline Fecha de estudio & Lunes 07 de agosto de 2017 a las 15:00 \\
\hline $\begin{array}{l}\text { Segmento de edad del } \\
\text { público evaluado }\end{array}$ & $\begin{array}{l}\text { Grupos de } 3 \text { a } 10 \text { personas } \\
\text { De } 18 \text { a } 65 \text { años. }\end{array}$ \\
\hline
\end{tabular}




\section{TÉCNICAS EMPLEADAS FOCUS GROUP No 4}

\begin{tabular}{|c|c|}
\hline Localización & Distrito de Villa el Salvador \\
\hline Universo muestral & $\begin{array}{l}\text { Hombres y mujeres de } 18 \text { años a más que vivan, } \\
\text { laboren y/o estudien en el distrito de Villa el } \\
\text { Salvador, que lleven un estilo de vida progresistas, } \\
\text { modernas, adaptados o conservadoras y pertenezcan } \\
\text { al NSE A, B y C. }\end{array}$ \\
\hline Técnica de reclutamiento & Por conveniencia \\
\hline Objetivos del estudio & $\begin{array}{l}\text { Recoger información cualitativa sobre el sector } \\
\text { gastronómico en Villa el Salvador para el desarrollo } \\
\text { de uno nuevo restaurante. }\end{array}$ \\
\hline Temas estudiados & $\begin{array}{l}\text { a) Conocimiento de preferencias gastronómicas. } \\
\text { b) Valoración de los atributos de un restaurante. } \\
\text { c) Importancia del ambiente del local. } \\
\text { d) Conocimiento de precios a pagar. } \\
\text { e) Frecuencia de consumo. } \\
\text { f) Opiniones de la propuesta de valor. }\end{array}$ \\
\hline Duración & 60 minutos \\
\hline Fecha de estudio & Martes 08 de agosto de 2017 a las 19:00 \\
\hline $\begin{array}{l}\text { Segmento de edad del } \\
\text { público evaluado }\end{array}$ & $\begin{array}{l}\text { Grupos de } 3 \text { a } 10 \text { personas } \\
\text { De } 18 \text { a } 65 \text { años. }\end{array}$ \\
\hline
\end{tabular}




\section{Anexo 2: Guía de pautas de Focus Group}

\section{Guía de pautas de estudio cualitativo para conocer los gustos y preferencias al} momento de elegir un restaurante.

Dirigido a: Hombres y mujeres de 18 años a más, pertenecientes a hogares de los NSE A, B y C de Lima Sur y que hayan comido fuera de casa en el último mes.

\section{Introducción}

1.1 Agradecer la participación

- Presentación del coordinador

- Breve descripción de por qué fueron elegidos (que son representantes de muchos otros)

- Breve descripción de los objetivos del encuentro.

- Notificar que se grabará la discusión para no perder partes de la discusión.

Buenas tardes, mi nombre es , soy de profesión y

actualmente me encuentro estudiando una maestría en Ciencias Empresariales en la Universidad San Ignacio de Loyola. Veo sus nombres en los stickers que tienen cada uno pegados al pecho, lo que nos va a ayudar a conocernos mejor y a que esta conversación sea más fluida. Esta sesión grupal tiene un fin netamente académico y busca conocer a profundidad cuáles son sus gustos y preferencias para elegir un restaurante. Ustedes fueron elegidos por ser una muestra representativa de la población que nos interesa estudiar, por lo que necesitamos que sean sinceros con sus respuestas. Además, bajo su consentimiento esta sesión será grabada en audio y video a fin de no perder ningún detalle de esta discusión.

\section{Explicación de la dinámica y presentación}

2.1 Descripción de la dinámica de la sesión

- Duración del encuentro

- Respeto de la anonimidad 
- Dejar claro que se espera que se hable de sus opiniones y que no vamos a discutir experiencias personales.

- Dejar claro que nos interesa hacer una conversación grupal y que cada uno de ellos expresen libremente sus ideas y opiniones (que no hay buenas o malas ideas o respuestas a las cosas que vamos a discutir)

- Dejar claro que, si bien no esperamos que se pida permiso para hablar, si esperamos que cada uno escuche al otro y espera que el compañero termine de hablar para expresar su opinión.

La reunión durará aproximadamente 1 hora y lo que esperamos es conocer sus opiniones, gustos y preferencias cuando eligen un restaurante, acá no se discutirán experiencias personales y no hay respuestas buenas ni malas, todas son igual de importantes y válidas para nosotros. Si tienen una opinión distinta a la del compañero, por favor, levanten la mano para participar cuando este haya terminado de hablar, así podremos mantener el orden dentro de la sesión. ¿Hasta acá hay alguna pregunta?

2.2. Presentación de los participantes.

Antes de comenzar me gustaría saber un poquito sobre cada uno. Podrían presentarse y decir unas pocas palabras sobre ustedes: su nombre, edad, a qué se dedican, con quiénes viven y algo que quisieran compartir en esta sesión.

\section{Rompimiento de Hielo}

A continuación, me gustaría que juguemos un poco: La dinámica consistente en tomar la primera letra de nuestro nombre y mencionar un plato que lleve la misma letra como inicial y comentar si nos gusta o no y el porqué. Por ejemplo, mi nombre es Valeria y lo asocio con vainitas saltadas con vinagreta y verduras... muchas $V$ 's. La verdad es que a mí me encantan las verduras. Seguimos por mi lado derecho. 


\section{Preguntas}

Ahora vamos a conversar sobre un tema que nos gusta mucho a todos, sobre todos a los peruanos: la comida.

\subsection{Asociación de Palabras}

4.1.1. ¿Qué es lo primero que se les viene a la mente cuando les digo "restaurante"?

4.1.2. ¿Qué es lo primero que se les viene a la mente cuando les digo "comida"?

\subsection{Preguntas generales}

4.2.1 A la hora del almuerzo en un día laborable, ¿suelen comer en su centro de trabajo, piden delivery o comen en algún restaurante?

4.2.2 A la hora de almuerzo en un fin de semana o feriado, ¿suelen comer en casa, piden delivery o comen en algún restaurante?

4.2.3 Normalmente, ¿a qué hora desayuna, almuerza y cena?

4.2.4 ¿Cuál es su plato de comida preferido?

4.2.5 ¿Quiénes suelen influir en la decisión de ir a determinado restaurante?

4.2.6 ¿Cuántas veces al mes suelen ir a comer fuera de casa?

4.2.7 ¿A qué chef admira y por qué?

4.2.8 Si el chef previamente mencionado, les recomienda un restaurante, ¿ustedes irían?

4.2.9 ¿Prefieren pedir un menú o un plato a la carta y por qué?

4.2.10 ¿Cuál es el rango de precios promedio que ustedes están dispuestos a pagar por un plato a la carta?

4.2.11 ¿Cuál es el precio más bajo que pagaría por un plato a la carta? ¿Cuál es el precio más alto que pagaría por este? ¿De qué depende estos precios que acaba de mencionar?

4.2.12 ¿Cuál es el rango de precios promedio que ustedes están dispuestos a pagar por un menú? 
4.2.13 ¿Cuál es el precio más bajo que pagaría por un menú? ¿Cuál es el precio más alto que pagaría por este? ¿De qué depende estos precios que acaba de mencionar?

4.2.14 ¿Cuáles son las características que más valoran en un restaurante?

4.2.15 ¿Cuánto tiempo están dispuestos a esperar por una mesa en un restaurante?

4.2.16 ¿Consideran importante el servicio de delivery? ¿Por qué?

4.2.17 ¿Suelen seguir a los restaurantes a través de las redes sociales? ¿Cuáles son las más utilizadas?

\subsection{Preguntas Específicas}

El restaurante tiene la siguiente propuesta de valor:

"Está ubicado en el distrito de Villa el Salvador cerca de las vías principales del distrito, se llama ENTRE COPAS Y TENEDORES, ofrece platos criollos, marinos y bebidas en un ambiente colorido y pintoresco, decorado con cuadros llenos de frases de tipografía artística que hacen alusión a la popularidad y buena sazón de la comida peruana, complementada con música y videos para el entretenimiento del cliente y que este pueda pasar un momento agradable. El menú costará S/ 11; los platos a la carta, S/ 18; y las bebidas, entre $S / 3$ - S/ 5.”

4.3.1 ¿Qué les parece nuestra propuesta de valor?

4.3.2 ¿Qué les parece nuestros rangos de precios para cada tipo de comida? ¿Sugiere alguna variación?

4.3.3 ¿Preferirían menú, platos a la carta o ambos?

4.3.4 ¿Entre los platos criollos, qué les gustaría encontrar?

4.3.5 ¿Entre los platos marinos, qué les gustaría encontrar?

4.3.6 ¿Qué tipos de menú les gustaría encontrar?

4.3.7 ¿Qué postres les gustaría encontrar?

4.3.8 ¿Tienen alguna fusión / combinación que les gustaría encontrar? 
4.3.9 ¿Qué bebidas y tragos les gustaría encontrar en este lugar?

4.3.10 ¿Qué promociones les gustaría que se ofrezcan?

4.3.11 ¿Qué les parece nuestros rangos de precios para cada tipo de comida? ¿Sugiere alguna variación?

4.3.12 ¿Qué tipo de música les gustaría escuchar dentro del establecimiento?

4.3.13 ¿Qué horario preferiría para la atención del restaurante?

4.3.14 ¿Qué tipo de decoración le gustaría en el restaurante?

4.3.15 ¿Está de acuerdo con el nombre del restaurante? ¿Qué otro nombre sugiere o le gustaría?

\subsection{Evaluación de la competencia}

4.4.1 ¿Suelen recomendar restaurantes a sus familiares y amigos? ¿Qué factores tienen en cuenta para esto?

4.4.2 ¿Cuál es su restaurante o restaurantes preferidos y por qué? ¿Qué tipo de comida venden allí?

4.4.3 ¿Cómo se enteró de la existencia de ese o esos restaurantes?

4.4.4 ¿Han tenido alguna experiencia o recuerdo en dichos locales que quisieran compartir?

4.4.5 De los restaurantes mencionados por cada uno de ustedes, ¿Qué es lo que les gusta y no les gusta de esos?

4.4.6 ¿Ustedes consideran que dentro del distrito de Villa El Salvador existe un restaurante que se ajuste a sus preferencias?

4.4.7 Si les pregunto por los restaurantes de Villa El Salvador, ¿cuáles se les vienen a la mente? ¿Qué les gusta de los restaurantes que han mencionado o en qué les gustaría que cambien?

4.4.8 ¿Tienen en mente algún otro restaurante que les gustaría que esté en el distrito de Villa El Salvador? 


\subsection{9 ¿Cuál es el restaurante ideal para usted?}

\section{Cierre del Focus Group}

Muchas gracias por su tiempo y su participación, sus respuestas y comentarios serán utilizadas con fines exclusivamente académicos y de investigación. Ha sido un grupo bastante divertido e interesante para nuestra investigación. Buenas Tardes

Anexo 3: Ficha técnica de entrevista a profundidad - Docente de carrera de Administración de Hoteles y Restaurantes en ISIL.

TECNICAS EMPLEADAS

Localización

Supervisión

Técnica de reclutamiento

Objetivos del estudio

Obtener información acerca del rubro gastronómico en general y su importancia

\section{ENTREVISTA PROFUNDIDAD}

\section{Distrito de La Molina}

Supervisión continua

Técnica de bola de nieve

a) Consideraciones para incursionar en el rubro

b) Rentabilidad de un negocio gastronómico

c) Retos y Dificultades del sector

d) Consejos y Sugerencias para abrir un restaurante

Duración 30 - 40 minutos 


\begin{tabular}{|l|l|}
\hline \multicolumn{2}{|l|}{ FICHA TECNICA DEL ENTREVISTADO } \\
\hline Nombre: & Jorge Cerna \\
\hline Edad: & 60 años \\
\hline Nacionalidad: & Peruana \\
\hline Ocupación: & Docente y Coordinador de carrera de \\
\hline Profesión: & Administración de Hoteles y Restaurantes en ISIL \\
\hline Distrito de Residencia: & La Molina, Perú \\
\hline Breve reseña: & Más de 30 años como docente de áreas \\
& relacionadas a alimentación, hotelería y turismo \\
\hline
\end{tabular}

Anexo 4: Guía de entrevista a profundidad - Coordinador y Docente de la carrera de Administración de Hoteles y Restaurantes en ISIL.

Buenos tardes. Mi nombre es Víctor Jara y estamos realizando un estudio de mercado de los restaurantes en el distrito de Villa el Salvador.

La idea es poder conocer distintas opiniones para el desarrollo e implementación del negocio de restaurantes gourmet.

En este sentido, siéntase libre de compartir sus ideas en este espacio. Aquí no hay respuestas correctas o incorrectas, lo que importa es justamente su opinión sincera.

Cabe aclarar que la información es sólo para nuestro trabajo, sus respuestas serán unidas a otras opiniones expertos para su posterior análisis.

Para agilizar la toma de la información, resulta de mucha utilidad grabar la conversación antes que tomar notas a mano ya que toma mucho tiempo y se pueden perder cuestiones importantes.

¿Existe algún inconveniente en que grabemos la conversación? El uso de la grabación es sólo para fines de estudio. 
¡Desde ya muchas gracias por su tiempo!

1. ¿Cómo se incursionó en el mundo de la gastronomía?

A inicios de nuestra formación profesional, empecé al principio por otra carrera, conocí del trabajo en un Hotel, en Miraflores Cesar Hotel, y dentro de ello despertó mis expectativas por las actividades gastronómicas. Pedí pasar a esa área y así aprendí las actividades elementales, como siempre lo digo con total satisfacción, LAVANDO PLATOS. Luego de ahí seguimos adelante, nos capacitamos, nos formamos pasando por algunas escuelas de gastronomía, el INAP en su tiempo y ahora Cordon Blue, y así fue naciendo entre nosotros la expectativa de este fantástico mundo de la gastronomía.

2. ¿Qué retos y dificultades tuvo en su profesión?

Adaptarse a los horarios, las tendencias que se tienen, también se tuvo el reto de llevar nuestra gastronomía a otros lugares. Afortunadamente hemos tenido la oportunidad de salir de nuestro país, llevar la gastronomía por el mundo entero, como Europa, y seguir adelante. Uno de los sueños que tengo es que se difunda la comida regional a través de todo el mundo.

3. ¿Cuáles son las funciones principales de un cocinero?

Son específicamente, en principio habilitar una buena infraestructura, tener insumos a mano de buena calidad y satisfacer al cliente, llegar al gusto del cliente.

4. ¿Cuán rentable es para usted la gastronomía en el Perú?

La rentabilidad en los establecimientos de restauración ha ido creciendo en los últimos tiempos, hemos visto a muchos cocineros surgir de manera avanzada, por lo que considero que la rentabilidad está asegurada y satisface la necesidad de toda persona que jamás terminará de demandar. 
5. ¿Cuáles considera usted que son los platos de mayor demanda?

Depende de los lugares, si hablamos en lima obviamente serán los de comida criolla, en el norte por pescados y mariscos, en la sierra central son platos típicos de la región. Arequipa hace pación por su comida y hace conocer la de su región. Para Lima la comida criolla en general, como el criollo, el chifa, influencia italiana, etc. Es lo mejor que se maneja en el país.

6. ¿Cuál es el porcentaje mínimo de ganancia por plato?

Hay mínimos y máximos, pero dentro de la carta lo que se trata de manejar mayor beneficio en unos platos y menor en otros, hay un sistema de ingeniería del menú, platos que se venden de forma masiva la rentabilidad es baja y los no masivos la rentabilidad es mayor, en $\%$ la rentabilidad debe ser no menor al 25\% con relación al precio de venta.

7. ¿Cómo y qué métodos se utilizan para costear un plato de comida?

Se considera 4 aspectos, costo de insumos, mano de obra, gastos generales (servicios) y la rentabilidad.

8. ¿Cuál es el tiempo promedio de preparación de un plato a la carta?

No debe exceder los 15 minutos, en lo masivo la duración está en la preparación previa, pero durante el servicio el tiempo debe ser menor. El menú está dirigido a personas con el tiempo apretado y debemos optimizar el tiempo de atención.

9. ¿Qué técnicas se utilizan para minimizar el tiempo de cocción de la comida?

Sí, los métodos de blanqueado o pre cocción, esto agiliza al momento efectivo de la preparación del plato de que ahorremos tiempo. 
10. ¿Qué tipos de platos llevan más tiempo en preparar o cuáles resultan más complicados?

En general, son los que requieren salsas de base, de fondo, que se hace con anticipación, pero se debe tener listo para el servicio en sí. Dentro de la comida criolla, hay algunos que necesitan mucho tiempo de cocción, en la cocina internacional también, un sauco por ejemplo requiere 3 horas más o menos. El lomo saltado es lo más rápido, no debe exceder de 10 minutos es que tenemos una reserva de papas fritas pero el blanqueado debe ser previo.

11. ¿Cuáles son los insumos básicos que no deben faltar en la cocina?

Sal y pimienta, comino, aceite, papa, arroz, hierbas aromáticas, y luego depende de la carta.

12. ¿Qué técnicas se deben de utilizar para un correcto almacenaje de los alimentos?

Existen métodos de frio, y existen métodos de calor para lograr en no caer en temperaturas de riesgo, entre 5 a 60 grados, la conservación tiene que estar por encima o de bajo según sea el caso.

13. ¿Qué recomendaciones da a sus alumnos en el arte de la gastronomía?

Que tenga vocación, dedicación y gusto por el placer del cliente.

14. ¿Cuáles consideran que son los factores de éxito de un restaurante y cuál sería la ponderación de cada uno?

Yo considero que los factores de éxito son: Tecnología empleada al 15\%, personal al 20\%, comunicación al 10\%, calidad de productos y servicios al 20\%, precios al $20 \%$ y posicionamiento en el mercado, el resto.

15. ¿En qué tipo de comida se especializan más sus alumnos? 
Por el auge de la comida peruana, hay ciertas preferencias de nuestra cocina, también hay interés de la comida francesa e italiana, que son fundamentales, cierta predilección de la comida oriental que son comunes en nuestro medio y satisfacen las necesidades de comensales como turismo, pero lo que más abunda es la comida peruana.

16. Para un emprendedor, ¿Alguna apreciación o consejo con respecto a incursionar en el mundo de la gastronomía?

Mucha vocación de servicio, gusto estar mucho tiempo en una cocina parado y saber que los feriados no existen y estar siempre a la atención del cliente. Un emprendedor que incursiona como empresario debe manejar muy bien la gestión de insumos, conocer el mercado de consumidores, tener buen equipamiento, saber que los costos son fundamentales para obtener la rentabilidad y tener un grupo humano acorde a las necesidades.

Muchas gracias por su tiempo y su atención, sus respuestas serán utilizadas con fines exclusivamente académicos y de investigación. Buenas Tardes 


\section{Anexo 5: Ficha técnica de entrevista a profundidad - Dueño de restaurante \\ TECNICAS EMPLEADAS \\ ENTREVISTA PROFUNDIDAD}

\begin{tabular}{ll}
\hline Localización & Distrito de Santiago de Surco \\
\hline Supervisión & Supervisión continua \\
\hline Técnica de reclutamiento & Técnica de bola de nieve \\
\hline Objetivos del estudio & Obtener información acerca de la viabilidad, gestión y \\
& mantenimiento adecuado de un restaurante en Lima \\
\hline Temas estudiados & a) Aspectos generales sobre el mercado \\
& b) Administración de un negocio gastronómico \\
& c) Viabilidad de un restaurante \\
& e) Importancia de la presentación del producto \\
\hline Duración & f) Importancia de la calidad de los productos \\
\hline Fecha de estudio & 30 - 40 minutos \\
\hline
\end{tabular}

\begin{tabular}{|l|l|}
\hline \multicolumn{2}{|l|}{ FICHA TÉCNICA DEL ENTREVISTADO } \\
\hline Nombre: & Christiam Segura \\
\hline Edad: & 33 años \\
\hline Nacionalidad: & Peruana \\
\hline Ocupación: & Dueño del restaurante "El Punto del Sabor", \\
& ubicado en Santiago de Surco. \\
\hline Profesión: & Administrador \\
\hline Distrito de Residencia: & Santiago de Surco, Perú \\
\hline Breve reseña: & Administra y gestiona un restaurante que tiene 4 \\
& meses de funcionamiento. \\
\hline
\end{tabular}




\section{Anexo 6: Guía de entrevista a profundidad - Dueño de restaurante}

Buenos tardes. Mi nombre es Yams Monteagudo y estamos realizando un estudio de mercado de los restaurantes en el distrito de Villa el Salvador.

La idea es poder conocer distintas opiniones para el desarrollo e implementación del negocio de restaurantes gourmet.

En este sentido, siéntase libre de compartir sus ideas en este espacio. Aquí no hay respuestas correctas o incorrectas, lo que importa es justamente su opinión sincera.

Cabe aclarar que la información es sólo para nuestro trabajo, sus respuestas serán unidas a otras opiniones expertos para su posterior análisis.

Para agilizar la toma de la información, resulta de mucha utilidad grabar la conversación antes que tomar notas a mano ya que toma mucho tiempo y se pueden perder cuestiones importantes.

¿Existe algún inconveniente en que grabemos la conversación? El uso de la grabación es sólo para fines de estudio.

¡Desde ya muchas gracias por su tiempo!

1. ¿Cuál es la antigüedad de su restaurante?

Aproximadamente tiene 4 meses de haber iniciado.

2. ¿Qué tipo de comida ofrece?

El tipo de comida que ofertamos es comida criolla en todas sus dimensiones, luego todo lo que tiene que ver pescados y mariscos.

3. ¿Qué restricciones, dificultades o riesgos tuvo antes de abrir su restaurante? ¿Cómo las solucionó?

Justo empezamos cuando estaba el problema de los huaicos y tuvimos una serie de desabastecimiento de insumos, los precios estaban elevados, con el paso del tiempo los precios se fueron estabilizando y teníamos que tomar otras alternativas.

Para solucionar estos problemas; por ejemplo, en el restaurante hacemos 
menú criollo, teníamos que ponerle limón, canchita y refresco, entonces con el problema del limón teníamos que salir a buscar los más baratos. Las dificultades en Surco para sacar licencia son bastante rigurosas, exigen que se cumpla hasta el mínimo detalle y lo más complicado es tramitar el papel de defensa civil ya que esta entidad exige muchas especificaciones técnicas.

4. ¿Cuánto tiempo lleva involucrado en el ámbito de este negocio?

Un promedio de 10 años.

5. ¿Cuáles considera que son los factores de éxito en un negocio de este tipo?

El éxito está en la innovación, no intentar hacer competencia a los que están alrededor tuyo sino crear tu propio concepto y que la gente logré probar e identificarte como algo bueno, porque si intentas superar a la competencia, terminas copiando lo que hace el de costado, por eso preferí crear un concepto nuevo y diferente sobre lo que quiero preparar y mostrar a mis clientes en comparación a los demás.

6. ¿Cuál es el perfil del cliente que comúnmente visita su restaurante?

La clase media alta, trabajadores de oficinas o familias.

7. ¿Cuál ha sido la clave para atraer nuevos clientes?

La innovación en el servicio.

8. ¿Qué técnicas usa para fidelizar y retener a sus clientes?

Un buen servicio, ofrecerles un buen sabor, tratar de identificar lo que ellos no te dicen, tratas de meterte en la cabeza del cliente, hay muchos que quieren algo y no te lo piden, allí es donde tienes que descubrirlo. 
9. ¿En qué se diferencia de su competencia directa?

En la sazón, el ambiente y sobre todo la atención, que deben estar de la mano. Si tienes todo y no una buena atención, es casi seguro que ese cliente no regresará.

10. ¿Qué factores cree usted que tienen en consideración las personas para escoger determinado restaurante?

Bueno, lo que he podido identificar es dependiendo del tipo cliente, si estas en un sitio difícil de entrar, si no hay estacionamiento, si tu servicio es bueno las personas quieren regresar por eso, si es un lugar campestre la personas buscan una buena vista, buena atención, buena música, diversión.

11. ¿Cuáles son los problemas más comunes que se tiene al momento de gestionar un restaurante?

A veces sobran algunas cosas, se quedan las cosas que ya están cocidas, otro problema es el de almacenaje, nosotros identificamos el problema e inmediatamente estamos buscando solucionarlo. Por ejemplo, el tipo de almacenaje de los productos al momento de refrigerarlos, nos falta un poco de espacio para las verduras, pero ya hemos visto la forma de solucionar ese problema.

12. ¿Cómo está compuesta su estructura organizacional?

El restaurante es pequeño, estamos trabajando tres personas y a veces los fines de semana o eventos somos 4 , cuando trabajan 2 personas es fácil como tu ayudante tiene ideas o el desempeño de ayudarte, al final lo más importante es el reflejo que daremos a nuestros clientes en el plato. 
13. ¿Cuáles son los criterios para el reclutamiento, selección y capacitación del personal? y ¿Hay mucha o poca rotación de los colaboradores?

Las personas por naturaleza somos diferentes y tenemos que identificar sus necesidades, por ende, al momento de buscar un ayudante, trato que se adecue un montón a las necesidades que me faltan, cuando es un mozo, que no solo se ocupe de poner los cubiertos, de mostrar la carta, quiero que venda y asesore al cliente para la elección de su plato. Se hace un reclutamiento, se selecciona y finalmente se entrevista, en esta etapa te ves los criterios de cada uno y cuando selecciones a tus candidatos pasas a la última prueba que es la parte practica en la cual deben hacer lo que dicen. Lo que más valoro en un colaborador es la entrega y la honestidad, de nada me serviría tener una persona hábil, rápida pero deshonesta, con esas personas podrías llegar más lejos así estuviera incapacitado técnicamente, pero con el tiempo aprenderá mucho y te servirá de más en el futuro.

14. ¿Cuál es la cantidad necesaria de empleados (cocineros, ayudantes de cocina, azafatas y mozos) para atender un día cualquiera y un fin de semana?

Como ya mencioné anteriormente, estamos trabajando tres personas (cocinero, ayudante de cocina y mozo) y los fines de semana o en eventos somos 4 personas.

15. ¿Cuál es el precio promedio que cobra para cada tipo de plato? Por ejemplo: Platos marinos, platos criollos y menú.

Un menú esta entre 9 y 15 soles, mientras que los platos a la carta están entre 18 y 25 soles.

16. ¿Cómo controla la venta del día (cantidad de platos y caja) para obtener un óptimo funcionamiento de la operación del restaurante? 
Los pedidos tienen que ser comandados y por lo que se ha boletado, ambos deben coincidir para saber lo que se ha recaudado.

17. ¿Qué recomendaciones podría dar a las personas que estarían interesadas en poner su propio restaurante para controlar sus costos y reducir sus gastos?

Deben conocer bastante el tema, deben empaparse bien sobre donde conseguir los insumos, que más van a usar o no, a cuanto apuntan en verdad su producto, por ejemplo, quieren vender un producto a 15 soles, pero quieren hacerlo con un presupuesto de 4 soles, deben saber dónde van a comprar esos insumos para lograr lo planeado.

18. Con la experiencia que usted tiene, ¿Cuál cree que son los principales errores que cometen los pequeños negocios que empiezan a emprender en la gastronomía? No saben manejar sus costos al margen que el sitio puede ser comerciar o no, hacer mal cálculo de los productos usados

19. ¿Qué técnicas usa para controlar el inventario de su Almacén?

Todo lo que es compras, personalmente yo hago un sistema de verificación sobre lo que estoy comprando, es fácil robarse insumos del almacén por eso debes llevar un control.

20. ¿Cuáles son las herramientas de publicidad que usa para con su restaurante?

Al principio volantes, crear una página en internet y en el mismo tienes que tener un buen panel publicitario, promocionarse por las redes. Si el restaurante tiene Facebook, los clientes hacen comentarios, falta que uno o dos hagan comentarios de insatisfacción es malo, pues las personas se dejan llevar por lo que se dice y eso no es de muy buena ayuda para tu negocio 
21. Para un emprendedor, ¿Alguna otra apreciación o consejo con respecto a una adecuada gestión un restaurante?

Lo que podría decidirles es que expresen en los platos lo que ellos quieren que sus clientes vena, expresar su calidad y personalidad, no copiar a lo que hacen los otros restaurantes del costado, que sean más originales, la gente busca siempre lo diferente y lo otro es la perseverancia

Muchas gracias por su tiempo y su atención, sus respuestas serán utilizadas con fines exclusivamente académicos y de investigación. Buenas Tardes 
Anexo 7: Ficha técnica de entrevista a profundidad - Chef

TECNICAS EMPLEADAS

Localización

\section{ENTREVISTA PROFUNDIDAD}

Distrito de Villa el Salvador

\begin{tabular}{ll}
\hline Supervisión & Supervisión continua \\
\hline Técnica de reclutamiento & Técnica de bola de nieve \\
\hline Objetivos del estudio & Obtener información acerca de la gestión y mantenimiento \\
& de una cocina. \\
\hline Temas estudiados & a) Procesos de Cocina importantes \\
& b) Tendencias del rubro gastronómico \\
& c) Insumos necesarios en la cocina \\
\hline Duración & c) Limpieza y mantenimiento de la cocina \\
\hline Fecha de estudio & 30 - 40 minutos \\
\hline
\end{tabular}

\begin{tabular}{|l|l|}
\hline \multicolumn{2}{|l|}{ FICHA TECNICA DEL ENTREVISTADO } \\
\hline Nombre: & Sergio Grillo \\
\hline Edad: & 39 años \\
\hline Nacionalidad: & Peruana \\
\hline Ocupación: & Chef de Restaurante "Manos Morenas". \\
\hline Profesión: & Chef - Cocinero Técnico \\
\hline Distrito de Residencia: & La Molina \\
\hline Breve reseña: & 16 años de experiencia como cocinero en \\
& restaurantes de comida criolla. \\
\hline
\end{tabular}




\section{Anexo 8: Guía de entrevista a profundidad - Chef}

Buenos tardes. Mi nombre es Víctor Jara y estamos realizando un estudio de mercado de los restaurantes en el distrito de Villa el Salvador.

La idea es poder conocer distintas opiniones para el desarrollo e implementación del negocio de restaurantes gourmet.

En este sentido, siéntase libre de compartir sus ideas en este espacio. Aquí no hay respuestas correctas o incorrectas, lo que importa es justamente su opinión sincera.

Cabe aclarar que la información es sólo para nuestro trabajo, sus respuestas serán unidas a otras opiniones de expertos para el análisis exclusivamente con fines académicos.

Para agilizar la toma de la información, resulta de mucha utilidad grabar la conversación antes que tomar notas a mano ya que toma mucho tiempo y se pueden perder cuestiones importantes.

¿Existe algún inconveniente en que grabemos la conversación? El uso de la grabación es sólo para fines de estudio.

¡Desde ya muchas gracias por su tiempo!

1. ¿Dónde se formó como chef? y ¿Cuánto tiempo de experiencia tiene en el rubro gastronómico?

Me he formado en varios restaurantes, empecé en comedores pequeños de universidades como ayudante, fue pasando el tiempo y fui escalando puestos; pasé a ser ayudante de cocina, luego cocinero, chef y en los últimos años he estado en el tema de supervisión de restaurantes y chef ejecutivo de una cadena de pollerías. Aproximadamente tengo 16 años de experiencia.

2. ¿Cuál es su especialidad en el rubro gastronómico?

Estoy enfocado en lo que es comida peruana o criolla y comida rápida. 
3. ¿Cuál considera usted que es la tendencia en el rubro gastronómico peruano?

La tendencia es la fusión y se está implementando también bastante lo que es la comida molecular, que lo hacen actualmente restaurantes como Central o la Huaca Pucllana, esta es la tendencia a nivel mundial.

4. ¿Cuáles son los platos que más le piden?

El peruano siempre pide el lomo saltado (todas sus variaciones) y el ceviche.

5. ¿Las preferencias de los comensales suelen cambiar de forma periódica?

Por el clima si cambian, en verano por ejemplo se consume bastante ceviche y en invierno tiende a bajar las ventas de pollo a la brasa. La comida criolla si mantiene su nivel de venta todo el año, no hay picos altos ni bajos.

6. ¿Cuál considera usted que es el plato más representativo de la comida peruana y por qué?

El ceviche debido a que muchos restaurantes de comida criolla a pesar de no tener platos marinos a la carta siempre van a haber un ceviche para ofrecer al cliente, también el reconocimiento que tiene este plato a nivel internacional es muy importante.

7. ¿De qué manera considera usted puede ser creativo un chef?

Un chef es creativo en cualquier momento, pero esta creatividad sale a la luz cuando el chef tiene los insumos reducidos porque cuando uno dispone de todos los insumos se puede ser creativo, pero salen mejores recetas cuando los ingredientes son limitados. Sin embargo, la diversidad de insumos que existe en el Perú permite a los cocineros tener cientos de ideas para poder hacer un plato; por ejemplo, en Central se usa los pelos fritos del choclo como decoración de los platos, a mí no se me hubiera ocurrido eso. 
8. ¿Qué elemento o insumo considera usted que es indispensable dentro de toda cocina?

Si hablamos de la cocina peruana los insumos indispensables son: el ají (todas sus variedades), el arroz, la cebolla y la papa y otros tubérculos

9. ¿Qué cuidados se debe de tener con los insumos (alimentos) para su correcta refrigeración y Almacenaje?

Tener buenos PEPS (Primeros en entrar, primeros en salir), eso quiere decir buena rotación de los productos dentro de una cocina. Luego medir adecuadamente las temperaturas de los refrigeradores, congeladores, conservadores; siempre tener un formato de medición diaria de temperatura para saber cuándo las máquinas están fallando o no. El almacenamiento, las medidas de seguridad que todo cocinero sabe (20 cm. del suelo y $10 \mathrm{~cm}$ de la pared), para que los productos puedan tener una adecuada oxigenación y no lleguen a malograrse.

10. ¿Qué técnicas o procedimientos utiliza usted para una atención más rápida al momento de cocinar un plato a la carta o menú?

En los restaurantes se utiliza mucho la pre producción, esto es por ejemplo si en carta existe el arroz con pollo, se hace la mezcla del culantro, el ají amarillo y la cerveza con el pollo ( $\sin$ el arroz, ni las alverjas y zanahoria), esto se produce un día antes o de acuerdo a los días de producción del restaurante y se guarda en bolsas o tapers para luego ser congelados. Una vez que piden el arroz con pollo, esta mezcla sale y va una sarten para descongelarlo y posteriormente calentarlo añadiéndole un poco de arroz y el resto de las verduras sancochas y se cocina en la sartén. Esto se llama "Mise en place" que consiste en tener los ingredientes a disposición para los platos que se van a vender en durante el día. 
11. ¿Cuál considera que es el tiempo promedio para poder atender un plato a la carta y un menú?

15 minutos para platos a la carta como máximo, en el menú es distinto debido a que se hace una carta fija de lo que se va a vender diario y eso es lo que se prepara (ciertas cantidades), por eso el menú debería salir en 5 minutos debido a que ya se tiene hecho el plato, simplemente se sirve.

12. ¿Cuántos ayudantes de cocina necesita un día de semana, y cuántos los fines de semana?

Depende mucho de la capacidad del restaurante, esta se mide por las mesas y por la capacidad que se vaya a tener en hora pico cuando estén todos sentados. Por ejemplo, si se va a tener 100 personas en el restaurante, se necesitan 6 en cocina en diversas áreas (fríos, calientes y frituras).

13. ¿Cuál es el rol de cada ayudante y o participante en la cocina?

Eso lo determina el jefe de cocina o el chef, de acuerdo a las habilidades y el perfil del personal, se puede tener por ejemplo un encargado de fríos, un encargado de frituras, un encargado de calientes, un jefe de cocina y un lavaplatos que es muy importante en los restaurantes, este debe ser muy ágil y muy rápido ya que debe de lavar todos los utensilios empleados en la cocina. Depende mucho del jefe de cocina el rol de cada participante, esto va de la mano con los conocimientos que poseen.

14. ¿Considera usted que el avance tecnológico juega un rol importante para la preparación de alimentos y platos? ¿De qué manera considera que influye en la cocina?

Si juega un rol importante; por ejemplo, yo he trabajado con un horno alemán que me facilitaba la programación y rapidez en la preparación de los alimentos, este horno era programable y se podían cocinar varios alimentos como el arroz o el pollo y salían de una calidad excelente. Hay otras cosas como los "pica todo" que 
ayudan mucho en restaurantes de comida criolla en donde se tienen que picar grandes cantidades de cebolla, por ejemplo; básicamente este avance tecnológico influye en la rapidez. En cuanto a sabor, hay algunos equipos que si ayudan, actualmente en algunos restaurantes de 5 o 4 tenedores se aplica la cocción lenta con hornos especiales que ayudan a que las carnes adquieran distintos sabores al cocinarse en agua en 24 horas y a fuego lento.

15. ¿Qué técnicas o procedimientos usa para poder maximizar la merma de los insumos y de que alimentos se pueden obtener más rendimiento?

Cuando uno abre un restaurante, el chef o los encargados de hacer la carta tienen que asegurarse que los productos con los que se van a trabajar sean maximizados, es decir se utilicen menos productos, se compren menos productos y salgan bastantes platos. Por ejemplo, en una cevicheria, a la cebolla se le saca el corazón, este corazón queda para los aderezos de platos calientes o en algunos casos se usan también para choritos a la chalaca, esta es una manera de maximizar el producto y no tener tanta merma. En carnes es complicado y en pollo también, pero en verduras si se puede maximizar su uso completo.

16. ¿Qué tipo de platos y o alimentos se pueden reutilizar para el día siguiente sin perjudicar a la sazón y la salubridad de los platos servidos?

Eso depende del almacenamiento, en un restaurante de platos a la carta se puede congelar algunos productos para que estos duren más, hay máquinas que permiten congelar alimentos en menos de 5 minutos, mientras más rápido se aplique el frío el producto va a durar más. También se debe controlar diariamente la temperatura de estas cámaras de frio y el tipo de almacenamiento que tienen los productos: tapers, bolsas enumeradas con fecha de producción y fecha de vencimiento (el chef determina cuantos días va a durar). Normalmente el arroz 
cuando queda se utiliza para el consumo del personal, no sale a la venta del público.

17. ¿Cada cuánto tiempo debe de cambiarse los utensilios más usados en la cocina? o ¿En qué momento deben de cambiarse?

Eso depende mucho del uso, ahora por ejemplo se utilizan tablas de plástico y si uno no las sabe lavar se pueden ir manchando, aquí el lava platos debe saber lavar estos utensilios adecuadamente remojando estas tablas en lejía; igual pasa con las sartenes, estas sartenes deben ser usadas correctamente y no hay una fecha exacta en la cual se deba cambiar estos utensilios. Hay algunos concesionarios de comida que establecen políticas de cambio de utensilios de cocina, pero en un restaurante al ser costos muy altos estos cambios, se deben aprovechar al máximo estos utensilios, salvo estén dañados o rotos, en este caso si necesitan ser cambiados rápidamente.

18. De acuerdo a sus conocimientos, ¿Qué normas o estándares existen para la preparación de alimentos y limpieza de la cocina?

Los BPM (Buenas Prácticas de Manufactura) son suficiente, en donde hablan de contaminaciones cruzadas, cómo guardar las cosas (de limpieza, insumos), posas adecuadas para lavar platos (posas de agua caliente y posas donde entran con residuos), limpieza de los pisos, trabajar con guantes, tapa bocas, etc. Actualmente la mayoría de municipalidades piden BPM e inclusive realizan capacitaciones anuales a los jefes de cocina de los restaurantes y cocineros certificando la asistencia de estos. Las municipalidades realizan inspecciones periódicas para supervisar la aplicación de las BPM.

19. Para un emprendedor, ¿Alguna apreciación o consejo con respecto a una adecuada gestión de la cocina en un restaurante? 
Muchos restaurantes tienen el error de establecer el salón más grande que la cocina, esto está mal, la cocina debe ser proporcional al salón. Primero hay que ver el tamaño de la cocina de acuerdo al servicio que se quiera dar, si se va a dar menú no es una cocina muy grande, si hay platos a la carta si se necesita una cocina amplia. Segundo, hay que ver bien qué es lo que se va a ofrecer y qué hay alrededor del restaurante (estacionamientos, ubicación). Finalmente aplicar un servicio excelente ya que esto muy importante, si el cliente ve que existe un servicio muy bueno a pesar que la comida no es tan buena, el cliente va a volver a tu restaurante. El mozo también, al ser la cara del restaurante debe saber vender la comida, este debe estar muy presentable para dar una buena impresión al cliente.

Muchas gracias por su tiempo y su atención, sus respuestas serán utilizadas con fines exclusivamente académicos y de investigación. Buenas Tardes. 
Anexo 9: Detalle de inversiones en activo fijos

- Inversión en Activos Fijos (Producción)

\begin{tabular}{|c|c|c|c|}
\hline Descripción & Cantidad & $\begin{array}{c}\text { Precio } \\
\text { Unitario }\end{array}$ & $\begin{array}{r}\text { Precio } \\
\text { Total }\end{array}$ \\
\hline Licuadora industrial & 2 & 750 & 1500 \\
\hline Extractor y exprimidor & 2 & 230 & 460 \\
\hline Congeladora & 2 & 1400 & 2800 \\
\hline Cocina Industrial & 2 & 600 & 1200 \\
\hline Plancha Lisa & 2 & 4000 & 8000 \\
\hline Horno Cocina & 1 & 800 & 800 \\
\hline Ventilador de techo & 4 & 70 & 280 \\
\hline Balanza para $300 \mathrm{~kg}$ & 1 & 250 & 250 \\
\hline Refrigeradora & 2 & 1199 & 2398 \\
\hline Horno Microonda & 2 & 400 & 800 \\
\hline Licuadora & 2 & 499 & 998 \\
\hline Mesa trabajo & 1 & 1500 & 1500 \\
\hline Escurridora de Platos & 1 & 220 & 220 \\
\hline Campana Extractora & 1 & 699 & 699 \\
\hline Total Maquinaria y Equipos & & & 21,905 \\
\hline Unidad de estación de acero de cocina & 1 & 1000 & 1000 \\
\hline $\begin{array}{l}\text { Lavadero de acero y poza con } \\
\text { escurridor }\end{array}$ & 1 & 1860 & 1860 \\
\hline Purificador de agua & 1 & 150 & 150 \\
\hline Dispensador de jabón & 2 & 40 & 80 \\
\hline Estante de acero inoxidable & 2 & 270 & 540 \\
\hline Rack para almacenamiento & 2 & 114 & 228 \\
\hline Reloj de pared & 1 & 50 & 50 \\
\hline Total muebles y enseres & & & 3,908 \\
\hline Set cuchillos & 2 & 50 & 100 \\
\hline Cucharon acero & 4 & 6 & 24 \\
\hline
\end{tabular}




\begin{tabular}{|c|c|c|c|}
\hline Jarra de plástico graduada & 4 & 6 & 24 \\
\hline Tabla de picar & 4 & 15 & 60 \\
\hline Envase salsero comercial & 1 & 45 & 45 \\
\hline Platos de segundo & 120 & 6.2 & 744 \\
\hline Platos de ensalada & 90 & 4.2 & 378 \\
\hline Tenedores de acero inoxidable & 120 & 3.3 & 396 \\
\hline Cucharas de sopa & 120 & 3.3 & 396 \\
\hline Cuchillos de acero inoxidable & 120 & 3.5 & 420 \\
\hline Vasos de vidrio & 60 & 2.5 & 150 \\
\hline Azafates & 30 & 10 & 300 \\
\hline Afilador de cuchillos & 2 & 15 & 30 \\
\hline Alfombra anti fatiga negro & 2 & 135 & 270 \\
\hline Bowl de acero inoxidable 32" & 4 & 23 & 92 \\
\hline Ollas de acero inoxidable con tapa & 6 & 111 & 666 \\
\hline Secadores & 10 & 5 & 50 \\
\hline Tijera de cocina ambidiestra & 1 & 34 & 34 \\
\hline Carta física (A4) & 24 & 2.5 & 60 \\
\hline Aceitera & 1 & 50 & 50 \\
\hline Tápers de plástico & 50 & 0.3 & 15 \\
\hline Prensador de papas & 3 & 25 & 75 \\
\hline Salero & 30 & 3 & 90 \\
\hline Tachos & 5 & 15 & 75 \\
\hline Vinagrera & 2 & 10 & 20 \\
\hline Total Utensilios y herramientas & & & 4,564 \\
\hline TOTAL PARTE PRODUCCIÓN & & & 30,377 \\
\hline
\end{tabular}

- Inversión en Activos Fijos (Administración)

\begin{tabular}{cccc}
\hline Descripción & Cantidad & $\begin{array}{c}\text { Precio } \\
\text { Unitario }\end{array}$ & $\begin{array}{c}\text { Precio } \\
\text { Total }\end{array}$ \\
\hline Cámaras de seguridad & 3 & 2,000 & 6,000 \\
Minicomponente & 1 & 1,000 & 1,000
\end{tabular}




\begin{tabular}{|c|c|c|c|}
\hline Ventilador de techo & 3 & 300 & 900 \\
\hline Luces de emergencia & 5 & 200 & 1,000 \\
\hline Sensor de humo & 4 & 125 & 500 \\
\hline Total Maquinaria y Equipos & & & 9,400 \\
\hline Mueble de caja & 1 & 2,860 & 2,860 \\
\hline Juego Mesa y Silla & 14 & 250 & 3,500 \\
\hline Asientos Altos & 5 & 120 & 600 \\
\hline Letreros de publicidad (externo) & 2 & 2,300 & 4,600 \\
\hline Porta servilletas & 20 & 3 & 50 \\
\hline Señales de seguridad & 10 & 32 & 320 \\
\hline Barra para restaurante & 1 & 900 & 900 \\
\hline Dispensador de jabón & 2 & 13 & 26 \\
\hline Espejo para baño & 2 & 20 & 40 \\
\hline Reloj de pared & 2 & 100 & 200 \\
\hline Pintura con diseño del local & 1 & 2,500 & 2,500 \\
\hline Cuadros de pared & 15 & 70 & 1,050 \\
\hline Extintor PQS tipo ABC y $\mathrm{CO} 2$ & 4 & 150 & 600 \\
\hline Extintor acetato de potasio & 1 & 500 & 500 \\
\hline Televisor & 2 & 1,800 & 3,600 \\
\hline Kit Limpieza & 2 & 800 & 1,600 \\
\hline Total muebles y enseres & & & 22,946 \\
\hline Laptop & 1 & 2,500 & 2,500 \\
\hline Impresora & 1 & 490 & 490 \\
\hline Caja registradora & 1 & 1,500 & 1,500 \\
\hline Total Equipo de Cómputo & & & 4,490 \\
\hline TOTAL ADMINISTRACIÓN Y & & & 36,836 \\
\hline SALÓN & & & \\
\hline
\end{tabular}


- Inversión en renovación de decoración, utensilios y menaje

\begin{tabular}{|c|c|c|c|}
\hline Descripción & Cantidad & $\begin{array}{c}\text { Precio } \\
\text { Unitario }\end{array}$ & $\begin{array}{c}\text { Precio } \\
\text { Total } \\
\end{array}$ \\
\hline Set cuchillos & 2 & 45.00 & 90.00 \\
\hline Platos de segundo & 100 & 6.20 & 620.00 \\
\hline Platos de ensalada & 90 & 4.20 & 378.00 \\
\hline Tenedores de acero inoxidable & 100 & 3.30 & 330.00 \\
\hline Cucharas de sopa & 100 & 3.30 & 330.00 \\
\hline Cuchillos de acero inoxidable & 100 & 3.50 & 350.00 \\
\hline Vasos de vidrio & 60 & 2.50 & 150.00 \\
\hline Azafates & 30 & 10.00 & 300.00 \\
\hline Ollas de acero inoxidable con tapa & 6 & 111.00 & 666.00 \\
\hline Carta física (A4) & 24 & 2.50 & 60.00 \\
\hline Pintura Kolor Látex & 10 & 45.00 & 450.00 \\
\hline Focos LED & 20 & 18 & 360.00 \\
\hline Cuadros decorativos & 3 & 160 & 480.00 \\
\hline $\begin{array}{l}\text { Total de reinversión en decoración, } \\
\text { menaje }\end{array}$ & silios y & & $4,564.00$ \\
\hline
\end{tabular}


Anexo 10: Detalle de costeo por tipo de plato

- Detalle anual de costeo por platos de entrada (en kilos y soles)

\begin{tabular}{|c|c|c|c|c|c|c|}
\hline Ingredientes & Kg Netos & Merma & Kg Brutos & Precio de compra & Costo con IGV & Costo sin IGV \\
\hline Aceite & 22.85 & $0.00 \%$ & 22.85 & 7.50 & 171.36 & 145.22 \\
\hline Aceituna & 32.84 & $1.00 \%$ & 33.18 & 5.50 & 182.47 & 154.63 \\
\hline Acelga & 2.14 & $3.00 \%$ & 2.21 & 6.00 & 13.25 & 11.23 \\
\hline Ají amarillo & 25.70 & $3.00 \%$ & 26.50 & 3.50 & 92.75 & 78.60 \\
\hline Ají panca & 1.43 & $3.00 \%$ & 1.47 & 16.00 & 23.55 & 19.96 \\
\hline Ajinomoto & 4.28 & $0.00 \%$ & 4.28 & 10.50 & 44.98 & 38.12 \\
\hline Ajos & 45.41 & $0.00 \%$ & 45.41 & 10.50 & 476.81 & 404.08 \\
\hline Apio & 64.26 & $2.00 \%$ & 65.57 & 5.50 & 360.64 & 305.63 \\
\hline Alverja & 42.84 & $3.00 \%$ & 44.16 & 4.00 & 176.66 & 149.71 \\
\hline Beterraga & 42.84 & $3.00 \%$ & 44.16 & 2.50 & 110.41 & 93.57 \\
\hline Brócoli & 31.42 & $3.00 \%$ & 32.39 & 2.80 & 90.69 & 76.85 \\
\hline Camote & 142.80 & $3.00 \%$ & 147.22 & 1.30 & 191.38 & 162.19 \\
\hline Cebolla & 135.66 & $5.00 \%$ & 142.80 & 2.50 & 357.00 & 302.54 \\
\hline Cerveza & 25.70 & $0.00 \%$ & 25.70 & 3.50 & 89.96 & 76.24 \\
\hline Choclo & 14.28 & $3.00 \%$ & 14.72 & 4.80 & 70.66 & 59.88 \\
\hline Choclo desgranado & 85.68 & $0.00 \%$ & 85.68 & 4.80 & 411.26 & 348.53 \\
\hline Choclo entero & 114.24 & $3.00 \%$ & 117.77 & 5.00 & 588.87 & 499.04 \\
\hline Coliflor & 21.42 & $3.00 \%$ & 22.08 & 3.80 & 83.91 & 71.11 \\
\hline Comino & 7.14 & $0.00 \%$ & 7.14 & 13.00 & 92.82 & 78.66 \\
\hline Espinaca & 57.12 & $3.00 \%$ & 58.89 & 2.80 & 164.88 & 139.73 \\
\hline Fideo tornillo & 99.96 & $0.00 \%$ & 99.96 & 3.20 & 319.87 & 271.08 \\
\hline Galleta soda & 21.42 & $0.00 \%$ & 21.42 & 6.50 & 139.23 & 117.99 \\
\hline Harina & 71.40 & $0.00 \%$ & 71.40 & 3.00 & 214.20 & 181.53 \\
\hline Huevo & 86.60 & $0.00 \%$ & 86.60 & 7.00 & 606.20 & 513.73 \\
\hline Jamón tipo pizza & 14.28 & $0.00 \%$ & 14.28 & 12.00 & 171.36 & 145.22 \\
\hline Ketchup & 11.52 & $0.00 \%$ & 11.52 & 6.00 & 69.12 & 58.58 \\
\hline Leche & 31.42 & $0.00 \%$ & 31.42 & 4.00 & 125.66 & 106.49 \\
\hline Lechuga & 277.15 & $3.00 \%$ & 285.72 & 2.20 & 628.59 & 532.71 \\
\hline Limón & 449.82 & $0.00 \%$ & 449.82 & 3.00 & $1,349.46$ & $1,143.61$ \\
\hline Maní & 5.71 & $1.00 \%$ & 5.77 & 4.50 & 25.96 & 22.00 \\
\hline Mantequilla & 10.00 & $0.00 \%$ & 10.00 & 7.00 & 69.97 & 59.30 \\
\hline Manzana & 57.12 & $3.00 \%$ & 58.89 & 6.00 & 353.32 & 299.42 \\
\hline Mayonesa & 127.16 & $0.00 \%$ & 127.16 & 15.00 & $1,907.46$ & $1,616.49$ \\
\hline Orégano & 2.86 & $0.00 \%$ & 2.86 & 8.00 & 22.85 & 19.36 \\
\hline Palito anticucho & 71.40 & $0.00 \%$ & 71.40 & 0.05 & 3.57 & 3.03 \\
\hline Palta & 199.92 & $3.00 \%$ & 206.10 & 4.00 & 824.41 & 698.65 \\
\hline Pan de molde & 27.13 & $1.00 \%$ & 27.41 & 10.00 & 274.06 & 232.25 \\
\hline Papa amarilla & 31.42 & $3.00 \%$ & 32.39 & 2.50 & 80.97 & 68.62 \\
\hline Papa blanca & 114.24 & $3.00 \%$ & 117.77 & 2.50 & 294.43 & 249.52 \\
\hline Papa canchán & 556.92 & $0.00 \%$ & 556.92 & 2.00 & $1,113.84$ & 943.93 \\
\hline
\end{tabular}




\begin{tabular}{ccccccc} 
Pasas & 14.28 & $1.00 \%$ & 14.42 & 8.00 & 115.39 & 97.79 \\
Pechuga de pollo & 57.12 & $0.00 \%$ & 57.12 & 13.00 & 742.56 & 629.29 \\
Perejil & 7.14 & $3.00 \%$ & 7.36 & 2.50 & 18.40 & 15.59 \\
Pescado & 171.36 & $3.00 \%$ & 176.66 & 12.00 & $2,119.92$ & $1,796.54$ \\
Pimienta & 20.00 & $0.00 \%$ & 20.00 & 5.20 & 104.02 & 88.15 \\
Piña & 42.84 & $3.00 \%$ & 44.16 & 3.00 & 132.49 & 112.28 \\
Queso & 62.83 & $0.00 \%$ & 62.83 & 18.00 & $1,130.98$ & 958.45 \\
Queso parmesano & 5.71 & $1.00 \%$ & 5.77 & 24.00 & 138.47 & 117.35 \\
Rocoto & 77.11 & $3.00 \%$ & 79.50 & 4.00 & 317.99 & 269.48 \\
Sal & 34.28 & $0.00 \%$ & 34.28 & 1.00 & 34.28 & 29.05 \\
Tomate & 98.53 & $3.00 \%$ & 101.58 & 2.10 & 213.32 & 180.78 \\
Vainita & 99.96 & $3.00 \%$ & 103.05 & 3.50 & 360.68 & 305.66 \\
Vinagre & 24.28 & $0.00 \%$ & 24.28 & 3.00 & 72.83 & 61.72 \\
Vinagre blanco & 2.86 & $0.00 \%$ & 2.86 & 3.00 & 8.57 & 7.26 \\
Vino blanco & 1.44 & $0.00 \%$ & 1.44 & 12.00 & 17.28 & 14.64 \\
Huacatay & 28.56 & $3.00 \%$ & 29.44 & 2.80 & 82.44 & 69.87 \\
Zanahoria & 149.94 & $2.00 \%$ & 153.00 & 2.00 & 306.00 & 259.32 \\
\hline Total & & & & $\mathbf{1 8 , 3 9 7 . 2 4}$ & $\mathbf{1 5 , 5 9 0 . 8 8}$ \\
\hline
\end{tabular}

- Detalle anual de costeo por platos de sopas (en kilos y soles)

\begin{tabular}{|c|c|c|c|c|c|c|}
\hline Ingredientes & Kg Netos & Merma & Kg Brutos & Precio de compra & Costo con IGV & Costo sin IGV \\
\hline Ají amarillo & 6.48 & $3.00 \%$ & 6.68 & 3.00 & 20.04 & 16.98 \\
\hline Ajinomoto & 1.30 & $0.00 \%$ & 1.30 & 10.50 & 13.61 & 11.53 \\
\hline Ajos & 11.66 & $0.00 \%$ & 11.66 & 10.50 & 122.47 & 103.79 \\
\hline Apio & 84.24 & $3.00 \%$ & 86.85 & 2.50 & 217.11 & 183.99 \\
\hline Arroz & 32.40 & $2.00 \%$ & 33.06 & 3.00 & 99.18 & 84.05 \\
\hline Alverja & 3.89 & $3.00 \%$ & 4.01 & 5.00 & 20.04 & 16.98 \\
\hline Cabeza de pescado & 71.28 & $0.00 \%$ & 71.28 & 5.00 & 356.40 & 302.03 \\
\hline Cancha & 12.96 & $2.00 \%$ & 13.22 & 5.00 & 66.12 & 56.04 \\
\hline Cebolla & 33.70 & $3.00 \%$ & 34.74 & 2.50 & 86.85 & 73.60 \\
\hline Choclo & 90.72 & $0.00 \%$ & 90.72 & 5.50 & 498.96 & 422.85 \\
\hline Choros & 45.36 & $5.00 \%$ & 47.75 & 4.50 & 214.86 & 182.09 \\
\hline Col & 12.96 & $3.00 \%$ & 13.36 & 2.50 & 33.40 & 28.31 \\
\hline Culantro & 34.99 & $3.00 \%$ & 36.07 & 2.00 & 72.15 & 61.14 \\
\hline Espinaca & 2.59 & $3.00 \%$ & 2.67 & 4.00 & 10.69 & 9.06 \\
\hline Fideo cabello de ángel & 38.88 & $0.00 \%$ & 38.88 & 2.91 & 113.14 & 95.88 \\
\hline Fideo canuto & 16.20 & $0.00 \%$ & 16.20 & 1.50 & 24.30 & 20.59 \\
\hline Fideo corbata & 48.60 & $0.00 \%$ & 48.60 & 1.50 & 72.90 & 61.78 \\
\hline Fideo munición & 84.24 & $0.00 \%$ & 84.24 & 2.30 & 193.75 & 164.20 \\
\hline Fideo espagueti grueso & 19.44 & $0.00 \%$ & 19.44 & 2.91 & 56.57 & 47.94 \\
\hline Frejol canario & 9.72 & $2.00 \%$ & 9.92 & 6.00 & 59.51 & 50.43 \\
\hline Gallina entera & 16.20 & $5.00 \%$ & 17.05 & 12.00 & 204.63 & 173.42 \\
\hline Habas & 103.68 & $2.00 \%$ & 105.80 & 4.00 & 423.18 & 358.63 \\
\hline Hierba buena & 1.62 & $5.00 \%$ & 1.71 & 3.00 & 5.12 & 4.34 \\
\hline
\end{tabular}




\begin{tabular}{|c|c|c|c|c|c|c|}
\hline Huevo & 35.64 & $0.00 \%$ & 35.64 & 7.00 & 249.48 & 211.42 \\
\hline Kion & 5.18 & $2.00 \%$ & 5.29 & 2.00 & 10.58 & 8.97 \\
\hline Leche & 97.20 & $0.00 \%$ & 97.20 & 4.00 & 388.80 & 329.49 \\
\hline Mondongo & 16.20 & $0.00 \%$ & 16.20 & 10.00 & 162.00 & 137.29 \\
\hline Mote & 19.44 & $2.00 \%$ & 19.84 & 4.20 & 83.31 & 70.61 \\
\hline Nabo & 37.58 & $3.00 \%$ & 38.75 & 1.80 & 69.74 & 59.10 \\
\hline Orégano & 11.66 & $0.00 \%$ & 11.66 & 6.00 & 69.98 & 59.31 \\
\hline Papa amarilla & 16.20 & $3.00 \%$ & 16.70 & 2.50 & 41.75 & 35.38 \\
\hline Papa blanca & 38.88 & $3.00 \%$ & 40.08 & 2.50 & 100.21 & 84.92 \\
\hline Perejil & 27.22 & $3.00 \%$ & 28.06 & 2.00 & 56.12 & 47.56 \\
\hline Pescado & 77.76 & $3.00 \%$ & 80.16 & 12.00 & 961.98 & 815.24 \\
\hline Pollo entero & 81.00 & $5.00 \%$ & 85.26 & 8.00 & 682.11 & 578.06 \\
\hline Poro & 84.24 & $3.00 \%$ & 86.85 & 2.50 & 217.11 & 183.99 \\
\hline Res sancochado & 195.70 & $3.00 \%$ & 201.75 & 14.00 & $2,824.48$ & $2,393.63$ \\
\hline Sal & 12.31 & $0.00 \%$ & 12.31 & 1.00 & 12.31 & 10.43 \\
\hline Sazonador doña gusta & 2.59 & $0.00 \%$ & 2.59 & 19.00 & 49.25 & 41.74 \\
\hline Tomate & 19.44 & $3.00 \%$ & 20.04 & 2.50 & 50.10 & 42.46 \\
\hline Vino blanco & 2.59 & $0.00 \%$ & 2.59 & 9.00 & 23.33 & 19.77 \\
\hline Zanahoria & 114.70 & $3.00 \%$ & 118.24 & 2.00 & 236.49 & 200.41 \\
\hline Zapallo & 129.60 & $5.00 \%$ & 136.42 & 2.00 & 272.84 & 231.22 \\
\hline Total & & & & & $9,546.97$ & $8,090.65$ \\
\hline
\end{tabular}

- Detalle anual de costeo de platos de menú (en kilos y soles)

\begin{tabular}{|c|c|c|c|c|c|c|}
\hline Ingredientes & Kg Netos & Merma & Kg Brutos & Precio de compra & Costo con IGV & Costo sin IGV \\
\hline Aceite & 136.09 & $1.00 \%$ & 137.47 & 7.50 & $1,031.00$ & 873.73 \\
\hline Ají amarillo & 56.10 & $3.00 \%$ & 57.84 & 3.50 & 202.42 & 171.54 \\
\hline Ají mirasol & 0.84 & $3.00 \%$ & 0.87 & 12.00 & 10.39 & 8.81 \\
\hline Ají panca & 24.36 & $3.00 \%$ & 25.11 & 12.00 & 301.36 & 255.39 \\
\hline Ajinomoto & 2.10 & $0.00 \%$ & 2.10 & 10.50 & 22.05 & 18.69 \\
\hline Ajos & 72.30 & $1.00 \%$ & 73.03 & 10.50 & 766.82 & 649.85 \\
\hline Albahaca & 4.20 & $3.00 \%$ & 4.33 & 1.50 & 6.49 & 5.50 \\
\hline Arroz & 519.60 & $1.00 \%$ & 524.85 & 3.00 & $1,574.55$ & $1,334.36$ \\
\hline Alverja & 20.46 & $1.00 \%$ & 20.67 & 6.50 & 134.33 & 113.84 \\
\hline Brócoli & 4.20 & $3.00 \%$ & 4.33 & 5.80 & 25.11 & 21.28 \\
\hline Camote & 88.20 & $3.00 \%$ & 90.93 & 1.30 & 118.21 & 100.17 \\
\hline Carne guiso & 38.88 & $3.00 \%$ & 40.08 & 14.00 & 561.15 & 475.55 \\
\hline Cebolla & 110.46 & $3.00 \%$ & 113.88 & 2.50 & 284.69 & 241.26 \\
\hline Chicha de jora & 9.14 & $1.00 \%$ & 9.24 & 5.00 & 46.18 & 39.14 \\
\hline Chincho & 5.04 & $3.00 \%$ & 5.20 & 3.00 & 15.59 & 13.21 \\
\hline Choclo desgranado & 48.30 & $3.00 \%$ & 49.79 & 5.00 & 248.97 & 210.99 \\
\hline Choclo entero & 16.80 & $3.00 \%$ & 17.32 & 4.00 & 69.28 & 58.71 \\
\hline Chuleta de cerdo & 50.40 & $3.00 \%$ & 51.96 & 15.00 & 779.38 & 660.49 \\
\hline Comino & 0.13 & $1.00 \%$ & 0.13 & 9.00 & 1.15 & 0.97 \\
\hline Culantro & 21.14 & $3.00 \%$ & 21.80 & 2.00 & 43.60 & 36.95 \\
\hline Fideo espagueti & 42.00 & $1.00 \%$ & 42.42 & 3.90 & 165.45 & 140.22 \\
\hline
\end{tabular}




\begin{tabular}{|c|c|c|c|c|c|c|}
\hline Habas & 6.30 & $3.00 \%$ & 6.49 & 4.00 & 25.98 & 22.02 \\
\hline Harina & 16.80 & $1.00 \%$ & 16.97 & 3.00 & 50.91 & 43.14 \\
\hline Hierba buena & 2.10 & $3.00 \%$ & 2.16 & 3.00 & 6.49 & 5.50 \\
\hline Hígado & 42.00 & $3.00 \%$ & 43.30 & 10.00 & 432.99 & 366.94 \\
\hline Hongos & 0.42 & $1.00 \%$ & 0.42 & 12.00 & 5.09 & 4.31 \\
\hline Huacatay & 4.20 & $3.00 \%$ & 4.33 & 2.80 & 12.12 & 10.27 \\
\hline Huevos & 5.88 & $1.00 \%$ & 5.94 & 7.00 & 41.58 & 35.23 \\
\hline Laurel & 1.26 & $1.00 \%$ & 1.27 & 12.00 & 15.27 & 12.94 \\
\hline Leche & 6.72 & $1.00 \%$ & 6.79 & 4.00 & 27.15 & 23.01 \\
\hline Limón & 12.60 & $0.00 \%$ & 12.60 & 3.00 & 37.80 & 32.03 \\
\hline Mantequilla & 5.88 & $0.00 \%$ & 5.88 & 7.00 & 41.16 & 34.88 \\
\hline Mistura de mariscos & 63.00 & $3.00 \%$ & 64.95 & 9.00 & 584.54 & 495.37 \\
\hline Mondongo & 50.40 & $3.00 \%$ & 51.96 & 10.00 & 519.59 & 440.33 \\
\hline Orégano & 0.42 & $1.00 \%$ & 0.42 & 13.50 & 5.73 & 4.85 \\
\hline Palillo & 12.60 & $1.00 \%$ & 12.73 & 6.00 & 76.36 & 64.71 \\
\hline Pan molido & 1.68 & $1.00 \%$ & 1.70 & 3.00 & 5.09 & 4.31 \\
\hline Panko & 16.80 & $1.00 \%$ & 16.97 & 11.00 & 186.67 & 158.19 \\
\hline Papa & 168.72 & $3.00 \%$ & 173.94 & 2.50 & 434.85 & 368.51 \\
\hline Papa canchán & 235.20 & $3.00 \%$ & 242.47 & 2.50 & 606.19 & 513.72 \\
\hline Pasta de tomate & 3.36 & $0.00 \%$ & 3.36 & 2.80 & 9.41 & 7.97 \\
\hline Pechuga de pavo & 100.80 & $3.00 \%$ & 103.92 & 19.50 & $2,026.39$ & $1,717.28$ \\
\hline Pechuga de pollo & 92.40 & $3.00 \%$ & 95.26 & 13.00 & $1,238.35$ & $1,049.45$ \\
\hline Perejil & 2.10 & $3.00 \%$ & 2.16 & 3.00 & 6.49 & 5.50 \\
\hline Pescado & 46.20 & $3.00 \%$ & 47.63 & 12.00 & 571.55 & 484.36 \\
\hline Pimienta & 43.33 & $1.00 \%$ & 43.76 & 5.20 & 227.58 & 192.86 \\
\hline Pimiento & 10.50 & $1.00 \%$ & 10.61 & 5.00 & 53.03 & 44.94 \\
\hline Pollo entero & 760.20 & $3.00 \%$ & 783.71 & 8.00 & $6,269.69$ & $5,313.30$ \\
\hline Res guiso & 88.20 & $3.00 \%$ & 90.93 & 14.00 & $1,272.99$ & $1,078.80$ \\
\hline Romero & 0.42 & $3.00 \%$ & 0.43 & 5.60 & 2.42 & 2.05 \\
\hline Sal & 68.36 & $1.00 \%$ & 69.05 & 1.15 & 79.41 & 67.30 \\
\hline Sazonador Doña Gusta & 2.10 & $1.00 \%$ & 2.12 & 23.00 & 48.79 & 41.35 \\
\hline Tomate & 12.60 & $1.00 \%$ & 12.73 & 2.50 & 31.82 & 26.96 \\
\hline Vinagre blanco & 13.02 & $1.00 \%$ & 13.15 & 3.00 & 39.45 & 33.44 \\
\hline Vino tinto & 4.20 & $1.00 \%$ & 4.24 & 9.00 & 38.18 & 32.36 \\
\hline Yuca & 357.00 & $1.00 \%$ & 360.61 & 1.40 & 504.85 & 427.84 \\
\hline Zanahoria & 92.76 & $1.00 \%$ & 93.70 & 2.00 & 187.39 & 158.81 \\
\hline Total & & & & & $22,131.53$ & $18,755.53$ \\
\hline
\end{tabular}




\begin{tabular}{|c|c|c|c|c|c|c|}
\hline Ingredientes & $\mathrm{Kg}$ Netos & Merma & Kg Brutos & Precio de compra & Costo con IGV & Costo sin IGV \\
\hline Aceite & 99.43 & $1.00 \%$ & 100.44 & 7.50 & 753.27 & 638.37 \\
\hline Aceituna & 7.10 & $3.00 \%$ & 7.32 & 8.00 & 58.59 & 49.65 \\
\hline Ají amarillo & 69.50 & $3.00 \%$ & 71.65 & 3.50 & 250.79 & 212.53 \\
\hline Ají panca & 8.71 & $3.00 \%$ & 8.98 & 12.00 & 107.78 & 91.34 \\
\hline Ajinomoto & 1.78 & $0.00 \%$ & 1.78 & 10.50 & 18.65 & 15.80 \\
\hline Ajos & 33.88 & $1.00 \%$ & 34.22 & 10.50 & 359.35 & 304.54 \\
\hline Arroz & 767.88 & $1.00 \%$ & 775.64 & 3.00 & $2,326.91$ & $1,971.96$ \\
\hline Alverja & 19.67 & $1.00 \%$ & 19.87 & 6.50 & 129.13 & 109.44 \\
\hline Alverja partida & 26.64 & $3.00 \%$ & 27.46 & 5.00 & 137.32 & 116.37 \\
\hline Carne de guiso & 133.20 & $3.00 \%$ & 137.32 & 14.00 & $1,922.47$ & $1,629.22$ \\
\hline Cebolla & 99.82 & $3.00 \%$ & 102.90 & 2.50 & 257.26 & 218.02 \\
\hline Cerdo pierna deshuesada & 106.56 & $3.00 \%$ & 109.86 & 15.00 & $1,647.84$ & $1,396.47$ \\
\hline Chicha de jora & 1.78 & $0.00 \%$ & 1.78 & 5.00 & 8.88 & 7.53 \\
\hline Choclo desgranado & 6.66 & $3.00 \%$ & 6.87 & 4.00 & 27.46 & 23.27 \\
\hline Churrasco & 51.60 & $1.00 \%$ & 52.12 & 18.00 & 938.18 & 795.07 \\
\hline Comino & 0.07 & $1.00 \%$ & 0.07 & 9.00 & 0.61 & 0.51 \\
\hline Crema de leche & 79.92 & $0.00 \%$ & 79.92 & 7.50 & 599.40 & 507.97 \\
\hline Culantro & 5.33 & $3.00 \%$ & 5.49 & 2.00 & 10.99 & 9.31 \\
\hline Espinaca & 3.55 & $3.00 \%$ & 3.66 & 2.80 & 10.25 & 8.69 \\
\hline Fetuccini & 53.28 & $1.00 \%$ & 53.82 & 3.90 & 209.89 & 177.87 \\
\hline Hierba buena & 4.44 & $1.00 \%$ & 4.48 & 3.00 & 13.45 & 11.40 \\
\hline Huevo & 39.96 & $1.00 \%$ & 40.36 & 7.00 & 282.55 & 239.45 \\
\hline Laurel & 1.52 & $1.00 \%$ & 1.53 & 12.00 & 18.36 & 15.56 \\
\hline Leche & 74.59 & $1.00 \%$ & 75.35 & 4.00 & 301.38 & 255.41 \\
\hline Leche en tarro & 6.66 & $1.00 \%$ & 6.73 & 4.00 & 26.91 & 22.80 \\
\hline Lenteja & 26.64 & $3.00 \%$ & 27.46 & 5.00 & 137.32 & 116.37 \\
\hline Mantequilla & 15.10 & $1.00 \%$ & 15.25 & 7.00 & 106.74 & 90.46 \\
\hline Manzana & 8.88 & $3.00 \%$ & 9.15 & 6.00 & 54.93 & 46.55 \\
\hline Mayonesa & 3.55 & $1.00 \%$ & 3.59 & 3.50 & 12.56 & 10.64 \\
\hline Olluco & 57.72 & $3.00 \%$ & 59.51 & 5.00 & 297.53 & 252.14 \\
\hline Pan & 17.76 & $1.00 \%$ & 17.94 & 2.50 & 44.85 & 38.01 \\
\hline Papa & 140.40 & $1.00 \%$ & 141.82 & 2.50 & 354.55 & 300.46 \\
\hline Papa canchán & 186.48 & $1.00 \%$ & 188.36 & 2.50 & 470.91 & 399.08 \\
\hline Pasas & 0.89 & $0.00 \%$ & 0.89 & 8.00 & 7.10 & 6.02 \\
\hline Pasta de tomate & 29.88 & $0.00 \%$ & 29.88 & 2.80 & 83.66 & 70.90 \\
\hline Pechuga de pavo & 53.28 & $3.00 \%$ & 54.93 & 14.50 & 796.45 & 674.96 \\
\hline Pescado & 53.28 & $3.00 \%$ & 54.93 & 12.00 & 659.13 & 558.59 \\
\hline Pimienta & 6.32 & $1.00 \%$ & 6.39 & 13.50 & 86.23 & 73.08 \\
\hline Piña & 6.66 & $3.00 \%$ & 6.87 & 3.00 & 20.60 & 17.46 \\
\hline Plátano isla & 17.76 & $3.00 \%$ & 18.31 & 2.50 & 45.77 & 38.79 \\
\hline Pollo entero & 386.28 & $3.00 \%$ & 398.23 & 8.00 & $3,185.81$ & $2,699.84$ \\
\hline Pollo pechuga & 44.40 & $3.00 \%$ & 45.77 & 13.00 & 595.05 & 504.28 \\
\hline Queso parmesano & 22.20 & $1.00 \%$ & 22.42 & 13.00 & 291.52 & 247.05 \\
\hline Res bisteck & 44.40 & $3.00 \%$ & 45.77 & 18.00 & 823.92 & 698.24 \\
\hline
\end{tabular}




\begin{tabular}{|c|c|c|c|c|c|c|}
\hline Sal & 11.17 & $1.00 \%$ & 11.28 & 1.15 & 12.98 & 11.00 \\
\hline Sazonador Doña Gusta & 1.33 & $1.00 \%$ & 1.35 & 23.00 & 30.95 & 26.22 \\
\hline Sillao & 3.55 & $1.00 \%$ & 3.59 & 3.50 & 12.56 & 10.64 \\
\hline Tocino & 5.33 & $3.00 \%$ & 5.49 & 16.00 & 87.88 & 74.48 \\
\hline Tomate & 30.64 & $1.00 \%$ & 30.95 & 2.50 & 77.36 & 65.56 \\
\hline Vinagre blanco & 8.88 & $1.00 \%$ & 8.97 & 3.00 & 26.91 & 22.80 \\
\hline Vinagre tinto & 0.44 & $1.00 \%$ & 0.45 & 3.00 & 1.35 & 1.14 \\
\hline Yuca & 53.28 & $1.00 \%$ & 53.82 & 1.40 & 75.35 & 63.85 \\
\hline Zanahoria & 31.80 & $1.00 \%$ & 32.12 & 2.00 & 64.24 & 54.44 \\
\hline Total & & & & & $18,881.87$ & $16,001.59$ \\
\hline Ingredientes & Kg Netos & Merma & Kg Brutos & Precio de compra & Costo con IGV & Costo sin IGV \\
\hline Aceite & 157.25 & $1.00 \%$ & 158.84 & 7.50 & $1,191.27$ & $1,009.55$ \\
\hline Aceituna & 6.72 & $3.00 \%$ & 6.93 & 8.00 & 55.42 & 46.97 \\
\hline Ají amarillo & 108.94 & $3.00 \%$ & 112.31 & 3.50 & 393.07 & 333.11 \\
\hline Ají panca & 26.04 & $3.00 \%$ & 26.85 & 12.00 & 322.14 & 273.00 \\
\hline Ajinomoto & 1.68 & $0.00 \%$ & 1.68 & 10.50 & 17.64 & 14.95 \\
\hline Ajos & 57.41 & $1.00 \%$ & 57.99 & 10.50 & 608.87 & 515.99 \\
\hline Arroz & $1,183.92$ & $1.00 \%$ & $1,195.88$ & 3.00 & $3,587.64$ & $3,040.37$ \\
\hline Asado pejerrey & 92.40 & $3.00 \%$ & 95.26 & 19.50 & $1,857.53$ & $1,574.17$ \\
\hline Brócoli & 16.80 & $3.00 \%$ & 17.32 & 6.00 & 103.92 & 88.07 \\
\hline Carne de guiso & 100.80 & $3.00 \%$ & 103.92 & 10.50 & $1,091.13$ & 924.69 \\
\hline Cebolla & 196.08 & $3.00 \%$ & 202.14 & 2.50 & 505.36 & 428.27 \\
\hline Chicha de jora & 16.80 & $0.00 \%$ & 16.80 & 5.00 & 84.00 & 71.19 \\
\hline Coliflor & 42.00 & $3.00 \%$ & 43.30 & 4.00 & 173.20 & 146.78 \\
\hline Culantro & 11.76 & $3.00 \%$ & 12.12 & 3.00 & 36.37 & 30.82 \\
\hline Fideo espagueti & 84.00 & $1.00 \%$ & 84.85 & 3.90 & 330.91 & 280.43 \\
\hline Frejol canario & 92.40 & $3.00 \%$ & 95.26 & 6.00 & 571.55 & 484.36 \\
\hline Guiso de res & 193.20 & $3.00 \%$ & 199.18 & 14.00 & $2,788.45$ & $2,363.10$ \\
\hline Harina & 30.24 & $1.00 \%$ & 30.55 & 3.00 & 91.64 & 77.66 \\
\hline Hongos & 0.84 & $1.00 \%$ & 0.85 & 12.00 & 10.18 & 8.63 \\
\hline Huevera & 100.80 & $3.00 \%$ & 103.92 & 11.00 & $1,143.09$ & 968.72 \\
\hline Huevo & 58.80 & $1.00 \%$ & 59.39 & 7.00 & 415.76 & 352.34 \\
\hline Kion & 33.60 & $1.00 \%$ & 33.94 & 5.00 & 169.70 & 143.81 \\
\hline Laurel & 2.73 & $1.00 \%$ & 2.76 & 12.00 & 33.09 & 28.04 \\
\hline Leche & 26.04 & $1.00 \%$ & 26.30 & 4.00 & 105.21 & 89.16 \\
\hline Limón & 12.96 & $3.00 \%$ & 13.36 & 3.00 & 40.08 & 33.97 \\
\hline Mantequilla & 66.36 & $1.00 \%$ & 67.03 & 7.00 & 469.21 & 397.64 \\
\hline Pallares & 46.20 & $3.00 \%$ & 47.63 & 5.00 & 238.14 & 201.82 \\
\hline Papa & 319.20 & $1.00 \%$ & 322.42 & 2.50 & 806.06 & 683.10 \\
\hline Papa canchán & 84.00 & $1.00 \%$ & 84.85 & 2.50 & 212.12 & 179.76 \\
\hline Pasta de tomate & 28.56 & $1.00 \%$ & 28.85 & 2.80 & 80.78 & 68.45 \\
\hline Pescado & 201.60 & $3.00 \%$ & 207.84 & 12.00 & $2,494.02$ & $2,113.58$ \\
\hline Pescado toyo de leche & 100.32 & $3.00 \%$ & 103.42 & 18.00 & $1,861.61$ & $1,577.63$ \\
\hline Pimienta & 10.99 & $3.00 \%$ & 11.33 & 13.50 & 152.98 & 129.65 \\
\hline
\end{tabular}




\begin{tabular}{|c|c|c|c|c|c|c|}
\hline Pimiento & 12.60 & $1.00 \%$ & 12.73 & 5.00 & 63.64 & 53.93 \\
\hline Plátano isla & 33.60 & $3.00 \%$ & 34.64 & 2.50 & 86.60 & 73.39 \\
\hline Pollo entero & 386.40 & $3.00 \%$ & 398.35 & 8.00 & $3,186.80$ & $2,700.68$ \\
\hline Res bisteck & 100.80 & $3.00 \%$ & 103.92 & 18.00 & $1,870.52$ & $1,585.18$ \\
\hline Res guiso & 84.00 & $3.00 \%$ & 86.60 & 14.00 & $1,212.37$ & $1,027.43$ \\
\hline Sal & 15.26 & $3.00 \%$ & 15.74 & 1.00 & 15.74 & 13.34 \\
\hline Sazonador Doña Gusta & 0.84 & $1.00 \%$ & 0.85 & 23.00 & 19.52 & 16.54 \\
\hline Tilapia & 100.80 & $3.00 \%$ & 103.92 & 20.00 & $2,078.35$ & $1,761.31$ \\
\hline Tocino & 3.36 & $3.00 \%$ & 3.46 & 16.00 & 55.42 & 46.97 \\
\hline Tomate & 46.20 & $1.00 \%$ & 46.67 & 2.50 & 116.67 & 98.87 \\
\hline Trigo & 6.72 & $3.00 \%$ & 6.93 & 6.00 & 41.57 & 35.23 \\
\hline Vainita & 35.28 & $3.00 \%$ & 36.37 & 3.50 & 127.30 & 107.88 \\
\hline Vinagre blanco & 7.30 & $1.00 \%$ & 7.37 & 3.00 & 22.11 & 18.74 \\
\hline Vinagre tinto & 0.84 & $1.00 \%$ & 0.85 & 3.00 & 2.55 & 2.16 \\
\hline Yuca & 91.20 & $1.00 \%$ & 92.12 & 1.40 & 128.97 & 109.30 \\
\hline Yuca & 100.80 & $1.00 \%$ & 101.82 & 1.40 & 142.55 & 120.80 \\
\hline Zanahoria & 130.44 & $1.00 \%$ & 131.76 & 2.00 & 263.52 & 223.32 \\
\hline Total & & & & & $31,476.31$ & $26,674.84$ \\
\hline
\end{tabular}

- Detalle anual de costeo de platos extras (en kilos y soles)

\begin{tabular}{|c|c|c|c|c|c|c|}
\hline Ingredientes & $\mathrm{Kg}$ Netos & Merma & Kg Brutos & $\begin{array}{l}\text { Precio de } \\
\text { compra }\end{array}$ & Costo con IGV & Costo sin IGV \\
\hline Bisteck & 569.14 & $5.00 \%$ & 599.10 & 18.00 & $10,783.74$ & $9,138.76$ \\
\hline Aceite & 416.25 & $1.00 \%$ & 420.45 & 5.50 & $2,312.50$ & $1,959.74$ \\
\hline Ají amarillo & 200.75 & $3.00 \%$ & 206.96 & 3.50 & 724.36 & 613.87 \\
\hline Ají panca & 41.91 & $3.00 \%$ & 43.21 & 12.00 & 518.47 & 439.38 \\
\hline Ajinomoto & 5.69 & $1.00 \%$ & 5.75 & 10.50 & 60.36 & 51.16 \\
\hline Ajos & 107.10 & $1.00 \%$ & 108.18 & 10.50 & $1,135.93$ & 962.65 \\
\hline Arroz & $2,276.57$ & $1.00 \%$ & $2,299.56$ & 2.30 & $5,288.99$ & $4,482.20$ \\
\hline Alverja & 31.04 & $1.00 \%$ & 31.36 & 6.50 & 203.82 & 172.73 \\
\hline Carne de lomo & $1,396.98$ & $5.00 \%$ & $1,470.51$ & 18.00 & $26,469.17$ & $22,431.50$ \\
\hline Cebolla & 342.52 & $3.00 \%$ & 353.11 & 2.50 & 882.78 & 748.12 \\
\hline Churrasco & 776.10 & $5.00 \%$ & 816.95 & 18.00 & $14,705.09$ & $12,461.94$ \\
\hline Crema de leche & 512.23 & $0.00 \%$ & 512.23 & 5.50 & $2,817.25$ & $2,387.50$ \\
\hline Culantro & 17.59 & $3.00 \%$ & 18.14 & 2.00 & 36.27 & 30.74 \\
\hline Fetuccini & 341.48 & $1.00 \%$ & 344.93 & 3.90 & $1,345.24$ & $1,140.04$ \\
\hline Fideo espagueti & 388.05 & $1.00 \%$ & 391.97 & 3.90 & $1,528.69$ & $1,295.50$ \\
\hline Hongos & 2.59 & $3.00 \%$ & 2.67 & 12.00 & 32.00 & 27.12 \\
\hline Huevo & 419.10 & $3.00 \%$ & 432.06 & 7.00 & $3,024.40$ & $2,563.05$ \\
\hline Laurel & 10.87 & $1.00 \%$ & 10.98 & 12.00 & 131.70 & 111.61 \\
\hline Leche & 341.48 & $0.00 \%$ & 341.48 & 4.00 & $1,365.94$ & $1,157.58$ \\
\hline Mantequilla & 85.37 & $1.00 \%$ & 86.23 & 3.00 & 258.70 & 219.24 \\
\hline Papa & $1,047.74$ & $3.00 \%$ & $1,080.14$ & 2.50 & $2,700.36$ & $2,288.44$ \\
\hline
\end{tabular}




\begin{tabular}{ccccccc} 
Papa canchán & 310.44 & $1.00 \%$ & 313.58 & 2.50 & 783.94 & 664.36 \\
Pasta de tomate & 66.23 & $1.00 \%$ & 66.90 & 2.80 & 187.31 & 158.74 \\
Pimienta & 53.81 & $1.00 \%$ & 54.35 & 13.50 & 733.77 & 621.84 \\
Plátano isla & 279.40 & $3.00 \%$ & 288.04 & 2.50 & 720.09 & 610.25 \\
Queso parmesano & 284.57 & $1.00 \%$ & 287.45 & 13.00 & $3,736.79$ & $3,166.77$ \\
Res bisteck & 620.88 & $5.00 \%$ & 653.56 & 18.00 & $11,764.07$ & $9,969.55$ \\
Sal & 56.40 & $1.00 \%$ & 56.97 & 1.00 & 56.97 & 48.28 \\
Sillao & 17.59 & $1.00 \%$ & 17.77 & 3.50 & 62.19 & 52.71 \\
Tomate & 239.04 & $3.00 \%$ & 246.43 & 2.50 & 616.08 & 522.10 \\
Vinagre tinto & 3.10 & $1.00 \%$ & 3.14 & 3.00 & 9.41 & 7.97 \\
Zanahoria & 38.81 & $3.00 \%$ & 40.01 & 2.00 & 80.01 & 67.81 \\
Total & & & & & $\mathbf{9 5 , 0 7 6 . 4 1}$ & $\mathbf{8 0 , 5 7 3 . 2 3}$ \\
\hline
\end{tabular}

- Detalle anual de refrescos

\begin{tabular}{ccccccc}
\hline Ingredientes & Kg Netos & Merma & Kg Brutos & Precio de compra & Costo con IGV & Costo sin IGV \\
\hline Azúcar & 650.06 & $0.00 \%$ & 650.06 & 2.50 & $1,625.15$ & $1,377.25$ \\
Carambola & 146.50 & $0.30 \%$ & 146.94 & 3.00 & 440.83 & 373.58 \\
Cebada & 664.10 & $0.30 \%$ & 666.10 & 5.50 & $3,663.53$ & $3,104.69$ \\
Emoliente & 664.10 & $0.30 \%$ & 666.10 & 6.00 & $3,996.58$ & $3,386.93$ \\
Maíz Morado & 664.10 & $0.30 \%$ & 666.10 & 4.00 & $2,664.39$ & $2,257.95$ \\
Manzana de Agua & 664.10 & $0.30 \%$ & 666.10 & 1.50 & 999.14 & 846.73 \\
Maracuyá & 664.10 & $0.30 \%$ & 666.10 & 3.50 & $2,331.34$ & $1,975.71$ \\
\hline Total & & & & & $\mathbf{1 5 , 7 2 0 . 9 6}$ & $\mathbf{1 3 , 3 2 2 . 8 5}$
\end{tabular}


Anexo 11: Detalle de plan de marketing anual, año 1

\begin{tabular}{lcccc}
\hline \multicolumn{1}{c}{ Concepto } & $\begin{array}{c}\text { Costos Unitarios } \\
(\text { Sin IGV) }\end{array}$ & Por mes & $\begin{array}{c}\text { Veces por } \\
\text { año }\end{array}$ & $\begin{array}{c}\text { Costo Total } \\
\text { (Sin IGV) }\end{array}$ \\
\hline Página de Facebook & $\mathrm{S} / .35 .00$ & 4 & 12 & $\mathrm{~S} / .1,680.00$ \\
Cuenta de Instagram & $\mathrm{S} / .35 .00$ & 4 & 12 & $\mathrm{~S} / .1,680.00$ \\
Publicidad radial & $\mathrm{S} / .500 .00$ & 1 & 12 & $\mathrm{~S} / .6,000.00$ \\
Material Impreso & $\mathrm{S} / .0 .25$ & 2500 & 4 & $\mathrm{~S} / .2,500.00$ \\
Volanteo & $\mathrm{S} / .400$ & 2 & 12 & $\mathrm{~S} / .9,600.00$ \\
Llaveros & $\mathrm{S} / .1 .20$ & 1000 & 1 & $\mathrm{~S} / .1,200.00$ \\
Lapiceros & $\mathrm{S} / .0 .50$ & 1000 & 1 & $\mathrm{~S} / .500 .00$ \\
Stickers & $\mathrm{S} / .0 .20$ & 5000 & 1 & $\mathrm{~S} / .1,000.00$ \\
Calendarios & $\mathrm{S} / .2 .45$ & 500 & 1 & $\mathrm{~S} / .1,225.00$ \\
\hline Total $(\sin \mathrm{IGV})$ & & & & $\mathrm{S} / .25,385.00$ \\
\hline
\end{tabular}


Encuesta

CUESTIONARIO

ENCUESTA - RESTAURANTE EN VES

NRO.

Buenos días / buenas tardes me encuentro llevando un curso de Proyecto de tesis y estoy haciendo un estudio de mercado sobre los restaurantes en Villa El Salvador. Por tal motivo me gustaría contar con su participación, siendo su opinión muy valiosa para mí. La encuesta dura aproximadamente 15 minutos, ¿podría contar con su participación? Muchas gracias.

\section{FILTROS GENERALES}

F1. ¿Podría decir qué edad tiene? (E: ESPONTÁNEA, E: RESPUESTA ÚNICA)

\begin{tabular}{|c|c|}
\hline CÓDIGO & EDAD \\
\hline 1 & De 18 a 30 años \\
\hline 2 & De 31 a 45 años \\
\hline 3 & De 46 a 65 años \\
\hline 4 & Más de 65 años \\
\hline (E: TERMINAR) & Menor de 18 años \\
\hline
\end{tabular}

F2. ¿Vive, labora o estudia cerca al lugar donde actualmente nos encontramos (Territorio III) ? (E:

\section{RESPUESTA ÚNICA)}

\begin{tabular}{|c|c|c|}
\hline 1 & Vive & $($ E: CONTINUAR $)$ \\
\hline 2 & Labora & $($ E: CONTINUAR $)$ \\
\hline 3 & Estudia & $($ E: CONTINUAR $)$ \\
\hline 4 & Ninguna de las anteriores & $($ E: FIN DE ENCUESTA $)$ \\
\hline
\end{tabular}

F3. En la última semana, ¿ha salido a comer fuera de casa?

\begin{tabular}{|c|c|c|}
\hline 1 & Sí & $($ E: CONTINUAR) \\
\hline 2 & No & $($ E: TERMINAR) \\
\hline
\end{tabular}


P1. ¿Qué tipo de comida prefiere entre días de semana? (E: RESPUESTA MÚLTIPLE)

\begin{tabular}{|c|c|}
\hline 1 & Marina \\
\hline 2 & Criolla \\
\hline 3 & Chifa \\
\hline 4 & Pastas \\
\hline 5 & Vegetariana \\
\hline 6 & Comida Rápida \\
\hline 7 & Pollo a la Brasa \\
\hline & Otros \\
\hline
\end{tabular}

P.2. ¿Qué comidas consume fuera de casa? (E: RESPUESTA MÚLTIPLE)

\begin{tabular}{|c|c|}
\hline 1 & Desayuno \\
\hline 2 & Almuerzo \\
\hline 3 & Lonche \\
\hline 4 & Cena \\
\hline
\end{tabular}

P3. Por lo general, ¿qué días suele ir a comer fuera de casa? (E: RESPUESTA MÚLTPLE)

\begin{tabular}{|c|c|}
\hline 1 & Días de semana \\
\hline 2 & Fines de semana \\
\hline
\end{tabular}

P.4. ¿Suele desayunar fuera de casa?

\begin{tabular}{|c|c|}
\hline 1 & Sí \\
\hline 2 & No \\
\hline
\end{tabular}

P.5. ¿Cuántas veces por semana suele desayunar fuera de casa?

\begin{tabular}{|c|c|}
\hline 1 & Una vez a la semana \\
\hline 2 & Dos veces a la semana \\
\hline 3 & Tres veces a la semana \\
\hline 4 & Cuatro veces a la semana \\
\hline
\end{tabular}




\begin{tabular}{|c|c|}
\hline 5 & Cinco veces a la semana \\
\hline 6 & Seis veces a la semana \\
\hline 7 & Siete veces a la semana \\
\hline
\end{tabular}

P.6. ¿Con cuántas personas suele desayunar fuera de casa?

\begin{tabular}{|c|c|}
\hline 1 & Solo Ud. \\
\hline 2 & De 2 a 3 personas \\
\hline 3 & De 4 a 5 personas \\
\hline
\end{tabular}

P.7 ¿Cuántas veces por semana suele almorzar fuera de casa?

\begin{tabular}{|c|c|}
\hline 1 & Una vez a la semana \\
\hline 2 & Dos veces a la semana \\
\hline 3 & Tres veces a la semana \\
\hline 4 & Cuatro veces a la semana \\
\hline 5 & Cinco veces a la semana \\
\hline 6 & Seis veces a la semana \\
\hline 7 & Siete veces a la semana \\
\hline
\end{tabular}

P.8. ¿Con cuántas personas suele almorzar fuera de casa?

\begin{tabular}{|c|c|}
\hline 1 & Solo Ud. \\
\hline 2 & De 2 a 3 personas \\
\hline 3 & De 4 a 5 personas \\
\hline
\end{tabular}

P.9. ¿Cuántas veces por semana suele cenar fuera de casa?

\begin{tabular}{|c|c|}
\hline 1 & Una vez a la semana \\
\hline 2 & Dos veces a la semana \\
\hline 3 & Tres veces a la semana \\
\hline 4 & Cuatro veces a la semana \\
\hline 5 & Cinco veces a la semana \\
\hline 6 & Seis veces a la semana \\
\hline
\end{tabular}




\begin{tabular}{|l|l|}
\hline 7 & Siete veces a la semana \\
\hline
\end{tabular}

P.10. ¿Con cuántas personas suele cenar fuera de casa?

\begin{tabular}{|c|c|}
\hline 1 & Solo Ud. \\
\hline 2 & De 2 a 3 personas \\
\hline 3 & De 4 a 5 personas \\
\hline
\end{tabular}

P.11. ¿Con qué suele acompañar su almuerzo o cena?

\begin{tabular}{|c|c|}
\hline 1 & Refresco \\
\hline 2 & Gaseosa \\
\hline 3 & Cerveza chica \\
\hline 4 & Pisco sour \\
\hline 5 & Chilcano \\
\hline
\end{tabular}

P.12. ¿Por qué motivo suele ir a comer fuera de casa? (E: RESPUESTA MÚLTPLE)

\begin{tabular}{|c|c|}
\hline 1 & Almuerzo cotidiano \\
\hline 2 & Disfrute/ Ocio \\
\hline 3 & Encuentro con amigos \\
\hline 4 & Reuniones de trabajo \\
\hline 5 & Aniversarios, cumpleaños \\
\hline
\end{tabular}

P.13. Clasifique los distintos atributos de restaurantes por orden de importancia. 1 es muy importante y 8 es menos importante.

\begin{tabular}{|c|c|}
\hline & Tranquilidad \\
\hline & Limpieza \\
\hline & Rapidez de entrega \\
\hline & Buen Sabor \\
\hline & Cantidad servida \\
\hline & Variedad de la carta \\
\hline & Precio \\
\hline
\end{tabular}


P.14. Cuando sale a comer fuera de casa, ¿Ud. prefiere pedir menú o plato a la carta? (E: RESPUESTA ÚNICA)

\begin{tabular}{|c|c|}
\hline 1 & Solo Menú \\
\hline 2 & Solo Plato a la Carta \\
\hline
\end{tabular}

P.15. ¿Cuánto está dispuesto a pagar por un menú? (E: RESPUESTA ÚNICA)

\begin{tabular}{|c|c|}
\hline 1 & $8-11$ soles \\
\hline 2 & $12-13$ soles \\
\hline 3 & $14-16$ soles \\
\hline 4 & $17-20$ soles \\
\hline
\end{tabular}

P.16. ¿Cuánto está dispuesto a pagar por un plato a la carta? (E: RESPUESTA ÚNICA)

\begin{tabular}{|c|c|}
\hline 1 & $15-20$ soles \\
\hline 2 & $21-25$ soles \\
\hline 3 & $26-30$ soles \\
\hline
\end{tabular}

P.17. ¿Cuánto tiempo está dispuesto a esperar por un menú? (E: RESPUESTA ÚNICA)

\begin{tabular}{|c|c|}
\hline 1 & Hasta 5 minutos \\
\hline 2 & De 6 a 10 minutos \\
\hline 3 & De 11 a 15 minutos \\
\hline
\end{tabular}

P.18. ¿Cuánto tiempo está dispuesto a esperar por un plato a la carta? (E: RESPUESTA ÚNICA)

\begin{tabular}{|c|c|}
\hline 1 & De 10 a 15 minutos \\
\hline 2 & De 16 a 20 minutos \\
\hline 3 & De 20 a 25 minutos \\
\hline
\end{tabular}


P.18.1 ¿Cuál es su horario habitual de almuerzo? (E: RESPUESTA ÚNICA)

\begin{tabular}{|c|c|}
\hline 1 & $12: 00-1: 00 \mathrm{pm}$ \\
\hline 2 & $1: 00 \mathrm{pm}-2: 00 \mathrm{pm}$ \\
\hline 3 & $2: 00 \mathrm{pm}-3: 00 \mathrm{pm}$ \\
\hline 4 & Otro horario diferente \\
\hline
\end{tabular}

P.18.2 ¿Cuál es el tiempo que demora en almorzar? (E: RESPUESTA ÚNICA)

\begin{tabular}{|c|c|}
\hline 1 & 30 minutos aproximadamente \\
\hline 2 & 45 minutos aproximadamente \\
\hline 3 & 60 minutos aproximadamente \\
\hline
\end{tabular}

P.18.3 ¿Cuál es su horario habitual de cena? (E: RESPUESTA ÚNICA)

\begin{tabular}{|c|c|}
\hline 1 & $7: 00 \mathrm{pm}-8: 00 \mathrm{pm}$ \\
\hline 2 & $8: 00 \mathrm{pm}-9: 00 \mathrm{pm}$ \\
\hline 3 & $9: 00 \mathrm{pm}-10: 00 \mathrm{pm}$ \\
\hline 4 & Otro horario diferente \\
\hline
\end{tabular}

P.18.4 ¿Cuál es el tiempo que demora en cenar? (E: RESPUESTA ÚNICA)

\begin{tabular}{|c|c|}
\hline 1 & 30 minutos aproximadamente \\
\hline 2 & 45 minutos aproximadamente \\
\hline 3 & 60 minutos aproximadamente \\
\hline
\end{tabular}

P.19. ¿Suele pedir delivery? De ser negativa la respuesta, indique el motivo (E: RESPUESTA ÚNICA)

\begin{tabular}{|c|c|}
\hline 1 & Sí \\
\hline 2 & No, porque no conozco un restaurante \\
& cercano que ofrezca este servicio. \\
\hline 3 & No, porque el restaurante al que suelo ir \\
& no ofrece servicio delivery. \\
\hline 4 & No, porque prefiero ir al restaurante. \\
\hline
\end{tabular}


P.20. ¿Cuándo pide un servicio delivery para cuántas personas lo solicita?

\begin{tabular}{|c|c|}
\hline 1 & Solo para Ud. \\
\hline 2 & Para 2 a 3 personas \\
\hline 3 & Para 4 a 5 personas \\
\hline
\end{tabular}

P.21. ¿Le cobran algún recargo adicional por el servicio de delivery? (E: RESPUESTA ÚNICA) (OMITIR SI RESPONDIÓ NEGATIVAMENTE P.12.)

\begin{tabular}{|c|c|}
\hline 1 & Sí \\
\hline 2 & No \\
\hline
\end{tabular}

P.22. ¿Qué ambiente prefiere para almorzar? (E: RESPUESTA ÚNICA)

\begin{tabular}{|c|c|}
\hline 1 & Totalmente silencioso \\
\hline 2 & Con música de fondo \\
\hline 3 & Viendo televisión \\
\hline
\end{tabular}

P.23. ¿Ud. tiene algún restaurante preferido en esta zona? (Territorio III de Villa El Salvador) (E: RESPUESTA ÚNICA)

\begin{tabular}{|c|c|}
\hline 1 & Sí \\
\hline 2 & No \\
\hline
\end{tabular}

P.24. Si en la pregunta anterior su respuesta ha sido positiva, ¿cuál es? (E: RESPUESTA ÚNICA Y ESPONTÁNEA)

\begin{tabular}{|c|c|}
\hline 1 & Puerto Palmeras \\
\hline 2 & El Encanto Marino \\
\hline 3 & Chifa When Wha \\
\hline 4 & Sabor Perú \\
\hline 5 & El Paraíso del Paladar \\
\hline 6 & Rokys \\
\hline 7 & Norkys \\
\hline 8 & \\
\hline
\end{tabular}




\begin{tabular}{|l|l|}
\hline 9 & Otros \\
\hline
\end{tabular}

P.25. ¿Cómo suele enterarse sobre nuevos restaurantes? (E: RESPUESTA MÚLTPLE)

\begin{tabular}{|c|c|}
\hline 1 & Periódicos \\
\hline 2 & Redes Sociales \\
\hline 3 & Recomendaciones \\
\hline 4 & Volantes \\
\hline 5 & Otros \\
\hline 6 & \\
\hline
\end{tabular}

P.26. ¿Cómo suele enterarse del menú o carta del día de un restaurante? (E: RESPUESTA MÚLTPLE)

\begin{tabular}{|c|c|}
\hline 1 & En el mismo restaurante \\
\hline 2 & Whatsapp \\
\hline 3 & Facebook Messenger \\
\hline 4 & Twitter \\
\hline 5 & Otros \\
\hline
\end{tabular}

\section{PREGUNTAS SOBRE LA PROPUESTA DE VALOR}

De abrirse un restaurante frente a la Municipalidad de Villa El Salvador, enfocado en el servicio al cliente, rapidez y sazón, que ofrece platos criollos, marinos y bebidas en un ambiente agradable, colorido y pintoresco, decorado con cuadros llenos de frases de tipografía artística que hacen alusión a la popularidad y buena sazón de la comida peruana, complementada con música y videos para el entretenimiento del cliente. El menú costará S/ 11; los platos a la carta, S/ 18; y las bebidas, entre S/ 3 - S/ 5 . El servicio de delivery sería sin costo adicional...

P.27. ¿Ud. iría a este restaurante? (E: RESPUESTA ÚNICA)

\begin{tabular}{|c|c|c|c|c|}
\hline $\mathbf{1}$ & $\mathbf{2}$ & $\mathbf{3}$ & $\mathbf{4}$ & $\mathbf{5}$ \\
\hline Definitivamente No & No & Indiferente & Sí & Definitivamente Sí \\
& & & & \\
\hline
\end{tabular}


P.28. ¿Ud. pediría delivery de este restaurante? (E: RESPUESTA ÚNICA)

\begin{tabular}{|c|c|c|c|c|}
\hline $\mathbf{1}$ & $\mathbf{2}$ & $\mathbf{3}$ & $\mathbf{4}$ & $\mathbf{5}$ \\
\hline Definitivamente No & No & Indiferente & Sí & Definitivamente Sí \\
& & & & \\
\hline
\end{tabular}

P.29 ¿Qué desayunos le gustaría encontrar?

\begin{tabular}{|c|c|c|c|c|c|c|c|}
\hline Combo 1 & & Combo 2 & & Combo 3 & & Combo 4 & \\
\hline Jugo & 1 & Jugo & 2 & Jugo & 3 & Jugo & 4 \\
\hline papaya/naranja/piña & & papaya/naranja/piña & & papaya/naranja/piña & & papaya/naranja/piña + & \\
\hline + Infusión o café+ & & + Infusión o café + & & + Infusión o café + & & Infusión o café + Pan & \\
\hline Huevos revueltos + & & Pan con & & Pan con Tamal & & con chicharrón & \\
\hline tostadas & & huevo/palta/pollo & & & & & \\
\hline
\end{tabular}

P.30. ¿Cuánto estaría dispuesto a pagar por un desayuno de este restaurante? (RESPUESTA ÚNICA)

\begin{tabular}{|c|c|}
\hline 1 & $5-7$ soles \\
\hline 2 & $8-10$ soles \\
\hline 3 & $11-15$ soles \\
\hline 4 & $16-20$ soles \\
\hline
\end{tabular}

P.31 ¿Cuál de estas entradas le gustaría encontrar en el restaurante? (RESPUESTA ÚNICA)

\begin{tabular}{|c|c|}
\hline 1 & Ocopa \\
\hline 2 & Ensalada Primor \\
\hline 3 & Ensalada Waldorf \\
\hline 4 & Ensalada Cesar \\
\hline 5 & Causa bicolor \\
\hline 6 & Solterito \\
\hline 7 & Otros \\
\hline 8 & \\
\hline
\end{tabular}


P.32 ¿Qué tipo de plato de fondo desearía encontrar? (RESPUESTA ÚNICA)

\begin{tabular}{|c|c|}
\hline 1 & Arroz a la jardinera \\
\hline 2 & Escabeche de pescado \\
\hline 3 & Ají de gallina \\
\hline 4 & Arverjita con guiso \\
\hline 5 & Lomo saltado \\
\hline 6 & Puré de espinaca \\
\hline 7 & Frejol con seco \\
\hline 8 & \\
\hline
\end{tabular}

P. 33: ¿Qué tipo de refresco le gustaría encontrar?

\begin{tabular}{|c|c|}
\hline 1 & Jugo de manzana \\
\hline 2 & Maracuyá \\
\hline 3 & Carambola \\
\hline 4 & Chicha morada \\
\hline 5 & Emoliente \\
\hline 6 & Cebada \\
\hline 7 & Limonada \\
\hline 8 & Otros \\
\hline
\end{tabular}

P.34. ¿Cuánto estaría dispuesto a pagar por un menú de este restaurante? (E: RESPUESTA ÚNICA)

\begin{tabular}{|c|c|}
\hline 1 & $8-11$ soles \\
\hline 2 & $12-13$ soles \\
\hline 3 & $14-16$ soles \\
\hline 4 & $17-20$ soles \\
\hline
\end{tabular}


P.35 Qué platos a la carta le gustaría encontrar?

\begin{tabular}{|c|c|}
\hline 1 & Lomo saltado \\
\hline 2 & Churrasco a lo pobre \\
\hline 3 & Fetuccini con bisteck \\
\hline 4 & Tallarín saltado \\
\hline 5 & Ceviche \\
\hline 6 & Menestrón \\
\hline 7 & Sancochado \\
\hline 8 & Carapulcra \\
\hline 9 & Puré con Asado \\
\hline 10 & Otros \\
\hline 11 &
\end{tabular}

P.36. ¿Cuánto está dispuesto a pagar por un plato a la carta de este restaurante? (E: RESPUESTA ÚNICA)

\begin{tabular}{|c|c|}
\hline 1 & $15-20$ soles \\
\hline 2 & $21-25$ soles \\
\hline 3 & $26-30$ soles \\
\hline
\end{tabular}

P.37. ¿Le gustaría encontrar bebidas alcohólicas? (E: RESPUESTA ÚNICA)

\begin{tabular}{|c|c|}
\hline 1 & Sí \\
\hline 2 & No \\
\hline
\end{tabular}

P.38. ¿Qué bebidas alcohólicas le gustaría encontrar? (E: ESPONTÁNEA RESPUESTA MÚLTPLE) OMITIR SI RESPONDIÓ NEGATIVAMENTE A LA PREGUNTA P.24.

\begin{tabular}{|c|c|}
\hline 1 & Cervezas \\
\hline 2 & Pisco Sour \\
\hline 3 & Vinos \\
\hline 4 & Chilcanos \\
\hline 5 & Otros \\
\hline
\end{tabular}


P.39. ¿Qué nombre le gustaría que tenga este restaurante? (E: RESPUESTA ÚNICA)

\begin{tabular}{|c|c|}
\hline 1 & Entre Copas y Tenedores \\
\hline 2 & El Buen Sabor de Villa \\
\hline 3 & Perú Buen Gusto \\
\hline 4 & El Encanto de Villa \\
\hline 5 & Otros \\
\hline
\end{tabular}

P.40 ¿Qué metodo de pago prefiere utilizar?

\begin{tabular}{|c|c|}
\hline 1 & Efectivo \\
\hline 2 & POS \\
\hline
\end{tabular}

DATOS DE CONTROL

Sexo del entrevistado (E: RESPUESTA ÚNICA)

\begin{tabular}{|c|c|}
\hline 1 & M \\
\hline 2 & F \\
\hline
\end{tabular}

Estado civil (E: RESPUESTA ÚNICA)

\begin{tabular}{|c|c|c|c|c|c|}
\hline 1 & Soltero (a) & 2 & Casado (a) & 3 & Conviviente \\
\hline 4 & Viudo (a) & 5 & Divorciado (a) & & \\
\hline
\end{tabular}

\begin{tabular}{|l|}
\hline Nombre del entrevistado: \\
\hline Teléfono del entrevistado: \\
\hline Distrito donde reside el entrevistado: \\
\hline Lugar donde se hizo la entrevista: \\
\hline Nombre del entrevistador: \\
\hline Fecha: \\
\hline Supervisado por: \\
\hline
\end{tabular}

TERMINAR Y AGRADECER 


\section{Referencias}

Andina (2017, enero 17) Recuperado de: http://www.andina.com.pe/agencia/noticia-ineilima-tiene-9-millones-752-mil-habitantes-al-cumplir-480-anos-fundacion539716.aspx.

Angelo, R. y Vladimir, A. (1998). Hospitality today, an introduction. Estados Unidos: Educational Institute.

Arqhys. (s/f). Historia de los Restaurantes. Recuperado de http://www.arqhys.com/contenidos/restaurantes-historia.html.

Discovery (2016, enero 29). Influencias históricas de la gastronomía peruana. Recuperado de https://www.gediscovery.edu.pe/blog/influencias-historicas-gastronomia-peruana/. Dittmer, P. (2002). Dimensions of the hospitality industry. Estados Unidos: John Wiley \&Sons.

Dittmer, P. (2002). Dimensions of the hospitality. Estados Unidos: John Wiley \&Sons. El Comercio (2017, abril 21) Sunarp facilitará constitución de empresas a "costo cero". Recuperado de: http://elcomercio.pe/economia/peru/sunarp-facilitara-constitucionempresas-costo-cero-noticia-1985727.

El Comercio (2017, abril 24) Cepal proyecta que PBI de Perú crecerá 3,5\% el 2017. Recuperado de: http://elcomercio.pe/economia/peru/cepal-proyecta-que-pbi-perucrecera-35-2017-noticia-1986485?ref=flujo_tags_514408\&ft=nota_3\&e=titulo. El Peruano (2016, enero 25). Gastronomía peruana apunta alto. Recuperado de http://www.elperuano.com.pe/noticia-gastronomia-peruana-apunta-alto-37654.aspx. Ernst And Young (2016, junio). Guías de Negocios e Inversión en el Perú. Recuperado de http://www.ey.com/Publication/vwLUAssets/EY-guia-de-negocios-e-inversion-peru2016-2017/\$FILE/EY-guia-de-negocios-e-inversion-2016-2017.pdf. 
Gallego, Jesús Felipe (2002). Gestión de alimentos y bebidas para hoteles, bares y restaurantes. España, Madrid: Editorial Paraninfo.

Gestión (2013, diciembre 16) INEI: Limeños destinan 35\% de su gasto en alimentos a comer fuera del hogar. Recuperado de: http://gestion.pe/economia/inei-limenos-destinan35- su-gasto-alimentos-comer-fuera-hogar-2083781

Gestión (2009, mayo 17) Sólo 800 de 220 mil restaurantes de Lima tienen certificación de saludables. Recuperado de: http://gestion.pe/noticia/287810/solo-800-220-milrestaurantes-lima-tienen-certificacion-saludables

Gestión (2014, setiembre 09). Gastronomía en Perú crece entre 7\% y 8\% al año, estima EY. Recuperado de http://gestion.pe/economia/gastronomia-peru-crece-entre-7-y-8-alano-estima-ey-2108084.

Gestión (2016, marzo 11). Sede de los Panamericanos se construirá en Villa El Salvador. Recuperado de http://gestion.pe/inmobiliaria/sede-panamericanos-se-construiravilla- salvador-2156206.

Gestión (2017, enero 21) Libro 'Perú, Mucho Gusto’ gana premio internacional en España. Recuperado de: http://gestion.pe/tendencias/libro-peru-mucho-gusto-gana-premiointernacional-espana-2180264.

Gestión (2017, febrero 07) Produce: Constitución de empresas en 24 horas se hará realidad en dos semanas. Recuperado de: http://gestion.pe/economia/produce-constitucionempresas-24-horas-se-hara-realidad-dos-semanas-2181517.

Griffin, R. (2011). Administración. México D.F.: Editorial Cengage Learning. HIRAOKA (2017). Catalogo http://www.hiraoka.com.pe/hiraoka/files/assets/basic-html/page-94.html INEI (2014). Directorio Central de Empresas y Establecimientos. Perú. INEI (2014). Una mirada a Lima Metropolitana. Perú. 
INEI (2015, junio). Perú: Estructura Empresarial, 2014. Recuperado de: https://www.inei.gob.pe/media/MenuRecursivo/publicaciones_digitales/Est/Lib1262 /1 ibro.pdf.

Javier Masías (2015, agosto 24). ¿Cómo se gestó el boom gastronómico peruano? Recuperado de http://semanaeconomica.com/article/sectores-yempresas/comercio/167768-como-se-gesto-el-boom-gastronomico-peruano/.

La República (2012, septiembre 25). El 90\% de los peruanos siente orgullo por su comida, y el ceviche es el plato bandera. http://larepublica.pe/25-09-2012/el-90-de-peruanossiente-orgullo-por-su-comida-y-el-ceviche-es-el-plato-bandera.

La República (2012, Setiembre 25) El 90\% de peruanos siente orgullo por su comida, y el ceviche es el plato bandera. Recuperado de: http://larepublica.pe/25-09-2012/el-90de-peruanos-siente-orgullo-por-su-comida-y-el-ceviche-es-el-plato-bandera.

La Republica (2016, junio 13) Expositores nacionales y extranjeros participarán en Gastromaq Perú 2016. Recuperado de: http://larepublica.pe/turismo/rumbos-aldia/776653-150-expositores-nacionales-y-extranjeros-participaran-en-gastromaqperu-2016.

La República (2016, marzo 03) Sector gastronómico genera 60 mil puestos laborales y tiene crecimiento sostenible. Recuperado de:

http://larepublica.pe/impresa/economia/745732-sector-gastronomico-genera-60-milpuestos-laborales-y-tiene-crecimiento-sostenible.

MAKRO (2017). Catálogo

https://issuu.com/makro-peru/docs/makro_encarte_norte24

Municipalidad de Villa El Salvador (2016) Plan Operativo Institucional con Enfoque de Resultados y Perspectiva de Programación Multianual

Perú 21 (2013, setiembre 05) Existen 100 mil restaurantes en Perú. Recuperado de: http://peru21.pe/economia/apega-peru-existen-100-mil-restaurantes-2147923. 
Perú 21 (2016, diciembre 05) Perú fue elegido por quinto año consecutivo como el Mejor Destino Culinario del Mundo. Recuperado de: http://peru21.pe/actualidad/peru-fueelegido-quinto-ano-consecutivo-como-mejor-destino-culinario-mundo-2264151.

Peru.com (2016, julio 07). Cocina Peruana llega a la lejana Moscú. Recuperado de: http://peru.com/estilo-de-vida/gastronomia/cocina-peruana-llega-al-lejano-moscunoticia-463396.

Pymex (2013, octubre 26) Como abrir un restaurante paso a paso. Recuperado de: https://pymex.pe/emprendedores/proyectos-de-inversion/como-abrir-un-restaurantepaso-a-paso.

Semana Económica (2016, enero 19) Las tendencias de la gastronomía peruana en el 2016. Recuperado de: http://semanaeconomica.com/article/entre-parentesis/estilo-devida/176373-las-tendencias-de-la-gastronomia-peruana-en-el-2016/.

Soto, B. (2015, marzo 19) El consumo de productos orgánicos crece entre los peruanos. El Comercio. Recuperado de http://www.actualidadambiental.pe/wpcontent/uploads/2015/03/elcomercio_2015-03-19_p12.pdf.

Thompson \& Strickland (2004) Administración Estratégica. Textos y Casos. México D.F.: Editorial McGraw-Hill

Hernández, Fernández \& Baptista (2014). Metodología de la Investigación. México D.F.: Editorial McGraw-Hill.

Méndez Álvarez, Carlos (2013). Metodología: Diseño y Desarrollo del proceso de Investigación con énfasis en ciencias empresariales. México D.F. Editorial Limusa. Apeim. (1 de Agosto de 2016). Recuperado el 05 de Junio de 2017, de Apeim: http://apeim.com.pe.

Czinkota, M. R., \& Ronkainen, I. (2013). Marketing Internacional. México D.F. Editorial Cengage Learning Editores, S.A. 
Ferrell, O. C., \& Hartline, M. D. (2012). Estrategia de marketing. México D.F. Editorial Cengage Learning Editores, S.A.

INEI. (2013). Los 10 Menús más Consumidos en los Restaurantes de Lima Metropolitana 2013. Una mirada a Lima Metropolitana, 41.

Stanton, Etzek y Waklker (2007). Fundamentos de Marketing. México D.F. Editorial McGraw-Hill.

Hanke \& Reitsch (2013). Pronósticos en los Negocios. México D.F. Editorial Pretince Hall Hispanoamérica SA.

Johnston \& Marshall (2009) Administración de Ventas. México D.F. Editorial McGrawHill.

Baca Urbina (2010) Evaluación de Proyectos. México D.F. Editorial McGraw-Hill.

Sapag Chain (2011) Proyectos de Inversión. Santiago de Chile. Editorial Pearson.

Chiavenato (2009) Gestión del Talento Humano. México D.F. Editorial McGraw-Hill. Robbins \& Coulter (2014) Administración. México D.F. Editorial Pearson.

Lovelock, C. \& Wirtz, J. (2015). Marketing de Servicios. Editorial Pearson.

Stickney, Weil, Schipper, Francis \& Avolio (2013). Contabilidad Financiera. Editorial Cengage Learning. 